\title{
Seasonal and Interannual Variability in the Hydrology and Geochemistry of an Outlet Glacier of the Greenland Ice Sheet
}

\author{
By \\ Benjamin Shawn Linhoff \\ B.S., Boise State University, 2005 \\ M.S., The University of Texas at Austin, 2008 \\ Submitted in partial fulfillment of the requirements for the degree of \\ Doctor of Philosophy \\ at the \\ MASSACHUSETTS INSTITUTE OF TECHNOLOGY \\ and the \\ WOODS HOLE OCEANOGRAPHIC INSTITUTION
}

February, 2016

\section{(C) 2016 Benjamin Shawn Linhoff \\ All rights reserved}

The author hereby grants to MIT and WHOI permission to reproduce and to distribute publicly paper and electronic copies of this thesis document in whole or in part in any medium now known or hereafter created.

Signature of Author

Joint Program in Chemical Oceanography

Massachusetts Institute of Technology and Woods Hole Oceanographic Institution

October 2, 2015

Certified by

Matthew A. Charette

Thesis Supervisor

Accepted by

Elizabeth Kujawinski

Chair, Joint Committee for Chemical Oceanography

Massachusetts Institute of Technology

Woods Hole Oceanographic Institution 


\title{
Seasonal and Interannual Variability in the Hydrology and Geochemistry of an Outlet Glacier of the Greenland Ice Sheet
}

\author{
by \\ Benjamin Shawn Linhoff
}

Thesis Abstract

In the spring and summer within the ablation zone of the Greenland Ice Sheet (GrIS), meltwater drains to the ice sheet bed through an evolving network of efficient channelized and inefficient distributed drainage systems. Distributed system drainage is a key component in stabilizing GrIS velocity on interannual time scales and controlling geochemical fluxes. During the spring and summer of 2011 and 2012, I conducted fieldwork at a large outlet glacier in southwest Greenland underlain by metamorphic silicate rocks. Data collected from a continuous ${ }^{222} \mathrm{Rn}$ monitor in the proglacial river were used as a component of a mass balance model. I demonstrated that $J_{d i s}$, the ${ }^{222} \mathrm{Rn}$ fraction derived from the distributed system, was $>90 \%$ of the ${ }^{222} \mathrm{Rn}$ flux on average, and therefore, ${ }^{222} \mathrm{Rn}$ can be used as a passive flow tracer of distributed system drainage. Supraglacial meltwater runoff estimated using two independent models was compared with ice velocity measurements across the glacier's catchment. Major spikes of $J_{d i s}$ occurred after rapid supraglacial meltwater runoff inputs and during the expansion of the subglacial channelized system. While increases in meltwater runoff induced ice acceleration, they also resulted in the formation of efficient subglacial channels and increased drainage from the distributed system, mechanisms known to cause slower late summer to winter velocities. $\mathrm{Sr}, \mathrm{U}$, and $\mathrm{Ra}$ isotopes and major and trace element chemistry were used to investigate the impact of glacial hydrology on subglacial weathering. Analysis of partial and total digestions of the riverine suspended load (SSL) found that trace carbonates within the silicate watershed largely controlled the ${ }^{87} \mathrm{Sr} /{ }^{86} \mathrm{Sr}$ ratio in the dissolved load. Experiments and sampling transects downstream from the GrIS demonstrated that $\delta^{234} \mathrm{U}$ in the dissolved phase decreased with increasing interaction with the SSL. The $\left({ }^{228} \mathrm{Ra}{ }^{226} \mathrm{Ra}\right)$ value of the dissolved load was significantly higher than that of the SSL and therefore, was not the result of the source rock material but of extensive mineral surface weathering and the faster ingrowth rate of ${ }^{228} \mathrm{Ra}\left(\mathrm{t}_{1 / 2}=5.75 \mathrm{y}\right)$ relative to ${ }^{226} \mathrm{Ra}\left(\mathrm{t}_{1 / 2}=1600 \mathrm{y}\right)$. In summary, extensive, repeated cycles of rapid supraglacial meltwater runoff to subglacial drainage networks leads to increased distributed system drainage and mineral weathering.

Thesis Supervisor: Matthew A. Charette

Title: Senior Scientist, Woods Hole Oceanographic Institution 


\section{Acknowledgements}

First, I would like to thank my advisor Matt Charette, whose extensive scientific knowledge, hard work, and generosity was a source of encouragement and inspiration through my five years of doctoral education. I am deeply grateful for the opportunity to have worked with Matt as he pushed me to be a better scientist and taught me many lasting lessons. I look forward to collaborating with Matt as a colleague in the coming years.

I am grateful to Bernhard Peucker-Ehrenbrink for serving on my committee and for all of his guidance through my $\mathrm{Ph} . \mathrm{D}$. education. Bernhard was always available to discuss my most challenging scientific problems and without fail provided invaluable advice. Sarah Das was also an integral part of my committee and provided extremely helpful scientific advice and encouragement. David McGee agreed to join my committee in the last year of my Ph.D. and offered valuable insight into my research. David is someone I sincerely hope to work with again in the future. Laboratory work completed for this thesis could not have happened without Jurek Blusztajn. I had the good fortune of spending many hours in the ICP lab working with Jurek as well as running together in the marathon relay and Friday 'Coffee O' runs. I would also like to thank Bill Thompson for the countless hours he spent helping me to refine my clean laboratory techniques, and for teaching me most of what I know about uranium geochemistry. Paul Henderson was a tremendous help during my lab work, in packing for Greenland, and was a great friend during my time at WHOI. Carl Lamborg provided the guidance and laboratory equipment that allowed me to collect the mercury data that appears in the appendix of this thesis. Many thanks to the Academic Programs Office staff members who keep the Joint Program running smoothly: Julia Westwater, Lea Fraser, Christine Charette, Meg Tivey, and Jim Yoder. Thanks also to Ronni Schwartz, Mary Elliff, and Ed Boyle at MIT. The MC and G administrative staff, Sheila Clifford, Donna Mortimer, and Mary Murphy, have been there to provide help instantly with whatever was needed.

This thesis involved extensive fieldwork in Greenland and there are many people that contributed to making that happen. I would especially like to thank Jemma Wadham of the University of Bristol and Pete Nienow at the University of Edinburgh for welcoming me into their field camp at Leverett Glacier. They were wonderful to work with in and out of the field and provided invaluable advice on Chapters 2 and 3 in this thesis. There are many people I worked with at Leverett Base camp who made this project possible. I would especially like to thank Catie Butler, David Chandler, Stewart Vinnen, John Hawkings, Mauro Werder, and Andrew Tedstone. Furthermore, Catie Butler and David Chandler helped collect some of the oxygen and deuterium isotope samples that appear in Chapter 3 of this thesis.

My life in Woods Hole was deeply enriched by great friends and I could not have completed my Ph.D. without them. I have been extremely luck to live for five years in such a welcoming and generous community. To my friends -Nicholas Macfarlane, Alice Alpert, Alexis Fisher, Jill McDermitt, Meagan Gonneea, Julian Schanze, Jeff Kaeli, Ellie Bors, Tyler Goepfert, Tristan Kading, Genevieve Goldleaf, Carly Buchwald, Laura Stevens, and my dog Kenai -all I can hope is that our paths will cross again often and that we will have many more adventures together. Woods Hole has been a blast and I'm deeply sorry to be leaving. To my girlfriend Lizzie Kripke, 
thank you for providing endless support through the best and hardest parts of my Ph.D. I couldn't be more excited for our future together.

Finally, I would like to thank my parents, John and Kristin Linhoff, for all the trips to the science museum so that I could see the dinosaurs, for all the trips to the Badlands of South Dakota so that I could look for dinosaurs, and for all the years of continual, unwavering support through the ups and downs of my education. You've always been there. To my siblings Jenny and Luke, you were my first friends and have always been a source of entertainment while your generosity has been an inspiration. None of this would exist without your love and dedication to me, and I thank you for this. For my family, this thesis is your success as much as it is mine.

Funding for this work was provided by the U.S. National Science Foundation Arctic Natural Sciences Program (ANS-1256669); Woods Hole Oceanographic Institution Arctic Research Initiative, Ocean Ventures Fund, and Ocean Climate Change Institute; United Kingdom Natural Environment Research Council studentship (NE/152830X/1); the Carnegie Trust, Edinburgh University Development Trust. 


\section{Table of Contents}

$\begin{array}{ll}\text { Abstract } & 3\end{array}$

Acknowledgements $\quad 5$

$\begin{array}{lr}\text { Table of Contents } & 7\end{array}$

$\begin{array}{lr}\text { List of Tables } & 10\end{array}$

List of Figures $\quad 11$

Chapter 1. Introduction $\quad 13$

Chapter 2. Utility of ${ }^{222} \mathrm{Rn}$ as a passive tracer of subglacial distributed system drainage 26

1. Introduction 27

2. Methods 29

$2.1 \quad$ Study area 29

2.2 Discharge, conductivity, and suspended sediment measurements $\quad 30$

2.3 Measuring radon in the proglacial river 30

$2.4 \quad{ }^{222} \mathrm{Rn}$ in subglacial distributed systems and sediment properties $\quad 32$

3. Results 33

$\begin{array}{lll}3.1 & \text { Discharge } & 33\end{array}$

3.2 EC and SSC $\quad 33$

3.3 Radon-222 in the Proglacial River 34

3.4 Radon in groundwater and estimated distributed systems 36

4. Discussion $\quad 37$

$\begin{array}{lll}4.1 & \text { Radon-222 sources and sinks } & 38\end{array}$

$\begin{array}{lll}\text { 4.1.1 Suspended sediment } & { }^{226} \mathrm{Ra}\left(\mathrm{P}_{\mathrm{SSL}}\right) & 38\end{array}$

4.1.2 Dissolved ${ }^{226} \mathrm{Ra}\left(\lambda^{226} \mathrm{Ra}\right) \quad 39$

4.1.3 Diffusive flux of ${ }^{222} \mathrm{Rn}$ in channels $\left(\mathrm{J}_{\text {cha }}\right) \quad 39$

4.1.4 Gas exchange $\left(\mathrm{F}_{\mathrm{atm}}\right) \quad 40$

4.1.5 Radon-222 decay $\left(\lambda^{222} \mathrm{Rn}\right) \quad 42$

$\begin{array}{lll}\text { 4.1.6 Distributed system flux }\left(\mathrm{J}_{\text {dis }}\right) & 43\end{array}$

4.2 Estimating the distributed system flux 44

$\begin{array}{lll}\text { 4.2.1 Model limitations and caveats } & 45\end{array}$

4.3 Interpretations of the distributed system flux 45

4.4 Interannual differences in the distributed system flux: implications for chemical fluxes from the Greenland Ice Sheet 47

5. Conclusions $\quad 48$

S1. Supporting information $\quad 57$

Chapter 3. Distributed system subglacial drainage controlled by channel expansion and meltwater runoff on the Greenland Ice Sheet $\quad 76$

$\begin{array}{ll}\text { 1. Introduction } & 77\end{array}$

1.1 Greenland Ice Sheet Hydrology 77

$\begin{array}{lll}1.2 & \text { Tracing distributed system drainage } & 79\end{array}$

$\begin{array}{lll}1.3 & \text { Estimating meltwater runoff inputs } & 80\end{array}$ 
$\begin{array}{lll}1.4 & \text { Setting and prior studies } & 81\end{array}$

2. Methods 83

$2.1 \quad$ Ice Motion $\quad 83$

$\begin{array}{lll}2.2 & \text { Proglacial river discharge } & 83\end{array}$

$\begin{array}{lll}2.3 & \text { Timing of supraglacial lake drainage events } & 84\end{array}$

2.4 Tracing surface meltwater using oxygen and deuterium isotopes $\quad 84$

2.5 Measuring radon in the proglacial river and calculating the subglacial $\begin{array}{lr}\text { distributed system flux } & 85\end{array}$

$\begin{array}{lll}2.6 & \text { Air temperature } & 87\end{array}$

2.7 Estimating meltwater runoff using a positive degree-day model 87

2.8 Meltwater runoff estimated using RACMO2.3

3. Results 90

$\begin{array}{lll}3.1 & \text { Discharge } & 90\end{array}$

$\begin{array}{ll}3.2 \text { Temperature } & 90\end{array}$

$\begin{array}{lll}3.3 & \text { Meltwater runoff } & 91\end{array}$

$3.4 \delta^{2} \mathrm{H}$ and $\delta^{18} \mathrm{O}$ of meltwater and ice $\quad 92$

$\begin{array}{lll}3.5 & \text { SSC and EC } & 94\end{array}$

3.6 Ice motion $\quad 94$

$\begin{array}{ll}3.7 \quad \text { Radon-222 and } \mathrm{J}_{\mathrm{dis}} & 95\end{array}$

4. Discussion $\quad 96$

4.1 Comparison between meltwater runoff models and proglacial river discharge 96

4.2 Source of meltwater runoff inferred from $\delta^{2} \mathrm{H}$ and $\delta^{18} \mathrm{O}$ isotopes $\quad 99$

4.3 Relationships between distributed system drainage, glacial velocity, and

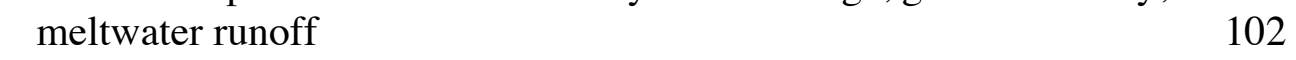

5. Summary and Conclusions 106

Chapter 4. Controls on the strontium, uranium, and radium isotope fluxes from the Greenland Ice Sheet

$\begin{array}{ll}1.1 & \text { Radium isotopes } \\ 1.2 & 138\end{array}$

$\begin{array}{lll}1.2 & \text { Uranium isotopes } & 139\end{array}$

$\begin{array}{lll}1.3 & \text { Strontium isotopes } & 141\end{array}$

2. Methods

142

$\begin{array}{lll}2.1 & \text { Site description } & 142\end{array}$

2.2 Sample collection 143

2.3 Suspended sediment digestion 144

$\begin{array}{lll}2.4 & \text { Radium analysis } & 144\end{array}$

2.5 Trace element, major cation and isotope analyses 145

$\begin{array}{lll}2.6 & \left({ }^{234} \mathrm{U} /{ }^{238} \mathrm{U}\right) \text { analysis } & 147\end{array}$

$2.7 \quad{ }^{87} \mathrm{Sr} /{ }^{86} \mathrm{Sr}$ analysis $\quad 148$

3. Results

$\begin{array}{lll}3.1 & \text { River discharge and } \mathrm{pH} & 149\end{array}$

3.2 Dissolved major and trace metals results 150

3.3 Results of acetic acid digestion of the suspended sediment load 151

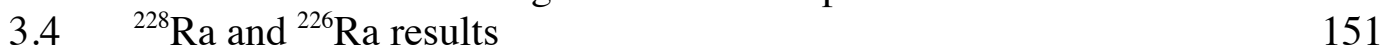


$3.5 \quad \delta^{234} U$ results $\quad 152$

$3.6 \quad{ }^{87} \mathrm{Sr} /{ }^{86} \mathrm{Sr}$ results $\quad 154$

4. Discussion $\quad 155$

4.1 Hydrogeochemistry of meltwaters 155

4.2 Radium isotopes 157

4.3 Potential impact of colloids on dissolved ${ }^{87} \mathrm{Sr} /{ }^{86} \mathrm{Sr}$ and $\delta^{234} \mathrm{U}$

4.4 Uranium isotopes 160

4.5 Strontium isotopes 163

4.6 Chemical index of alteration 165

4.7 Flux of Ra, Sr and U from the Greenland Ice Sheet 165

$\begin{array}{ll}\text { 5. Conclusions } & 167\end{array}$

Chapter 5: Concluding remarks and future research directions 205

Appendix. Mercury in glacial meltwater 213 


\section{List of Tables}

\section{Chapter 2}

S1. Summary of $250 \mathrm{~mL}$ discrete ${ }^{222} \mathrm{Rn}$ samples collected in 2011

Chapter 3

1. Mean temperature on the ice sheet surface 109

2. $\delta^{18} \mathrm{O}$ and $\delta^{2} \mathrm{H}$ results from ice and precipitation in $2012 \quad 110$

Chapter 4

1. Trace metal and major cation analyses of certified reference materials 169

2. $\mathrm{pH}$ of Leverett Glacier proglacial river in $2011 \quad 170$

3. Results of elemental and isotopic analyses of Leverett Glacier proglacial river 172

4. Results of elemental and isotopic analyses of samples moving downstream of the

Greenland Ice Sheet

5. Results of elemental and isotopic analyses of fjord and pond, and delayed filtering samples

6. Results of elemental and isotopic analyses of acetic acid digestion of riverine suspended sediments

7. Elemental results of total sediment digestion completed by

Hindshaw et al. (2014)

179

8. Radium isotope analyses

178 


\section{List of Figures}

Chapter 1

1. Schematic of changing ice mass of the Greenland Ice Sheet 19

2. Illustration of elements of subglacial hydrological system 20

Chapter 2

1. Map of Leverett Glacier and sampling location 50

2. ${ }^{222} \mathrm{Rn}, \mathrm{Ec}, \mathrm{SSC}$, and discharge results from 2011 and 2012

3. Close up of ${ }^{222} \mathrm{Rn}, \mathrm{Ec}, \mathrm{SSC}$, and discharge results in 2012

4. $\quad{ }^{222} \mathrm{Rn}$ vs. discharge, EC, and SSC during a spike in the 222Rn flux 53

5. Summary of ${ }^{222} \mathrm{Rn}$ sources and sinks in the subglacial system 54

6. Relative contributions of subglacial ${ }^{222} \mathrm{Rn}$ sources $\quad 55$

7. Estimated distributed system flux 56

S1 Discrete ${ }^{222} \mathrm{Rn}$ samples compared to time-series ${ }^{222} \mathrm{Rn}$ measurements 62

$\mathrm{S} 2 \quad$ Equilibrium time of the ${ }^{222} \mathrm{Rn}$ water probe 63

Chapter 3

1. Map of the inferred Leverett Glacier catchment 111

2. Map of Leverett Glacier and RACMO2.3 grid 112

3. Results of discharge with PDD and RACMO2.3 runoff 113

4. Detail of RACMO2.3 runoff and discharge in $2011 \quad 114$

5. Detail of RACMO2.3 and PDD runoff with discharge in 2012

6. $\delta^{2} \mathrm{H}$ results in 2011 and 2012 with estimated elevation of runoff 116

7. The local meteoric water line constructed using $\delta^{2} \mathrm{H}$ and $\delta^{18} \mathrm{O}$ results 117

8. $\quad{ }^{222} \mathrm{Rn}$ flux, runoff, discharge, EC, and SSC results from 2011 and $2012 \quad 118$

9. Glacial velocity, meltwater runoff, and river discharge 119

10. Meltwater runoff and river discharge compared to vertical displacement on the ice $\begin{array}{ll}\text { sheet surface } & 120\end{array}$

11. Distributed system ${ }^{222} \mathrm{Rn}$ flux compared with meltwater runoff and river discharge

12. Distributed system ${ }^{222} \mathrm{Rn}$ flux compared to glacial velocity 122

13. Timing of distributed system drainage and supraglacial lake drainage events 123

Chapter 4

1. Map of Leverett Glacier and sampling locations 181

2. Geological map of region surrounding Leverett Glacier 182

3. Results from Leverett Glacier proglacial river of ${ }^{87} \mathrm{Sr} /{ }^{86} \mathrm{Sr}, \mathrm{Sr}$, discharge, and $\begin{array}{ll}\mathrm{Ca} / \mathrm{Na} \text { molar ratios } & 183\end{array}$

4. Delayed filtering experiment of ${ }^{87} \mathrm{Sr} /{ }^{86} \mathrm{Sr}$ and $\delta^{234} \mathrm{U}$ isotope systems $\quad 184$

5. Molar ratios of $\mathrm{Mg} / \mathrm{Na}$ versus $\mathrm{Ca} / \mathrm{Na}$ and $\mathrm{Ca} / \mathrm{Na}$ and $\mathrm{Sr} / \mathrm{Na}$ for Leverett Glacier $\begin{array}{ll}\text { samples and various watershed types } & 185\end{array}$

6. Radium isotope results from the Leverett Glacier proglacial river in $2011 \quad 186$

7. Uranium isotope and concentration results from the Leverett Glacier proglacial river 
8. Strontium and uranium isotope results from sampling transect moving downstream of the Greenland Ice Sheet

9. Temporal changes in the molar ratios of $\mathrm{Mg} / \mathrm{Na}, \mathrm{Ca} / \mathrm{Na}, \mathrm{Sr} / \mathrm{Na}$, and $\mathrm{Ca} / \mathrm{Sr}$ in the Leverett Glacier proglacial river

10. The potential effect of sub $0.45 \mu \mathrm{m}$ particles on the measured $\delta^{234} \mathrm{U}$ and ${ }^{87} \mathrm{Sr} /{ }^{86} \mathrm{Sr}$ results

11. Coral records showing how marine $\delta^{234} U$ may have change from glacial to interglacial periods

12. ${ }^{87} \mathrm{Sr} /{ }^{86} \mathrm{Sr}$ results compared with molar ratios of $\mathrm{Ca} / \mathrm{Sr}, \mathrm{Na} / \mathrm{Sr}$, and $\mathrm{Ca} / \mathrm{Na}$ of Leverett Glacier proglacial samples. 


\section{Chapter 1}

\section{Introduction}

\subsection{Motivation for research}

Mass loss from the Greenland Ice Sheet (GrIS) has rapidly increased over the last several decades (Figure 1; Rignot and Kanagaratnam, 2006; Velicogna and Wahr, 2013). Much of the uncertainty related to sea level rise in the next century and beyond is associated with unknowns in the contributions from the Greenland and Antarctic ice sheets (Alley et al., 2005). As melting of the GrIS makes up a major contribution to sea level rise (Jacob et al., 2012), climate models require a greater understanding of the mechanisms that drive ice transport from high accumulation zones to down slope ablation zones. With this increased mass loss there is the potential for increased glacial weathering products and dissolved chemical fluxes. Significantly, the annual flux of meltwater from the GrIS is currently equivalent to the Mississippi River (Velicogna and Wahr, 2013), and some chemical fluxes from the GrIS have been estimated to be as large those from major Arctic rivers (Bhatia et al., 2013; Hawkings et al., 2014). Therefore, determining the chemical composition of the meltwater draining the Greenland Ice Sheet and the mechanisms that influence downhill motion, and therefore accelerate melting, is critical. As the rapid melting of the GrIS is an analog to past global deglaciations, it is also important to study geochemical fluxes thought to be influenced by glacial cycles (Hodell et al., 1990; Blum and Erel, 1995; Rhodes et al., 2002; Robinson et al., 2004).

Predicting the impact of the world's polar ice melt on sea level rise and chemical inputs to the ocean rests on understanding ice sheet and glacier hydrology (Alley et al., 2005; Anderson et al., 2003b; Hindshaw et al., 2011; Shepherd and Wingham, 2007). Glaciers and ice sheets 
transport ice through plastic deformation of ice, deformation of the bed and through basal sliding (Bartholomew et al., 2011b; Cuffey and Paterson, 2010). While internal deformation is fairly steady with relatively little interannual variability, basal sliding varies over sub diurnal to annual timescales (Bell, 2008) and is controlled by the highly dynamic hydrological system of a glacier (Figure 2; Cowton et al., 2013; Das et al., 2008; Joughin et al., 2008).

In the spring and summer, supraglacial streams and lakes drain through moulins to the ice sheet bed (Figure 2) where the flux of meltwater increases basal water pressure and induces short-term glacial acceleration (Das et al., 2008; Bartholomew et al., 2010; Chu, 2014). While climate warming may be responsible for recent accelerations of the GrIS and doubling of GrIS's contribution to sea level rise between 1996 and 2005 (Rignot and Kanagaratnam, 2006), the influence of hydrologically forced basal sliding on GrIS mass loss is unclear. At the onset of spring melt, outlet glaciers of the GrIS accelerate and reach maximum annual velocities (Bartholomew et al., 2010). By mid-summer ice velocity slows despite increased meltwater inputs (Tedstone et al., 2013). Mid-summer slow downs are thought to be the result of the development of large, efficient channels at the ice sheet bed capable of quickly evacuating large volumes of meltwater (Rothlisberger, 1969). Observations have found that spring ice acceleration events are more than compensated for by slower mid-summer and winter velocities such that interannual glacial velocity appears to remain relatively constant regardless of meltwater inputs (Sole et al., 2013; Tedstone et al., 2013). This effectively creates a feedback mechanism whereby faster glacial speeds driven by increased supraglacial meltwater runoff are compensated by slower speeds later in the summer and into the winter. Recent research has suggested that slower velocities observed following large meltwater runoff events may be the result of increased connectivity of non-channelized distributed drainage networks (Sole et al., 
2013; Andrews et al., 2014). Furthermore, in addition to influencing glacial dynamics, the path meltwater travels through and under a glacier controls meltwater chemistry and chemical weathering (Raiswell, 1984).

Though direct observations of subglacial hydrology are inherently difficult to obtain, characterizing the basal hydrologic system under glaciers and ice sheets is critical to understanding ice flow and the interaction of meltwater with its surroundings, as well as predicting future behavior. Purposeful tracer releases (e.g. Rhodamine and $\mathrm{SF}_{6}$ ) into moulins on the ice sheet surface have aided the characterization of the subglacial hydrologic system (Anderson et al., 2003; Chandler et al., 2013; Cowton et al., 2013; Hock et al., 1999); however, they have limited ability to trace exchange between distributed and channelized systems. Using hydrochemistry to trace glacial hydrology is problematic as source waters and chemical weathering rates vary on several time scales (Tranter et al., 1997), and post-mixing solute acquisition alters the chemical composition of meltwater causing non-conservative chemical mixing (Raiswell, 1984). Boreholes offer direct observations, but also require extraordinary effort (Harper et al., 2005; Andrews et al., 2014), and as discrete point observations they may be a poor representation of the overall inhomogeneous basal hydrological environment. Because of the importance of subglacial distributed and channelized system drainage in influencing glacial dynamics and meltwater chemistry, there is a need to develop robust methods for tracing distributed system flows.

Chemical weathering of continental silicate rocks results in drawdown of carbon dioxide from the Earth's atmosphere regulating the Earth's climate on long timescales (Walker et al., 1981). Studies of glacier-covered alpine catchments have found that chemical weathering rates are much higher than the global average, which has led to speculation that glacial weathering can 
cause significant atmospheric $\mathrm{CO}_{2}$ drawdown (Blum and Erel, 1995). However, the subglacial weathering is driven by weathering of trace carbonates regardless of bedrock type (Anderson et al., 1997). While glaciers produce highly abraded and strained mineral surfaces that are easily weathered, subglacial weathering may not have a major effect on the global carbon cycle (Tranter et al., 2002) nor sediments at a glacier's margin (Anderson et al., 2000). However, glacially derived sediments transported downstream could have a major effect on the carbon cycle (Anderson, 2007; Zachos et al., 1999), and solute fluxes for certain trace elements may be on par with major rivers when scaled up to the entire Greenland Ice Sheet (Bhatia et al., 2013; Hagedorn and Hasholt, 2004). What is not known is how the dynamic subglacial hydrological system influences subglacial weathering and glacial weathering products.

Through a two-year field study of a land-terminating glacier on the Greenland Ice Sheet, this dissertation presents a comprehensive view of how glacial hydrology influences glacial dynamics and meltwater geochemistry while also examining the impact of supraglacial meltwater runoff on subglacial drainage pathways.

\subsection{Data collection}

The work presented in this dissertation is based on samples and data collected during two field seasons (over 180 days of data collection) in the spring and summer of 2011 and 2012 at the margins of the GrIS. During both field seasons, I measured and collected samples from the large proglacial river of Leverett Glacier, a land terminating glacier in southwest Greenland. The focus of my fieldwork was measuring ${ }^{222} \mathrm{Rn}$ activities in the proglacial river and collecting samples for $\mathrm{Ra}, \mathrm{Sr}$, and $\mathrm{U}$ isotopes as well as major cation and trace metal concentrations. While in the field, I also assisted in the maintenance of on-ice global positioning systems (GPS), temperature 
sensors, and helped make river discharge measurements -other data that appears in this work.

Furthermore, I collected hundreds of samples for tracer experiments used to determine the transit time of supraglacial meltwater inputs (Chandler et al., 2013), data that I use in Chapter I to constrain ${ }^{222} \mathrm{Rn}$ decay during transit through the subglacial channelized system.

\subsection{Chapter introductions}

In Chapter 2, I build on the work of Bhatia et al. (2011) who examined the utility of ${ }^{222} \mathrm{Rn}$ as a tracer of delayed flow waters beneath the GrIS. The conclusions of Bhatia et al. (2011) were that discrete ${ }^{222} \mathrm{Rn}$ measurements can aid in hydrograph separation of the relative contributions of delayed flow and quick flow meltwater. During the 2011 and 2012 field seasons, I produced the first multi-season continuous record of ${ }^{222} \mathrm{Rn}$ activities in a river. By quantifying each subglacial

${ }^{222} \mathrm{Rn}$ source and sink, I show that ${ }^{222} \mathrm{Rn}$ measurements in a proglacial river can be used to estimate the flux of distributed system meltwater.

In Chapter 3, I examine the relationship between supraglacial meltwater runoff, glacial velocity, and the flux of distributed system drainage. I utilize two independent models of supraglacial meltwater runoff to infer the timing of meltwater inputs to the ice sheet bed. I compare these results with glacial velocity and the flux of distributed system meltwater as inferred from the continuous ${ }^{222} \mathrm{Rn}$ record. This work shows for the first time the relationships between these parameters using a tracer of distributed system meltwater. Furthermore, while previous work has speculated on the importance of distributed system drainage on regulating glacial velocity (Sole et al., 2013; Andrews et al., 2014), in Chapter 3, I evaluate the cause and effect of variable distributed system drainage on glacial velocity using my unique observations. 
In Chapters 2 and 3, I show that subglacial meltwater travels through both slow and fast flow paths and that meltwater rapidly moves between distributed and channelized systems. In Chapter 4, I examine the effect of the subglacial hydrological system on subglacial rock weathering. I use $\mathrm{Sr}, \mathrm{U}$, and Ra isotopes and major and trace element chemistry to evaluate how the seasonal evolution of glacial hydrology influences meltwater chemistry and subglacial weathering. Notably, this work is the first investigation of the Ra flux from the GrIS as well as how $\mathrm{U}$ and $\mathrm{Ra}$ isotope systems are influenced by the evolution of subglacial hydrology. Using the $\mathrm{U}$ and Ra systems, I found evidence that the subglacial hydrological system causes significant chemical weathering of rock material. Contrary to the assumption made in Robinson et al. (2004) that glacial meltwater is a source of ${ }^{234} \mathrm{U}$ to the ocean, I found that glacial meltwater has surprisingly low $\delta^{234} \mathrm{U}$ values more similar to watersheds draining regions with intense chemical weathering. The ${ }^{228} \mathrm{Ra} /{ }^{226} \mathrm{Ra}$ ratio in the dissolved phase was significantly higher than the solid phase suggesting that Ra weathering was significant enough that the faster ingrowth rate of ${ }^{228} \mathrm{Ra}\left(\mathrm{t}_{1 / 2}=5.75 \mathrm{y}\right)$ relative to ${ }^{226} \mathrm{Ra}\left(\mathrm{t}_{1 / 2}=1600 \mathrm{y}\right)$ accounted for the high ${ }^{228} \mathrm{Ra} /{ }^{226} \mathrm{Ra}$ values. So while glaciers cause extreme physical weathering (Egholm et al., 2009), subglacial routing of meltwater between distributed and channelized systems drives substantial chemical weathering. I also found that similar to watersheds in the Himalayas (Blum et al., 1998), the ${ }^{87} \mathrm{Sr} /{ }^{86} \mathrm{Sr}$ ratio in the dissolved phase of the proglacial river was controlled by weathering of radiogenic carbonates. Finally, as the marine $\mathrm{U}$ and $\mathrm{Sr}$ isotope systems are thought to be influenced by glacial weathering products (Hodell et al., 1990; Blum and Erel, 1995; Rhodes et al., 2002; Robinson et al., 2004), this chapter examines how glaciation might have influenced these systems in past glacial cycles. 


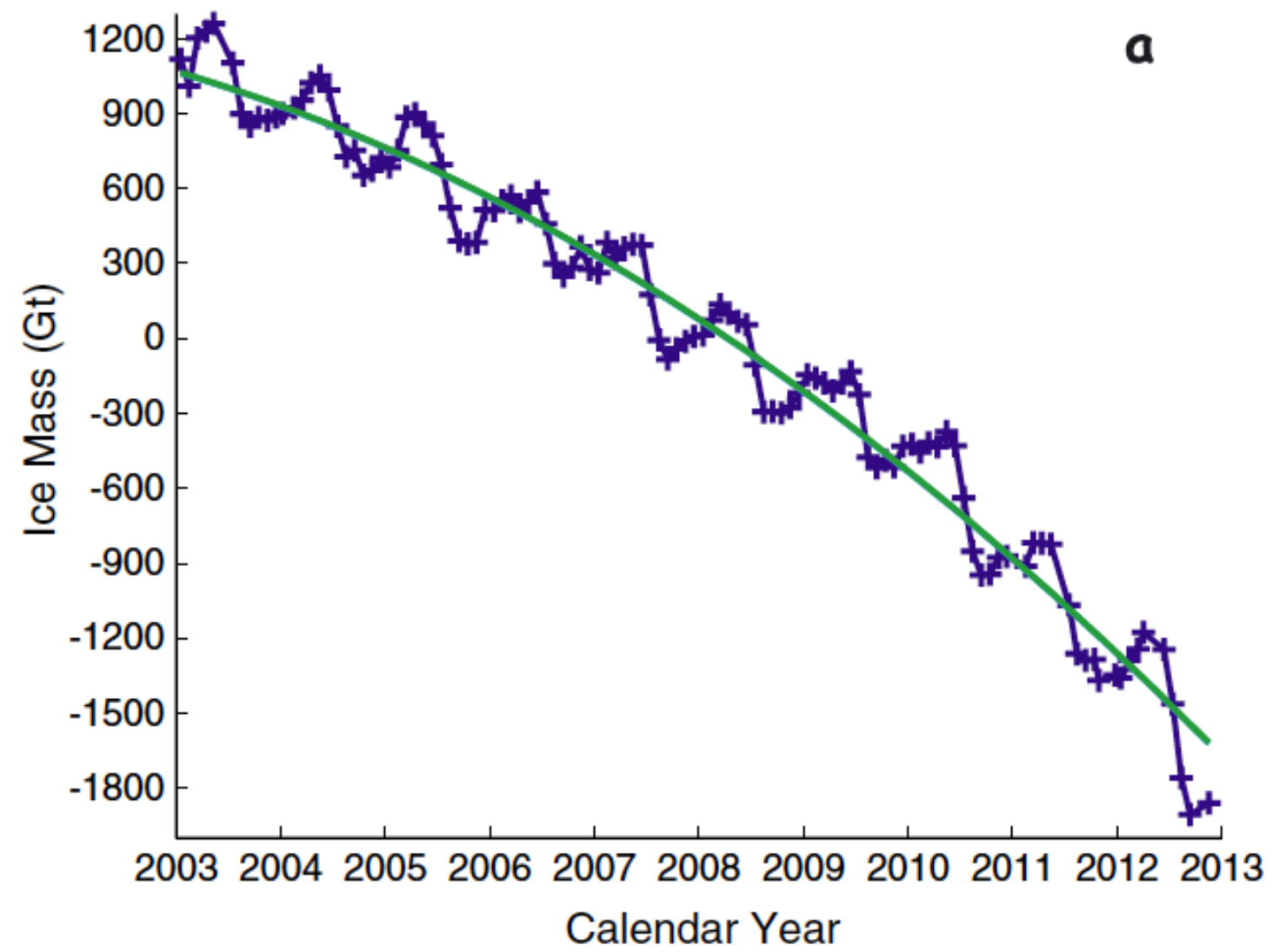

Figure 1: Time series of ice mass changes in gigatons relative to an arbitrary datum for the Greenland Ice Sheet from January 2003 to November 2012. The best-fit quadratic trend is shown in green (Figure from Velicogna and Wahr, 2013). 


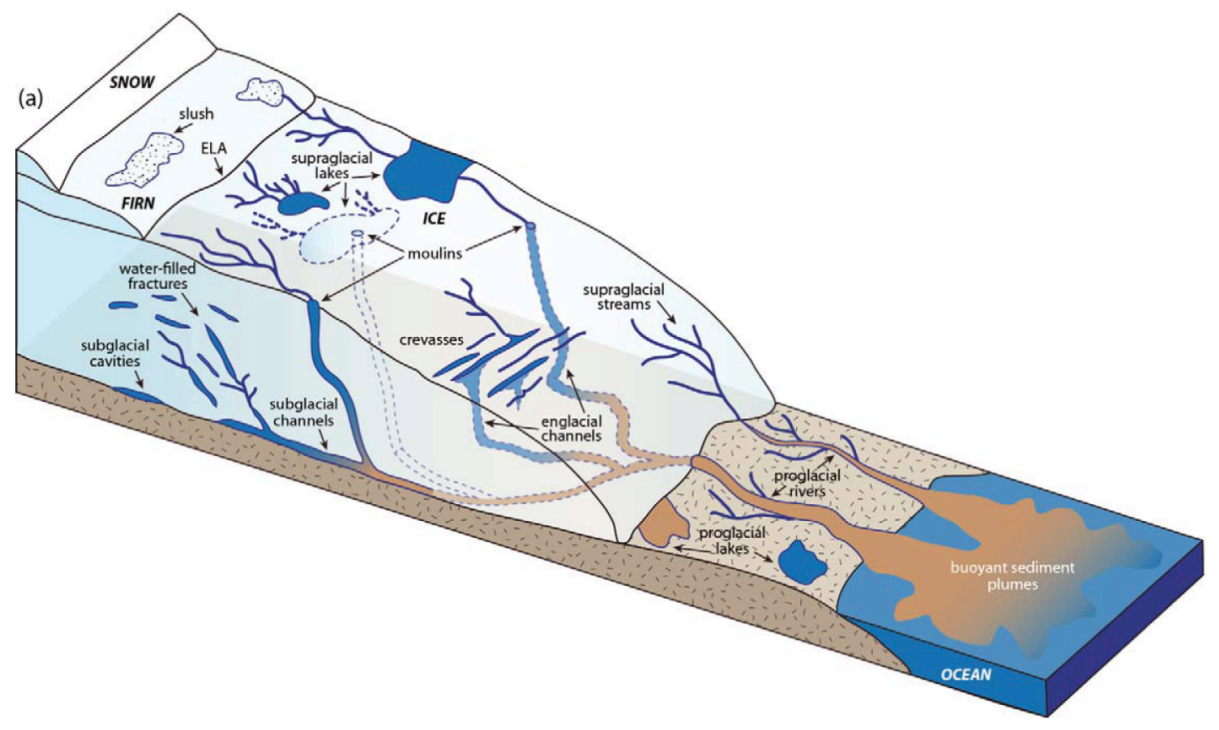

Figure 2: Illustration from Chu, 2014, showing the elements of the GrIS hydrologic system. In the summer below the equilibrium line altitude (ELA) meltwater forms in the ablation zone where it travels through supraglacial streams towards lakes and moulins. There it travels englacially and subglacially to the ice sheet margin. During mid-summer flows, the majority of meltwater travels through large channels that are fed by moulins and meltwater in the the nonchannelized distributed sections of the ice sheet bed (Werder et al., 2013). 


\section{References}

Alley, R. B., P. U. Clark, P. Huybrechts, and I. Joughin (2005), Ice-sheet and sea-level changes., Science, 310(5747), 456-60, doi:10.1126/science.1114613.

Anderson, S. P. (2007), Biogeochemistry of Glacial Landscape Systems, Annu. Rev. Earth Planet. Sci., 35(1), 375-399.

Anderson, S. P., J. I. Drever, and N. F. Humphrey (1997), Chemical weathering in glacial environments, Geology, 25(5), 399-402.

Anderson, S. P., J. I. Drever, C. D. Frost, and P. Holden (2000), Chemical weathering in the foreland of a retreating glacier, Geochim. Cosmochim. Acta, 64(7), 1173-1189.

Anderson, S. P., S. A. Longacre, and E. R. Kraal (2003), Patterns of water chemistry and discharge in the glacier-fed Kennicott River, Alaska : evidence for subglacial water storage cycles, Chem.Geol., 202, 297 - 312, doi:10.1016/j.chemgeo.2003.01.001.

Andrews, L. C., G. A. Catania, M. J. Hoffman, J. D. Gulley, M. P. Luthi, C. Ryser, R. L. Hawley, and T. A. Neumann (2014), Direct observations of evolving subglacial drainage beneath the Greenland Ice Sheet, Nature, 514(7520), 80-83.

Bartholomew, I., P. Nienow, D. Mair, A. Hubbard, M. a. King, and A. Sole (2010), Seasonal evolution of subglacial drainage and acceleration in a Greenland outlet glacier, Nat. Geosci., 3(6), 408-411, doi:10.1038/ngeo863. 
Bhatia, M. P., S. B. Das, E. B. Kujawinski, P. Henderson, A. Burke, and M. A. Charette (2011), Seasonal evolution of water contributions to discharge from a Greenland outlet glacier : insight from a new isotope-mixing model, J. Glaciol., 57(205), 929-941.

Bhatia, M. P., E. B. Kujawinski, S. B. Das, C. F. Breier, P. B. Henderson, and M. A. Charette (2013), Greenland meltwater as a significant and potentially bioavailable source of iron to the ocean, Nat. Geosci., 6(4), 274-278, doi:10.1038/ngeo1746.

Blum, J. D., and Y. Erel (1995), A silicate weathering mechanism linking increases in marine 87Sr/86Sr with global glaciation, Nature, 373, 415-418, doi:doi:10.1038/373415a0.

Chandler, D. M., J. L. Wadham, G. P. Lis, T. Cowton, A. Sole, I. Bartholomew, J. Telling, P. Nienow, E. B. Bagshaw, and D. Mair (2013), Evolution of the subglacial drainage system beneath the Greenland Ice Sheet revealed by tracers, Nat. Geosci., 6(3), 195-198.

Chu, V. W. (2014), Greenland ice sheet hydrology: A review, Prog. Phys. Geogr., 38(1), 19-54.

Cowton, T., P. Nienow, A. Sole, J. Wadham, G. Lis, I. Bartholomew, D. Mair, and D. Chandler (2013), Evolution of drainage system morphology at a land-terminating Greenlandic outlet glacier, J. Geophys. Res. Earth Surf., 118(1), 29-41.

Das, S. B., I. Joughin, M. D. Behn, I. M. Howat, M. A. King, D. Lizarralde, and M. P. Bhatia (2008), Fracture propagation to the base of the Greenland ice sheet during supraglacial lake drainage, Science, 320(5877), 778-781.

Egholm, D. L., S. B. Nielsen, V. K. Pedersen, and J.-E. Lesemann (2009), Glacial effects limiting mountain height, Nature, 460(7257), 884-887. 
Hagedorn, B., and B. Hasholt (2004), Hydrology, geochemistry and Sr isotopes in solids and solutes of the meltwater from Mittivakkat Gletscher, SE Greenland., Nord. Hydrol., 35, $369-380$.

Harper, J. T., N. F. Humphrey, W. T. Pfeffer, T. Fudge, and S. O. Neel (2005), Evolution of subglacial water pressure along a glacier's length, Ann. Glaciol., (1981), 31-36.

Hawkings, J. R., J. L. Wadham, M. Tranter, R. Raiswell, L. G. Benning, P. J. Statham, A. Tedstone, P. Nienow, K. Lee, and J. Telling (2014), Ice sheets as a significant source of highly reactive nanoparticulate iron to the oceans, Nat. Commun., 5 , doi:10.1038/ncomms4929.

Hindshaw, R. S., E. T. Tipper, B. C. Reynolds, E. Lemarchand, J. G. Wiederhold, J. Magnusson, S. M. Bernasconi, R. Kretzschmar, and B. Bourdon (2011), Hydrological control of stream water chemistry in a glacial catchment, Chem. Geol., 285(1-4), 215-230, doi:10.1016/j.chemgeo.2011.04.012.

Hock, R. (2003), Temperature index melt modelling in mountain areas, J. Hydrol., 282(1-4), 104-115, doi:http://dx.doi.org/10.1016/S0022-1694(03)00257-9.

Hodell, D. A., G. A. Mead, and P. A. Mueller (1990), Variation in the strontium isotopic composition of seawater ( $8 \mathrm{Ma}$ to present): Implications for chemical weathering rates and dissolved fluxes to the oceans, Chem. Geol. Isot. Geosci. Sect., 80(4), 291-307.

Jacob, T., J. Wahr, W. T. Pfeffer, and S. Swenson (2012), Recent contributions of glaciers and ice caps to sea level rise, Nature, 482(7386), 514-518. 
Raiswell, R. (1984), Chemical models of solute acquisition in glacial meltwaters, J. Glaciol., 30(104), 49-57.

Rhodes, M. K., A. R. Carroll, J. T. Pietras, B. L. Beard, and C. M. Johnson (2002), Strontium isotope record of paleohydrology and continental weathering, Eocene Green River Formation, Wyoming, Geology, 30(2), 167-170.

Rignot, E., and P. Kanagaratnam (2006), Changes in the velocity structure of the Greenland Ice Sheet, Science, 311(5763), 986-990.

Robinson, L. F., G. M. Henderson, and L. Hall (2004), Climatic Control of Riverine and Seawater Uranium-Isotope Ratios, Science, 305(851), 89, doi:10.1126/science.1099673.

Shepherd, A., and D. Wingham (2007), Recent sea-level contributions of the Antarctic and Greenland ice sheets, Science, 315(5818), 1529-1532.

Sole, A., P. Nienow, I. Bartholomew, D. Mair, T. Cowton, A. Tedstone, and M. A. King (2013), Winter motion mediates dynamic response of the Greenland ice sheet to warmer summers, Geophys. Res. Lett., 40(15), 3940-3944.

Tranter, M., M. J. Sharp, G. H. Brown, I. C. Willis, B. P. Hubbard, M. K. Nielsen, C. C. Smart, S. Gordon, M. Tulley, and H. R. Lamb (1997), Variability in the chemical composition of in situ subglacial meltwaters, Hydrol. Process., 11(1), 59-77, doi:10.1002/(SICI)10991085(199701)11:1<59::AID-HYP403>3.0.CO;2-S. 
Tranter, M., M. J. Sharp, H. R. Lamb, G. H. Brown, B. P. Hubbard, and I. C. Willis (2002), Geochemical weathering at the bed of Haut Glacier d'Arolla, Switzerland a new model, Hydrol. Process., 16(5), 959-993.

Velicogna, I., and J. Wahr (2013), Time-variable gravity observations of ice sheet mass balance: Precision and limitations of the GRACE satellite data, Geophys. Res. Lett., 40(12), 30553063.

Walker, J. C. G., P. B. Hays, and J. F. Kasting (1981), A negative feedback mechanism for the long-term stabilization of the Earth's surface temperature, J. Geophys. Res., 86(C10), 97769782.

Werder, M. A., I. J. Hewitt, C. G. Schoof, and G. E. Flowers (2013), Modeling channelized and distributed subglacial drainage in two dimensions, J. Geophys. Res. Earth Surf., 118(4), 2140-2158.

Zachos, J. C., B. N. Opdyke, T. M. Quinn, C. E. Jones, and A. N. Halliday (1999), Early cenozoic glaciation, antarctic weathering, and seawater ${ }^{87} \mathrm{Sr} /{ }^{86} \mathrm{Sr}$ : is there a link?, Chem . Geol., 161(1), 165-180. 


\title{
Chapter 2
}

\section{Utility of ${ }^{222} \mathrm{Rn}$ as a passive tracer of subglacial distributed system drainage}

\begin{abstract}
At the margin of the Greenland Ice Sheet (GrIS), most surface meltwater drains through moulins to the ice sheet bed. Once there, meltwater may partition between efficient channelized and inefficient distributed drainage systems; this partitioning plays an important role in meltwater chemistry and glacial velocity. Radon-222, which is continuously produced via the decay of ${ }^{226} \mathrm{Ra}$, can only accumulate in meltwater that has had significant contact with rock and/or sediment. Hence, it should be an ideal tracer of distributed system flow. In the spring and summer of 2011 and 2012, we made hourly ${ }^{222} \mathrm{Rn}$ measurements in the proglacial river of an outlet glacier of the GrIS. Radon-222 activities were highest in the early melt season (10-15 dpm $\mathrm{L}^{-1}$ ); following the onset of widespread melt, ${ }^{222} \mathrm{Rn}$ typically varied between $3-5 \mathrm{dpm} \mathrm{L}^{-1}$. We quantified glacial meltwater ${ }^{222} \mathrm{Rn}$ sources and sinks and determined that distributed system meltwater contributed $>90 \%$ of the ${ }^{222} \mathrm{Rn}$ flux. Using laboratory estimates of the ${ }^{222} \mathrm{Rn}$ activity of distributed system meltwater, we estimated the distributed system meltwater flux. This flux varied between $0.1-16 \mathrm{~m}^{3} \mathrm{~s}^{-1}$ representing between $0.7-2.4 \%$ of total proglacial river discharge. Diurnal variations in the distributed system flux were between 1-3 $\mathrm{m}^{3} \mathrm{~s}^{-1}$ in 2011 and between 2$6 \mathrm{~m}^{3} \mathrm{~s}^{-1}$ in 2012 when, due to warmer temperatures, nearly twice as much discharge occurred. The highest distributed system fluxes occurred during spikes of distributed system meltwater,
\end{abstract}


which occurred on the falling limb of the hydrograph or during expansion of the channelized system.

\section{$1 \quad$ Introduction}

Under the marginal zones of the Greenland Ice Sheet (GrIS), meltwater flow paths influence glacial speeds and bulk meltwater chemistry (Collins, 1979; Bindschadler, 1983; Raiswell, 1984). After the onset of spring melt, the majority of surface derived meltwater travels to the glacier or ice sheet bed through fractures, crevasses and moulins (Sharp et al., 1993; Fountain and Walder, 1998; Das et al., 2008). During the summer, bulk meltwater is largely composed of two components, quick flow (channelized drainage) and delayed flow (distributed drainage), which are both derived from snow and ice melt (Tranter et al., 1993). On the time scale of an entire melting season, the major component is quick flow, which pertains to meltwater moving through large channels (Röthlisberger, 1969). In contrast, delayed flow refers to meltwater in slow transit through either a distributed system composed of cavities that open behind bedrock bumps due to ice sliding (linked-cavity system; Walder, 1986), a water sheet of near uniform thickness at the ice bed (Flowers and Clarke, 2002; Creyts and Schoof, 2009), or water flow through permeable subglacial till (Shoemaker, 1986; Boulton et al., 2009). In general, while delayed flow meltwaters tend to have higher ion concentrations than quick flow meltwaters, mixing between these end members result in post-mixing solute acquisition reactions. These reactions occur when sediments traveling through closed, $\mathrm{CO}_{2}$ limited, distributed systems mix with open-system, low ionic strength channelized meltwater, resulting in rapid mineral weathering reactions (Raiswell, 1984; Tranter et al., 1993). 
Channels at the ice sheet bed are zones of low-pressure relative to the surrounding distributed system (Röthlisberger, 1969) and generally act to scavenge distributed system meltwater (Boulton et al., 2007a, 2007b). However, daily cycles of water pressure driven by variable meltwater inputs may lead to exchange between the distributed and channelized systems on diurnal scales (Hubbard et al., 1995; Werder et al., 2013). During large surface runoff events, such as supraglacial lake drainages, channels may be overwhelmed, in which case water is forced into the distributed system (Gulley et al., 2012); this distributed system water may drain back into channels once surface meltwater inputs decrease (Hubbard et al., 1995; Boulton et al., 2009). Therefore, the timing of distributed system drainage is related to subglacial pressures and glacial dynamics. Furthermore, there is some evidence that distributed system water flow through till plays a role in determining subglacial hydraulic pressure distributions, channel spacing, basal sliding and bed deformation (Boulton and Caban, 1995; Boulton et al., 2007a, 2007b; Boulton et al., 2009; Rempel, 2009). However, effective methods for monitoring the timing and magnitude of distributed system fluxes to the ice margin have remained elusive.

Radon-222 has been used extensively to examine groundwater-surface water exchange processes in a wide range of freshwater and marine systems, as groundwater activities are typically highly enriched relative to surface waters (Burnett and Dulaiova, 2003; Cook et al., 2003; Dulaiova et al., 2008; McCallum et al., 2012). Recently, discrete ${ }^{222} \mathrm{Rn}$ measurements in glacial meltwater have been used to infer seasonal changes in meltwater storage times and the development of channelized flow (Kies et al., 2010; Bhatia et al., 2011). A relatively soluble, inert noble gas that does not participate in biogeochemical or weathering reactions once in solution, ${ }^{222} \mathrm{Rn}\left(\mathrm{t}_{1 / 2}=3.82\right.$ days $)$ is continuously added to glacial meltwater during water-rock interactions through the radioactive decay of ${ }^{226} \mathrm{Ra}$, a daughter product of the ${ }^{238} \mathrm{U}$ decay series. 
Hence, distributed system meltwater should acquire significantly higher ${ }^{222} \mathrm{Rn}$ activities than meltwater that flows through efficient channels.

This examines the utility of continuous ${ }^{222} \mathrm{Rn}$ measurements in the proglacial river of a GrIS outlet glacier during the spring and summer of 2011 and 2012. We provide evidence that

${ }^{222} \mathrm{Rn}$ is a passive tracer of meltwater flow from the distributed system that can be used to infer the timing and magnitude of distributed system fluxes. To our knowledge this is the first time that continuous, high-resolution ${ }^{222} \mathrm{Rn}$ measurements have been reported from a proglacial river.

\section{Methods}

\section{$2.1 \quad$ Study Area}

Chemical and physical measurements, including continuous ${ }^{222} \mathrm{Rn}$ measurements, were made in the proglacial river of Leverett Glacier, a large land-terminating glacier on the western margin of the GrIS $\left(67^{\circ} 03^{\prime} 57.81^{\prime \prime} \mathrm{N}, 50^{\circ} 10^{\prime} 01.83^{\prime \prime}\right.$; Figure 1). The glacier's meltwater is channeled through a single large proglacial river and, consequently, the proglacial river is representative of bulk meltwater. A glacier's catchment is the superficial area from where the glacier receives and releases the snow and ice material over the course of the summer. Leverett Glacier's hydrological catchment was inferred by its surface elevation and covers $>600 \mathrm{~km}^{2}$, reaching an elevation of $1500 \mathrm{~m}$ and ranging in width from 10-40 km (Bartholomew et al., 2011). At peak discharge, the proglacial river typically flows between $300-400 \mathrm{~m}^{3} \mathrm{~s}^{-1}$ (Bartholomew et al., 2010; Cowton et al., 2012) though during exceptional melting in 2012, the river reached 800 $\mathrm{m}^{3} \mathrm{~s}^{-1}$ (Tedstone et al., 2013). Similar to the regional geology of southwest Greenland (Henriksen et al., 2009), bedrock at the field site is mostly composed of granitic gneiss with occasional 
outcrops of other metamorphic rocks such as garnet biotite schist and slate. Glacial outwash and till fills the proglacial valley.

\subsection{Discharge, conductivity, and suspended sediment measurements}

Proglacial river discharge was measured using continuous water stage monitoring through a stable bedrock section of the river (Sole et al., 2013; Tedstone et al., 2013). Stage was converted to discharge using a continuous stage-discharge curve created from repeat Rhodamine WT and Rhodamine B dye injections throughout both melt seasons as described by Bartholomew et al. (2011). Concurrent measurements of electrical conductivity (EC) and the suspended sediment concentration (SSC) are also presented here and in Hawkings et al. (2014). EC was recorded every five minutes using a Campbell Scientific 247 combined temperature-EC sensor, and logged using Campbell Scientific CR1000 and CR800 loggers. EC was calibrated using a $\mathrm{KCl}$ solution of known concentration; errors on EC measurements are $\pm 10 \% 1$ s.d. SSC was estimated from turbidity measurements made with a Partech IR 15C turbidity probe. Calibration curves were created from discrete suspended sediment samples collected from the proglacial river. Errors on SSC were estimated at $\pm 6 \% 1$ s.d.

\subsection{Measuring radon in the proglacial river}

Radon-222 was measured in the Leverett Glacier proglacial river during 2011 (May 8August 5) and 2012 (May 12-July 28). Continuous (hourly) measurements were made using a RAD7 (Durridge Inc.) radon-in-air monitor in series with a desiccant chamber and a RAD7 water probe, a submersible air-filled gas-permeable membrane coil made from Accruel@ tubing (henceforth the term "water probe" will refer to the ${ }^{222} \mathrm{Rn}$ extraction unit). River water ${ }^{222} \mathrm{Rn}$ 
equilibrates with air in the membrane coil through passive diffusion; the air is continuously circulated in a closed loop through the RAD7 radon-in-air monitor system (Hofmann et al., 2011; Schubert et al., 2012). Radon-in-air activities were then converted to radon-in-water activity via the temperature dependent air-water partition coefficient as described by Schubert et al. (2012). The water probe was deployed on the northern bank of the river as close to the glacier's terminus as possible $(0-1 \mathrm{~km})$ to minimize potential evasion of ${ }^{222} \mathrm{Rn}$ from the river to the atmosphere (Supporting Information, page 57). Rising river stage required that we periodically moved the water probe downstream to a more stable riverbank. Typical 1-sigma counting errors for the water probe were $\pm 5-20 \%$ of measured ${ }^{222} \mathrm{Rn}$ activities with higher errors associated with lower activities. For example, counting errors at 10 and $1 \mathrm{dpm} \mathrm{L}^{-1}$ are 10 and $19 \%$, respectively. To check the continuous ${ }^{222} \mathrm{Rn}$ measurements, discrete ${ }^{222} \mathrm{Rn}$ samples were collected in $250 \mathrm{~mL}$ bottles without headspace and analyzed using a RAD7 plus $\mathrm{Rad}-\mathrm{H}_{2} \mathrm{O}$ attachment on a regular basis (Figure S1; Supporting Information, page 62). These discrete ${ }^{222} \mathrm{Rn}$ samples agree within the statistical counting errors of the corresponding continuous ${ }^{222} \mathrm{Rn}$ measurements (Figure S1; Supporting Information, page 62).

Measurements of ${ }^{222} \mathrm{Rn}$ via the water probe system may lag actual aqueous ${ }^{222} \mathrm{Rn}$ due to the time required to equilibrate ${ }^{222} \mathrm{Rn}$ across the gas-permeable membrane (Schubert et al., 2012). To assess the magnitude of this offset, we analyzed field equilibration times during instrument startup and performed laboratory experiments to estimate the water probe's response time to changes in ${ }^{222} \mathrm{Rn}$ activity. Key factors that control this equilibration time scale include the air volume in the system (RAD7 unit, tubing, desiccant and membrane coil), the membrane coil surface area, and the ${ }^{222} \mathrm{Rn}$ activity gradient across the membrane water/air interface (Schubert et al., 2012). The equilibration time can be minimized when the air volume of the system is low (i.e. 
using less tubing between RAD7 and membrane), the membrane interface area is maximized (i.e. lengthening the membrane tubing), and the water/air ${ }^{222} \mathrm{Rn}$ activity gradient across the membrane coil is large. The activity gradient at the membrane water/air interface has by far the largest effect on the equilibration and response time of the water probe; in stagnant water the water probe system can take hours longer to equilibrate than when deployed in a small stream (Hofmann et al., 2011; Schubert et al., 2012). In a flowing river, the activity gradient at the water/air interface is maintained at near $100 \%$ and the equilibration and response time can be reduced to $<1$ hour, similar to results obtained using an air-water equilibrating spray chamber such as the RAD-Aqua (Durridge Inc.; Schubert et al., 2012). In our case, the equilibration time of the water probe when deployed in the proglacial river was determined to be $<2$ hours based on laboratory experiments and about 1 hour using field observations. A detailed description of these tests and associated results is presented in the Supporting Information (page 57).

\section{$2.4 \quad{ }^{222} \mathrm{Rn}$ in subglacial distributed systems and sediment properties}

Because we were unable to obtain in-situ distributed system samples from beneath the ice sheet, we estimated ${ }^{222} \mathrm{Rn}$ in this environment via two approaches: (1) groundwater samples from the proglacial aquifer and (2) laboratory-based equilibration experiments (Chanyotha et al., 2014) using sediments discharged from the subglacial environment. Proglacial groundwater samples were taken at $\sim 0.2 \mathrm{~m}$ depth using a stainless-steel push point piezometer (MHE Products) and peristaltic pump. These samples were collected in $250 \mathrm{~mL}$ bottles without headspace and analyzed using a RAD7 equipped with the $\mathrm{Rad}-\mathrm{H}_{2} \mathrm{O}$ (Durridge Inc.) attachment. Collection locations included the bank of the proglacial river, the shores of a proglacial pond, and a pingo located within $500 \mathrm{~m}$ of the glacier's terminus. 
For the laboratory-based equilibration tests, four separate aliquots of sediment (50 g) from the proglacial river were incubated with Ra-free water in a sealed $1 \mathrm{~L}$ high-density polyethylene bottle for greater than five half lives ( $>20$ days). Samples were flushed into a cold trap and scintillation cells using helium and analyzed in triplicate on alpha scintillation counters (Corbett et al., 1998). Wet sediment ${ }^{222} \mathrm{Rn}$ activities in $\mathrm{dpm} \mathrm{g}^{-1}$ were converted to pore water

${ }^{222} \mathrm{Rn}$ activities ( $\mathrm{dpm} \mathrm{L} \mathrm{L}^{-1}$ ) using wet bulk densities and porosities (Supporting Information page $57)$.

\section{$3 \quad$ Results}

\subsection{Discharge}

Warmer average air temperatures resulted in approximately twice as much annual discharge in 2012 as in 2011, corresponding to 2.4 and $1.4 \mathrm{~km}^{3}$ of ice melt respectively within the Leverett Glacier catchment (Figure 2). Average flows of the proglacial river in the summer were $\sim 200 \mathrm{~m}^{3} \mathrm{~s}^{-1}$ in 2011 (Sole et al., 2013) and $\sim 400 \mathrm{~m}^{3} \mathrm{~s}^{-1}$ in 2012 (Tedstone et al., 2013). In 2012, the largest melting event since at least 1889 , as indicated by ice cores at the Summit Station, occurred on July $12^{\text {th }}$ (day 194) when over $98 \%$ of the surface of the GrIS experienced melting (Nghiem et al., 2012). During this period, river discharge reached $\sim 800 \mathrm{~m}^{3} \mathrm{~s}^{-1}$ (Tedstone et al., 2013), almost three times larger than maximum discharge in 2011 (Figure 2; Sole et al., 2013). Furthermore, in 2011 the river was largely ice-covered until day 160, while in 2012 the river was ice free from the start of sampling (day 133) onward.

\subsection{EC and SSC}


We used EC as a proxy for the concentration of dissolved solutes in the proglacial river. During both 2011 and 2012, EC was elevated in the early season (60-100 $\left.\mu \mathrm{S} \mathrm{cm}^{-1}\right)$ and decreased to $10-20 \mu \mathrm{S} \mathrm{cm}^{-1}$ with increasing river discharge (Figure 2; Hawkings et al., 2014). These results are consistent with the EC range reported in 2009 (Bartholomew et al., 2011). Diurnal variations in EC are observed through much of the 2011 and 2012 seasons and in general are inverse to river discharge. During both seasons, the EC record is punctuated by spikes of high EC waters, where EC rises substantially above the values recorded in the days before and after.

SSC varied between 1-7 $\mathrm{g} \mathrm{L}^{-1}$ in 2011 and 1-4 $\mathrm{g} \mathrm{L}^{-1}$ in 2012 (Hawkings et al., 2014); these concentrations are similar to values reported for 2009 and 2010 (Cowton et al., 2012). Like EC, diurnal variations in SSC occurred throughout much of the 2011 and 2012 melt seasons; however, these diurnal variations in SSC generally increased with rising river discharge. In 2012, spikes of SSC and EC (here defined as periods when these parameters increased sharply beyond concentrations observed days prior) generally occurred simultaneously (Figure 2) as observed by Bartholomew et al. (2011). Henceforth, simultaneous SSC and EC spikes, which indicate the expulsion of dissolved solutes and suspended sediment material from the subglacial environment, will be referred to as SSC/EC spikes. These events are highlighted in Figure 2 with dotted boxes. In 2011, SSC and EC spikes are not closely coupled (Figure 2).

\subsection{Radon-222 in the Proglacial River}

In both 2011 and 2012, the highest ${ }^{222} \mathrm{Rn}$ activities were observed in the early season and generally decreased with increasing river discharge (Figure 2). In 2011, typical ${ }^{222} \mathrm{Rn}$ activities in the early season (days 132-160) were between 10-15 dpm $\mathrm{L}^{-1}$ while following day 170, activities were generally between $2-5 \mathrm{dpm} \mathrm{L} \mathrm{L}^{-1}$. In 2012 , higher ${ }^{222} \mathrm{Rn}$ activities were observed in the early 
season, typically between 5-18 dpm L $\mathrm{L}^{-1}$, while after day $150{ }^{222} \mathrm{Rn}$ activities varied between 2-10 dpm L- ${ }^{-1}$. In contrast to our results, Bhatia et al. (2011) reported significantly higher ${ }^{222} \mathrm{Rn}$ activities in a small proglacial river to the north of our field site. They reported average early season ${ }^{222} \mathrm{Rn}$ activities of $76 \mathrm{dpm} \mathrm{L}{ }^{-1}$ and late season ${ }^{222} \mathrm{Rn}$ activities of $25 \mathrm{dpm} \mathrm{L} \mathrm{L}^{-1}$ though peak discharge rates $\left(\sim 2 \mathrm{~m}^{3} \mathrm{~s}^{-1}\right)$ were orders of magnitude lower than at Leverett Glacier. However, activities measured in this study and in Bhatia et al. (2011) are much higher than those generally measured in non-glaciated river catchments. For example, both Cook et al. (2003) and McCallum et al. (2012) report maximum ${ }^{222} \mathrm{Rn}$ activities of $<1 \mathrm{dpm} \mathrm{L}^{-1}$ in river water in non-glaciated catchments.

The ${ }^{222} \mathrm{Rn}$ flux $\left(\mathrm{dpm} \mathrm{s}^{-1}\right)$, calculated by multiplying ${ }^{222} \mathrm{Rn}$ activity $\left(\mathrm{dpm} \mathrm{m}^{-3}\right)$ by river discharge $\left(\mathrm{m}^{3} \mathrm{~s}^{-1}\right)$, increased with rising river discharge as the growing water flux outweighed the decrease in ${ }^{222} \mathrm{Rn}$ activity (Figure 2). Following the onset of large-scale runoff in both seasons (river discharge $>100 \mathrm{~m}^{3} \mathrm{~s}^{-1}$ ), the ${ }^{222} \mathrm{Rn}$ flux was between $6.2 \times 10^{2}-4.6 \times 10^{6} \mathrm{dpm} \mathrm{s}^{-1}$ in 2011 and $1.4 \times 10^{5}-3.1 \times 10^{6} \mathrm{dpm} \mathrm{s}^{-1}$ in 2012 . Assuming the entire $600 \mathrm{~km}^{2}$ catchment is open, this corresponds to $0.08-690 \mathrm{dpm} \mathrm{m}^{-2} \mathrm{~d}^{-1}$. For comparison, Cable et al. (1996) found a diffusive flux of ${ }^{222} \mathrm{Rn}$ through marine sediments of $115-220 \mathrm{dpm} \mathrm{m}^{-2} \mathrm{~d}^{-1}$. Diurnal cycles of high and low ${ }^{222} \mathrm{Rn}$ fluxes (which corrects for dilution effects), were generally inverse to river discharge. These diurnal cycles occurred between days 178-188 and 204-214 in 2011 and between days 200-206 in 2012. Several breaks in the $2011{ }^{222} \mathrm{Rn}$ record correspond to periods when the riverbank collapsed and a RAD7 water probe system was lost or when river ice prevented deployment of the water probe.

Spikes in ${ }^{222} \mathrm{Rn}$, defined as periods when ${ }^{222} \mathrm{Rn}$ activities increased sharply in excess of activities observed days prior, are highlighted in Figure 2 by grey shaded boxes. In 2011, the 
early season record is marked by a significant spikes of ${ }^{222} \mathrm{Rn}$ (days 148-150) reaching $\sim 75 \mathrm{dpm}$ $\mathrm{L}^{-1}$ (Figure 2). During this time, the river was ice covered and a small upwelling spring appeared at the glacier portal through which nearly all river discharge originated. The late season 2011 record is marked by a second large spike in ${ }^{222} \mathrm{Rn}$ (days 190-200) when activities reached $\sim 15$ $\mathrm{dpm} \mathrm{L} \mathrm{L}^{-1}$ from a pre-outburst baseline of $3 \mathrm{dpm} \mathrm{L} \mathrm{L}^{-1}$ (Figure 2). The $2012{ }^{222} \mathrm{Rn}$ record is marked by ${ }^{222} \mathrm{Rn}$ spikes that occurred nearly every 8-10 days throughout the season (Figure 2). Hysteresis was often observed between ${ }^{222} \mathrm{Rn}$ and river discharge during spikes in ${ }^{222} \mathrm{Rn}$ (Figure 4). During the $2012^{222} \mathrm{Rn}$ spikes, the ${ }^{222} \mathrm{Rn}$ flux increased on the falling limb of the hydrograph and generally decreased when river discharge increased (Figures 2, 3 and 4).

Temporal variability in ${ }^{222} \mathrm{Rn}, \mathrm{SSC}$ and EC shows consistent relationships between these parameters (Figures 2, 3 and 3). In general, spikes in ${ }^{222} \mathrm{Rn}$ occurred in between peaks in SSC/EC or when SSC/EC was decreasing (Figures 3 and 4). Radon-222 spikes ended either during the onset of rapidly increasing SSC/EC (Figure 3 and 4, days 176-180, 2012), or when SSC/EC was relatively stable (Figure 2, days 195-200, 2011). One exception of the decoupling of ${ }^{222} \mathrm{Rn}$ and SSC/EC spikes was the large early season ${ }^{222} \mathrm{Rn}$ spike in 2011 on day 148 when a notable peak in EC was also observed, though no corresponding SSC peak was observed (Figure 2).

\subsection{Radon in groundwater and estimated distributed systems}

Six shallow proglacial groundwater samples collected near the ice margin had ${ }^{222} \mathrm{Rn}$ activities between 3.7-60 dpm L $\mathrm{L}^{-1}$ (Table S1; Supporting Information). Laboratory derived subglacial till ${ }^{222} \mathrm{Rn}$ activities were estimated using the ${ }^{222} \mathrm{Rn}$ activity of wet sediments collected from the proglacial river and sediment properties including bulk density and porosity (Chanyotha et al., 2014). Wet sediment ${ }^{222} \mathrm{Rn}$ activities were $0.064-0.093 \mathrm{dpm} \mathrm{g}^{-1}\left(\operatorname{avg}=0.076 \mathrm{dpm} \mathrm{g}^{-1}, \mathrm{n}=4\right)$. 
This result was tested by measuring ${ }^{226} \mathrm{Ra}$ activities of the sediments using a well-type gamma counter (Gonneea et al., 2008). Particle density, bulk density and porosity measurements were identical for the three glacial flour samples analyzed and were $2.7 \mathrm{~g} / \mathrm{cm}^{3}, 1.7 \mathrm{~g} / \mathrm{cm}^{3}$ and 0.37 respectively. Using these results, the ${ }^{222} \mathrm{Rn}$ activity of water-saturated glacial sediment at secular equilibrium was determined to be $330-430 \mathrm{dpm} \mathrm{L}^{-1}\left(\operatorname{avg}=350 \mathrm{dpm} \mathrm{L}^{-1}, \mathrm{n}=4\right)$. Given the range of likely porosities in the subglacial till of 0.3-0.4 (Dow et al. 2013) and average wet sediment ${ }^{222} \mathrm{Rn}$ activity, ${ }^{222} \mathrm{Rn}$ activities in subglacial till would be expected to range from $270-430 \mathrm{dpm} \mathrm{L} \mathrm{L}^{-1}$. Radon-222 activities measured in shallow proglacial groundwater as well as laboratory estimates of subglacial till were significantly lower than proglacial groundwater samples reported by Bhatia et al. (2011), which were between 1626-2750 dpm L $\mathrm{L}^{-1}$.

\section{Discussion}

\subsection{Radon-222 sources and sinks}

Radon-222 has been used as a tracer of sediment pore water-surface water exchange processes in a diverse range of environmental systems including rivers (McCallum et al., 2012), the coastal ocean, (Burnett and Dulaiova, 2003; Dulaiova et al., 2008) and recently in glacial settings (Kies et al., 2010; Bhatia et al., 2011). In the following discussion, we explore the utility of ${ }^{222} \mathrm{Rn}$ in tracing and quantifying meltwater fluxes from the subglacial distributed system at Leverett Glacier. There are a number of sources and sinks capable of modulating ${ }^{222} \mathrm{Rn}$ activities in a proglacial river. We use a mass balance approach similar to those employed in studies of submarine groundwater discharge to the coastal ocean (Burnett and Dulaiova, 2003; Dulaiova et al., 2008). A mass balance model for ${ }^{222} \mathrm{Rn}$ in the proglacial river is illustrated in Figure 5 and can be written as: 


$$
J_{\text {riv }}=J_{\text {dis }}+J_{\text {cha }}+P_{S S L}+\lambda^{226} R a-F_{a t m}-\lambda^{222} R n
$$

Sources of ${ }^{222} \mathrm{Rn}$ include production from ${ }^{226} \mathrm{Ra}$ associated with suspended sediments $\left(P_{S S L}\right)$, production of ${ }^{222} \mathrm{Rn}$ through the decay of dissolved ${ }^{226} \mathrm{Ra}\left(\lambda^{226} \mathrm{R} a\right.$ where $\lambda$ is the decay constant for $\left.{ }^{222} \mathrm{Rn}\right),{ }^{222} \mathrm{Rn}$ diffusion through the sediment floors of subglacial channels $\left(J_{c h a}\right)$, and distributed system meltwater $\left(J_{d i s}\right)$. Radon-222 sinks include radioactive decay $\left(\lambda^{222} R n\right)$ and atmospheric evasion across the water/air interface $\left(F_{a t m}\right)$. Finally, $J_{r i v}$ is ${ }^{222} \mathrm{Rn}$ exported to the glacier's front via the proglacial river and is what we observed via our continuous ${ }^{222} \mathrm{Rn}$ measurements (combined with the discharge record to derive ${ }^{222} \mathrm{Rn}$ flux). All source/sink terms can be directly evaluated except for $J_{d i s}$; hence we use the "flux by difference" approach (Charette et al., 2008), which assumes that the unaccounted for ${ }^{222} \mathrm{Rn}$ in the mass balance model must be due to distributed system meltwater $\left(J_{d i s}\right)$. We discuss and evaluate each source and sink term in Equation 1 in the following sections.

\subsubsection{Suspended sediment ${ }^{226} \mathrm{Ra}\left(P_{\text {SSL }}\right)$}

Suspended sediments are a potential source of ${ }^{222} \mathrm{Rn}$ to the river through decay of sediment bound ${ }^{226} \mathrm{Ra}$. From the laboratory equilibration experiments described above (Section 2.4) we determined that surface-bound ${ }^{222} \mathrm{Rn}$ activity of sediments at secular equilibrium is 0.076 $\mathrm{dpm} \mathrm{g}^{-1}$ (Section 3.4). Coupling this result with SSC measurements, we estimated the maximum potential contribution from $P_{S S L}$ to $J_{r i v}$. For this calculation, we assumed that suspended sediments could produce ${ }^{222} \mathrm{Rn}$ via ${ }^{226} \mathrm{Ra}$ decay over the course of 80 hours, which is an upper limit of transit times observed for surface meltwater during tracer studies (Chandler et al., 2013). With this 
assumption, $P_{S S L}$ contributed on average $4.0 \% \pm 12 \%$ and $0.97 \% \pm 0.81 \%$ of $J_{r i v}$ in 2011 and 2012, respectively.

\subsubsection{Dissolved ${ }^{226} \mathrm{Ra}\left(\lambda^{226} \mathrm{Ra}\right)$}

The proglacial river also carries dissolved ${ }^{226} \mathrm{Ra}$, which could support ${ }^{222} \mathrm{Rn}$ via its decay. Dissolved ${ }^{226}$ Ra was measured throughout the 2011 and 2012 field seasons using methods described by Charette et al. (2001). We observed ${ }^{226} \mathrm{Ra}$ activities of $0.02-0.09 \mathrm{dpm} \mathrm{L} \mathrm{L}^{-1}$ (avg 0.04 $\mathrm{dpm} \mathrm{L}^{-1} \pm 0.05 \mathrm{dpm} \mathrm{L}^{-1}, \mathrm{n}=21$ ), with higher values in the early season and lower values in the late season. Based on these results, $\lambda^{226} R a$ can account for no more than $1 \%$ of $J_{r i v}$.

\subsubsection{Diffusive flux of ${ }^{222} R n$ in channels $\left(J_{\text {cha }}\right)$}

The diffusive flux of ${ }^{222} \mathrm{Rn}$ from sediments in channels (subglacial or proglacial) could potentially be a significant source of ${ }^{222} \mathrm{Rn}$ following widespread melting across the catchment and development of an extensive channelized system. Before the river reaches $100 \mathrm{~m}^{3} \mathrm{~s}^{-1}$, snow still covers much of the glacier's catchment and we assume $J_{c h a}$ is minimal. To quantify $J_{c h a}$, we first determined the diffusive flux of ${ }^{222} \mathrm{Rn}$ from sediments collected at the bed of the proglacial river. Following a laboratory method described by Chanyotha et al. (2014), the diffusive flux was determined using a measured mass of wet subglacial sediment and ${ }^{222} \mathrm{Rn}$-free water. Water and sediment were sealed inside a gas tight reaction flask connected in a closed loop with a RAD7. Air was pumped through a gas diffusion stone immersed in the water phase using the built in RAD7 pump, then through the desiccant, and back to the radon analyzer where the activity was measured and recorded. Using this method, the diffusive flux of ${ }^{222} \mathrm{Rn}$ was determined to be $0.006 \mathrm{dpm} \mathrm{m}^{-2} \mathrm{~s}^{-1}$. 
To calculate $J_{\text {cha }}$, we estimated the area of subglacial channel floors. For the purpose of calculating the maximum potential channel floor area, we assumed that all discharge moved through channels, that channels extended out to $41 \mathrm{~km}$ from the ice margin (Chandler et al., 2013), and that channel density was 4 per km catchment width (Schoof, 2010; Werder et al., 2013). Assuming the catchment width is $40 \mathrm{~km}$ (Bartholomew et al., 2011), and that water moved through channels at $3 \mathrm{~m} \mathrm{~s}^{-1}$ (Cowton et al., 2013), we calculated an upper bound of channel floor area of $5.5 \mathrm{~km}^{2}$ during the extreme melt event in 2012 (day 194). This estimate amounts to $\sim 1 \%$ of the glacier's catchment area covered by channels and is consistent with models describing the channelized system (Schoof, 2010; Werder et al., 2013). During the extreme melting event in 2012 (Nghiem et al., 2012), when we assume the channel floor area reached its maximum, $J_{c h a}$ may have accounted for up to $4.0 \times 10^{4} \mathrm{dpm} \mathrm{s}^{-1}$ or $\sim 3 \% J_{r i v}$. Using this upper bound of channel floor area $\left(5.5 \mathrm{~km}^{2}\right)$ after discharge reached $>100 \mathrm{~m}^{3} \mathrm{~s}^{-1}, J_{\text {cha }}$ could have accounted for $1.8 \% \pm 1.3 \%$ of $J_{r i v}$ in 2012. Completing similar calculations for 2011 gives a maximum channel floor area of $3 \mathrm{~km}^{2}$. Assuming channels covered $3 \mathrm{~km}^{2}$ in 2011 after discharge reached $>100 \mathrm{~m}^{3} \mathrm{~s}^{-1}, J_{\text {cha }}$ may have contributed $1.8 \times 10^{4} \mathrm{dpm} \mathrm{s}^{-1}$ or $1.6 \% \pm 1.6 \% 1$ s.d. of $J_{r i v}$. The major exception to this was during exceptionally low ${ }^{222} \mathrm{Rn}$ activities during days 202-204 in 2011 when $J_{c h a}$ could have fully accounted for $J_{r i v}$ (Figure 6).

\subsubsection{Gas exchange $\left(F_{\text {atm }}\right)$}

Radon-222 may evade from the meltwater in the proglacial river upstream of the ${ }^{222} \mathrm{Rn}$ sampling site (Figure 1) and subglacially in air-filled cavities at the ice bed. The atmospheric evasion of ${ }^{222} \mathrm{Rn}$ is a function of molecular diffusion produced by the activity gradient at the 
water/air interface as well as turbulent transfer, which is governed by physical processes such as wind, current, and topography. $F_{a t m}$ can be written as:

$$
F_{a t m}=k\left(C_{w}-\alpha C_{a t m}\right)
$$

where $C_{w}$ is the ${ }^{222} \mathrm{Rn}$ activity of water, $C_{a t m}$ is the ${ }^{222} \mathrm{Rn}$ activity in air (assumed to be negligible relative to the water activity), $\alpha$ is Ostwald's solubility constant and $k$ is the gas transfer velocity. The gas transfer velocity is dependent on kinematic viscosity, molecular diffusion, and turbulence and is determined based on empirical relationships observed in different environments for different gases. Borges et al. (2004) suggested that the gas transfer velocity $k$ should be in the range of 3-7 $\mathrm{cm} \mathrm{hr}^{-1}$ while Dulaiova and Burnett (2006) calculated a gas transfer velocity for ${ }^{222} \mathrm{Rn}$ up to $10 \mathrm{~cm} \mathrm{hr}^{-1}$ in moving water and high winds.

Using Equation 2, we estimated $F_{a t m}$ during all continuous ${ }^{222} \mathrm{Rn}$ measurements. Because of occasional strong winds and a river current of $\sim 1-3 \mathrm{~m} \mathrm{~s}^{-1}$ (Cowton et al., 2013) we chose to fix $k$ at $12 \mathrm{~cm} \mathrm{hr}^{-1}$ for the duration of the time series. With these assumptions, $F_{\text {atm }}$ varied between $<0.01-0.7 \mathrm{dpm} \mathrm{m}^{-2} \mathrm{~s}^{-1}$ in 2011 and between $0.03-0.6 \mathrm{dpm} \mathrm{m}^{-2} \mathrm{~s}^{-1}$ in 2012. Using river stage (which determines river width) and the distance between the ice terminus and the sampling site to estimate the river surface area, we determined that $F_{a t m}$ accounts for $<1 \%$ of the $J_{r i v}$. This was true even when increasing $k$ to $20 \mathrm{~cm} \mathrm{hr}^{-1}$. The negligible effect of gas loss suggested by the model is supported by discrete ${ }^{222} \mathrm{Rn}$ samples collected at the glacier's terminus, which were within error of the continuous measurements made $1 \mathrm{~km}$ downstream (Figure S1; Supporting Information). 
Meltwater ${ }^{222} \mathrm{Rn}$ may also partition into the headspace of subglacial air-filled cavities. However, in closed system cavities, ${ }^{222} \mathrm{Rn}$ would build up in the headspace thereby reducing the water-air concentration gradient and therefore the ${ }^{222} \mathrm{Rn}$ loss from the water phase. While there is evidence for open system channels at the ice bed within several $\mathrm{km}$ from the ice margin (Chandler et al., 2013), subglacial gas loss is likely much smaller than in the proglacial river. Furthermore, air-filled subglacial channels will only exist during the falling limb of the hydrograph following substantial surface meltwater inputs and channel expansion. These cavities will close within hours to days of opening because of glacial creep (Meierbachtol et al., 2013). If large quantities of ${ }^{222} \mathrm{Rn}$ were lost to air-filled cavities, then ${ }^{222} \mathrm{Rn}$ activities would decrease on the falling limb of the hydrograph yet we observed the opposite trend (Figures 2, 3 and 4).

\subsubsection{Radon-222 decay $\left(\lambda^{222} R n\right)$}

When distributed system meltwater discharges into the channelized system far from the ice margin, some fraction of ${ }^{222} \mathrm{Rn}$ will decay before reaching the ice terminus. For example, during a typical 7 hour transit through the channelized system (Cowton et al., 2013), 5\% of unsupported ${ }^{222} \mathrm{Rn}$ will decay. Based on the work by Cowton et al. (2013) and Chandler et al. (2013), during the early melt season when the snow line is low on the glacier's catchment and river discharge is $<10 \mathrm{~m}^{3} \mathrm{~s}^{-1}$, meltwater transit times are likely no more than 3 hours. In this case, $2 \%$ of the unsupported ${ }^{222} \mathrm{Rn}$ decays in the channelized system before reaching the ice margin. Extensive channelization at Leverett Glacier occurs once the snow line has receded higher than the glacier's catchment and river discharge is $>100 \mathrm{~m}^{3} \mathrm{~s}^{-1}$ (Chandler et al., 2013; Cowton et al., 2013). By mid July channelization likely extends to at least $41 \mathrm{~km}$ from the ice margin and meltwater transit times in the channelized system may be up to 12 hours for meltwaters far from 
the ice margin (Chandler et al., 2013). As the distributed system flux is composed of a mixture of meltwaters with varying channelized system transit times, we assume that once river discharge reaches $>100 \mathrm{~m}^{3} \mathrm{~s}^{-1}$, channelized system meltwater transit times average 7 hours. This could represent up to $5 \%$ of the ${ }^{222} \mathrm{Rn}$ flux.

\subsubsection{Distributed system flux $\left(J_{\text {dis }}\right)$}

By rearranging Equation 1, excluding the negligible $F_{a t m}$ flux, we solve for $J_{d i s}$.

$$
J_{\text {dis }}=J_{\text {riv }}-J_{\text {cha }}-P_{S S L}-\lambda^{226} R a+\lambda^{222} R n
$$

$P_{S S L}$ and $\lambda^{226} R a$ were measured and contributed relatively small amounts of ${ }^{222} \mathrm{Rn}$ throughout the 2011 and 2012 melt seasons (Figure 6). $J_{\text {cha }}$ is a significant ${ }^{222} \mathrm{Rn}$ source following channelization, which we assume occurs once river discharge reaches $>100 \mathrm{~m}^{3} \mathrm{~s}^{-1}$. We estimated that $J_{\text {cha }}$ likely accounted for $1 \%$ and $1-5 \%$ of $J_{\text {riv }}$ in the early and late melt season respectively (Figure 6). An exception to this occurred on days 202-204 in 2011 when $J_{\text {riv }}$ was very small and could have been supplied by $P_{S S L}$ or $J_{\text {cha }}$ (Figure 6). Based on tracer experiments we assume a range of channelized system transit times (likely averaging $\sim 7$ hours) during which unsupported ${ }^{222} \mathrm{Rn}$ could decay. Because ${ }^{222} \mathrm{Rn}$ has a half-life of 3.82 days, we assume that $\lambda^{222} R n$ may account for up to $5 \%$ of $J_{r i v}$.

Because the ${ }^{222} \mathrm{Rn}$ sources described above cannot account for $J_{\text {riv }}$, we conclude that $J_{d i s}$ must contribute the bulk of the ${ }^{222} \mathrm{Rn}$ flux to the ice margin. While $J_{\text {riv }}$ is likely impacted by decay in channels and to a smaller extent other sources and sinks, the riverine ${ }^{222} \mathrm{Rn}$ flux traces the timing and relative magnitude of the distributed system flux. Unlike EC measurements in 
proglacial rivers that are affected by post-mixing solute acquisition reactions (Raiswell, 1984;

Tranter et al., 1993), we conclude that ${ }^{222} \mathrm{Rn}$ can be used as a passive tracer of distributed system flows to the ice margin.

\subsection{Estimating the distributed system flux}

Using Equation 4 the distributed system meltwater flux $\left(Q_{d i s}\right)$ can be calculated if $J_{d i s}$ and the ${ }^{222} \mathrm{Rn}$ activity of distributed system meltwater $\left(R n_{\text {dis }}\right)$ are known.

$$
Q_{d i s}=J_{d i s} / R n_{d i s}
$$

We assume $R n_{\text {dis }}$ was similar to our laboratory based estimates of the ${ }^{222} \mathrm{Rn}$ activity in glacial sediments (270-430 dpm L ${ }^{-1}$; Sections 2.4 and 3.4). We use the laboratory based estimate of

${ }^{222} \mathrm{Rn}$ activity in pore waters rather than field proglacial groundwater measurements for two main reasons. First, our laboratory experiments represent ${ }^{222} \mathrm{Rn}$ activities in saturated subglacial sediments that have reached secular equilibrium. Second, permafrost prevented us from probing into proglacial sediment beyond $15 \mathrm{~cm}$ on average. Hence, these samples are more likely representative of river water than stored water along the lines of that originating from the distributed system.

Our estimate of $Q_{d i s}$ is shown in Figure 7. The range of $Q_{d i s}$ shown in Figure 7 accounts for uncertainty related to drainage transit times (which impact $\lambda^{222} R n$ ) and the range of values we used for $R n_{d i s}$, and uncertainty in the river discharge measurements used to calculate the ${ }^{222} \mathrm{Rn}$ flux. These results suggest that $Q_{d i s}$ changes significantly on diurnal and seasonal scales. $Q_{d i s}$ varied from $<0.1$ to $17 \mathrm{~m}^{3} \mathrm{~s}^{-1}$ in 2011 and from $<0.1$ to $14 \mathrm{~m}^{3} \mathrm{~s}^{-1}$ in 2012 (Figure 7). Diurnal 
cycles in $Q_{d i s}$ were generally between $1-3 \mathrm{~m}^{3} \mathrm{~s}^{-1}$ in 2011 and 2-6 $\mathrm{m}^{3} \mathrm{~s}^{-1}$ in 2012 . In both 2011 and 2012, diurnal cycles were punctuated by spikes in $Q_{d i s}$ which reached $>6 \mathrm{~m}^{3} \mathrm{~s}^{-1}$. The weighted mean $Q_{\text {dis }}$ relative to total river discharge was $1-2.4 \%$ in 2011 and $0.7-1.6 \%$ in 2012 . The percent of river discharge composed of $Q_{d i s}$ varied through both melt seasons (Figure 7). In 2011, $Q_{d i s}$ reached a maximum of $\sim 22 \%$ of river flow between days $148-150$ when river discharge was $\sim 1$ $\mathrm{m}^{3} \mathrm{~s}^{-1}$ and a minimum of $\sim 0 \%$ between days 202-204 following a large spike in $Q_{\text {dis }}$ (Figure 7). In 2012, the percent of river flow composed of $Q_{d i s}$ was between 3-5\% in the early season (days $130-150)$ and $1-4 \%$ following day 150.

\subsubsection{Model limitations and caveats}

Distributed system ${ }^{222} \mathrm{Rn}$ activities are not likely constant but rather variable between the potential types of distributed system flows (linked cavities, till or thin film) and the residence time of meltwater in the distributed system. For example, upon initial contact of meltwater with sediment or rock in the distributed system, it will take 20 days for ${ }^{222} \mathrm{Rn}$ to reach secular equilibrium; meltwater stored for 4 days will acquire $54 \%$ of the ${ }^{222} \mathrm{Rn}$ activity it would acquire after 20 days. Using a lower $R n_{\text {dis }}$ estimate (such as that observed for the field groundwater ${ }^{222} \mathrm{Rn}$ samples) would drive $Q_{d i s}$ proportionally higher, while using a higher $R n_{d i s}$ estimate (as observed by Bhatia et al., 2011) would drive $Q_{d i s}$ lower. While our laboratory-based estimates of subglacial distributed system pore water ${ }^{222} \mathrm{Rn}$ activities represent our best approximation, future studies should endeavor to directly sample subglacial groundwater, which could be accomplished through borehole experiments (Lamb et al., 1995; Tranter et al., 1997; Andrews et al., 2014).

\subsection{Interpretations of the distributed system flux}


In 2012, the largest melt event since at least 1889 took place between days 191-195 during which over 98\% of the surface of the GrIS experienced melting (Nghiem et al., 2012). During this event, discharge from Leverett Glacier reached $800 \mathrm{~m}^{3} \mathrm{~s}^{-1}$ (Figure 7; Tedstone et al., 2013). On the falling limb of peak discharge from this event, the highest $Q_{d i s}$ of the season occurred ( $15 \mathrm{~m}^{3} \mathrm{~s}^{-1}$ on day 196; Figure 7). Prior to this time, the 2012 record was punctuated by numerous additional spikes of $Q_{d i s}\left(8-10 \mathrm{~m}^{3} \mathrm{~s}^{-1}\right)$ that also occurred on the falling limb of the hydrograph (Figure 7; e.g. days 157-166; 174-178; 182-188; 189-191). All of these events suggest draining of the distributed system when subglacial water pressure decreases similar to observations made in alpine glaciers (e.g. Hubbard et al., 1995).

In 2011, the largest spike in $Q_{d i s}$ (days 190-200) occurred simultaneously with the onset of melting at higher elevations within the catchment (Sole et al., 2013) and the expansion of the channelized system to at least $40 \mathrm{~km}$ from the ice sheet margin (Chandler et al., 2013). This implies flushing of long-stored distributed system meltwater during expansion of the channelized system to higher elevations. This is similar to the findings of Andrews et al. (2014) who observed isolated regions of the subglacial distributed system becoming connected following large surface meltwater inputs. Between days 202-204 in 2011, $Q_{d i s}$ essentially decreases to zero, suggesting a very efficient channelized system following expansion of the channelized system.

Bartholomew et al. (2011) and Butler (2014) found that SSC/EC spikes at Leverett Glacier are triggered by supraglacial lake drainage events and therefore, SSC/EC spikes can be used as a proxy for rapid surface meltwater inputs and inferred subglacial water-sediment evacuation. In general, peaks in $Q_{d i s}$ and ${ }^{222} \mathrm{Rn}$ occur in between SSC/EC spikes (Figures 2, 3 and 4). Hence, our findings suggest that while SSC/EC spikes are triggered by supraglacial lake drainage events, $Q_{d i s}$ spikes are not. Variations in EC and ${ }^{222} \mathrm{Rn}$ were generally not correlated on 
any timescale (Figure 3 and 4). The exception to this was between days 200-204 in 2012 when

EC and ${ }^{222} \mathrm{Rn}$ were positively correlated $\left(\mathrm{r}^{2}=0.66\right)$. During this time both constituents underwent diurnal cycles, rising on the falling limb of the hydrograph. The reason for this correlation is unclear though it suggests that following the extreme surface melting event, which occurred between days 191-195, the distributed system constituted the largest source of solutes that are measured by EC.

All of the major spikes of $Q_{d i s}$ are likely the consequence of large changes in the rate of surface meltwater inputs or expansion of the channelized system. During a rapid increase in surface melt inputs (such as rapid warming or a supraglacial lake drainage event), channels are pressurized and widened while meltwater is forced into the distributed system (Schoof, 2010; Bartholomew et al., 2012; Doyle et al., 2013;). Once the period of high meltwater inputs has ceased, river discharge and subglacial water pressure decreases and ${ }^{222} \mathrm{Rn}$-rich water stored in the distributed system is permitted to drain into channels and be transported to the margin. In the absence of major meltwater inputs, daily maxima and minima of surface meltwater production drives meltwater into and out of the distributed system from channels (Hubbard et al., 1995; Werder et al., 2013). This may explain the diurnal cycles in $Q_{\text {dis }}$ observed between days 204-210 in 2011 and 198-205 in 2012.

\subsection{Interannual differences in the distributed system flux: implications for chemical fluxes} from the Greenland Ice Sheet

Between days 173-210, the time period where we have data overlap for both 2011 and 2012, the total integrated flux of $Q_{d i s}$ was estimated to be $1.6 \times 10^{7} \mathrm{~m}^{3}$ in 2011 and $1.9 \times 10^{7} \mathrm{~m}^{3}$ in 2012. This corresponds to $20 \%$ more $Q_{\text {dis }}$ released between days 173-210 in 2012 despite a two- 
fold increase in river discharge during in the same time period in 2012. This result is similar to the observation that despite exceptional melting in 2012, glacial velocity did not substantially increase at Leverett Glacier (Tedstone et al., 2013). Because the bulk of solute fluxes in glacial meltwater originate in the distributed system (Wadham, et al., 2001), it remains unclear whether or not increased melting will lead to proportional increases in subglacial weathering processes and the associated chemical load transported to the ocean.

Glacial meltwater-derived chemical fluxes to the ocean have been shown to play an important role in biogeochemical cycling and the budgets of trace elements and isotopes used to study weathering processes on geological time scales. For example, much of the ecosystems in the oceans around the Antarctica Ice Sheet and to a lesser extent the GrIS are Fe limited (Mills et al., 2004; de Baar et al., 2008; Nielsdóttir et al., 2009); consequently higher Fe fluxes from increased subglacial distributed system fluxes could contribute to Fe fertilization (Bhatia et al., 2013; Hawkings et al., 2014). During past deglaciation events, weathering of fine-grained glacial flour may have released large fluxes of ${ }^{234} \mathrm{U}$ into rivers draining retreating ice sheets (Robinson et al., 2004). This may have contributed to the observed correlations between glacial-interglacial cycles and the ${ }^{234} \mathrm{U} /{ }^{238} \mathrm{U}$ record preserved in corals (Robinson et al., 2004). Similarly, glaciers are thought to influence the ocean's ${ }^{87} \mathrm{Sr} /{ }^{86} \mathrm{Sr}$ ratio due to the extensive physical and chemical weathering of glacial till (Zachos et al., 1999). If the distributed system meltwater flux plays a key role in these ocean trace element and isotopic cycles, then our results suggest that there is large variability in their timing and magnitude.

\section{Conclusions}


A mass balance model for ${ }^{222} \mathrm{Rn}$ in a large GrIS glacial catchment revealed that on average, $>90 \%$ of the ${ }^{222} \mathrm{Rn}$ in meltwater is sourced from the subglacial distributed system. At diurnal and weekly time scales, $Q_{d i s}$ appears to be governed by surface meltwater inputs. In particular, $Q_{d i s}$ spikes generally occurred on the falling limb of the hydrograph (Figure 7) and between SSC/EC spikes.

We propose the following explanation for these observations. During large increases in the rate of surface meltwater inputs, such as rapid warming or supraglacial lake drainage events, the channelized system is pressurized and water is forced into the distributed system. During decreases in surface meltwater inputs (such as during the falling limb of the hydrograph or following supraglacial lake drainage) the flow of water from channels to the distributed system is reversed, and the meltwater stored in the distributed system drains to the ice sheet margin. Seasonal variability is also observed between the 2011 and 2012 melt seasons. In 2011, the $Q_{\text {dis }}$ flux is dominated by a single, large spike between days 190-200 while in 2012, multiple smaller spikes of $Q_{d i s}$ characterized the record. The large $Q_{\text {dis }}$ spike in 2011 (days 190-200) was likely due to expansion of the channelized system observed during this same period (Chandler et al., 2013) when long-stored distributed system meltwater may have been flushed to the margin. Similar to the findings of Andrews et al. (2014), this implies that the connectivity of the nonchannelized regions beneath Leverett Glacier is altered during large surface meltwater inputs. In contrast, during the warmer 2012 melt season, melting occurred at higher elevations significantly earlier in the season; as a result, a fully channelized drainage system on the scale of the entire catchment may have been open during most of the melt season.

Despite the longer melt season, higher temperatures and a doubling of the total meltwater flux in 2012, the distributed system flux was not significantly different from 2011 . Hence, given 
that the distributed system is likely the main source of solutes in glacial meltwater, at present it is not clear whether or not accelerated melting of the GrIS will lead to a proportional increase in subglacial solute fluxes to the ocean. Future work will be needed to investigate the impact that these processes have on ocean ecosystems and numerous marine elemental and isotopic budgets during glacial-interglacial transitions. 


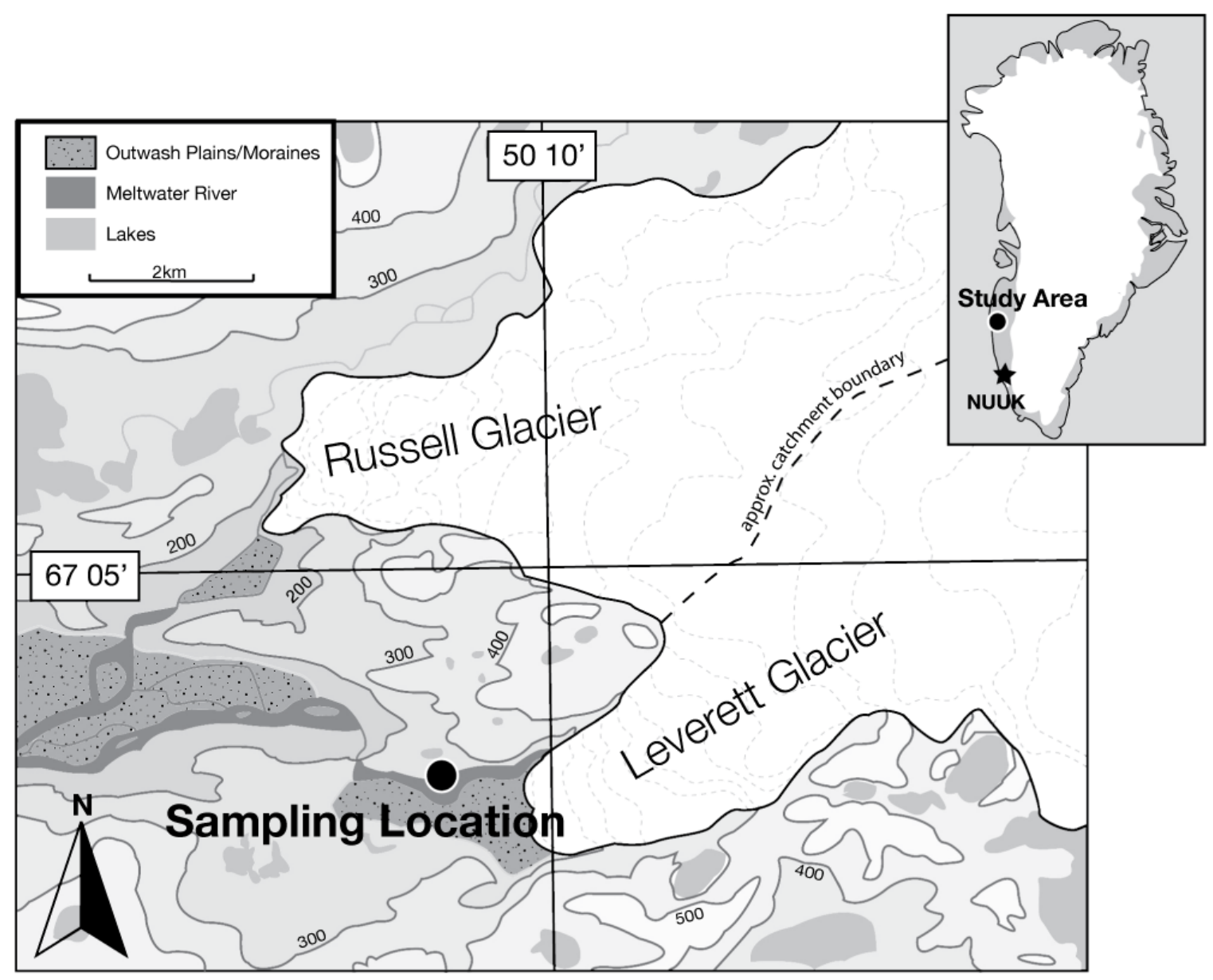

Figure 1: Location of Leverett Glacier in west Greenland. The primary sampling location for continuous ${ }^{222} \mathrm{Rn}$ measurements is indicated by the black circle though some early season deployments of the ${ }^{222} \mathrm{Rn}$ sensor occurred much closer to the glacier terminus. Figure adapted from Hawkings et al. (2014). 

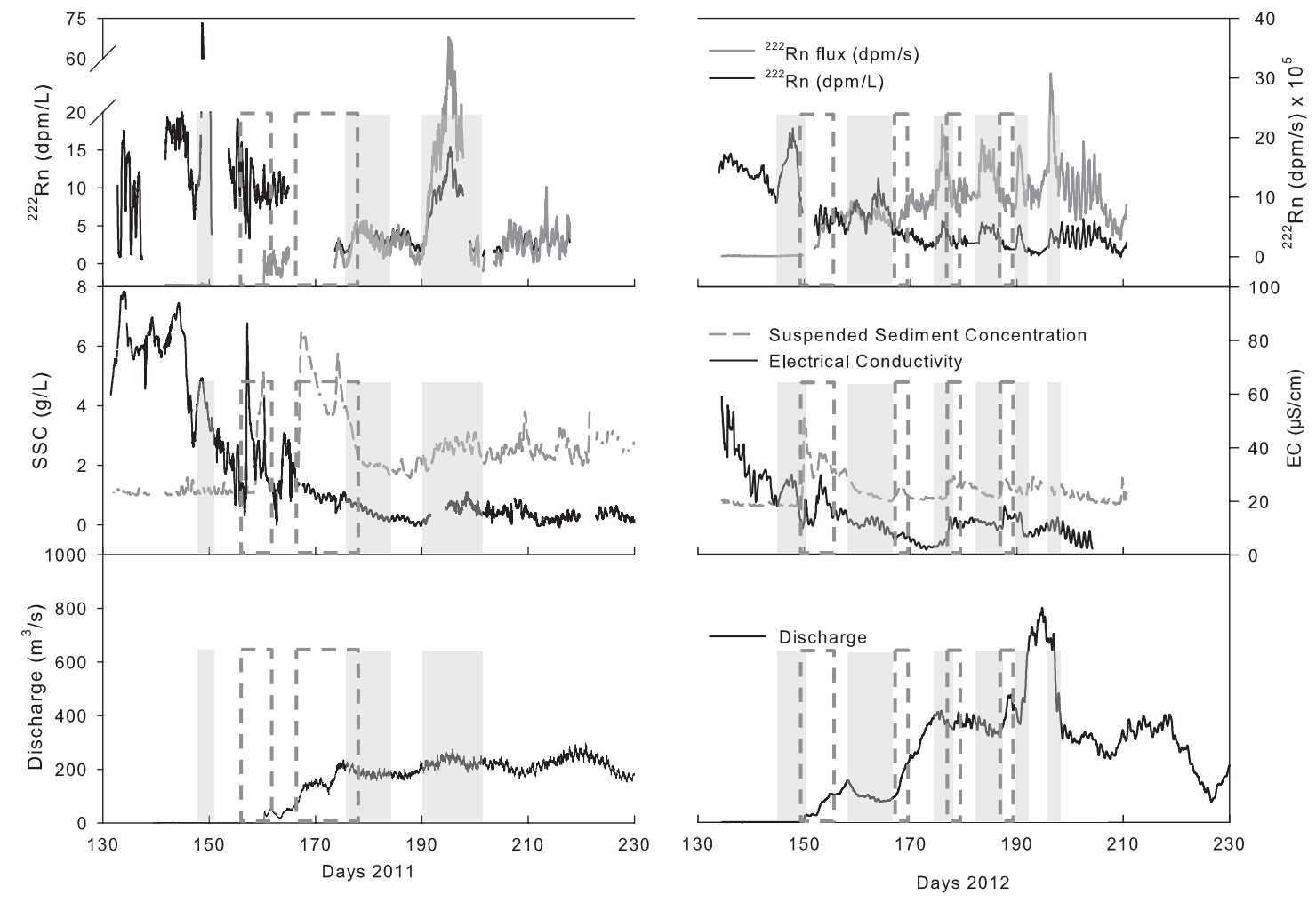

Figure 2: Results from 2011 and 2012 field seasons. Top panels: radon-222 activity (dpm L ${ }^{-1}$ ) and the ${ }^{222} \mathrm{Rn}$ flux (dpm s${ }^{-1}$ ); middle panels: EC and SSC (Hawkings et al., 2014). bottom panels: river discharge (Sole et al., 2013; Tedstone et al., 2013). Shaded grey boxes represent ${ }^{222} \mathrm{Rn}$ outburst events while dashed grey boxes are SSC/EC outburst events (discussed in text). 


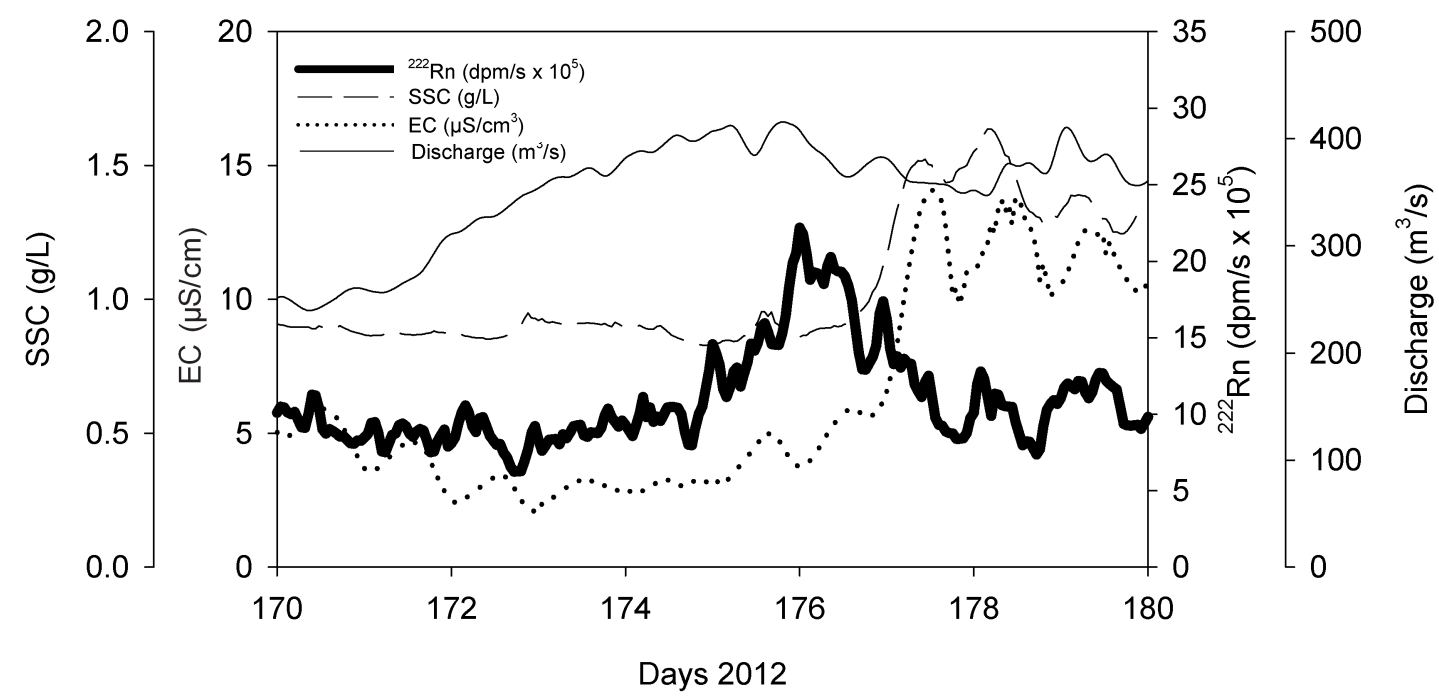

Figure 3: Radon-222, EC, suspended sediment concentration (SSC) and river discharge between days 170-180 in 2012. In this example, a ${ }^{222} \mathrm{Rn}$ outburst (days 175-178) occurred following an increase in river discharge while ${ }^{222} \mathrm{Rn}$ decreased during the onset of an SSC/EC outburst event (days $177-178$. We hypothesize that ${ }^{222} \mathrm{Rn}$ traces meltwater from the distributed system, which drains into the channelized system on the falling limb of the hydrograph. The SSC/EC outburst event (day 177-180) is likely indicative of a supraglacial lake drainage event during which time the channelized system was pressurized and the flux of distributed system meltwater decreased. 

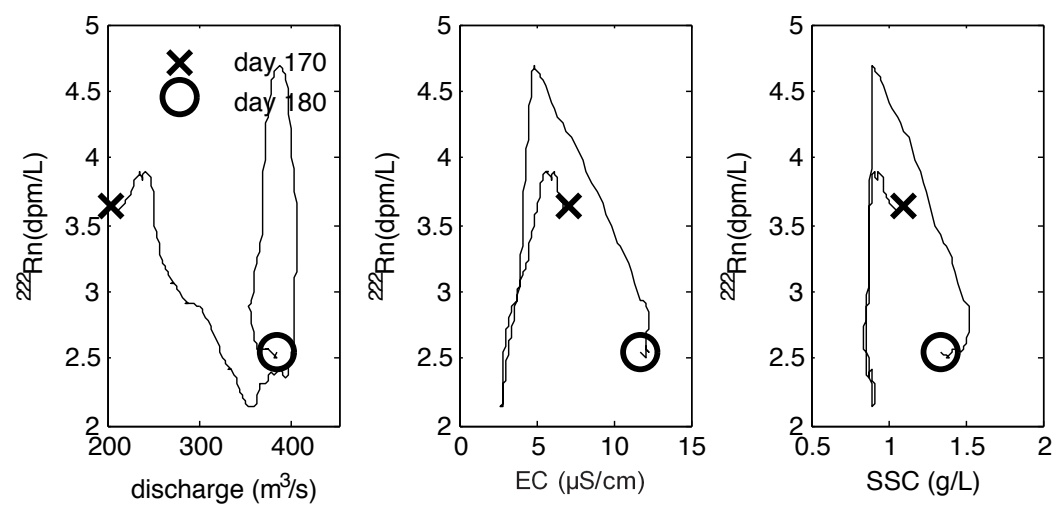

Figure 4: Radon-222 versus river discharge, EC and SSC between days 170-180 in 2012. The x symbol represents day 170 while the circle represents day 180 . In this figure, ${ }^{222} \mathrm{Rn}, \mathrm{EC}, \mathrm{SSC}$ and river discharge data have been smoothed using a 24-hour moving average window. The left figure shows that the ${ }^{222} \mathrm{Rn}$ outburst occurred following an increase in river discharge. The middle and right figures demonstrate that the ${ }^{222} \mathrm{Rn}$ flux decreased during the onset of an SSC/EC outburst event, which was likely triggered by a supraglacial lake drainage event. 


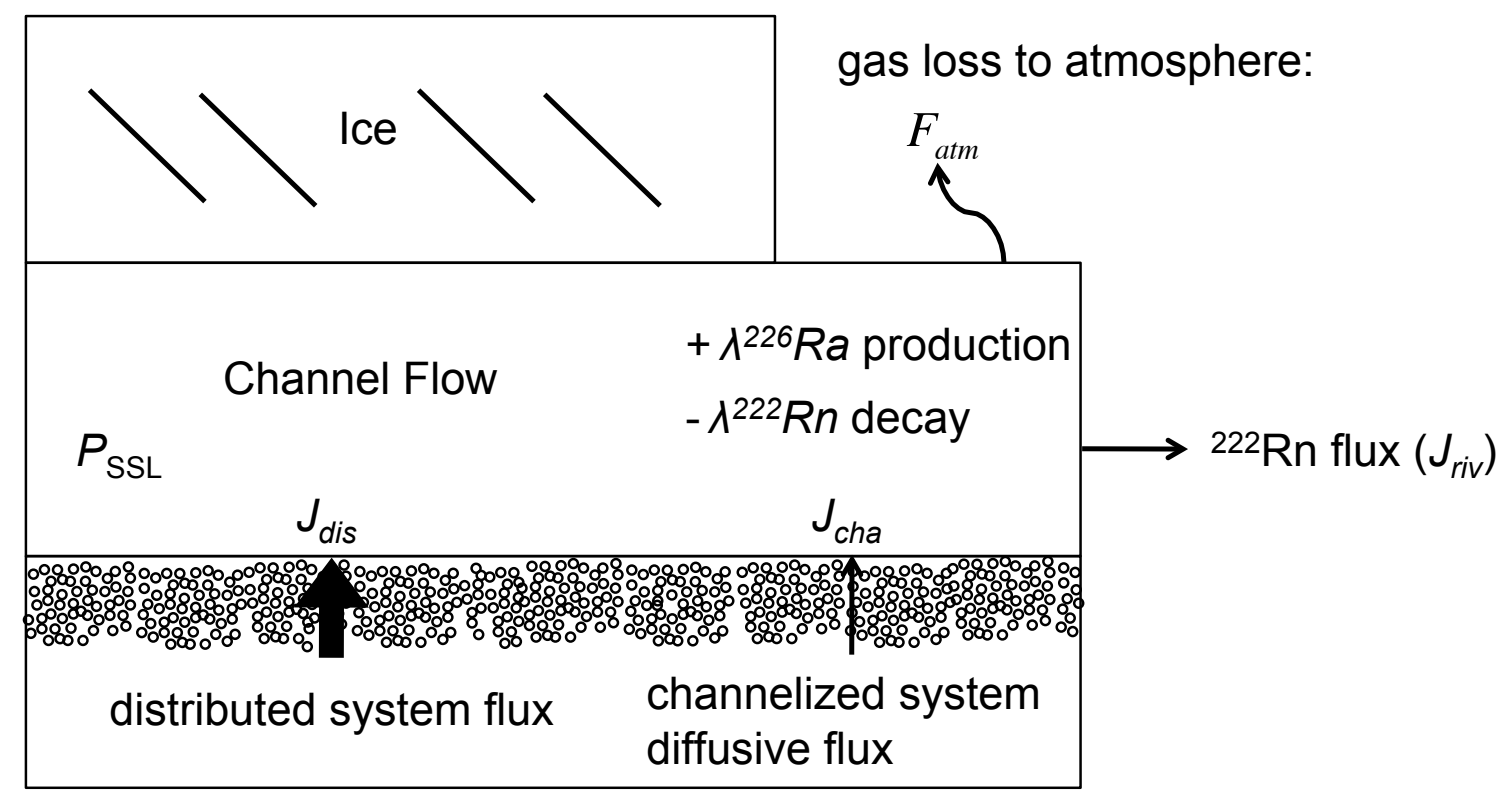

Figure 5: Summary of ${ }^{222} \mathrm{Rn}$ sources and sinks in the proglacial river. Sources of ${ }^{222} \mathrm{Rn}$ include the distributed system flux $\left(J_{d i s}\right),{ }^{222} \mathrm{Rn}$ diffusion through sediments into channels and cavities $\left(J_{\text {cha }}\right)$, ${ }^{226} \mathrm{Ra}$ bound to the surface of the suspended sediment load $\left(P_{S S L}\right)$, and the decay of dissolved ${ }^{226} \mathrm{Ra}$ $\left(\lambda^{226} R a\right)$. The sinks of ${ }^{222} \mathrm{Rn}$ include gas loss to the atmosphere $\left(F_{a t m}\right)$ and radioactive decay of ${ }^{222} \operatorname{Rn}\left(\lambda^{222} R n\right)$. The flux of ${ }^{222} \mathrm{Rn}$ from the river $\left(J_{\text {riv }}\right)$ is the summation of these variables. 

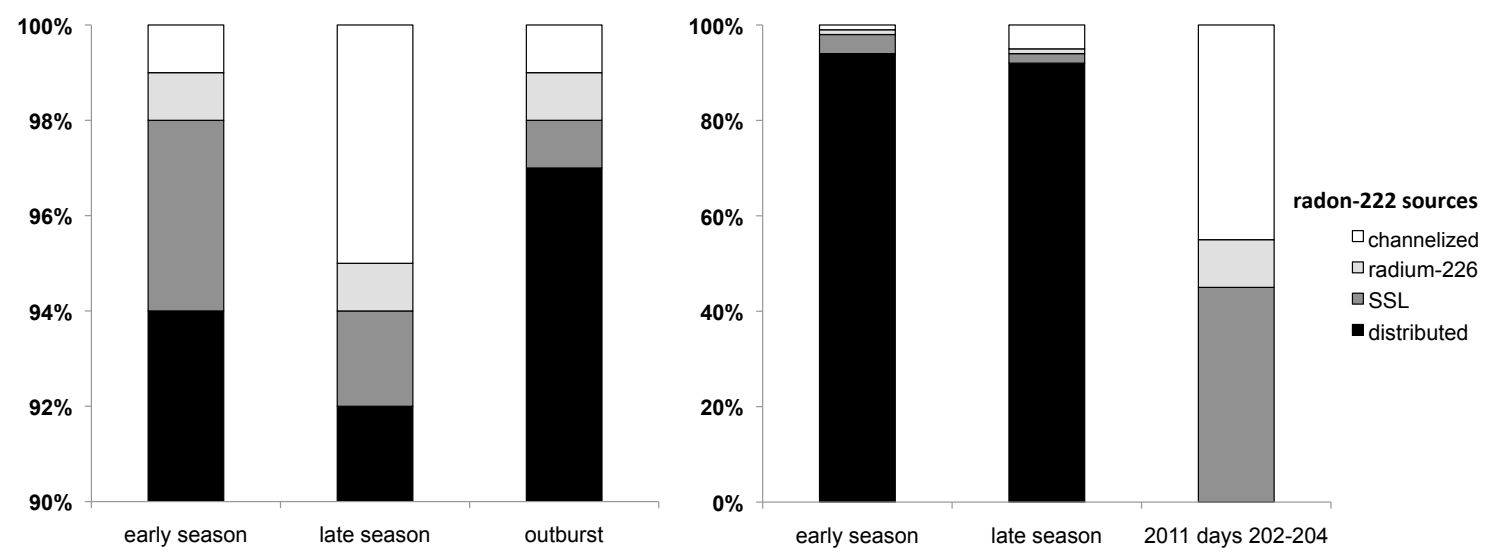

Figure 6: Relative contributions of ${ }^{222} \mathrm{Rn}$ sources in the model. The left panel shows the percent of the total ${ }^{222} \mathrm{Rn}$ flux supported by the distributed system $\left(J_{d i s}\right)$, the suspended sediment load $\left(P_{S S L}\right),{ }^{226} \mathrm{Ra}$ decay $\left(\lambda^{226} \mathrm{Ra}\right)$ and sediment diffusion in the channelized system $\left(J_{\text {cha }}\right)$ during early melt season (when discharge is $<10 \mathrm{~m}^{3} \mathrm{~s}^{-1}$ ), late season (discharge $>100 \mathrm{~m}^{3} \mathrm{~s}^{-1}$ ) and during a typical ${ }^{222} \mathrm{Rn}$ outburst. The right panel shows the early and late season ${ }^{222} \mathrm{Rn}$ sources relative to days 202-204 in 2011 when the distributed system cannot explain the ${ }^{222} \mathrm{Rn}$ flux. Note the right panel has an expanded y-axis. 


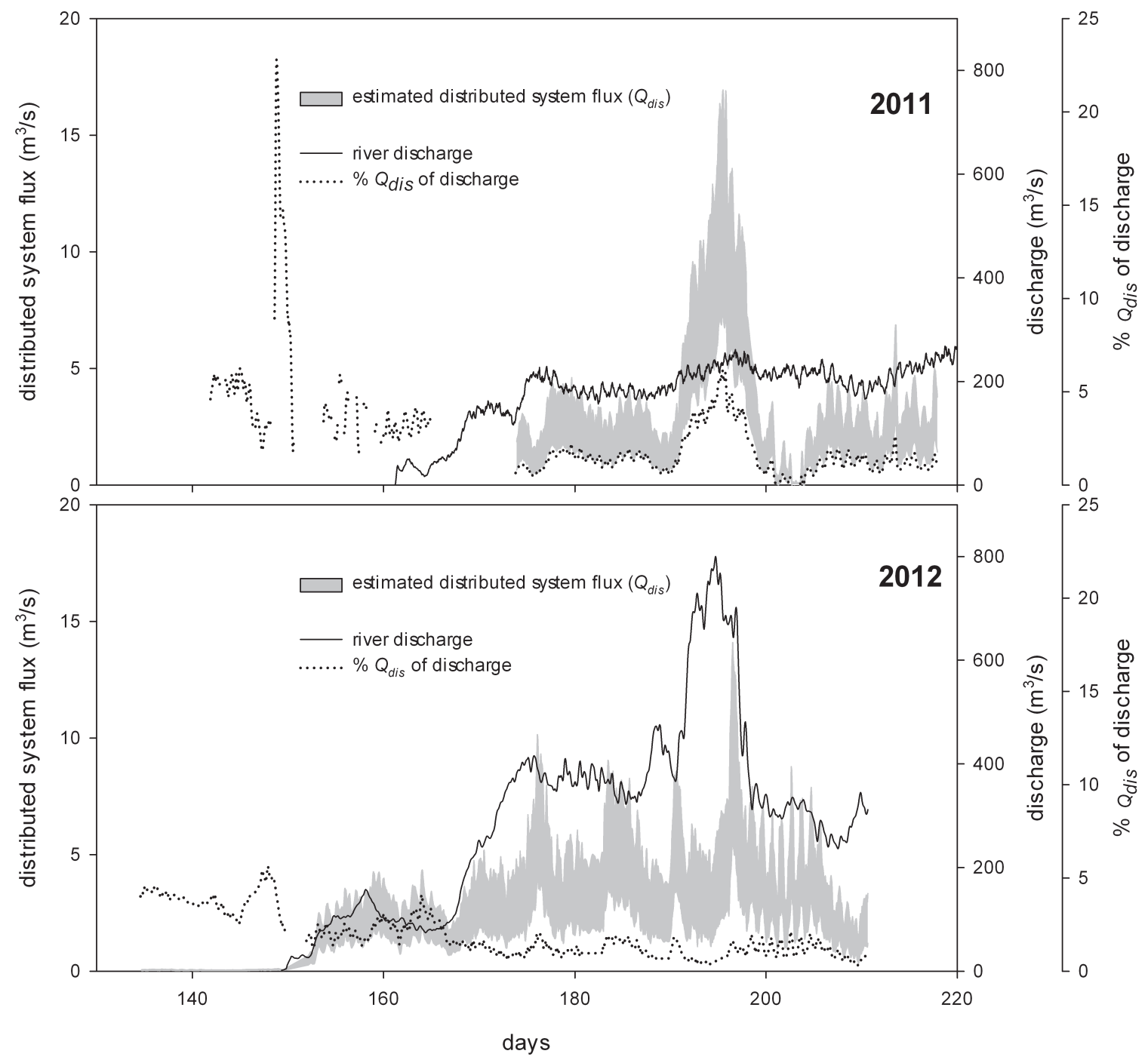

Figure 7: The estimated subglacial distributed system flux $\left(Q_{d i s}\right)$ from Leverett Glacier (grey area) and discharge of the proglacial river in 2011 and 2012 (black line). The width of the distributed system flux estimate represents the range in model uncertainty from $\lambda^{222} R n$ and $R n_{d i s}$ (see text). Also shown is the percent of the distributed system flux of total discharge calculated from the average upper and lower distributed system flux range (dotted line). 


\section{Chapter 2 Supporting Information}

\section{S1 Water probe response time}

During the 2011 and 2012 field seasons, several factors related to the water probe setup may have influenced the response time of the water probe. First, in order to keep the RAD7 a safe distance from the unstable riverbank, the length of tubing between the detector and water probe had to be increased (from 8 to $12.5 \mathrm{~m}$ ) effectively changing the system air volume from 1650 to $1750 \mathrm{~cm}^{3}$. Furthermore, the interface area of the membrane coil changed as two Accruel® membrane coils of slightly different lengths (a $2.1 \mathrm{~m}$ coil and the $2.2 \mathrm{~m}$ coil within the Durridge Inc. 'water probe') were used interchangeably across the two field seasons. The effect of these changes was quantified using the empirical relationships developed by Shubert et al., (2012), which suggest that our minor changes in air volume and membrane interface area likely only caused a 12-minute difference in equilibration time. This is a negligible difference when considering that the minimum time-scale over which significant changes in observed river ${ }^{222} \mathrm{Rn}$ were diurnal. Furthermore, a field test was conducted in which both membrane coils were simultaneously deployed in the proglacial river for 12 hours. During this test, both systems recorded ${ }^{222} \mathrm{Rn}$ activities well within the statistical counting errors. Consequently, the continuous

${ }^{222} \mathrm{Rn}$ record reported here is a compilation of results obtained using both water probes.

To assess the water probe's response to changes in ${ }^{222} \mathrm{Rn}$ activity, we conducted several laboratory experiments. First, the water probe was deployed simultaneously with the more conventional air-water equilibrating spray chamber (Burnett and Dulaiova, 2003) in a 200 L tank of circulating $10^{\circ} \mathrm{C}$ seawater for 70 hours. Seawater was continuously pumped into the tank from 
Vineyard Sound, 50 m offshore of Woods Hole (MA). The air-water equilibrator spray chamber provided a baseline from which to compare the water probe, because with an optimum setup, its equilibration time is less than 30 minutes (Schubert et al., 2012). The residence time of seawater in the tank was $<1$ hour and water was kept in constant motion using six submersible bilge pumps, each capable of pumping $\sim 30 \mathrm{~L} \mathrm{~min}^{-1}$. Slow but significant changes in ${ }^{222} \mathrm{Rn}$ were observed by both the spay chamber and water probe likely caused by the changing tide and submarine groundwater discharge (Burnett and Dulaiova, 2003). The equilibration time was defined as the length of time at which the recorded ${ }^{222} \mathrm{Rn}$ activities reached an activity plateau within the statistical counting errors. With this experimental setup, the water probe required an initial six-hour equilibration time while the spray chamber reached equilibrium in $<30 \mathrm{~min}$. Subsequent changes in ${ }^{222} \mathrm{Rn}$ activity measured by the water probe lagged 1-2 hours behind the spray chamber. In a separate experiment, the water probe and spray chamber were allowed to equilibrate with ${ }^{222} \mathrm{Rn}$-free water before being moved quickly into a tank containing ${ }^{222} \mathrm{Rn}$ enriched groundwater. In this case, both water probe and spray chamber systems responded to the activity change in $<30$ minutes though the water probe required much longer to reach the new equilibrium plateau.

To determine the equilibration time of the water probe system in the proglacial river, we examined the first six hours of data recorded after the water probe was freshly deployed (Figure 1 for example). Our analysis included 14 separate deployments in 2011 and 2012 in river flows ranging from $1 \mathrm{~m}^{3} \mathrm{~s}^{-1}$ to $750 \mathrm{~m}^{3} \mathrm{~s}^{-1}$. In each case, an equilibration plateau was reached within two hours of deployment regardless of river flow rate or system configuration (as described above). The equilibration time was therefore three times faster than the laboratory experiments. This was likely because water in the proglacial river was flowing much faster than in laboratory 
experiments keeping the ${ }^{222} \mathrm{Rn}$ activity gradient at the water/air interface of the membrane coil closer to $100 \%$. These results support the findings of Hofmann et al. (2011) and Schubert et al. (2012) showing that the water flow rate over the membrane coil is the most important factor for passive ${ }^{222} \mathrm{Rn}$ extraction. Because of the much faster equilibration time in the proglacial river, we expect the water probe's response time to changing ${ }^{222} \mathrm{Rn}$ activities was also faster in the field than the one to two hours suggested by laboratory experiments.

In summary, when interpreting results from continuous ${ }^{222} \mathrm{Rn}$ measurements, we assume changes in ${ }^{222} \mathrm{Rn}$ activity recorded by our methods occurred within one hour of actual ${ }^{222} \mathrm{Rn}$ activity changes in the proglacial river. Also, we have excluded ${ }^{222} \mathrm{Rn}$ results from the first two hours from each fresh deployment while the water probe was equilibrating.

\section{S2 Sediment Properties}

The porosity and bulk density of glacial flour collected in the proglacial river was determined using the moisture content and particle density measured in the laboratory. Moisture content $(\% \mathrm{M})$ was determined by weighing sediments before and after drying at $100^{\circ} \mathrm{C}$ : using Equation 1:

$$
\% M=\frac{\text { wet } w t .-d r y w t .}{w e t w t .} \times 100
$$

\section{Equation S1}


Grain density $\left(\rho_{s}\right)$ was determined using the oven dry weight and volume of sediment. The volume of sediment was determined by adding the sediments to a volumetric flask and measuring the weight of water displaced by the sediments.

Bulk density $\left(\beta_{D}\right)$ was calculated using Equation 2

Equation S2

$$
\beta_{D}=\frac{1}{\left(\left[\frac{1}{100-\% M}\right] \times 100+\frac{1}{\rho_{s}}\right)-1}
$$

where $\rho_{s}$ is the average sediment grain density of triplicate analysis. Finally, posority $(\phi)$ was

estimated from

Equation S3

$$
\phi=\left(\rho_{s}-\beta_{D}\right) / \rho_{s}
$$




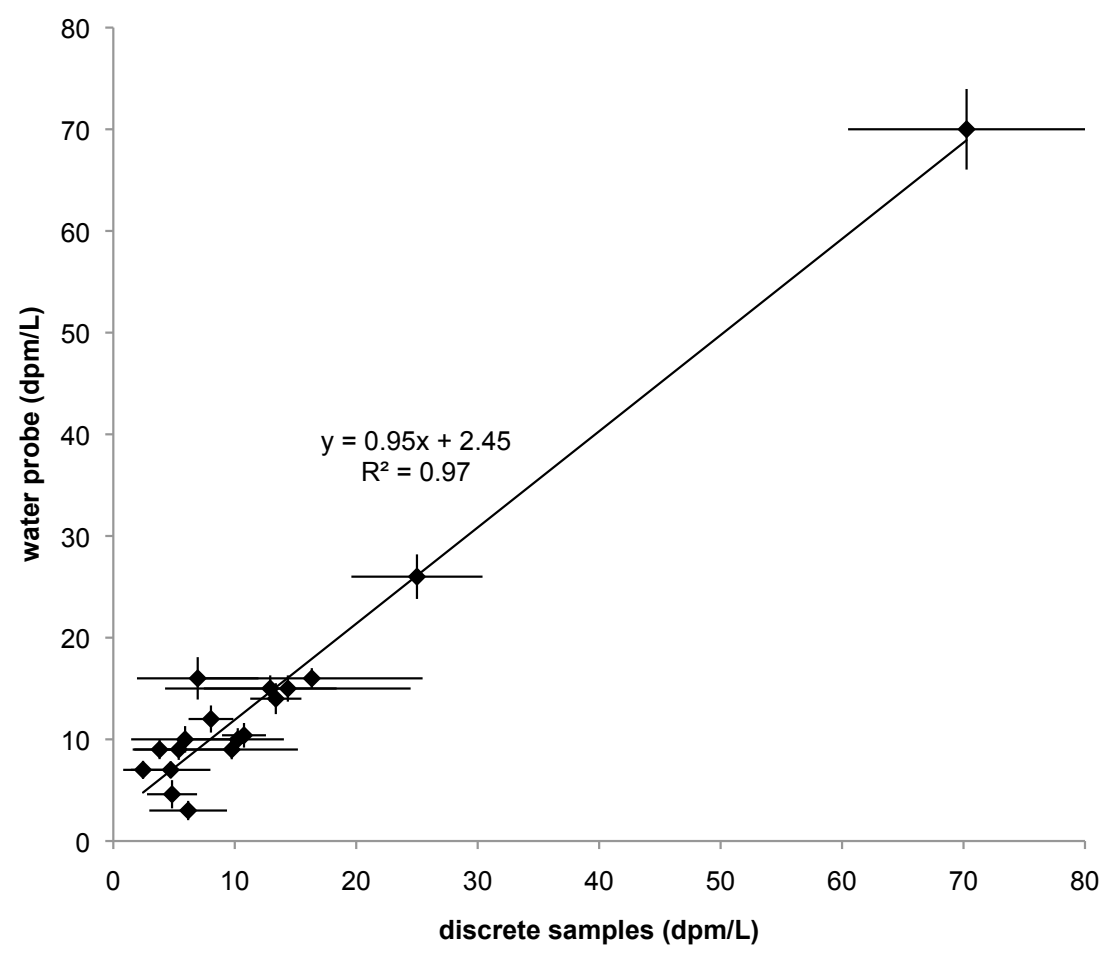

Figure S1: Comparison of discrete ${ }^{222} \mathrm{Rn}$ samples with comparable time-series measurements using the water probe. Error bars represent 1-sigma counting errors on each measurement. Many of these discrete ${ }^{222} \mathrm{Rn}$ samples were taken at the ice terminus while the water probe measured ${ }^{222} \mathrm{Rn}$ downstream. This implies that gas loss in the proglacial river between the ice terminus and the water probe was within the errors of our measurements. 


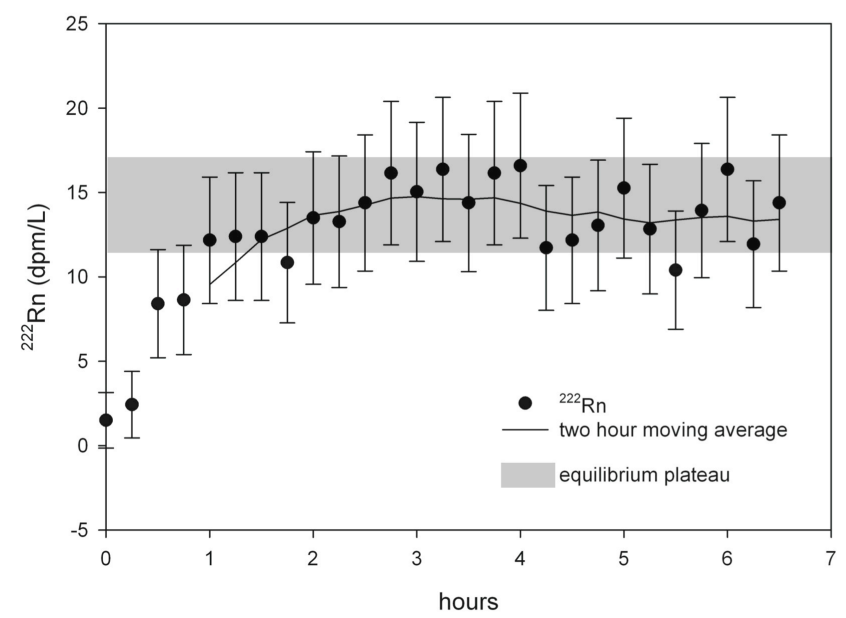

Figure S2: Equilibration time of the ${ }^{222} \mathrm{Rn}$ water probe on $6 / 2 / 2011$ (day 153) after being deployed in the proglacial river. Throughout the 2011 and 2012 field seasons, the water probed required 1-2 hours to reach an equilibrium plateau, the time at which the recorded radon activities reach an equilibrium activity plateau within the statistical counting errors. 
Table S1. Summary of $250 \mathrm{~mL}$ discrete ${ }^{222} \mathrm{Rn}$ samples collected in 2011.

\begin{tabular}{llllllll} 
Distance & Location & Day & Date & ${ }^{222} \mathrm{Rn}$ & + +- & EC & $\mathrm{pH}$ \\
& & & & & & & \\
\hline & & & & dpm L & & $\mu \mathrm{S} \mathrm{cm}^{-1}$ & \\
\hline 0.5 & River & 128.5 & $5 / 8 / 11$ & 15.9 & 6.4 & & \\
0.5 & River & 129.6 & $5 / 9 / 11$ & 3.2 & 2.1 & & \\
0.5 & River & 132.5 & $5 / 12 / 11$ & 3.2 & 2.8 & 69 & 7.9 \\
0.5 & River & 132.5 & $5 / 12 / 11$ & 7.0 & 5.4 & 69 & 7.9 \\
0.5 & River & 132.8 & $5 / 12 / 11$ & 4.3 & 3.0 & 75 & 7.9 \\
0.5 & River & 132.8 & $5 / 12 / 11$ & 5.9 & 4.4 & 75 & 7.9 \\
0.5 & River & 133.4 & $5 / 13 / 11$ & 4.8 & 2.1 & 94 & 8.0 \\
0.5 & River & 133.4 & $5 / 13 / 11$ & 7.0 & 6.4 & 94 & 8.0 \\
0.5 & River & 133.7 & $5 / 13 / 11$ & 18.2 & 10.1 & 79 & 7.9 \\
0.5 & River & 133.7 & $5 / 13 / 11$ & 14.5 & 7.5 & 89 & 7.9 \\
0 & River & 133.6 & $5 / 13 / 11$ & 4.3 & 3.9 & & 7.9 \\
0 & River & 133.6 & $5 / 13 / 11$ & 13.4 & 2.1 & & 7.9 \\
0.5 & River & 134.5 & $5 / 14 / 11$ & 9.1 & 2.1 & 90 & 7.9 \\
0.5 & River & 134.5 & $5 / 14 / 11$ & 7.0 & 4.4 & 90 & 7.9 \\
0.5 & River & 135.5 & $5 / 15 / 11$ & 5.4 & 2.8 & 74 & 7.8 \\
0.5 & River & 135.5 & $5 / 15 / 11$ & 7.0 & 6.2 & 76 & 7.8 \\
0.5 & River & 136.0 & $5 / 16 / 11$ & 10.8 & 1.8 & 81 & 7.8 \\
0.5 & River & 137.5 & $5 / 17 / 11$ & 9.1 & 6.2 & 76 & 7.8 \\
0.5 & River & 137.5 & $5 / 17 / 11$ & 1.6 & 2.0 & 76 & 7.8 \\
0.5 & River & 139.6 & $5 / 19 / 11$ & 4.3 & 1.8 & 81 & 7.9 \\
0.5 & River & 140.8 & $5 / 20 / 11$ & 5.9 & 1.1 & 73 & 7.8 \\
0.5 & River & 140.8 & $5 / 20 / 11$ & 5.4 & 2.8 & 73 & 7.8 \\
0.5 & River & 141.6 & $5 / 21 / 11$ & 14.0 & 4.1 & 75 & 7.9 \\
0.5 & River & 145.8 & $5 / 25 / 11$ & 4.3 & 4.7 & 65 & 7.8 \\
0.5 & River & 144.6 & $5 / 24 / 11$ & 6.9 & 3.2 & 88 & 8.0 \\
0 & River & 147.7 & $5 / 27 / 11$ & 67.4 & 11.6 & 49 & 7.7 \\
0 & River & 147.7 & $5 / 27 / 11$ & 32.2 & 7.3 & 45 & 7.7 \\
0.5 & River & 147.8 & $5 / 27 / 11$ & 7.5 & 2.8 & 45 & 7.7 \\
0.5 & River & 147.8 & $5 / 27 / 11$ & 12.9 & 3.0 & 45 & 7.7 \\
0 & River & 148.5 & $5 / 28 / 11$ & 41.4 & 8.1 & 85 & 7.8 \\
0 & River & 148.5 & $5 / 28 / 11$ & 54.3 & 7.3 & 84 & 7.8 \\
0.5 & River & 148.5 & $5 / 28 / 11$ & 70.3 & 9.7 & 62 & 7.8 \\
0.5 & River & 149.8 & $5 / 29 / 11$ & 24.3 & 6.2 & 40 & 7.7 \\
0 & River & 149.8 & $5 / 29 / 11$ & 17.8 & 8.8 & 40 & 7.7 \\
0 & River & 151.9 & $5 / 31 / 11$ & 17.8 & 3.1 & 37 & 7.5 \\
0 & River & 148.8 & $5 / 28 / 11$ & 6.5 & 3.5 & 61 & 7.7 \\
0 & River & 150.8 & $5 / 30 / 11$ & 5.4 & 1.3 & 40 & 7.6 \\
0.5 & River & 150.8 & $5 / 30 / 11$ & 14.7 & 6.8 & 40 & 7.6
\end{tabular}




\begin{tabular}{|c|c|c|c|c|c|c|c|}
\hline Distance & Location & Day & Date & ${ }^{222} \mathrm{Rn}$ & $+/-$ & $\mathrm{EC}$ & $\mathrm{pH}$ \\
\hline & & & & $\mathrm{dpm} \mathrm{L} \mathrm{L}^{-1}$ & & $\mu \mathrm{S} \mathrm{cm}^{-1}$ & \\
\hline 0.5 & River & 153.7 & $6 / 2 / 11$ & 22.6 & 9.5 & 36 & 7.4 \\
\hline 0 & River & 153.7 & $6 / 2 / 11$ & 3.2 & 2.8 & 36 & 7.4 \\
\hline 0 & River & 152.7 & $6 / 1 / 11$ & 24.1 & 7.0 & 36 & 7.5 \\
\hline 0.5 & River & 156.6 & $6 / 5 / 11$ & 5.4 & 3.7 & 14 & 7.3 \\
\hline 0.5 & River & 156.6 & $6 / 5 / 11$ & 4.1 & 4.8 & 15 & 7.3 \\
\hline 0.5 & River & 156.7 & $6 / 5 / 11$ & 17.1 & 3.0 & 12 & 7.3 \\
\hline 0.5 & River & 156.7 & $6 / 5 / 11$ & 17.2 & 5.3 & 12 & 7.3 \\
\hline 0 & River & 157.7 & $6 / 6 / 11$ & 4.3 & 3.0 & 44 & \\
\hline 0 & River & 157.7 & $6 / 6 / 11$ & 6.5 & 5.3 & 45 & 8.0 \\
\hline 0.5 & River & 158.3 & $6 / 7 / 11$ & 4.8 & 3.1 & 21 & 7.7 \\
\hline 0.5 & River & 159.2 & $6 / 8 / 11$ & 3.8 & 2.1 & 37 & 7.9 \\
\hline 0.5 & River & 159.3 & $6 / 8 / 11$ & 9.7 & 5.4 & 36 & 7.9 \\
\hline 0.5 & River & 153.7 & $6 / 2 / 11$ & 8.2 & 5.7 & 42 & 7.4 \\
\hline 0.5 & River & 153.7 & $6 / 2 / 11$ & 20.5 & 5.5 & 50 & 7.4 \\
\hline 0.5 & River & 162.7 & $6 / 11 / 11$ & 1.6 & 1.1 & 16 & 8.5 \\
\hline 0.5 & River & 162.7 & $6 / 11 / 11$ & 3.3 & 1.2 & 16 & 8.5 \\
\hline 0.5 & River & 165.0 & $6 / 14 / 11$ & 4.9 & 6.9 & 35 & 9.0 \\
\hline 0.5 & River & 165.5 & $6 / 14 / 11$ & 5.4 & 2.1 & 27 & 9.0 \\
\hline 0 & River & 166.7 & $6 / 15 / 11$ & 3.2 & 2.1 & 23 & 9.0 \\
\hline 0 & River & 166.7 & $6 / 15 / 11$ & 10.7 & 5.8 & 23 & 9.0 \\
\hline 0.5 & River & 167.5 & $6 / 16 / 11$ & 2.7 & 1.1 & 18 & 8.8 \\
\hline 1 & River & 167.6 & $6 / 16 / 11$ & 2.7 & 3.2 & 18 & 8.8 \\
\hline 1 & River & 170.0 & $6 / 19 / 11$ & 3.8 & 1.1 & 12 & 8.8 \\
\hline 1 & River & 170.0 & $6 / 19 / 11$ & 4.3 & 1.8 & 12 & 8.8 \\
\hline 0 & River & 172.7 & $6 / 21 / 11$ & 2.7 & 2.7 & 14 & 8.8 \\
\hline 0 & River & 172.7 & $6 / 21 / 11$ & 4.8 & 4.7 & 14 & 8.8 \\
\hline 0 & River & 184.6 & $7 / 3 / 11$ & 2.1 & 0.9 & & \\
\hline \multirow[t]{7}{*}{1} & River & 198.9 & 7/17/11 & 1.6 & 2.0 & & \\
\hline & Groundwater & 133.8 & $5 / 13 / 11$ & 3.7 & 2.7 & 156 & \\
\hline & Groundwater & 133.8 & $5 / 13 / 11$ & 9.1 & 6.1 & 156 & \\
\hline & Groundwater & 199.8 & $7 / 18 / 11$ & 60.3 & 14.4 & & \\
\hline & Groundwater & 134.7 & $5 / 14 / 11$ & 17.8 & 5.4 & 139 & \\
\hline & Groundwater & 198.9 & 7/17/11 & 35.8 & 8.0 & & \\
\hline & Groundwater & 198.9 & $7 / 17 / 11$ & 19.5 & 3.1 & & \\
\hline
\end{tabular}




\section{References}

Andrews, L. C., G. A. Catania, M. J. Hoffman, J. D. Gulley, M. P. Luthi, C. Ryser, R. L. Hawley, and T. A. Neumann (2014), Direct observations of evolving subglacial drainage beneath the Greenland Ice Sheet, Nature, 514(7520), 80-83.

De Baar, H. J. W., L. J. A. Gerringa, P. Laan, and K. R. Timmermans (2008), Efficiency of carbon removal per added iron in ocean iron fertilization, Mar. Ecol. Prog. Ser., 364(7223), 269-282.

Bartholomew, I., P. Nienow, A. Sole, D. Mair, T. Cowton, S. Palmer, and J. Wadham (2011a), Supraglacial forcing of subglacial drainage in the ablation zone of the Greenland ice sheet, Geophys. Res. Lett., 38(8).

Bartholomew, I., P. Nienow, A. Sole, D. Mair, T. Cowton, and M. A. King (2012), Short-term variability in Greenland Ice Sheet motion forced by time-varying meltwater drainage: Implications for the relationship between subglacial drainage system behavior and ice velocity, J. Geophys. Res. Earth Surf., 117(F3), doi:10.1029/2011JF002220.

Bartholomew, I. D., P. Nienow, A. Sole, D. Mair, T. Cowton, M. A. King, and S. Palmer (2011b), Seasonal variations in Greenland Ice Sheet motion: Inland extent and behaviour at higher elevations, Earth Planet. Sci. Lett., 307(3), 271-278.

Bhatia, M. P., S. B. Das, E. B. Kujawinski, P. Henderson, A. Burke, and M. A. Charette (2011), Seasonal evolution of water contributions to discharge from a Greenland outlet glacier: insight from a new isotope-mixing model, J. Glaciol., 57(205), 929-941. 
Bindschadler, R. (1983), The importance of pressurized subglacial water in separation and sliding at the glacier bed, J. Glaciol., 29(101), 3-19.

Borges, A. V., J.-P. Vanderborght, L.-S. Schiettecatte, F. Gazeau, S. Ferrón-Smith, B. Delille, and M. Frankignoulle (2004), Variability of the gas transfer velocity of $\mathrm{CO} 2$ in a macrotidal estuary (the Scheldt), Estuaries, 27(4), 593-603.

Boulton, G. S., and P. Caban (1995), Groundwater flow beneath ice sheets: part II—its impact on glacier tectonic structures and moraine formation, Quat. Sci. Rev., 14(6), 563-587.

Boulton, G. S., R. Lunn, P. Vidstrand, and S. Zatsepin (2007a), Subglacial drainage by groundwater-channel coupling, and the origin of esker systems: part 1—glaciological observations, Quat. Sci. Rev., 26(7), 1067-1090.

Boulton, G. S., R. Lunn, P. Vidstrand, and S. Zatsepin (2007b), Subglacial drainage by groundwater-channel coupling, and the origin of esker systems: part II—-theory and simulation of a modern system, Quat. Sci. Rev., 26(7), 1091-1105.

Boulton, G. S., M. Hagdorn, P. B. Maillot, and S. Zatsepin (2009), Drainage beneath ice sheets: groundwater-channel coupling, and the origin of esker systems from former ice sheets, Quat. Sci. Rev., 28(7), 621-638.

Burnett, W. C., and H. Dulaiova (2003), Estimating the dynamics of groundwater input into the coastal zone via continuous radon-222 measurements, J. Environ. Radioact., 69(1), 21-35. 
Cable, J. E., G. C. Bugna, W. C. Burnett, and J. P. Chanton (1996), Application of 222Rn and CH4 for assessment of groundwater discharge to the coastal ocean, Limnol. Oceanogr., 41(6), 1347-1353, doi:10.4319/1o.1996.41.6.1347.

Chandler, D. M., J. L. Wadham, G. P. Lis, T. Cowton, A. Sole, I. Bartholomew, J. Telling, P. Nienow, E. B. Bagshaw, and D. Mair (2013), Evolution of the subglacial drainage system beneath the Greenland Ice Sheet revealed by tracers, Nat. Geosci., 6(3), 195-198.

Chanyotha, S., C. Kranrod, and W. C. Burnett (2014), Assessing diffusive fluxes and pore water radon activities via a single automated experiment, J. Radioanal. Nucl. Chem., 1-8.

Charette, M. A., and M. C. Allen (2006), Precision Ground Water Sampling in Coastal Aquifers Using a Direct-Push, Shielded-Screen Well-Point System, Ground Water Monit. Remediat., 26(2), 87-93, doi:10.1111/j.1745-6592.2006.00076.x.

Charette, M. A., K. O. Buesseler, and J. E. Andrews (2001), Utility of radium isotopes for evaluating the input and transport of groundwater-derived nitrogen to a Cape Cod estuary, Limnol. Oceanogr., 46(2), 465-470.

Charette, M. A., W. S. Moore, and W. C. Burnett (2008), Uranium-and thorium-series nuclides as tracers of submarine groundwater discharge, U-Th Ser. nuclides Aquat. Syst. Elsevier, $155-191$.

Chen, J., N. M. Rahman, and I. A. Atiya (2010), Radon exhalation from building materials for decorative use, J. Environ. Radioact., 101(4), 317-322, doi:http://dx.doi.org/10.1016/j.jenvrad.2010.01.005. 
Collins, D. N. (1979), Hydrochemistry of meltwaters draining from an alpine glacier, Arct. Alp. Res., 307-324.

Cook, P. G., G. Favreau, J. C. Dighton, and S. Tickell (2003), Determining natural groundwater influx to a tropical river using radon, chlorofluorocarbons and ionic environmental tracers, J. Hydrol., 277(1), 74-88.

Corbett, D. R., W. C. Burnett, P. H. Cable, and S. B. Clark (1998), A multiple approach to the determination of radon fluxes from sediments, J. Radioanal. Nucl. Chem., 236(1), 247-253.

Cowton, T., P. Nienow, I. Bartholomew, A. Sole, and D. Mair (2012), Rapid erosion beneath the Greenland ice sheet, Geology, 40(4), 343-346.

Cowton, T., P. Nienow, A. Sole, J. Wadham, G. Lis, I. Bartholomew, D. Mair, and D. Chandler (2013), Evolution of drainage system morphology at a land-terminating Greenlandic outlet glacier, J. Geophys. Res. Earth Surf., 118(1), 29-41.

Creyts, T. T., and C. G. Schoof (2009), Drainage through subglacial water sheets, J. Geophys. Res. Earth Surf., 114(F4).

Das, S. B., I. Joughin, M. D. Behn, I. M. Howat, M. A. King, D. Lizarralde, and M. P. Bhatia (2008a), Fracture propagation to the base of the Greenland ice sheet during supraglacial lake drainage, Science, 320(5877), 778-781.

Das, S. B., I. Joughin, M. D. Behn, I. M. Howat, M. a King, D. Lizarralde, and M. P. Bhatia (2008b), Fracture propagation to the base of the Greenland Ice Sheet during supraglacial lake drainage., Science, 320(5877), 778-81, doi:10.1126/science.1153360. 
Dow, C. F., A. Hubbard, A. D. Booth, S. H. Doyle, A. Gusmeroli, and B. Kulessa (2013), Seismic evidence of mechanically weak sediments underlying Russell Glacier, West Greenland, Ann. Glaciol., 54(64), 135-141, doi:10.3189/2013AoG64A032.

Doyle, S. H., A. L. Hubbard, C. F. Dow, G. A. Jones, A. Fitzpatrick, A. Gusmeroli, B. Kulessa, K. Lindback, R. Pettersson, and J. E. Box (2013), Ice tectonic deformation during the rapid in situ drainage of a supraglacial lake on the Greenland Ice Sheet, Cryosph., 7(1), 129-140, doi:10.5194/tc-7-129-2013.

Dulaiova, H., and W. C. Burnett (2006), Radon loss across the water-air interface (Gulf of Thailand) estimated experimentally from ${ }^{222} \mathrm{Rn}^{-224} \mathrm{Ra}$, Geophys. Res. Lett., 33(5), doi:10.1029/2005GL025023.

Dulaiova, H., M. E. Gonneea, P. B. Henderson, and M. A. Charette (2008), Geochemical and physical sources of radon variation in a subterranean estuary—implications for groundwater radon activities in submarine groundwater discharge studies, Mar. Chem., 110(1), 120-127.

Flowers, G. E., and G. K. C. Clarke (2002), A multicomponent coupled model of glacier hydrology 1. Theory and synthetic examples, J. Geophys. Res. Solid Earth, 107(B11), ECV-9.

Fountain, A. G., and J. S. Walder (1998), Water flow through temperate glaciers, Rev. Geophys., 36(3), 299-328.

Gonneea, M. E., P. J. Morris, H. Dulaiova, and M. A. Charette (2008), New perspectives on radium behavior within a subterranean estuary, Mar. Chem., 109(3), 250-267. 
Gulley, J. D., D. I. Benn, E. Screaton, and J. Martin (2009), Mechanisms of englacial conduit formation and their implications for subglacial recharge, Quat. Sci. Rev., 28(19), 1984 1999.

Hawkings, J. R., J. L. Wadham, M. Tranter, R. Raiswell, L. G. Benning, P. J. Statham, A. Tedstone, P. Nienow, K. Lee, and J. Telling (2014), Ice sheets as a significant source of highly reactive nanoparticulate iron to the oceans, Nat. Commun., 5(3929), doi:10.1038/ncomms4929.

Henriksen, N., A. K. Higgins, F. Kalsbeek, and T. C. R. Pulvertaft (2009), Greenland from Archaean to Quaternary: descriptive text to the 1995 geological map of Greenland, 1: 2 500 000, Geological Survey of Denmark and Greenland.

Hofmann, H., B. S. Gilfedder, and I. Cartwright (2011), A novel method using a silicone diffusion membrane for continuous ${ }^{222} \mathrm{Rn}$ measurements for the quantification of groundwater discharge to streams and rivers, Environ. Sci. Technol., 45(20), 8915-8921.

Hubbard, B., M. Sharp, M. Nielsen, I. C. Willis, and C. C. Smart (1995), Borehole water-level variations and the structure of the subglacial hydrological systelll of Haut Glacier d' Arolla, Valais, Switzerland, J. Glaciol., 41(139), 572-583.

Kies, A., A. Nawrot, Z. Tosheva, and J. Jania (2011), Natural radioactive isotopes in glacier meltwater studies, Geochem. J., 45(6), 423-429.

Lamb, H. R., M. Tranter, G. H. Brown, B. P. Hubbard, M. J. Sharp, S. Gordon, C. C. Smart, I. C. Willis, and M. K. Nielsen (1995), The composition of subglacial meltwaters sampled from 
boreholes at the Haut Glacier d'Arolla, Switzerland, IAHS Publ. Proc. Reports-Intern Assoc Hydrol. Sci., 228, 395-404.

McCallum, J. L., P. G. Cook, D. Berhane, C. Rumpf, and G. A. McMahon (2012), Quantifying groundwater flows to streams using differential flow gaugings and water chemistry, $J$. Hydrol., 416, 118-132.

Meierbachtol, T., J. Harper, and N. Humphrey (2013), Basal drainage system response to increasing surface melt on the Greenland Ice Sheet, Science, 341(6147), 777-779.

Mills, M. M., C. Ridame, M. Davey, J. La Roche, and R. J. Geider (2004), Iron and phosphorus co-limit nitrogen fixation in the eastern tropical North Atlantic, Nature, 429(6989), 292294.

Nghiem, S. V, D. K. Hall, T. L. Mote, M. Tedesco, M. R. Albert, K. Keegan, C. A. Shuman, N. E. DiGirolamo, and G. Neumann (2012), The extreme melt across the Greenland ice sheet in 2012, Geophys. Res. Lett., 39(20).

Nielsdóttir, M. C., C. M. Moore, R. Sanders, D. J. Hinz, and E. P. Achterberg (2009), Iron limitation of the postbloom phytoplankton communities in the Iceland Basin, Global Biogeochem. Cycles, 23(3).

Raiswell, R. (1984), Chemical models of solute acquisition in glacial meltwaters, J. Glaciol., 30(104), 49-57.

Rempel, A. W. (2009), Transient effective stress variations forced by changes in conduit pressure beneath glaciers and ice sheets, Ann. Glaciol., 50(52), 61-66. 
Robinson, L. F., G. M. Henderson, L. Hall, and I. Matthews (2004), Climatic control of riverine and seawater uranium-isotope ratios, Science, 305(851-854).

Rothlisberger, H. (1969), Water pressure in subglacial channels, in Union Géodésique et Géophysique Internationale. Association Internationale d'Hydrologie Scientifique. Commission de Neiges et Glaces. Symposium on the hydrology of Glaciers, Cambridge, 7, p. 97.

Schoof, C. (2010), Ice-sheet acceleration driven by melt supply variability, Nature, 468(7325), $803-806$.

Schubert, M., A. Paschke, D. Bednorz, W. Bürkin, and T. Stieglitz (2012), Kinetics of the water/air phase transition of radon and its implication on detection of radon-in-water concentrations: practical assessment of different on-site radon extraction methods, Environ. Sci. Technol., 46(16), 8945-8951.

Sharp, M., K. Richards, I. Willis, N. Arnold, P. Nienow, W. Lawson, and J. Tison (1993), Geometry, bed topography and drainage system structure of the Haut Glacier d'Arolla, Switzerland, Earth Surf. Process. Landforms, 18(6), 557-571.

Shoemaker, E. M. (1986), Subglacial hydrology for an ice sheet resting on a deformable aquifer, J. Glaciol, 32(110), 20-30.

Sole, A., P. Nienow, I. Bartholomew, D. Mair, T. Cowton, A. Tedstone, and M. A. King (2013), Winter motion mediates dynamic response of the Greenland ice sheet to warmer summers, Geophys. Res. Lett., 40(15), 3940-3944. 
Tedstone, A. J., P. W. Nienow, A. J. Sole, D. W. F. Mair, T. R. Cowton, I. D. Bartholomew, and M. A. King (2013), Greenland ice sheet motion insensitive to exceptional meltwater forcing, Proc. Natl. Acad. Sci., 110(49), 19719-19724.

Tranter, M. (1993), A conceptual model of solute acquisition by Alpine glacial meltwaters, $J$. Glaciol., 39(133).

Tranter, M., M. J. Sharp, G. H. Brown, I. C. Willis, B. P. Hubbard, M. K. Nielsen, C. C. Smart, S. Gordon, M. Tulley, and H. R. Lamb (1997), Variability in the chemical composition of in situ subglacial meltwaters, Hydrol. Process., 11(1), 59-77, doi:10.1002/(SICI)10991085(199701)11:1<59::AID-HYP403>3.0.CO;2-S.

Wadham, J. L., R. J. Cooper, M. Tranter, and R. Hodgkins (2001), Enhancement of glacial solute fluxes in the proglacial zone of a polythermal glacier, J. Glaciol., 47(158), 378-386.

Walder, J. S. (1986), Hydraulics of subglacial cavities, J. Glaciol, 32(112), 439-445.

Werder, M. A., I. J. Hewitt, C. G. Schoof, and G. E. Flowers (2013), Modeling channelized and distributed subglacial drainage in two dimensions, J. Geophys. Res. Earth Surf., 118(4), $2140-2158$.

Zachos, J. C., B. N. Opdyke, T. M. Quinn, C. E. Jones, and A. N. Halliday (1999), Early cenozoic glaciation, antarctic weathering, and seawater $87 \mathrm{Sr} / 86 \mathrm{Sr}$ : is there a link?, Chem. Geol., 161(1), 165-180. 


\title{
Chapter 3
}

\section{Distributed system subglacial drainage controlled by channel expansion and meltwater runoff on the Greenland Ice Sheet}

\begin{abstract}
Each summer in the ablation zone of the Greenland Ice Sheet (GrIS) supraglacial meltwater runs off of the ice sheet surface into moulins and crevasses where it travels to the ice sheet bed. There it moves to the margin through an evolving network of efficient channelized and slow moving distributed drainage systems. Distributed drainage plays a major role in meltwater chemistry, ice sheet motion, and has long been a focus of glaciology research. Despite its importance, tracing meltwater fluxes from distributed system drainage has remained elusive and the relationships between distributed system drainage, meltwater runoff, and glacial velocity have not been observed in unison. Over the course of two summers, I investigated these relationships at Leverett Glacier, a large $\left(600 \mathrm{~km}^{2}\right)$ land-terminating outlet glacier of the GrIS. I used ${ }^{222} \mathrm{Rn}$, a relatively soluble inert noble gas that is acquired in meltwater during interaction with the ice sheet bed, as a tracer of distributed system fluxes after quantifying the non-distributed system ${ }^{222} \mathrm{Rn}$ sources. Hourly changes in meltwater runoff were estimated from a positive degree-day model while daily changes in runoff were estimated from the regional atmospheric climate
\end{abstract}


model RACMO2.3. These runoff models were significantly related $\left(r^{2}=0.73, p=0.02\right)$ though the PDD runoff model provided higher temporal resolution. The timing of supraglacial lake drainage events was inferred through concurrent spikes in electrical conductivity and the suspended sediment load measured in the proglacial river. Inferred supraglacial lake drainage events did not correlate with ${ }^{222} \mathrm{Rn}$-derived system fluxes suggesting that lake drainages do not result in immediate flushing of distributed system meltwaters. The source of meltwater runoff was determined using $\delta^{2} \mathrm{H}$ and $\delta^{18} \mathrm{O}$ isotopes. $\delta^{2} \mathrm{H}$ varied between $-218--171 \%$ while $\delta^{18} \mathrm{O}$ was between $-28--23 \%$ in the proglacial river. Changes in $\delta^{2} \mathrm{H}$ and $\delta^{18} \mathrm{O}$ isotopes reflected changes in meltwater sources from basal ice, snow melt, and supraglacial ice. The ${ }^{222} \mathrm{Rn}$ flux associated with the distributed system, $J_{d i s}$ was largely controlled by rapid changes in surface meltwater runoff. Distributed system drainage was greatest during periods of inferred channel expansion and following rapid increases in meltwater runoff. It can be expected that following a warm summer with many runoff induced glacial accelerations, which led to enhanced draining distributed system meltwaters, less water will remain in the non-channelized regions of the ice sheet bed. This could lead to less basal sliding in late summer though the winter, and may provide a feedback mechanism to explain observations that increased warming has not led to faster annual glacial velocities on the GrIS.

\section{Introduction}

\subsection{Greenland Ice Sheet Hydrology}

During the spring and summer in the ablation zone of the Greenland Ice Sheet (GrIS), the majority of surface meltwater drains through cracks and moulins to the ice sheet bed (Sharp et al., 1993; Fountain and Walder, 1998; Das et al., 2008; Bartholomew et al., 2012). This leads to 
increased basal water pressure and sliding, a feedback mechanism that has been hypothesized to accelerate the dynamic thinning of the GrIS (Zwally et al., 2002; Parizek and Alley, 2004). However, the capacity of subglacial drainage systems change in response to increasing surface meltwater inputs (Rothlisberger, 1969; Schoof, 2010), acting to reduce basal sliding (Cowton et al., 2013; Tedstone et al., 2013). Consequently, subglacial water pressure and ice velocity remain high until efficient channelized drainage develops that is capable of quickly evacuating large quantities of meltwater and lowering subglacial pressures (Bartholomew et al., 2011; van de Wal et al., 2015). Prior to the formation of a channelized system, drainage is through a distributed system thought to be composed of water moving slowly through cavities (Walder, 1986), a water sheet (Flowers and Clarke, 2002; Creyts and Schoof, 2009), or through permeable subglacial till (Shoemaker, 1986; Boulton et al., 2009). Once channels form, they act to scavenge meltwater from the adjacent distributed system (Weder et al., 2013). However, observations and models suggest that the direction of flow is reversed during periods of high meltwater inputs when water pressure in channels increases, resulting in recharge of the distributed system (Gulley et al., 2012; Werder et al., 2013; Andrews et al., 2014).

In alpine glaciers and the marginal zones of the GrIS, ice motion slows in mid-summer following the formation of channelized drainage. Subsequent acceleration events require either large meltwater pulses or reductions in drainage system capacity - the latter process acts to decrease the quantity of meltwater required to over-pressurize the system (Bartholomew et al., 2010; Cowton et al., 2013). Despite the relationships between meltwater runoff and glacial velocity, annual glacial motion may be independent of meltwater inputs (Sole et al., 2013; Tedstone et al., 2013; van de Wal et al., 2015). In land-terminating sections of the GrIS, slow mid-summer through winter velocities appear to compensate for fast glacial motion in the spring 
(Sole et al., 2013). This results in relatively constant interannual glacial motion (van de Wal et al., 2015). Recent research has found that the cause of mid-summer ice slowdowns may be increasing connectivity of the non-channelized sections of the ice bed caused by increasing surface meltwater inputs (Andrews et al., 2014). Hence, the relationship between distributed system drainage and meltwater runoff likely plays a major role in modulating the ice motion in the ablation zones of the GrIS. Despite their interdependence, the relationships between distributed system drainage, ice motion, and meltwater runoff have not been investigated simultaneously, other than through models (e.g. Werder et al., 2013; Flowers et al. 2015), as tracing distributed system flows has remained elusive. This study seeks to combine observations of meltwater runoff, proglacial river discharge, glacial motion, and a newly developed chemical tracer of distributed system drainage.

\subsection{Tracing distributed system drainage}

In Chapter 1, I presented a method to trace the timing and relative magnitude of distributed system fluxes using continuous ${ }^{222} \mathrm{Rn}$ measurements of bulk meltwater. Radon-222 $\left(\mathrm{t}_{1 / 2}=3.82\right.$ days $)$ is a relatively soluble, inert noble gas that does not participate in biogeochemical or weathering reactions once in solution. It is continuously added to glacial meltwater during water-rock interactions through the radioactive decay of ${ }^{226} \mathrm{Ra}$, a daughter product of the ${ }^{238} \mathrm{U}$ decay series. Previous work has shown that ${ }^{222} \mathrm{Rn}$ activities in glacial meltwater are higher in the early melt season when subglacial meltwater residence times are longer (Kies et al., 2011; Bhatia et al., 2011), and that ${ }^{222} \mathrm{Rn}$ can be used to separate the hydrograph of a proglacial river into delayed flow and quick flow components (Bhatia et al., 2011). In Chapter I, I quantified the subglacial ${ }^{222} \mathrm{Rn}$ sources from Leverett Glacier and 
demonstrated that, on average, $>90 \%$ of ${ }^{222} \mathrm{Rn}$ in glacial meltwater must be derived from the distributed system. Similar to ${ }^{222} \mathrm{Rn}$, solute concentrations are also elevated in distributed system drainage due to greater water-rock interactions in the slower moving water. Previous attempts have been made to use dissovled solute concentrations for hydrograph separation in glacial settings (e.g. Collins, 1979). However, rapid mineral weathering reactions can occur during mixing of distributed and chanelized system meltwater, hence unlike ${ }^{222} \mathrm{Rn}$, total solute concentration is not a conservative tracer of distributed system flows (Raiswell, 1984; Tranter et al., 1993).

\subsection{Estimating meltwater runoff inputs}

I used two independent methods to estimate meltwater runoff: the regional atmospheric climate model RACMO2.3 (van Wessem et al., 2014; Van Angelen et al., 2012) and a positive degree-day (PDD) meltwater runoff model (Hock, 2003). The RACMO2.3 meltwater runoff model was used to estimate runoff in both 2011 and 2012 while the PDD meltwater runoff model was only used in 2012. The PDD meltwater runoff model was not used in 2011 because in situ ablation measurements using ablation stakes were not made. Both of these model types have proven valuable tools for estimating meltwater runoff from alpine glaciers and the GrIS (Bartholomaus et al., 2008; Moon et al., 2014; Van As et al., 2014). Supraglacial lake drainage events act to rapidly increase subglacial water pressure and cause shot-term glacial acceleration and uplift (Das et al., 2008; Stevens et al., 2015). Hence, these events could potentially lead to higher connectivity of the distributed system. Supraglacial lake drainage events act to increase the suspended sediment concentration (SSC) and the total dissolve solute load measured by electrical conductivity (EC) in proglaical rivers (Bartholomew et al., 2011a). Hence, the timing 
of supraglacial lake drainage events may be inferred through spikes in SSC and EC in proglacial rivers (Bartholowmew et al., 2011a; Butler, 2014; Hawkings et al., 2014).

Surface meltwater runoff estimates were compared to stable $\delta^{18} \mathrm{O}$ and $\delta^{2} \mathrm{H}$ measurements of bulk meltwaters to infer changes in meltwater sources through the summer (Andreasen, 1984; Yde et al., 2004; Bhatia et al., 2011; Hindshaw et al., 2014). This is possible because there are large differences between isotopically light up-sheared basal ice at the GrIS edge (Knight, 1989), progressively heavier supraglacial Holocene ice further from the margin (Reeh et al., 1987), and much heavier modern precipitation at the margins of the GrIS (Bhatia et al., 2011).

\subsection{Setting and prior studies}

Leverett Glacier is a relatively large $\left(600 \mathrm{~km}^{2}\right)$ land-terminating outlet glacier of the GrIS at $67^{\circ} \mathrm{N}, 50^{\circ} \mathrm{W}$. The glacier is somewhat unique for Greenland in that all of the glacier's discharge is routed through a single portal on the north side of the glacier's snout. The proglacial region is filled with glacial outwash sediments and multiple lakes. The catchment of Leverett Glacier has previously been delineated (Bartholomew et al., 2011a) based on the surface topography inferred from a digital elevation model (Palmer et al., 2011). This study includes data collected during the spring through the end of the melt seasons in 2011 and 2012. Published data used in this work include river discharge, glacial velocity, and temperature data from 2011 (Sole et al., 2013) and 2012 (Tedstone et al., 2013). The SSC and dissolved solute concentration data, inferred through electrical conductivity (EC) measurements of bulk meltwater, have also been published in 2011 (Butler, 2014) and 2012 (Hawkings et al., 2014).

This work builds on numerous studies that have been conducted at Leverett Glacier. Bartholomew et al. (2010) demonstrated that during the summer months, ice velocity increased 
up to $220 \%$ above winter background values and that the locations of these speed-up events migrate up the glacier over the course of the summer. Bartholomew et al. (2011a) investigated the seasonal up-glacier expansion of hydraulic efficiency of the subglacial drainage system across the catchment. It was found that this expansion occurred episodically in response to surface meltwater inputs. Bartholomew et al. (2011b) found observed a strong positive relationship between rates of annual ablation and changes in annual ice motion along a transect over the GrIS with sites nearest the margin experiencing the greatest variations in annual ice motion. It was furthermore inferred that the timing of and rate of meltwater delivery to the bed was a key control in hydrologically-forced velocity variations at the GrIS margin. Bartholomew et al. (2012) used a simple model of subglacial conduit behavior to show that the duration and rate of meltwater delivery to the subglacial drainage system, rather than the absolute meltwater volume inputs, are important controls on short-term patterns of subglacial water pressure, and therefore ice velocity. Sole et al. (2013) observed no significant correlation between surface melt and interannual ice flow, though there was a significant correlation between surface melt and summer ice flow. Sole et al. (2013) also speculated that greater summer melting led to greater drainage of non-channelized distributed systems leading to slower winter speeds. Cowton et al. (2013) and Chandler et al. (2013) used tracer experiments to demonstrate increasing drainage efficiency through a melt season with increasing meltwater inputs. Cowton et al. (2013) deduced that inputs to the drainage system regularly exceeded outputs causing the englacial water level to rise to the ice sheet surface. During these times, a rapid transition was observed from inefficient to efficient drainage in areas that had been closed by ice deformation over winter. Tedstone et al. (2013) found that despite extreme surface melting during the summer of 2012, annual glacial motion was less than during the much cooler 2009 summer. Tedstone et al. (2014) found that 
while absolute annual velocities vary substantially on the GrIS surface, the proportional contribution of summer motion to annual motion does not.

\section{Methods}

\subsection{Ice Motion}

Observations from a transect of six global positioning system (GPS) stations positioned from $395 \mathrm{~m}$ above sea level (a.s.l) near the ice front up to $1482 \mathrm{~m}$ a.s.l. (Stations 1-6; Figure 1) were used to derive daily ice motion (Bartholomew et al., 2010). Ice motion was recorded in $10 \mathrm{~s}$ intervals using dual-frequency GPS receivers mounted on poles and frozen into the ice. Data were processed kinematically in overlapping $28 \mathrm{~h}$ windows in Track 1.21 (Chen, 1999) using International Global Navigation Satellite System Service relative to an off-ice base station (Tedstone et al., 2013). Positions were filtered using a high-pass Gaussian filter to suppress highfrequency noise without distorting the long-term signal and then differenced every $24 \mathrm{~h}$ to calculate daily velocities and vertical displacement (Sole et al., 2013). Stations 1-3 are within the inferred hydrological catchment of Leverett Glacier whereas Stations 4-6 are directly north of the catchment at progressively higher elevations (Figure 1; Bartholomew et al., 2011).

\subsection{Proglacial River Discharge}

Discharge of the proglacial river was measured using continuous water stage monitoring through a stable bedrock section of the river (Sole et al., 2013; Tedstone et al., 2013). Stage was converted to discharge using stage-discharge curves created from repeat Rhodamine WT and Rhodamine B dye injections throughout the 2011 and 2012 melt seasons (Sole et al., 2013; 
Tedstone et al., 2013). Errors on discharge measurements at Leverett Glacier have been estimated previously at $\pm 15 \%$ (1 s.d.) (Bartholomew et al., 2011).

\subsection{Timing of supraglacial lake drainage events}

Electrical conductivity (EC) and SSC were measured at a location with stable bedrock $~ 1$ km downstream of the glacier's terminus. Previous work has shown that EC and SSC measured downstream do not deviate significantly from measurements taken at the glacier's terminus (Bartholomew et al., 2011a). EC was recorded using a Campbell Scientific 247 combined temperature-EC sensor with Campbell Scientific CR1000 and CR800 loggers. EC was calibrated using a $\mathrm{KCl}$ solution of known concentration; EC measurement errors were estimated to be $\pm 10 \%$. SSC (1 s.d.) was estimated from turbidity measurements made with a Partech IR 15C turbidity probe (Butler et al. 2014; Hawkings et al. 2014). Calibration curves were created from discrete suspended sediment samples collected from the proglacial river; errors on SSC were estimated to be $\pm 6 \%, 1$ s.d.

Bartholomew et al. (2011) found that spikes in SSC/EC, defined as periods when both parameters increase rapidly, are connected to supraglacial lake drainage events. I confirmed the relationship between the timing of SSC/EC spikes and supraglacial lake drainage events using Moderate-Resolution Imaging Spectoradiometer (MODIS) true-color images for the 2011 and 2012 seasons. All cloud-free atmospherically-corrected images were downloaded and visually inspected for supraglacial lake disappearances during SSC/EC spikes. Over this period, the disappearance of lakes observed between subsequent days did correspond to spikes in SSC/EC.

\subsection{Tracing surface meltwater using oxygen and deuterium isotopes}


Time series samples were collected for oxygen $(\mathrm{O})$ and deuterium $\left({ }^{2} \mathrm{H}\right)$ isotope analysis from the proglacial river. Additionally, snow, rain, and ice samples including basal ice at the ice sheet terminus were collected in $2 \mathrm{~mL}$ glass vials, and surface ice at $2 \mathrm{~km}, 8 \mathrm{~km}$ and $40 \mathrm{~km}$ away from the ice sheet margin. Samples analyzed for $\mathrm{O}$ and ${ }^{2} \mathrm{H}$ isotopes from 2011 were analyzed at Bristol University using a Picarro L1102-i Isotopic Liquid Water and Water Vapor Analyzer (Butler, 2014). The analyzer was calibrated using IAEA standard reference materials (VSMOW, GISP, and SLAP). All samples were injected five times, with the first three injections clearing the analyzer and an average taken of the final two injections to determine the final measurement. Samples analyzed for $\mathrm{O}$ and ${ }^{2} \mathrm{H}$ isotopes from the 2012 season were analyzed at the Stable Isotope Laboratory at the University of California, Davis, using a Laser Water Isotope Analyzer VS (Los Gatos Research, Inc.) For each ${ }^{18} \mathrm{O}$ and ${ }^{2} \mathrm{H}$ analysis, the sample was injected eight times. The first four injections were discarded to eliminate memory effects while the average of the last four injections were used for isotope ratio calculations. Isotope ratios were standardized using a range of standards calibrated against IAEA standard reference materials (VSMOW, GISP, and SLAP). Precision was $\leq 0.3 \%$ for $\delta^{18} \mathrm{O}$ and $\leq 2.0 \%$ for $\delta^{2} \mathrm{H} . \quad \delta^{2} \mathrm{H}$ and $\delta^{18} \mathrm{O}$ values are reported relative to VSMOW.

2.5 Measuring radon in the proglacial river and calculating the subglacial distributed system flux

I measured ${ }^{222} \mathrm{Rn}$ in the Leverett Glacier proglacial river in 2011 (May 8-August 5) and 2012 (May 12-July 28). Continuous (hourly) measurements were made using a RAD7 (Durridge Inc.) radon-in-air monitor in series with a desiccant chamber and a RAD7 water probe, a submersible air-filled gas-permeable membrane coil made from Accruel ${ }^{\circledR}$ tubing. In this method, 
${ }^{222} \mathrm{Rn}$ in river water equilibrates with air in the membrane coil through passive diffusion; the air is continuously circulated in a closed loop through the RAD7 radon-in-air monitor system (Hofmann et al., 2011; Schubert et al., 2012). Radon-in-air activities were then converted to radon-in-water activity by calculating the temperature dependent air-water partition coefficient as described by Schubert et al. (2012). Typical 1-sigma counting errors were between 5-20\% with lower errors associated with higher ${ }^{222} \mathrm{Rn}$ activities. A four-hour moving average filter was applied to the ${ }^{222} \mathrm{Rn}$ activity measurements to smooth data. The ${ }^{222} \mathrm{Rn}$ flux $\left(\mathrm{dpm} \mathrm{s}^{-1}\right)$ was calculated by multiplying ${ }^{222} \mathrm{Rn}$ activities $\left(\mathrm{dpm} \mathrm{m}^{-3}\right)$ measured in the proglacial river by river discharge $\left(\mathrm{m}^{3} \mathrm{~s}^{-1}\right)$. Errors in the ${ }^{222} \mathrm{Rn}$ flux are therefore the combination of discharge and ${ }^{222} \mathrm{Rn}$ activity measurements.

I next quantified each ${ }^{222} \mathrm{Rn}$ source and sink in the glacial system. Sources of ${ }^{222} \mathrm{Rn}$ include ${ }^{226} \mathrm{Ra}$ associated with the suspended sediment load $\left(P_{S S L}\right)$, dissolved ${ }^{226} \mathrm{Ra}\left(\lambda^{226} \mathrm{Ra}\right.$ where $\lambda$ is the decay constant of $\left.{ }^{222} \mathrm{Rn}\right),{ }^{222} \mathrm{Rn}$ diffusion through the sediment floors sediments of the subglacial channelized system $\left(J_{\text {cha }}\right)$, and distributed system meltwater $\left(J_{d i s}\right)$. Radon-222 sinks consist of radioactive decay of unsupported ${ }^{222} \mathrm{Rn}$ during transit in the channelized system $\left(\lambda^{222} R n\right)$ and atmospheric evasion across the water/air interface $\left(F_{a t m}\right)$. Finally, $J_{r i v}$ is ${ }^{222} \mathrm{Rn}$ exported to the glacier's front through the proglacial river. The mass balance model for ${ }^{222} \mathrm{Rn}$ in the proglacial river can be written as:

$$
J_{\text {riv }}=J_{\text {dis }}+J_{\text {cha }}+P_{S S L}+\lambda^{226} R a-F_{a t m}-\lambda^{222} R n
$$


Each term can be quantified except for $J_{d i s}$, hence I used a "flux by difference" approach (Charette et al., 2008), which assumes that unaccounted for ${ }^{222} \mathrm{Rn}$ in the mass balance model must be from the distributed system (Chapter I).

\subsection{Air temperature}

Air temperature was measured in 15 minute intervals $\sim 2 \mathrm{~m}$ above the ice sheet surface. At Stations 1, 3, and 6 temperature was measured using a shielded Campbell Scientific T107 temperature sensor, and at Stations 2 and 4 air temperature was measured using shielded HOBO U21-044 temperature sensors (Sole et al., 2013; Tedstone et al., 2013). Temperature sensors were connected to Campbell Scientific CR 800 data loggers. Ablation was measured in 2012 using ablation stakes at Stations 1-6 with known winter snow depth and density measured at each station prior to the onset of melt. Ablation stakes were not used during the 2011 field season.

\subsection{Estimating meltwater runoff using a positive degree-day model}

In collaboration with Andrew Tedstone at the University of Edinburgh, I estimated meltwater runoff using a positive degree-day (PDD) meltwater runoff model for the 2012 field season (Hock, 2003; Barthomaus et al., 2008). As this method relies on accurate in situ ablation measurements, which were not collected in 2011, the PDD meltwater runoff model was only used to estimate runoff in 2012. A PDD model assumes that for each PDD (average temperature $>0^{\circ} \mathrm{C}$ over a period of time), a certain depth of snow or ice melts and that no melt occurs below $0^{\circ} \mathrm{C}$. This approach is based on the strong connection between temperature and variables highly correlated to ice ablation such as longwave atmospheric radiation, global radiation, and the

sensible heat flux (Kuhn, 1993; Ohmura, 2001; Braithwaite and Olesen 1989). While this method 
takes into account the total amount of heat energy available to melt snow and ice, it does not account for additional melting that might result from rainfall. Furthermore, as this study was completed within the ablation zone with low accumulation rates (van de Wal et al., 2014), we did not consider refreezing in calculating runoff. Topographic effects such as shading, slope and aspect angles also limit the accuracy of PDD models (Hock, 2003) though these issues are likely less important on the Leverett Glacier catchment compared with alpine glaciers. Despite some limitations, PDD meltwater runoff models are powerful tools in estimating meltwater runoff and typically produce runoff estimates comparable to more sophisticated remote sensing based models (Hock, 2003).

Degree-day factors (DDF), the amount of melt that occurs per positive degree-day, for snow and ice were determined by combining PDDs with ablation measurements at each station. Meltwater runoff was calculated using Equation 1

$$
\sum_{i=1}^{n} M=D D F_{\text {snow } / \text { ice }} \sum_{i=1}^{n} T^{+} \Delta t
$$

where $\mathrm{M}$ is water equivalent melt $(\mathrm{m})$ and $\mathrm{T}^{+}$is the PDDs or the sum of positive temperatures over a period of time $(\Delta t) . \mathrm{DDF}_{\text {snow }}$ and $\mathrm{DDF}_{\text {ice }}$ are the degree-day factors for snow and ice respectively. $\mathrm{DDF}_{\text {snow }}$ varied from $48-81 \mathrm{~mm} \mathrm{~h}^{-1} \mathrm{PDD}^{-1}$ between $600-1580 \mathrm{~m}$ a.s.l. while $\mathrm{DDF}_{\text {ice }}$ varied from 58-152 $\mathrm{mm} \mathrm{h}^{-1} \mathrm{PDD}^{-1}$ between 140-1580 $\mathrm{m}$ a.s.l. Snow cover was gone at the start of the 2012 field season between 140-600 $\mathrm{m}$ a.s.1. $\mathrm{DDF}_{\text {snow }}$ were used at each elevation band until the water equivalent snow depth had melted; following this, $\mathrm{DDF}_{\text {ice }}$ was used to calculate runoff. To determine meltwater runoff from the Leverett Glacier catchment, DDFs and PDDs were interpolated vertically at $20 \mathrm{~m}$ intervals between known elevation points (Stations 1-6; Figure 1), and then expanded to the inferred hydrological catchment. The meltwater runoff model was then run in one-hour time steps to produce cumulative runoff. 


\section{$2.8 \quad$ Meltwater runoff estimated using RACMO2.3}

In addition to the PDD meltwater runoff model, I used daily ice sheet runoff data from the Royal Netherlands Meteorological Institute (KNMI) regional atmospheric climate model RACMO2.3 (van Wessem et al., 2014; Van Angelen et al., 2012). This is the most recent version of the model, which includes the 2011 and 2012 melt seasons. RACMO2.3 incorporates a surface layer of snow and ice coupled to the atmosphere that allows for representative calculation of the surface energy balance and mass fluxes at the ice-atmosphere interface. This makes it possible to estimate meltwater refreezing in the snowpack, subsurface heat, and mass fluxes on a multilevel grid (Reijmer at al., 2012). The model also accounts for albedo changes due to snow metamorphosis and the appearance of bare-ice (Rae et al., 2012), which is a first order feedback on surface melt (Box et al., 2012). RACMO2.3 has been evaluated against in-situ surface temperature, wind, and surface energy balance observations from weather stations (Ettema et al., 2010; Van Angelen et al., 2012). The model is forced at the boundaries by the European Centre for Medium-Range Weather Forecasts (ECMWF) reanalysis data (Dee et al., 2011), and is run at $11 \mathrm{~km}$ horizontal grid resolution (Figure 2). Similar to the PDD meltwater runoff model, the Leverett Glacier catchment was defined as the inferred hydrological catchment based on surface topography (Bartholomew et al., 2011a). RACMO2.3 defines meltwater runoff as the water equivalent of ice melt and rain that is not retained through refreezing in firn at the ice sheet surface and consequently, may be available to drain to the ice bed. This is in contrast to the PDD model, which does not include meltwater retention on the ice surface through refreezing or storage in firn. Neither model accounts for meltwater storage in supraglacial lakes. 


\section{Results}

\subsection{Discharge}

Leverett Glacier experienced significantly more discharge in 2012 than in 2011 (2.4 \pm 0.4 $\mathrm{km}^{3}$ in 2012 vs. $1.4 \pm 0.2 \mathrm{~km}^{3}$ in 2011), due to warmer summer temperatures and a longer melt season. In comparison, total discharge measured in 2009 and 2010 was $1 \mathrm{~km}^{3}$ and $2 \mathrm{~km}^{3}$ respectively (Sole et al., 2013), hence, 2012 had the largest runoff since measurements began in 2009. Discharge measurements from Leverett Glacier have previously been reported for 2011 (Sole et al., 2013) and 2012 (Tedstone et al., 2013). Early melt season measurements, defined as when discharge was $<10 \mathrm{~m}^{3} / \mathrm{s}$, were between days 130-162 in 2011 and 130-150 in 2012 . Following this, discharge rapidly increased and averaged $\sim 200 \mathrm{~m}^{3} \mathrm{~s}^{-1}$ in 2011 and $\sim 400 \mathrm{~m}^{3} \mathrm{~s}^{-1}$ (Figure 3) while diurnal variations were generally $\sim 15 \mathrm{~m}^{3} \mathrm{~s}^{-1}$ in magnitude. Discharge began decreasing following day 220 in 2011 and 2012. However, in 2011, a late season discharge peak was observed between days 235-250 during which discharge reached the seasonal maximum of $290 \mathrm{~m}^{3} \mathrm{~s}^{-1}$. On July $12^{\text {th }}$ (day 194), 2012 an extreme melting event occurred during which over 98\% of the surface of the GrIS was melting (Nghiem et al., 2012). At Leverett Glacier, river discharge peaked at $>800 \mathrm{~m}^{3} \mathrm{~s}^{-1}$ following this event (Figure 3). Following day 250, river discharge ceased in both seasons.

\subsection{Temperature}

Table 1 shows the mean temperature measured at Sites 1-6 between days 161-220 (periods for which there is overlapping data from both field seasons). This data shows that while temperature was similar at Sites 1 and 6 between 2011 and 2012, Sites $2-5$ recorded significantly higher temperatures in 2012. Diurnal temperature variations in 2011 and 2012 were generally 
$>0^{\circ} \mathrm{C}$ at Sites 1-3 while at Sites 4-6 evening temperatures dropped below $0^{\circ} \mathrm{C}$. These observations are consistent with the greater discharge in 2012 and suggest that more intense melting rather than a larger catchment caused the increased discharge in 2012.

\subsection{Meltwater runoff}

In 2011, total runoff for the whole melt season predicted by RACMO2.3 was $2.4 \mathrm{~km}^{3}$ while discharge from the river was $1.4 \mathrm{~km}^{3}$, a difference of $42 \%$ (Figure 3). In 2012, runoff for the whole melt season predicted by RACMO2.3 and PDD runoff models was 2.5 and $2.7 \mathrm{~km}^{3}$ respectively (Figure 3). Total observed discharge in 2012 was $2.4 \mathrm{~km}^{3}$, which was $6 \%$ and $11 \%$ less than the runoff predicted by RACMO2.3 and the PDD model, respectively. Widespread melting across the catchment, defined as when temperatures $>0^{\circ} \mathrm{C}$ were measured at Site 6 , occurred between days 149-237 in 2012 and at least by day 161 (when measurements began) and ending after day 250 in 2011. Following the onset of wide scale melting across the catchment, average runoff predicted by RACMO2.3 in 2011 was $200-400 \mathrm{~m}^{3} \mathrm{~s}^{-1}$ while in 2012 , average runoff predicted by RACMO2.3 and the PDD model was between 200-700 $\mathrm{m}^{3} \mathrm{~s}^{-1}$ (Figure 3). Runoff predicted by RACMO2.3 and the PDD model was significantly correlated $\left(\mathrm{r}^{2}=0.73\right.$, $\mathrm{p}=0.02$ ); there was a $9 \%$ difference in the total volume of runoff predicted between each method.

During the 2011 melt season, there was on average a four-day lag between the onset of runoff predicted by RACMO2.3 and increasing river discharge (Figures 3 and 4A). Furthermore, between days 230-250, a rapid increase in meltwater runoff between days 238 and 241 resulted in a similarly large response in discharge from days 239 through 246 (Figure 4D). In 2012, increasing meltwater runoff predicted by RACMO2.3 and the PDD runoff model preceded increases in discharge by several days. The lag between meltwater runoff and discharge decresed 
between the beginning and end of the melt season. For example, an increase in runoff that peaked on day 150 resulted in a subsequent increase in discharge on day 159 (Figure 5A). The major meltwater runoff event from days 190-194 resulted in a peak in discharge two days after the peak in runoff (Figure 5B). Following this, major peaks in runoff did not result in similar magnitude peaks in discharge between days 205 and 225 (Figure 5C). Near the end of the melt season, a peak in runoff that occurred on day 228 was followed by a peak in discharge several days later on day 231 (Figure 5D).

\section{$3.4 \delta^{2} H$ and $\delta^{18} O$ of meltwater and ice}

Results from $\delta^{2} \mathrm{H}$ and $\delta^{18} \mathrm{O}$ analyses, reported using standard delta notation relative to VSMOW, are shown in Figures 6 and 7, and are summarized in Table 2. Similar to polar glaciers basal ice is exposed at the margins of the GrIS (Sugden et al., 1987; Knight, 1989), and ten ice samples collected at the terminus of Leverett Glacier had mean $\delta^{2} \mathrm{H}$ and $\delta^{18} \mathrm{O}$ values of $-247 \%$, $($ stdev $=16.4)$ and $-31.3 \%$ o (stdev=2.4) respectively. These values were within the range of the isotopic composition of basal ice measured at the terminus of Russell Glacier, which is adjacent to Leverett Glacier (Sugden et al., 1987; Knight, 1989). Surface ice samples isotopic values become progressively more enriched moving away from the ice margin. For example, samples collected $2 \mathrm{~km}, 8 \mathrm{~km}$, and $40 \mathrm{~km}$ from the margin had mean $\delta^{18} \mathrm{O}$ values of -30.9 (stdev=1), $27.0(\operatorname{stdev}=1.3)$, and $-24.2($ stdev=0.3) respectively (Table 2$)$. These surface ice values are similar to those observed by Reeh et al. (1987) who found progressively $\delta^{18} \mathrm{O}$ enriched surface ice moving away from the GrIS margin until $\sim 50 \mathrm{~km}$. From $\sim 50 \mathrm{~km}$ to the center of the ice sheet, surface ice $\delta^{18} \mathrm{O}$ becomes progressively depleted until the summit of the ice sheet where $\delta^{18} \mathrm{O}$ values are similar to those measured in basal ice exposed at the margin (Reeh et al., 1987). 
The local meteoric water line was constructed using rain and snow samples collected at Leverett Base Camp and was $\delta^{2} \mathrm{H}=7.79 \delta^{18} \mathrm{O}+1.35$ (Figure 7); this was offset slightly from the global meteoric water line $\left(\delta^{2} \mathrm{H}=8 \delta^{18} \mathrm{O}+10\right.$; IAEA/WMO, 2013). In the proglacial river both seasonal and diurnal variations were observed in the $\delta^{18} \mathrm{O}$ and $\delta^{2} \mathrm{H}$ values. Early season samples collected between days 130-155 in 2011 and 132 and 145 were significantly more depleted than samples collected through the rest of the melt season (Figure 6). The early season 2011 samples were notably more depleted than samples collected over a similar time period in 2012. During the early season sampling, river discharge was substantially lower than in $2012\left(\sim 1 \mathrm{~m}^{3} / \mathrm{s}\right.$ in 2011 vs. $\sim 10 \mathrm{~m}^{3} / \mathrm{s}$ in 2012) suggesting more early season surface meltwater was occurring in 2012 . Following these early season samples, $\delta^{18} \mathrm{O}$ and $\delta^{2} \mathrm{H}$ values in the proglacial river become more enriched on day 155 in 2011 and day 142 in 2012. These times correspond to increasing discharge of the proglacial river and the onset of significant melting on the ice sheet surface. Interestingly, in both 2011 and 2012 a sharp drop in $\delta^{18} \mathrm{O}$ and $\delta^{2} \mathrm{H}$ values was observed at the onset of melting on the ice sheet surface (day 160 in 2011 and 150 in 2011). Overall, samples collected in 2012 were more enriched than those collected in 2011 during early and late season sampling (Table 2). In both years, the mean mid-summer values are similar to the isotopic composition of surface ice collected $40 \mathrm{~km}$ from the ice margin (Table 2); however, there were a significant amount of $\delta^{2} \mathrm{H}$ and $\delta^{18} \mathrm{O}$ values observed in the late summer that were more depleted than ice samples collected at $40 \mathrm{~km}$ (Figure 7).

We used the PDD model built for the 2012 melt season to determine the weighted mean of the elevation of meltwater runoff -i.e. the ice surface elevation most runoff is derived from. Results of this calculation suggest that discharge originated from between 1100-1200 m for 2012 (Fig. 6). This elevation range corresponds to the widest portion of the surface elevation 
catchment about 40-50 km from the ice margin and is similar to the results of the proglacial $\delta^{2} \mathrm{H}$ and $\delta^{18} \mathrm{O}$ analyses, which were most similar to ice samples collected from $40-50 \mathrm{~km}$ from the margin.

\section{$3.5 \quad$ SSC and EC}

We use EC as a proxy for total solute concentrations in bulk meltwater. EC varied between 1-98 $\mu \mathrm{S} \mathrm{cm}^{-1}$ in 2011 and 2-62 $\mu \mathrm{S} \mathrm{cm}^{-1}$ in 2012 with higher concentrations being

observed in the early melt season (Figure 8; Chapter I). SSC varied between 1-6.7 $\mathrm{g} \mathrm{L}^{-1}$ in 2011 and 0.6-3.6 $\mathrm{g} \mathrm{L}^{-1}$ in 2012. In 2012, the highest SSC values were observed following the onset of wide spread melt across the catchment while in 2011 the maximum SSC values were seen shortly after melting began (Figure 8).

\subsection{Ice Motion}

In both 2011 and 2012, early season ice acceleration at Site 1 occurred approximately one day after the onset of surface meltwater runoff at Site 1, while at Site 3 acceleration occurs five days after surface melting begins at Site 3 (Figure 9). At Site 6, surface melting occurs at least by day 161 in 2011 and by day 149 in 2012 . However, acceleration above winter background speeds does not begin until day 170 in both 2011 and 2012. As observed by others (Sole et al., 2013; Tedstone et al., 2013), following these initial speed-up events, the ice sheet at Site 1 rapidly slowed to near winter background speeds $\left(\sim 100 \mathrm{~m} \mathrm{y}^{-1}\right)$ while at Site 3 this slowing occurred over several weeks. At the higher elevation Site 6, velocity dropped to winter background speeds (100 $\mathrm{m} \mathrm{y}^{-1}$ ) after day 210 in 2011 and day 200 in 2012. Following these mid-season slow downs, several rapid acceleration events occur during which velocity reach $>300 \mathrm{~m} \mathrm{y}^{-1}$ for $\sim 2$ days. 
These late season acceleration events correspond to rapid increases in meltwater runoff (Figure 9). Prior research at Leverett Glacier also found a positive relationship between increased temperature and temporary increases in summer velocity (Bartholomew et al., 2010; 2011a; 2011b; 2012; Cowton et al., 2013; Sole et al., 2013; Tedstone et al., 2013; 2014).

In 2011, uplift of $\sim 0.25 \mathrm{~m}$ was observed at Site 1 during the onset of surface meltwater runoff predicted by RACMO2.3 (Figure 10). While surface height at Site 1 remained relatively constant for the remaining observation period (through day 200), uplift was observed at Site 3 until day 190 when surface lowering began to occur (Figure 10). A subsequent uplift was observed beginning on day 200 at Sites 3 and 5 that corresponded to a rapid increase in runoff predicted by RACMO2.3. Following day 200, surface lowering occurred over the remaining observation period. A similar trend of surface uplift in the early season followed by surface lowering mid season was observed in 2012. Uplift was observed during the major meltwater runoff event over days 190-195, which was followed by a period of surface lowering across the catchment. Uplift was again observed between days 206 through 214 during a large increase in meltwater runoff predicted by the PDD runoff model and RACMO2.3. This trend of surface uplift in the early melt season followed by a period of surface lowering mid-season was observed by Bartholomew et al. (2010) for the 2009 melt season.

\subsection{Radon-222 and $J_{\text {dis }}$}

In both 2011 and $2012,{ }^{222} \mathrm{Rn}$ activities measured in the proglacial river were elevated in the early season and decreased following widespread melting across the catchment (Chapter I). Several breaks in the $201{ }^{222} \mathrm{Rn}$ record correspond to periods when the riverbank collapsed and a RAD7 water probe system was lost or when river ice prevented deployment of the water probe. 
The ${ }^{222} \mathrm{Rn}$ flux increased with rising river discharge as the growing water flux outweighed the decreasing ${ }^{222} \mathrm{Rn}$ activities. After the river reached $>100 \mathrm{~m}^{3} \mathrm{~s}^{-1}$, the ${ }^{222} \mathrm{Rn}$ flux varied between 6.2 $\times 10^{2}-46 \times 10^{5} \mathrm{dpm} \mathrm{s}^{-1}$ in 2011 and $1.4 \times 10^{5}-31 \times 10^{5} \mathrm{dpm} \mathrm{s}^{-1}$ in 2012 (Figure 8). Diurnal variations in ${ }^{222} \mathrm{Rn}$ were observed from days 199-205 in 2012 and were anticorrelated with river discharge.

During both 2011 and 2012 significant variations were observed in $J_{d i s}$, the ${ }^{222} \mathrm{Rn}$ flux I have attributed to the distributed system (Section 2.5; Chapter I). Notably, major spikes in $J_{d i s}$, periods when the $J_{d i s}$ increased significantly higher than observed in days prior, were seen in both 2011 and 2012. A major spike in $J_{d i s}$ occurred between days 190-200 in 2011 (Figure11) while in 2012, four substantial spikes punctuate the $J_{\text {dis }}$ record (days: $175-178,182-187,190-191,195-$ 197; Figure 12). These spikes in $J_{d i s}$ occur when meltwater runoff and/or river discharge were decreasing (Figure 11). All four spikes in $J_{\text {dis }}$ in 2012 begin decreasing as meltwater runoff increased (Figure 11). The large spike in $J_{\text {dis }}$ that occurred in 2011 between days 190-200 followed the onset of melting and ice accelerations to above winter background speeds at GPS Stations 5 and 6 and increased velocity at Stations 2-4 (Figure 12). Meltwater runoff decreased between days 187-191 and 195-200 in 2011, a similar time period as major spike in $J_{\text {dis }}$ (Figure 11).

\section{Discussion}

\subsection{Comparison between meltwater runoff models and proglacial river discharge} In 2011 , RACMO2.3 predicted $42 \%$ more meltwater runoff than was observed in the Leverett Glacier proglacial river (Figures 3 and 4). While there are no published error estimates of RACMO2.3 runoff, if it accurately predicted meltwater runoff then either the hydrological 
catchment inferred from surface ice topography (Bartholomew et al., 2011a) was not representative of the subglacial catchment, or there were drainage pathways through adjacent glaciers. Alternatively, if the hydrological catchment I used accurately represented drainage through Leverett Glacier, then RACMO2.3 largely overestimated meltwater runoff in 2011. Previous studies note the uncertainties in defining hydrological catchments of a single outlet glacier of the GrIS (van As et al., 2012; Clason et al., 2012), the possibility of water piracy of an adjacent glacier (Fitzpatrick et al., 2014), and the tendency of regional atmospheric climate models to overestimate meltwater runoff in this region of Greenland (Smith et al., 2015). Theoretical evaluations of the hydraulic potential of the Leverett Glacier catchment using recent bed topography data (Morlighem et al., 2013) suggest that meltwater drains through Leverett Glacier when subglacial water pressure is equal to ice overburden pressure; at lower water pressures a portion of the meltwater drains via the adjacent Russell Glacier (Figure 1; Tedstone et al., 2014). While water pressure likely varied between below and above ice overburden pressure for much of the summer (Cowton et al., 2013), it is clear from reconstructions of the hydraulic gradient that the largest subglacial channel beneath the catchment drained through Leverett Glacier (Tedstone et al., 2014). Although I did not quantify discharge from Russell Glacier, anecdotal observations in 2011 and 2012 suggest discharge from Russell Glacier was significantly higher in 2011 than in 2012 despite the cooler temperatures in 2011. Hence, water piracy from Russell Glacier could explain the discrepancy between RACMO2.3 runoff and river discharge in 2011 (Figures 3 and 4).

In 2012, there was relatively good agreement between the PDD and RACMO2.3 runoff models and discharge over the whole observation period. However, several periods exist when the predicted runoff was significantly offset from observed discharge, notably in the early and 
late melt season (Figures 5A and 5D). For example, after the onset of melting both RACMO2.3 and the PDD runoff models predicted significantly more runoff than the observed river discharge (Figure 5A). This implies either problems with catchment delineation, errors in the runoff models, or subglacial water storage. Clearly, there is a delay between the first peak in runoff (day 150 ) and discharge (day 160) suggesting inefficient drainage during this early season and potential subglacial water storage (Figure 5A). Following the massive influx of meltwater runoff between days 190-195 (Figure 5B), subsequent increases in meltwater runoff did not result in equivalent river discharge (Figure 5C and D). This suggests hydrological reorganization of the subglacial drainage system and partial drainage through another glacier in the vicinity. For example, lower hydraulic pressures as a result of more efficient drainage could have led to increased drainage through Russell Glacier as predicted by Tedstone et al. (2014). While studies of alpine glaciers have used meltwater runoff models to quantify glacier meltwater storage by comparing surface runoff with glacial discharge (e.g. Bartholomaus et al. 2008), limitations inherent to determining subglacial water routing within the GrIS impede similar calculations. Furthermore, while I show that there was generally good agreement between the RACMO2.3 and PDD runoff models $\left(\mathrm{r}^{2}=0.73, \mathrm{p}=0.02\right)$, I did not directly measure runoff in situ so I cannot determine the errors of either method.

Regardless of the catchment size and whether a portion of meltwater from the Leverett Glacier catchment drained to an adjacent glacier, both meltwater runoff models likely captured the timing of meltwater inputs to the subglacial environment. The correlation between the predicted meltwater runoff and ice motion (Figure 9) implies that these models can be used to determine when subglacial water pressure was increasing or decreasing as a result of meltwater runoff. Exceptions may have occurred during supraglacial lake drainage events, which may have 
temporarily overwhelmed the subglacial drainage system (Das et al., 2008). However, the vast majority of supraglacial meltwater is not stored in supraglacial lakes, but is instead transported rapidly by supraglacial streams and rivers to moulins (Smith et al., 2015). Consequently, changes in meltwater runoff predicted by the runoff models should approximate proportional changes in meltwater inputs to the subglacial environment.

\subsection{Source of meltwater runoff inferred from $\delta^{2} \mathrm{H}$ and $\delta^{18} \mathrm{O}$ isotopes}

The $\delta^{2} \mathrm{H}$ and $\delta^{18} \mathrm{O}$ values measured in the proglacial river were the result of mixing between supraglacial ice melt, basal ice melt, and modern precipitation. The source of distributed system meltwater is largely surface ice and snowmelt and to a lesser extent basal ice melt (Bell, 2008). Hence, $\delta^{2} \mathrm{H}$ and $\delta^{18} \mathrm{O}$ in distributed system meltwater cannot be expected to have the isotopic composition of basal ice as was assumed in Bhatia et al. (2011) and Arendt et al. (2015). Consequently, I did not use $\delta^{2} \mathrm{H}$ and $\delta^{18} \mathrm{O}$ to differentiate between channelized and distributed system drainage. Instead I used these isotopes to infer the source of bulk meltwater based on measurements of supraglacial ice, basal ice, and precipitation.

Up-sheared basal ice is present on the ice sheet surface at the glacier's terminus and at least to $2 \mathrm{~km}$ from the margins of Russell Glacier (Sugden et al., 1987; Knight, 1989) and Leverett Glacier (Table 2). Consequently, early season meltwater inputs are likely largely derived from mixing snowmelt with basal ice and subglacial meltwater stored overwinter. Assuming bulk meltwater in the early season represents mixing between basal ice melt and snowmelt, and that meltwater stored over winter is negligible, two-component mixing equations can be used to estimate the relative fractions of each. This can be done using the equations 


$$
\mathrm{f}_{1} \delta^{2} \mathrm{H}_{1}+\mathrm{f}_{2} \delta^{2} \mathrm{H}_{2}=\delta^{2} \mathrm{H}_{3}
$$

where $\mathrm{f}$ is the fraction of flow and the subscripts indicate basal ice melt (1), snowmelt (2), and bulk meltwater in the proglacial river (3). For this calculation I used the mean $\delta^{2} \mathrm{H}$ values of: river water prior to day 161 in $2011\left(\delta^{2} \mathrm{H}=-200\right)$, basal ice samples $\left(\delta^{2} \mathrm{H}=-249\right)$, and precipitation $\left(\delta^{2} \mathrm{H}=-131\right)$. Solving this equation indicated that prior to day 161 in $2011 \sim 58 \%$ of bulk meltwater was composed of basal ice melt while $\sim 42 \%$ was composed of snowmelt. A similar calculation using mean $\delta^{2} \mathrm{H}$ river water samples prior to day 150 in 2012 found that $\sim 42 \%$ of bulk meltwater was basal ice while $\sim 58 \%$ was composed of snowmelt.

Following the 2011 early season samples, bulk meltwater briefly became more enriched (higher $\delta^{2} \mathrm{H}$ and $\delta^{18} \mathrm{O}$ values) before again moving towards more depleted values (lower $\delta^{2} \mathrm{H}$ and $\delta^{18} \mathrm{O}$ values; days $157-161$ in 2011; Figure 6). I interpret this spike in $\delta^{2} \mathrm{H}$ and $\delta^{18} \mathrm{O}$ values as evidence of the onset of significant snow melt higher in the catchment as these days also correspond to the initial summer speed-up at Station 1 (Figure 9). The return to more depleted values on days 157-161 was likely the result of the loss of snow cover at lower elevations and enhanced ice melt of up-sheared basal ice. A similar trend was seen in the early season of 2012 though only one sample point (Figure 6; day 149) exists that shows a temporary drop in the proglacial river's $\delta^{2} \mathrm{H}$ and $\delta^{18} \mathrm{O}$ values. However, the PDD meltwater runoff model predicted that there was snow melting across the catchment until day 181 in 2012. Following the onset of widespread melting across the catchment as inferred from on-ice temperature measurements, $\delta^{2} \mathrm{H}$ and $\delta^{18} \mathrm{O}$ values in the proglacial river remained relatively stable through the middle of the 
summer (Figures 6; Table 2), and are similar to or slightly enriched relative to supraglacial ice samples collected at $40 \mathrm{~km}$ from the margin (Table 2). This implies that the hydrological catchment of Leverett Glacier extends to at least $40 \mathrm{~km}$ from the margin and likely beyond as many mid summer samples were heavier than supraglacial ice at $40 \mathrm{~km}$ (Figure 7). This is consistent with the hydrological catchment inferred from ice surface topography used in this study, and the results of the PDD meltwater runoff model that predicted that the majority of meltwater runoff occurred between 40-50 km from the ice margin (Figure 6).

On average, samples collected during the 2012 field season were isotopically heavier than samples collected in 2011 (Figure 7). As snow was predicted to be absent following day 181 in 2012, these heavier values must be the result of a greater proportion of ice melt from higher in the catchment relative to 2011. This interpretation is supported by the warmer temperatures observed at Sites 3 and 4 in 2012 (Table 1). Based on the isotopic composition of the proglacial river, mid-season bulk meltwater (after day 161 in 2011 and 155 in 2012) was likely derived predominately from meltwater from $>40 \mathrm{~km}$ from the ice sheet margin.

Diurnal variations in $\delta^{2} \mathrm{H}$ and $\delta^{18} \mathrm{O}$ were observed following days 162 in 2011 and 152 in 2012. Hindshaw et al. (2014) observed similar diurnal variations in the Leverett Glacier proglacial river; enriched $\delta^{2} \mathrm{H}$ and $\delta^{18} \mathrm{O}$ values occurred during high afternoon discharge while depleted $\delta^{2} \mathrm{H}$ and $\delta^{18} \mathrm{O}$ values were observed at low discharge during the night. Hindshaw et al. (2014) interpreted this result as increased snowmelt during the day. However, based on my work, snow is absent from the catchment by mid-summer and therefore diurnal variations in $\delta^{2} \mathrm{H}$ and $\delta^{18} \mathrm{O}$ isotopes are likely the result of the transit time of isotopically enriched meltwater from high in the catchment. Based on tracer experiments, a 12-hour transit time of meltwater originating 40 $\mathrm{km}$ from the margin is reasonable (Chandler et al., 2013). Consequently, isotopically enriched 
meltwater likely arrives at the margin at night during low discharge. $\delta^{18} \mathrm{O}$ values observed during peak afternoon discharge are the result of increased melt of depleted $\delta^{2} \mathrm{H}$ up-sheared basal ice at the margin and the rapid transit time of this meltwater (Cowton et al., 2013; Chandler et al., 2013).

\subsection{Relationships between distributed system drainage, glacial velocity, and meltwater runoff}

We used $J_{d i s}$ as a tracer for the timing and magnitude of distributed system drainage.

Radon-222 activities in snow and ice are negligible and hence, glacial meltwater only acquires

significant quantities of ${ }^{222} \mathrm{Rn}$ during sediment-water interactions beneath the ice sheet. Previous studies have utilized ${ }^{222} \mathrm{Rn}$ activities in proglacial rivers to infer the timing of delayed flow waters of land-terminating glaciers (Kies et al., 2011; Bhatia et al., 2011). In Chapter I, I showed that distributed system drainage is the main source of ${ }^{222} \mathrm{Rn}$ in glacial meltwater, and that $J_{d i s}$ can be used as a passive flow tracer of distributed system drainage.

In 2011, the large $J_{d i s}$ spike that occurred between days 190-200 indicated a major drainage event of distributed system waters. The event was preceded on days 187-190 by increased glacier velocity at GPS Stations 2-6 (Figure 12). RACMO2.3 results also suggest an increase in meltwater runoff between days 186-189 (Figure 11). Directly before and after this large spike in $J_{d i s}$ (on days 185 and 213), Chandler et al. (2013) completed two $\mathrm{SF}_{6}$ tracer experiments $41 \mathrm{~km}$ from the Leverett Glacier terminus, which showed a dramatic transition from inefficient to efficient drainage that was interpreted as the formation of channelized drainage extending to at least $41 \mathrm{~km}$. Therefore, the large pulse of $J_{d i s} I$ observed between days 190-200 was likely caused by the extension of the channelized system to higher elevations in the catchment. This channel expansion, which I hypothesize was initiated by increased meltwater 
runoff between days 186-189, appears to have caused a major flushing of distributed system meltwater. While there was not a corresponding increase in river discharge, channel expansion does not result in increased river discharge and the distributed system flux only comprises 1-5\% of river discharge (Chapter 2). Following this pulse in $J_{d i s}$, meltwater runoff increased markedly on days 200-202 (Figure 11) and corresponded to ice acceleration at Stations 4-6 (Figure 12) and uplift at sites 4 and 5 (Figure 10). During this period, $J_{\text {dis }}$ decreased to near zero. This can be interpreted as the result of pressurized channels blocking the flow of distributed system drainage. Following day $202, J_{d i s}$ returns to values similar to those observed earlier in the melt season. The major meltwater runoff event that occurred in 2012 between days 190-195 caused the proglacial river discharge to double in size and glacial velocity to increase (Tedstone et al., 2013). Because of the extreme volume of meltwater runoff, the channelized system must have been significantly expanded while water was pushed into the distributed system forming new connections with non-channelized regions of the ice bed. Consequently, following this event as surface meltwater runoff and river discharge ebbed from days 195-198, the largest spike of $J_{d i s}$ of the 2012 field season was observed. This was followed on days 198-205 by diurnal peaks in $J_{\text {dis }}$ activities that were anticorrelated with river discharge. Diurnal variations in $J_{d i s}$ are likely the result of daily changes in channel pressure. Absent major meltwater runoff events, afternoon highs in meltwater runoff pressurize channels and drive water laterally into the distributed system. In the evening during lower meltwater inputs, distributed system water is drawn into channels as channel pressure decreases (Gulley et al., 2012; Werder et al., 2013). Hence, diurnal changes in $J_{d i s}$ activity can be interpreted as the subglacial pressure regime attaining a balance between meltwater runoff and the capacity of channels to transmit water, as the time scale for significant channel evolution is longer than $24 \mathrm{~h}$ (Schoof, 2010). The observation that these 
diurnal changes in $J_{d i s}$ were observed following the massive meltwater runoff event implies that newly opened channels must have rapidly narrowed or closed until ice overburden pressure equaled hydraulic pressure in the channels.

The association between supraglacial lake drainage events and spikes in SSC/EC implies sudden access to stored sediments and a dramatic increase in the ability of subglacial waters to mobilize and evacuate them. The simultaneous increase in EC suggests either the displacement of solute-rich stored water or rapid mineral weathering reactions during mixing of distributed and channelized meltwater (Raiswell, 1984; Tranter et al., 1993). My finding that spikes in $J_{d i s}$ do not covary with SSC/EC spikes (Figure 13) suggests that lake drainages mobilize relatively small quantities of distributed system meltwater. Alternatively, supraglacial lake drainage events could mobilize solute rich distributed system meltwater with low ${ }^{222} \mathrm{Rn}$ activities though this seems unlikely. If lake drainages do not mobilize distributed system meltwater, then the small increase in EC may be the result of gouging sediments from channel floors with relatively solute-rich pore waters or rapid mineral weathering reactions. To test these hypotheses, further chemical analysis of bulk meltwater during SSC/EC spikes would be needed. For example, elemental ratios of $\mathrm{Ca} / \mathrm{Na}$ and $\mathrm{Mg} / \mathrm{Na}$ could be used to infer rapid carbonate weathering.

In 2012, there was a clear connection between the major spikes in $J_{d i s}$, decreasing meltwater runoff, and decreasing river discharge (Figure 11). These spikes in $J_{d i s}$ also occurred in between acceleration events at Station 3 (Figure 12) and spikes in SSC/EC (Figure 13). Absent from the 2012 record was a major outburst of $J_{d i s}$ similar to what was observed in 2011. Instead, there were multiple spikes in $J_{\text {dis }}$ that appeared to be turned on and off by either decreasing meltwater runoff or decreasing discharge. I interpret these results as follows. During rapid meltwater runoff inputs, water pressure increases in subglacial channels and new flow paths are 
created into the distributed system as water is forced laterally out of channels. During this time, distributed system drainage to the margin decreases while the connectivity to the nonchannelized distributed system increases as new flow paths are created. As the effective pressure (ice overburden pressure - water pressure) decreases, resistance to sliding decreases and the glacier accelerates. After rapid inputs of meltwater runoff and subsequent evacuation to the ice margin, water pressure in channels decreases, effective pressure increases, the glacier slows, and the previously isolated sections of the distributed system drain into channels and to the margin resulting in the spikes in $J_{d i s}$. This provides a mechanism for regulating glacial velocity within the ablation zone of the GrIS. While rapid increases in meltwater runoff causes basal sliding, the subsequent drainage of distributed regions of the ice bed lowers basal water pressure and may result in less sliding through the rest of the year. In a warmer climate, this mechanism may regulate the flow of the GrIS such that annual glacial velocity varies little between cold and warm summers (Andrews et al., 2014).

My observation that the distributed system drains into the channelized system on variable time scales is consistent with the model developed by Werder et al. (2013), theoretical predictions of Gulley et al. (2012), and observations at alpine glaciers (Bartholomaus et al., 2008; Hubbard et al., 1995). Andrews et al. (2014) and Sole et al. (2013) speculated that distributed system connectivity may help regulate interannual ice sheet motion. For example, despite much larger supraglacial meltwater runoff in 2012 than 2011, annual glacial velocity between these years at Leverett Glacier was minimal (Tedstone et al., 2013). My research provides observation-based evidence that the motion of the GrIS may be self-regulated by rapid increases in meltwater runoff that subsequently allow for drainage of meltwater in the nonchannelized distributed regions of the ice sheet bed. 


\section{Summary and Conclusions}

Over the course of two melt seasons, I observed the relationships between meltwater runoff, glacial velocity and distributed system drainage. To measure the timing and magnitude of distributed system drainage, I used continuous ${ }^{222} \mathrm{Rn}$ measurements in the proglacial river of a large outlet glacier of the GrIS. The ${ }^{222} \mathrm{Rn}$ attributed to non-distributed system sources was quantified and subtracted from the total ${ }^{222} \mathrm{Rn}$ flux to derive $J_{d i s}$, the ${ }^{222} \mathrm{Rn}$ flux I attribute to distributed system drainage. $J_{d i s}$ was compared with ice velocity, surface meltwater runoff, supraglacial lake drainage events, and $\delta^{2} \mathrm{H}$ and $\delta^{18} \mathrm{O}$ isotope measurements in the proglacial river. These observations are important as the behavior of the subglacial hydrological system affects ice dynamics in the ablation zone (Sole et al., 2013; Tedstone et al., 2013), and potentially farther inland during the winter (Doyle et al., 2014).

RACMO2.3 and a PDD meltwater runoff model were used to predict meltwater runoff. While it is difficult to constrain catchment area in an outlet glacier of the GrIS (van As et al., 2012; Clason et al., 2012) and water piracy of an adjacent glacier is possible (Fitzpatrick et al., 2014), I showed that meltwater runoff models can be used to infer the timing of meltwater runoff to the subglacial environment.

Time series $\delta^{2} \mathrm{H}$ and $\delta^{18} \mathrm{O}$ measurements in the proglacial river traced the changing source of meltwater from up-sheared basal ice and snowmelt in the early summer to surface ice melt from high within the glacier's catchment. Many late summer $\delta^{2} \mathrm{H}$ and $\delta^{18} \mathrm{O}$ values observed in the proglacial river were more enriched than supraglacial ice collected $40 \mathrm{~km}$ from the ice sheet margin. This implies that the catchment extended beyond $40 \mathrm{~km}$ from the margin, consistent with the hydrological catchment, inferred from surface ice topography (Bartholomew 
et al., 2011a), that I used to calculate meltwater runoff. The average $\delta^{2} \mathrm{H}$ and $\delta^{18} \mathrm{O}$ values in the proglacial river were heavier in 2012 than in 2011 (Table 2) suggesting more intense melting from higher in the catchment in 2012. Higher temperatures at Sites 3 and 4 in 2012 support this result (Table 1). I attribute diurnal variations observed in $\delta^{2} \mathrm{H}$ and $\delta^{18} \mathrm{O}$ values to increased melting of up-sheared basal ice during peak discharge and the transit time of isotopically heavier meltwater further from the margin, which arrives at the margin during low discharge at night.

Simultaneous spikes in SSC and EC measured in bulk meltwater occur during supraglacial lake drainage events (Bartholomew et al., 2011a). These spikes in SSC and EC, which were observed in 2012, were not correlated to spikes in $J_{\text {dis }}$ suggesting that supraglacial lake drainage events do not mobilize large volumes of distributed system meltwater. Instead, they may mobilize sediments with solute-rich pore waters or the mobilized sediments may undergo rapid weathering reactions (Raiswell, 1984; Tranter et al., 1993).

Results of continuous ${ }^{222} \mathrm{Rn}$ measurements in the proglacial river show that the ${ }^{222} \mathrm{Rn}$ flux in glacial meltwater varies on diurnal and seasonal timescales. In 2011, a major spike in $J_{d i s}$ was observed that followed melting and glacial acceleration at high elevations within the catchment. Tracer experiments conducted during the same time period demonstrated a dramatic transition from inefficient to efficient drainage from a site $41 \mathrm{~km}$ from the ice margin (Chandler et al., 2013). This supports the hypothesis that channel expansion allowed for significant drainage of distributed system meltwater from the ice sheet bed.

In 2012 there were four large spikes in $J_{d i s}$ following periods of rapid increases in supraglacial meltwater runoff (Figure ). This finding suggested that during rapid surface meltwater inputs to the subglacial system, channels are pressurized and meltwater is forced out of channels and into the adjacent the distributed system. The larger and more rapid the meltwater 
runoff event is, the higher the volume of meltwater pushed into the distributed system will be. This provides a clear mechanism for creating new pathways into previously isolated regions of the ice sheet bed. The large spikes in $J_{d i s}$ following rapid meltwater runoff inputs implies that previously isolated regions of the ice sheet bed were drained. Less meltwater in the nonchannelized regions of the ice sheet bed will lead to less basal sliding late in the melt season and into the winter (Andrews et al., 2014). This may explain why interannual glacial velocity did not significantly vary between 2011 and 2012 at Leverett Glacier (Tedstone et al., 2013) and why, despite the influence of supraglacial meltwater runoff on short term glacial velocity, interannual variation in glacial velocity within the ablation zone of the GrIS is minimal (Sole et al., 2013; Chu, 2014). 
Table 1: Mean temperature observed at GPS Sites 1-6 in 2011 and 2012 between days 161-220. While mean temperatures at Sites 1 and 6 are fairly similar between both years, mean temperatures in 2012 were significantly warmer at Sites 2-5 than in 2011. This suggests that additional runoff in 2012 was the result of more intense melting within the catchment rather than an expanded catchment.

\begin{tabular}{ccc} 
& \multicolumn{2}{c}{ Mean temperature ${ }^{\circ} \mathrm{C}$} \\
& 2011 & 2012 \\
\hline Site 1 & 5.8 & 5.9 \\
Site 2 & 2.7 & 4.4 \\
Site 3 & 2.4 & 2.9 \\
Site 4 & 1.9 & 2.8 \\
Site 5 & 0.1 & 0.7 \\
Site 6 & 0.6 & 0.3
\end{tabular}


Table 2: Results from $\delta^{18} \mathrm{O}$ and $\delta^{2} \mathrm{H}$ analyses of basal ice and ice collected on the ice sheet surface at $2 \mathrm{~km}, 8 \mathrm{~km}$, and $40 \mathrm{~km}$ from the margin in 2012. Also shown are mid-summer $\delta^{18} \mathrm{O}$ and $\delta^{2} \mathrm{H}$ values from the proglacial river. Results are reported in standard delta notation relative to VSMOW.

\begin{tabular}{|c|c|c|c|c|c|c|c|}
\hline & & & & & & & \\
\hline & & & & & & river 2011 & river 2012 \\
\hline & basal ice & $2 \mathrm{~km}$ & $8 \mathrm{~km}$ & $40 \mathrm{~km}$ & snow/rain & days $161-230$ & days $155-210$ \\
\hline & $\delta^{18} \mathrm{O}$ & $\delta^{18} \mathrm{O}$ & $\delta^{18} \mathrm{O}$ & $\delta^{18} \mathrm{O}$ & $\delta^{18} \mathrm{O}$ & $\delta^{18} \mathrm{O}$ & $\delta^{18} \mathrm{O}$ \\
\hline $\mathrm{n}$ & 9 & 3 & 3 & 45 & 13 & 283 & 177 \\
\hline mean & -31.6 & -30.9 & -27.0 & -24.2 & -17.0 & -24.3 & -23.5 \\
\hline median & -31.6 & -31.5 & -26.3 & -24.3 & -16.2 & -24.2 & -23.5 \\
\hline \multirow[t]{2}{*}{ stdev } & 2.3 & 1.0 & 1.3 & 0.3 & 2.9 & 0.3 & 0.3 \\
\hline & $\delta^{2} \mathrm{H}$ & $\delta^{2} \mathrm{H}$ & $\delta^{2} \mathrm{H}$ & $\delta^{2} \mathrm{H}$ & $\delta^{2} \mathrm{H}$ & $\delta^{2} \mathrm{H}$ & $\delta^{2} \mathrm{H}$ \\
\hline mean & -249 & -242 & -207 & -185 & -131 & -185 & -177 \\
\hline median & -253 & -246 & -202 & -185 & -124 & -185 & -177 \\
\hline stdev & 15.2 & 7.7 & 9.8 & 1.8 & 23.5 & 2.4 & 2.2 \\
\hline
\end{tabular}




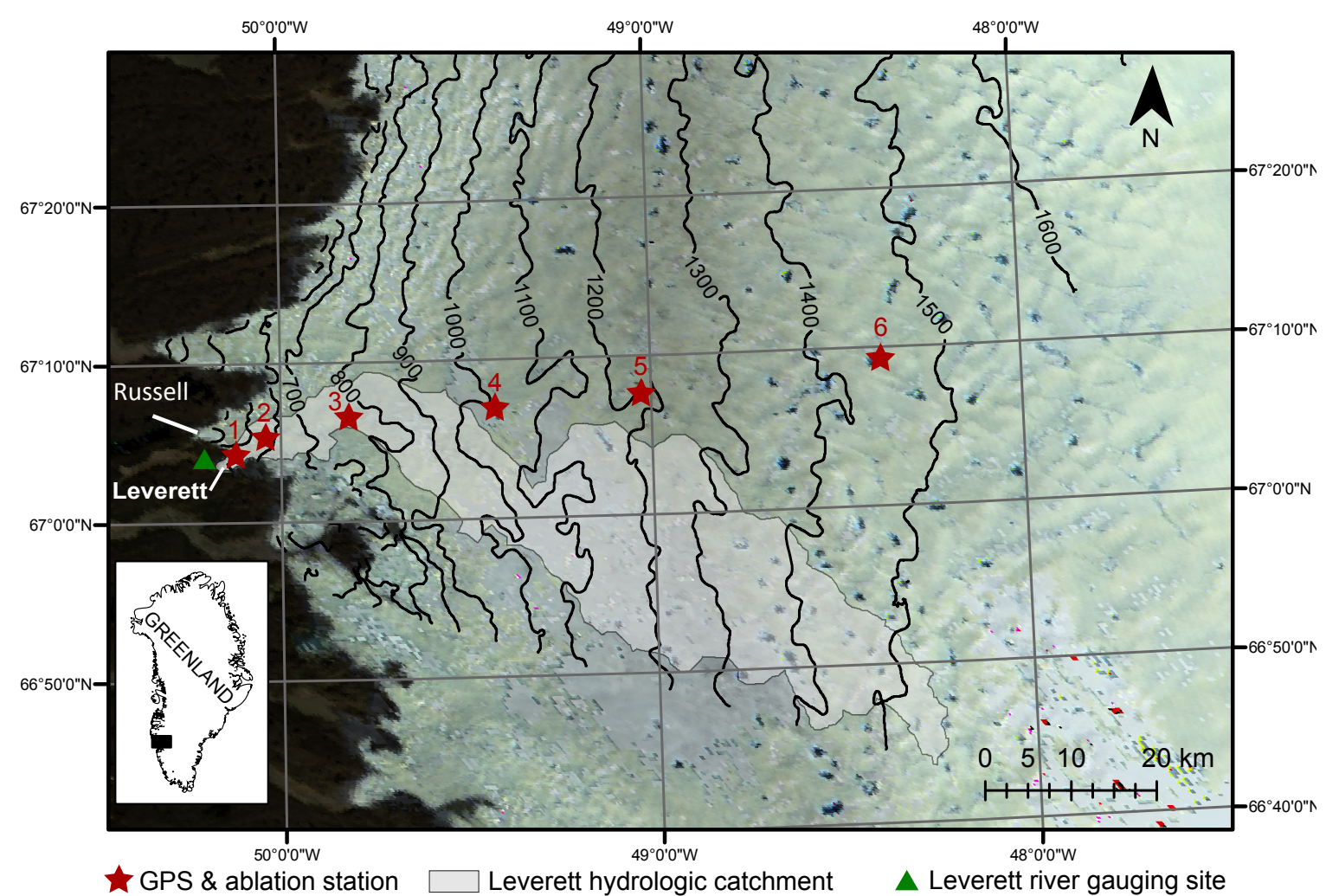

Figure 1: $\quad$ Leverett Glacier is a $600 \mathrm{~km}^{2}$ land-terminating glacier in southwest Greenland (map inset). The hydrologic catchment (Bartholomew et al., 2011) was inferred from surface topography (Palmer et al., 2011) and is shown in light grey. GPS, ablation, and temperature sites are shown as red stars, and the proglacial river gauging and sampling site is shown by the green triangle. This figure was altered with permission from the original in Tedstone et al. (2013). 


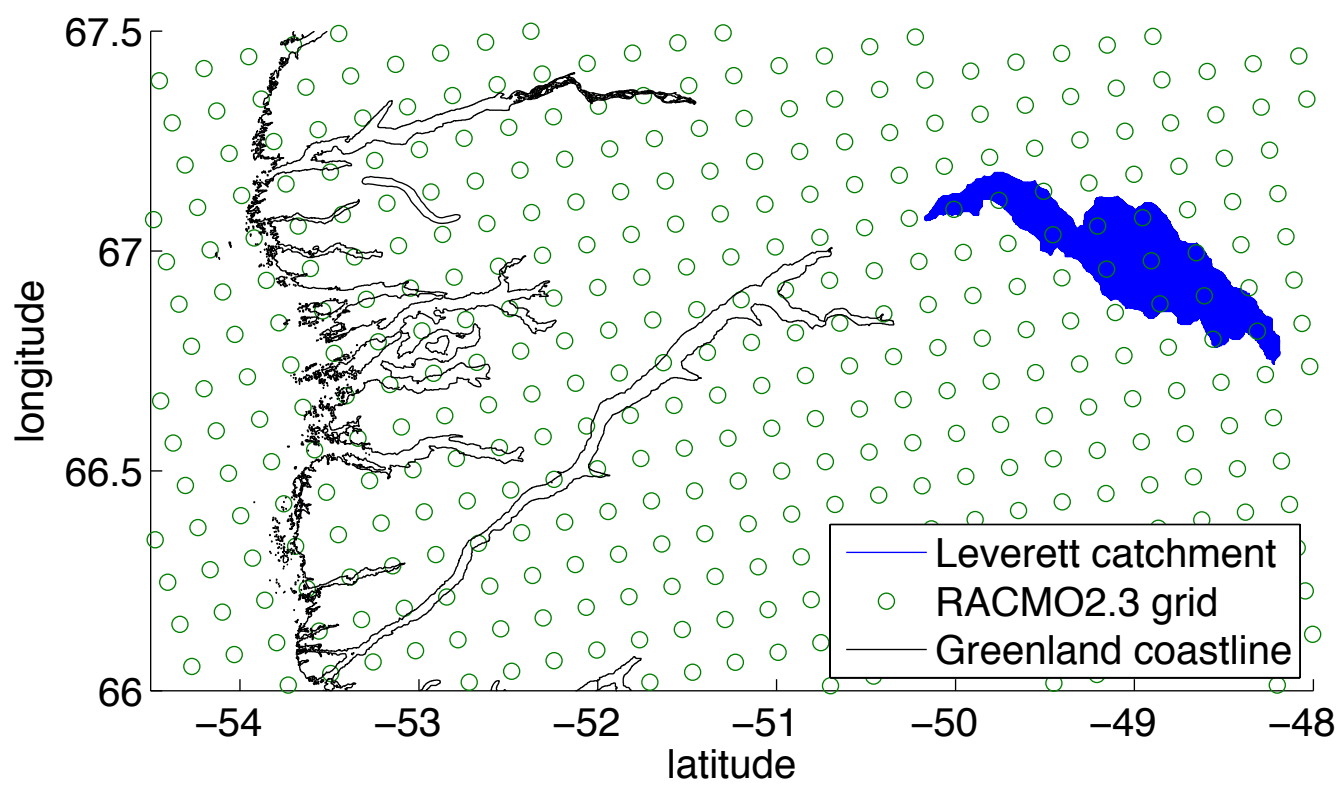

Figure 2: The location of Leverett Glacier's catchment relative to the RACMO2.3 grid and Greenland's coastline. Green circles represent points where ice and snowmelt were calculated. RACMO2.3 infers meltwater runoff between these points. 

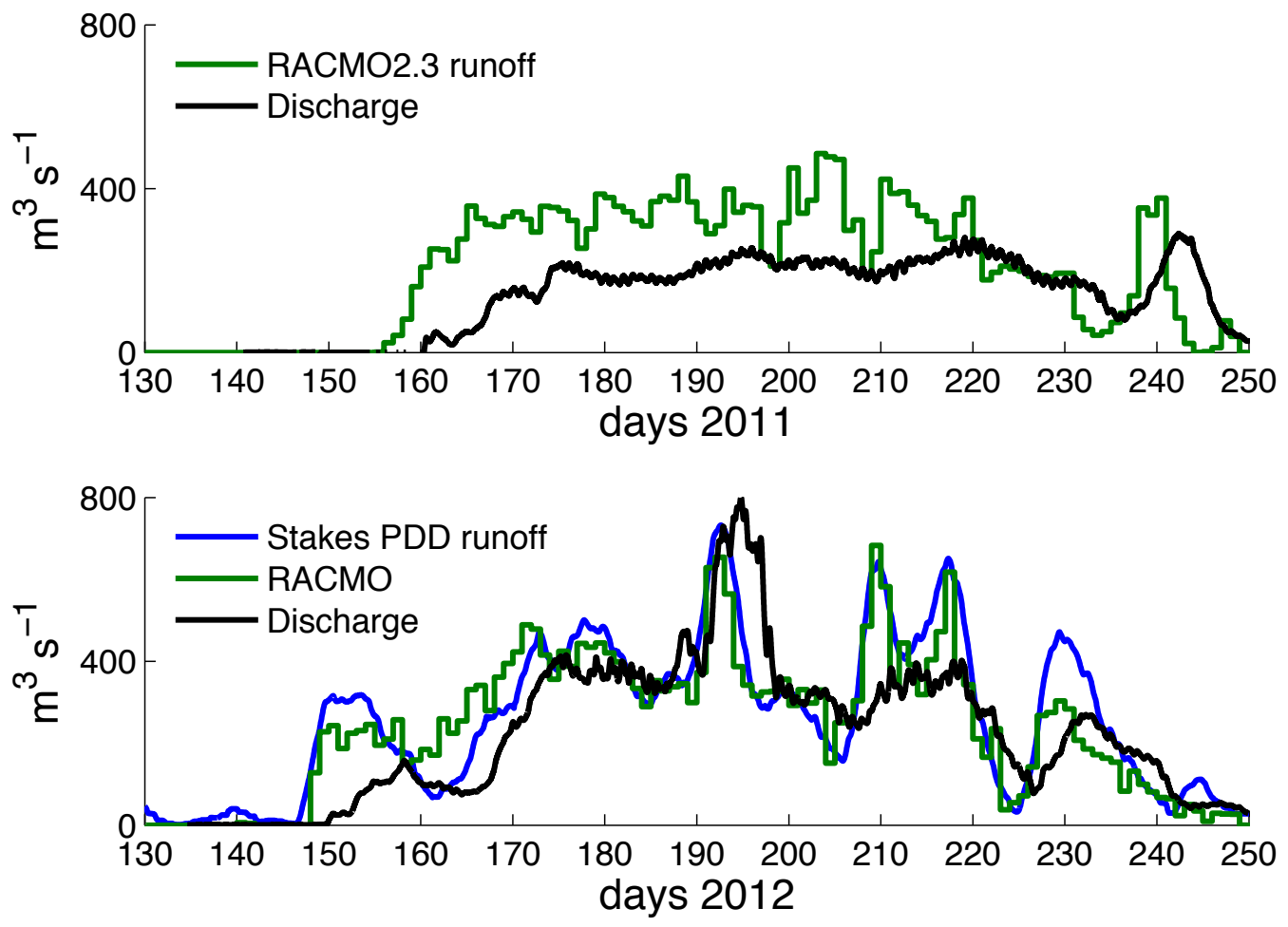

Figure 3: Results from discharge measurements of the Leverett Glacier proglacial river, and the predicted meltwater runoff of the inferred Leverett Glacier catchment from RACMO2.3 and the PDD meltwater runoff models from 2011 (top plot) and 2012 (bottom plot). 

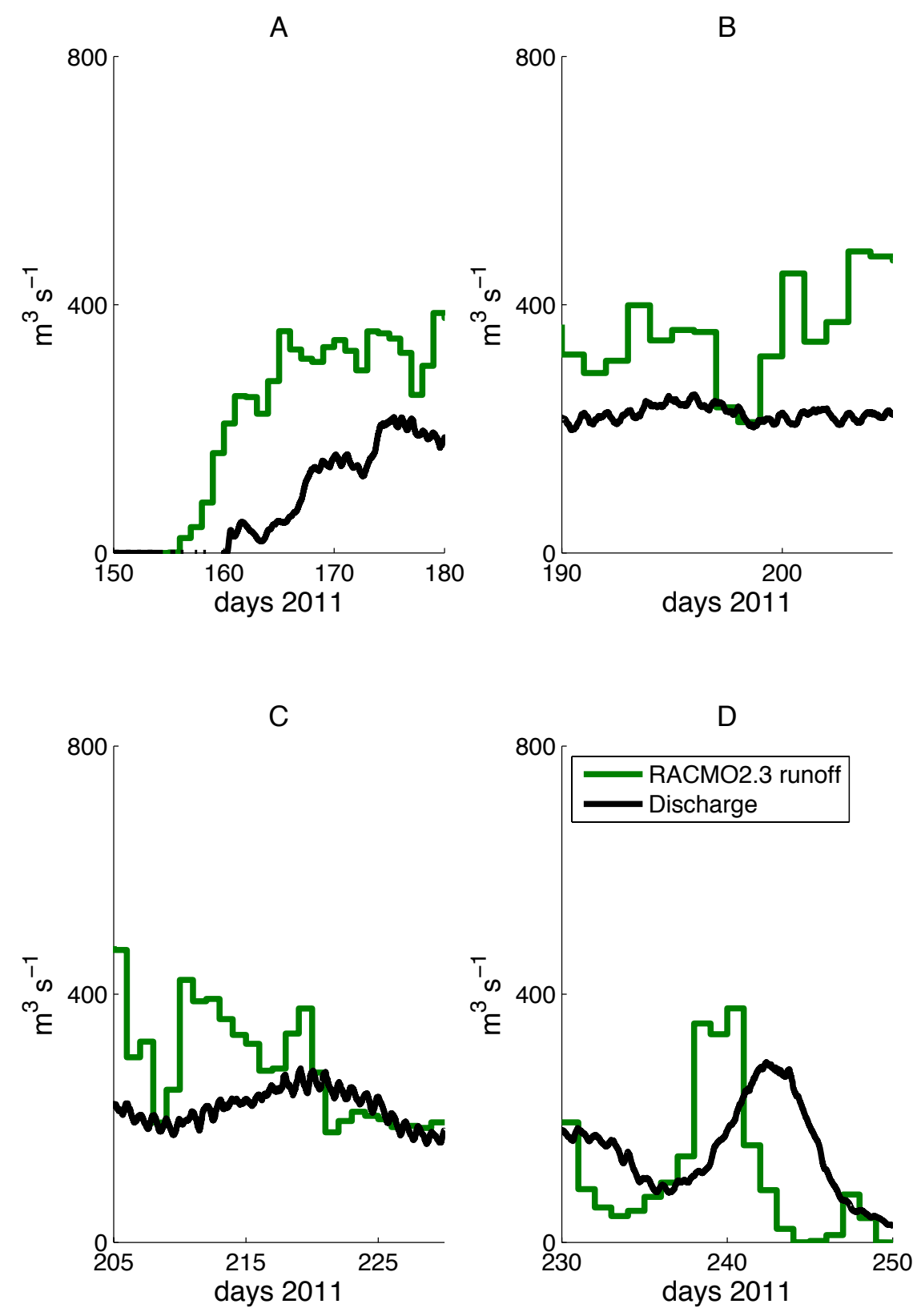

Figure 4: Detail of meltwater runoff predicted by RAMOC2.3 of the Leverett Glacier inferred hydrological catchment and the discharge measured in the Leverett Glacier proglacial river in 2011. Plots A, B, and C show little relationship between the magnitude of runoff and the observed discharge while plot $\mathrm{D}$ shows a notable delay between a late season peak in runoff and discharge. 

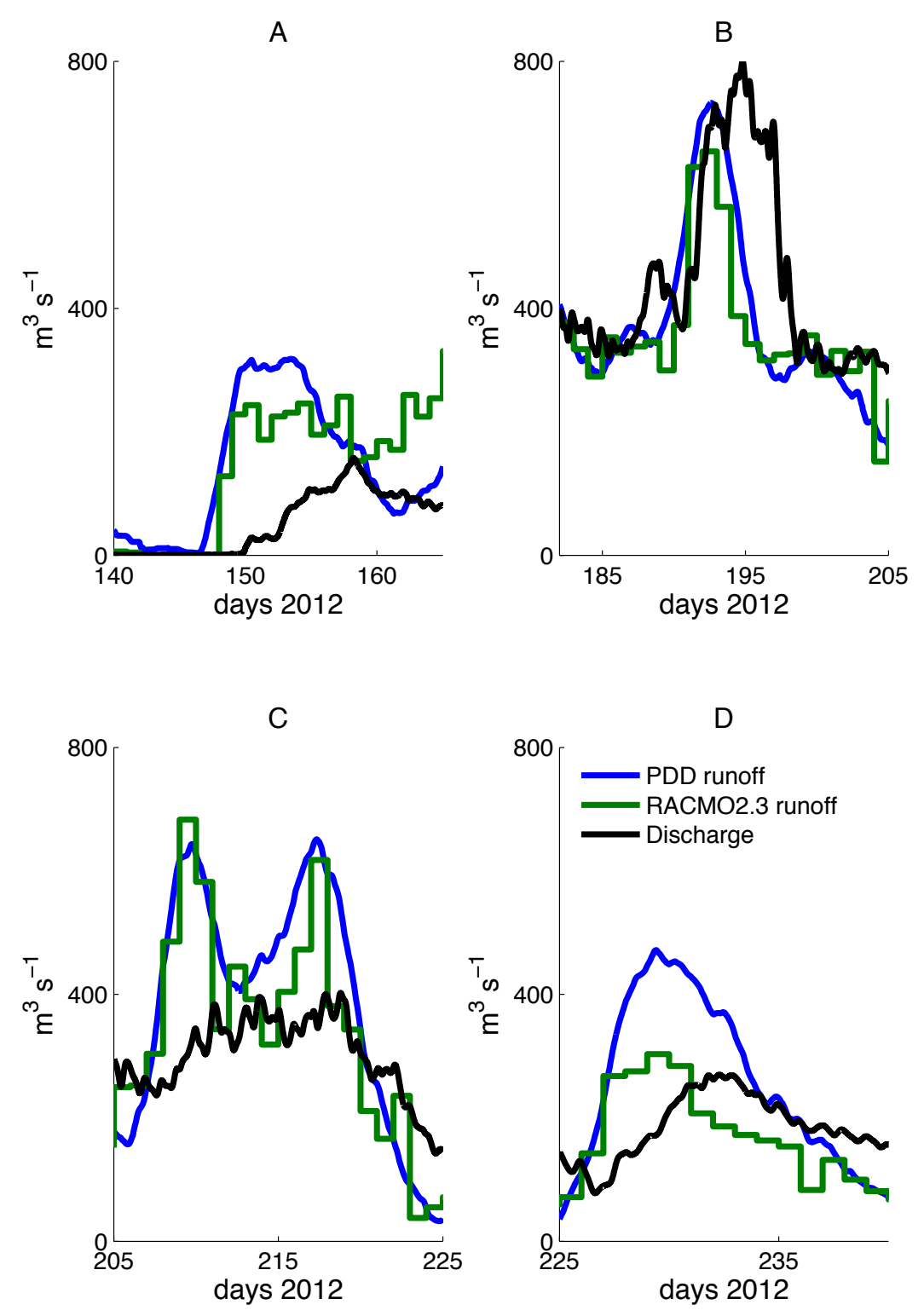

Figure 5: Detail of meltwater runoff predicted for the inferred Leverett Glacier catchment by the PDD and RACMO2.3 meltwater runoff models, and the observed discharge of the Leverett Glacier proglacial river in 2012. Peaks in predicted runoff were notably higher than observed discharge in plots $\mathrm{A}, \mathrm{C}$, and $\mathrm{D}$, while the large meltwater runoff event in plot B shows that discharge was greater than the predicted runoff. 

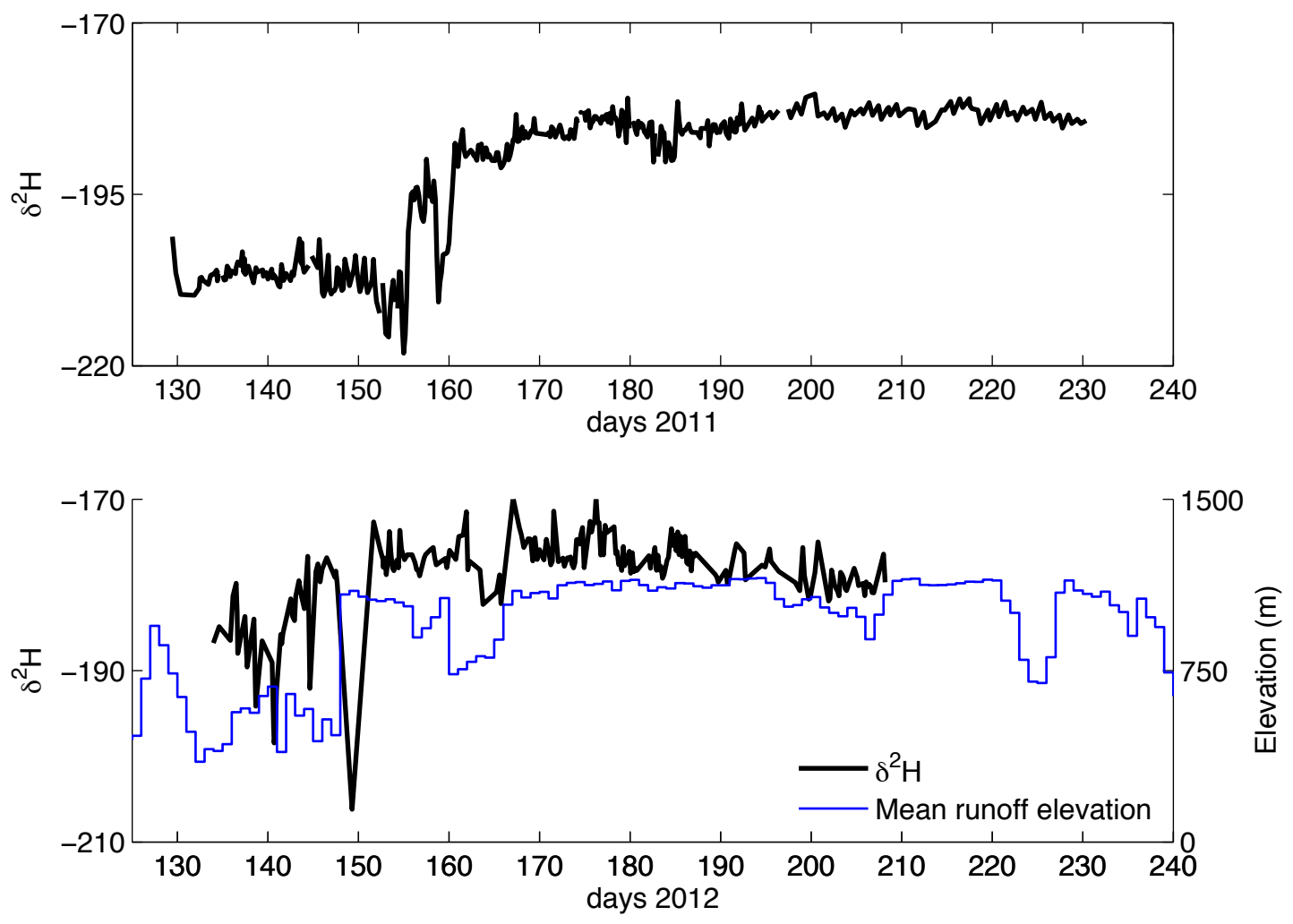

Figure

6: Results from $\delta^{2} \mathrm{H}$ analysis in 2011 and 2012. Also shown is the weighted mean elevation of meltwater runoff, predicted by the PDD meltwater runoff model, in 2012. 

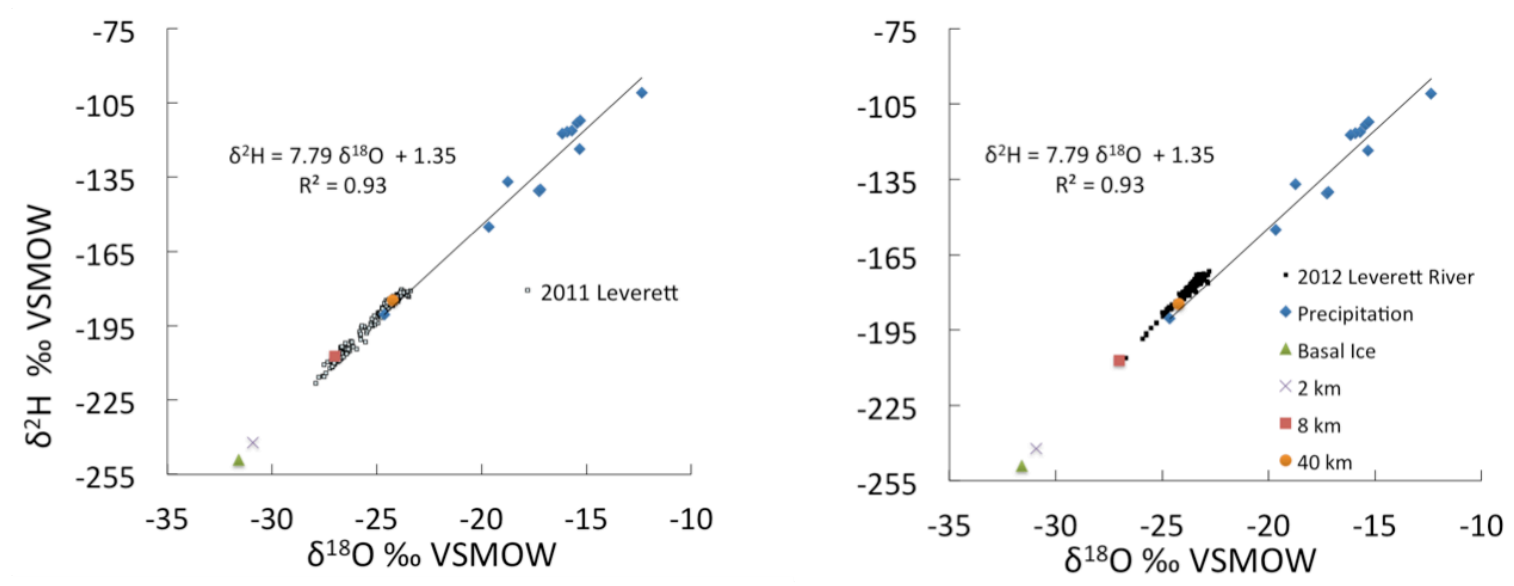

Figure 7: The local meteoric water line, calculated using rain and snow samples collected at Leverett Base Camp in 2011 and 2012, is $\delta^{2} \mathrm{H}=7.79 \delta^{18} \mathrm{O}+1.35$. Also shown are mean values of surface ice samples from $2 \mathrm{~km}, 8 \mathrm{~km}$, and $40 \mathrm{~km}$ from the ice sheet margin as well as river Leverett Glacier proglacial river samples collected in 2011 (left plot) and 2012 (right plot). 

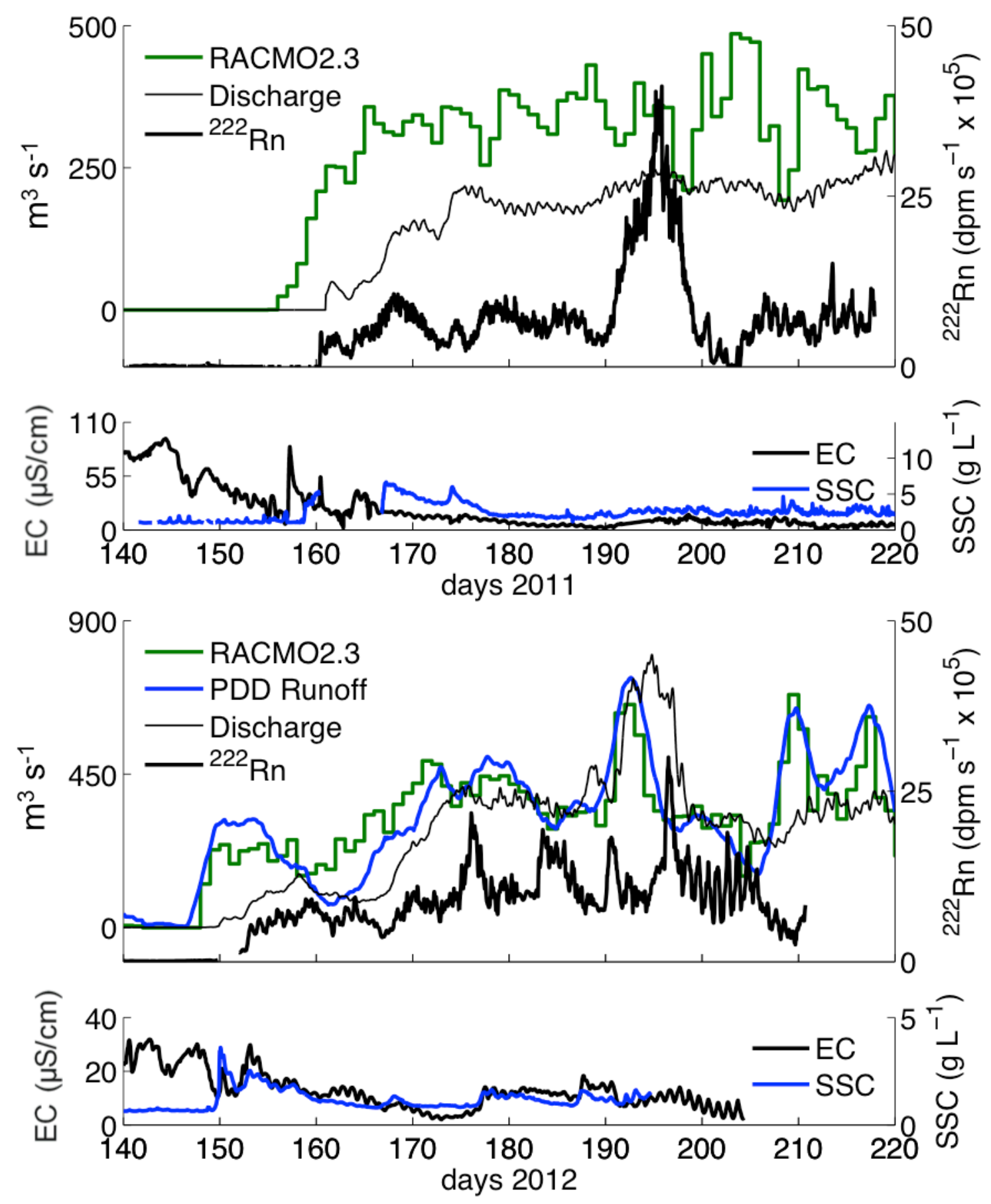

Figure 8: Whole season comparison between the ${ }^{222} \mathrm{Rn}$ flux and meltwater runoff, river discharge, SSC, and EC in both 2011 and 2012. 

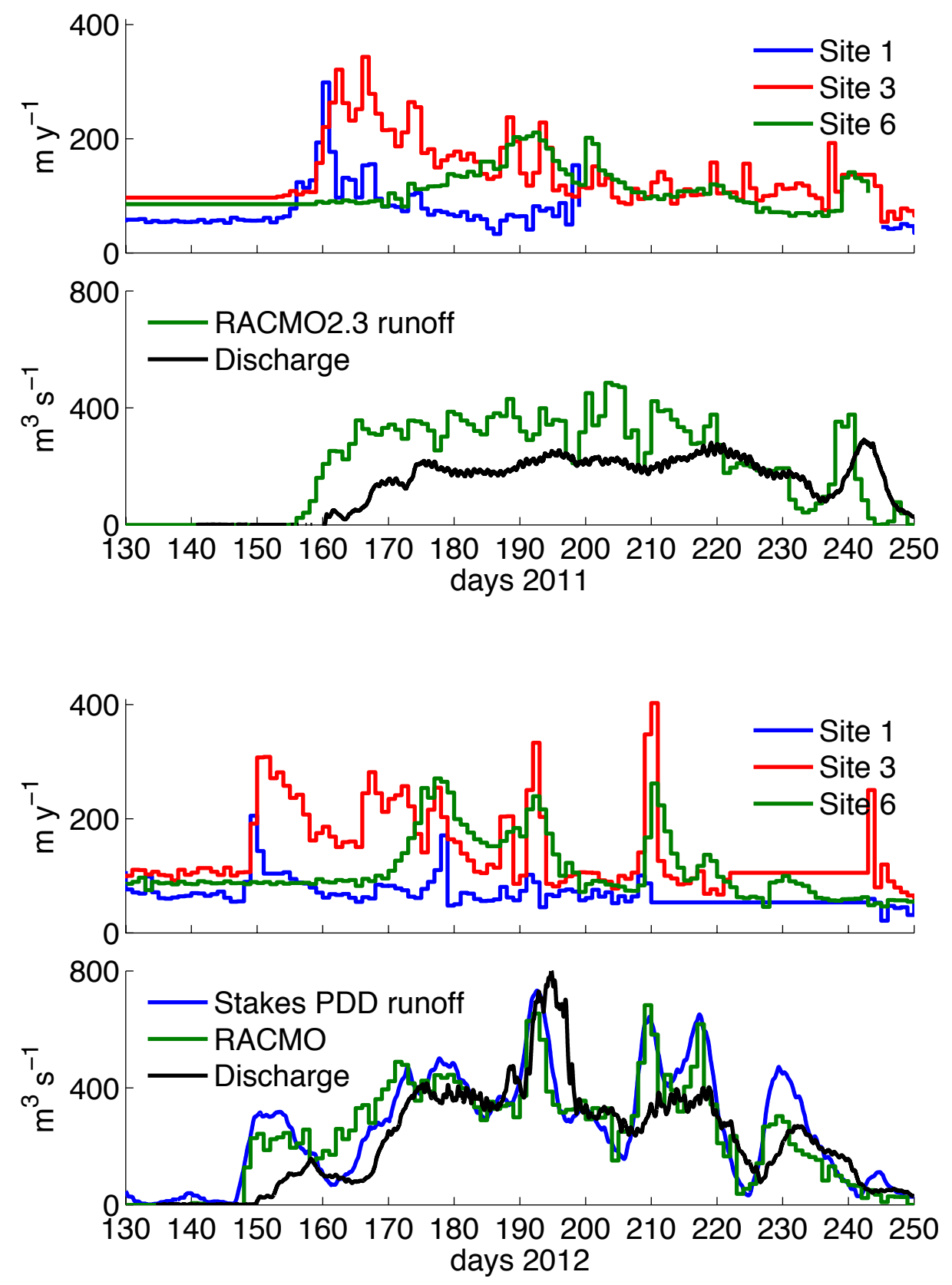

Figure 9: Glacial velocities at Sites 1,3, and 6 compared to the predicted meltwater runoff and the observed meltwater discharge of the proglacial river. In general, periods of increasing meltwater runoff correspond to increased glacial velocity in both 2011 and 2012. 

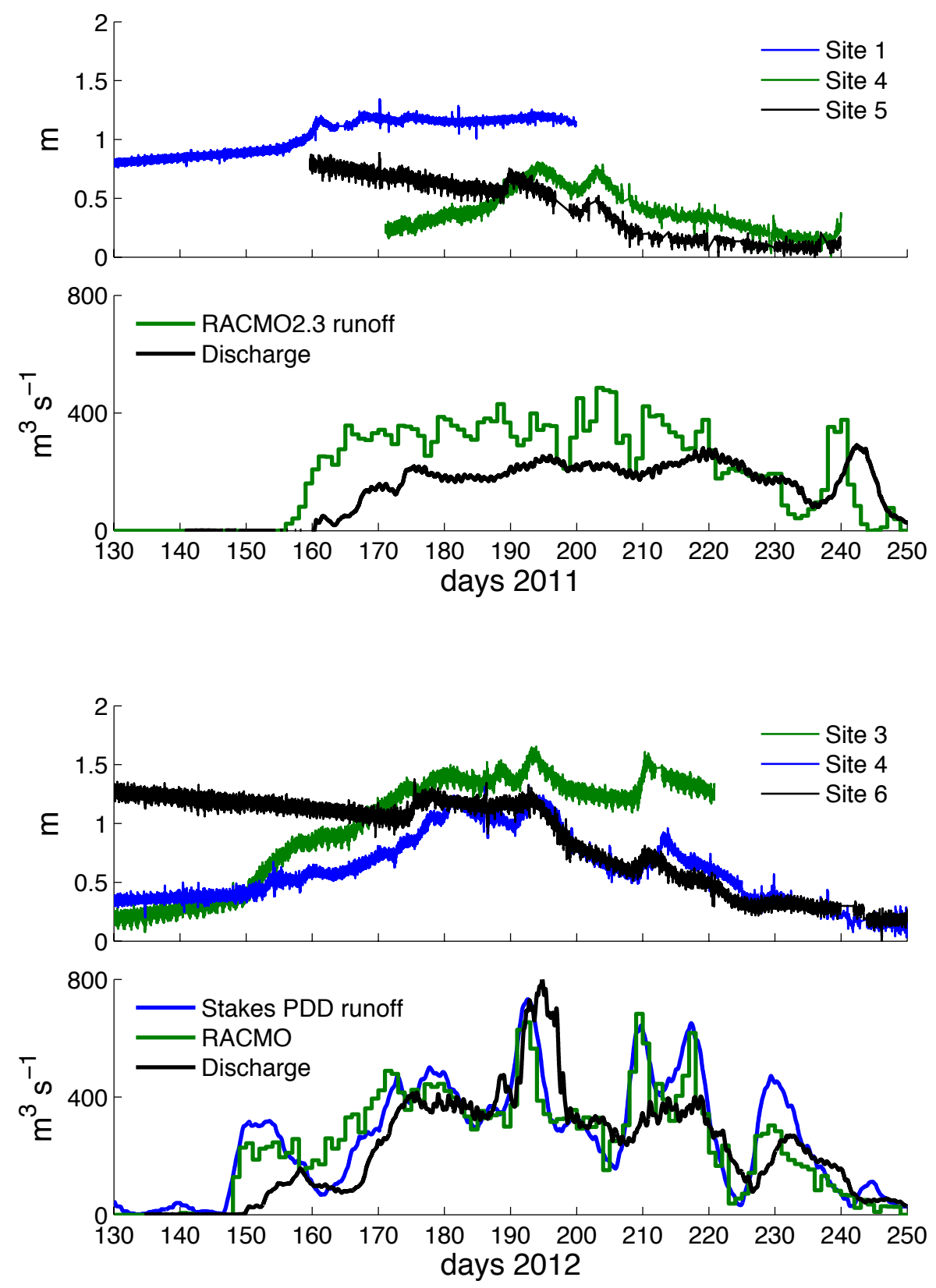

Figure 10: Vertical displacements at Sites 1, 4, and 5 in 2011 and Sites 3, 4, and 6 in 2012 compared to the observed proglacial river discharge and the predicted meltwater runoff. At Sites 3 and 4, uplift is observed in the early season and lowering in the late season while short-term peaks correspond to periods of significant meltwater runoff. Note the same GSP stations were not used between 2011 and 2012 because overlapping data from all stations was not available. 


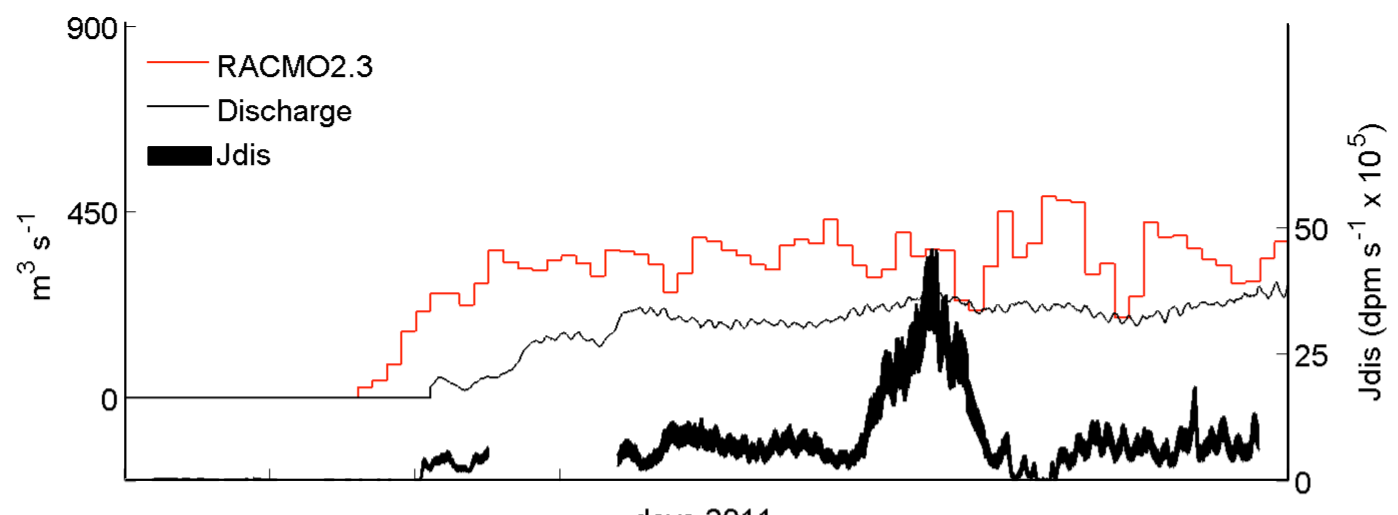

days 2011

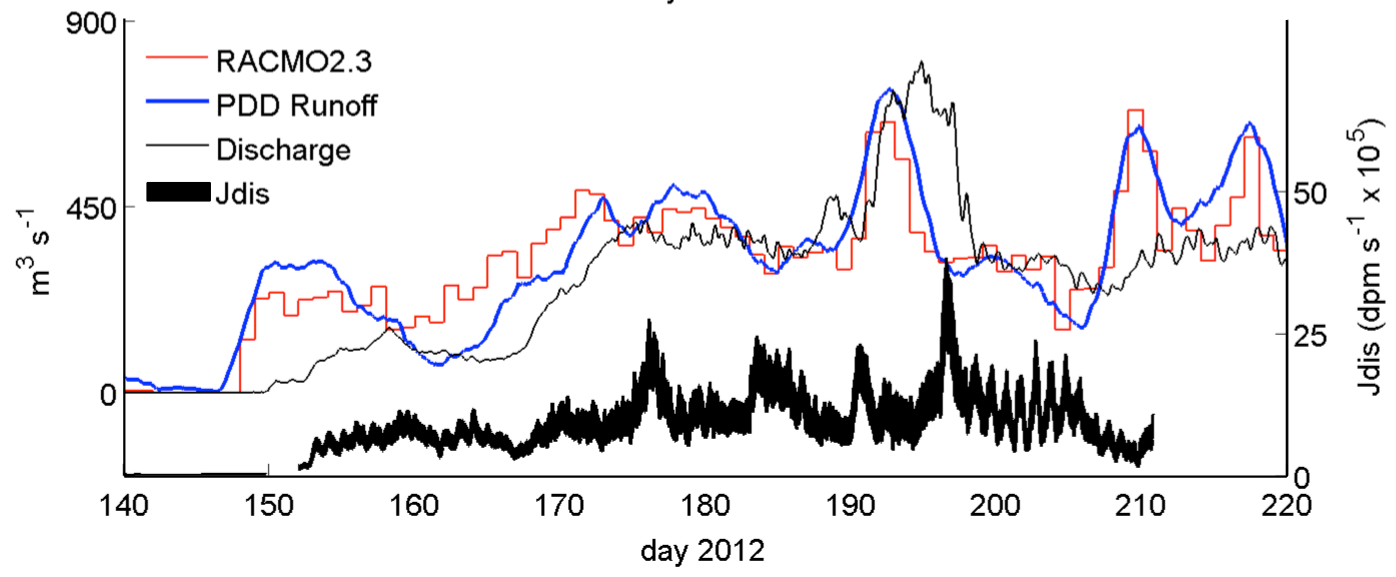

Figure 11: A comparison between $J_{d i s}$, predicted meltwater runoff and observed discharge in the proglacial river. The width of $J_{d i s}$ indicates the uncertainty of the flux. In $2011, J_{d i s}$ has one major peak which corresponded to an inferred period of channel expansion to higher elevations (see text) while in 2012, multiple peaks in $J_{d i s}$ are attributed to decreasing meltwater runoff and/or proglacial river discharge. 


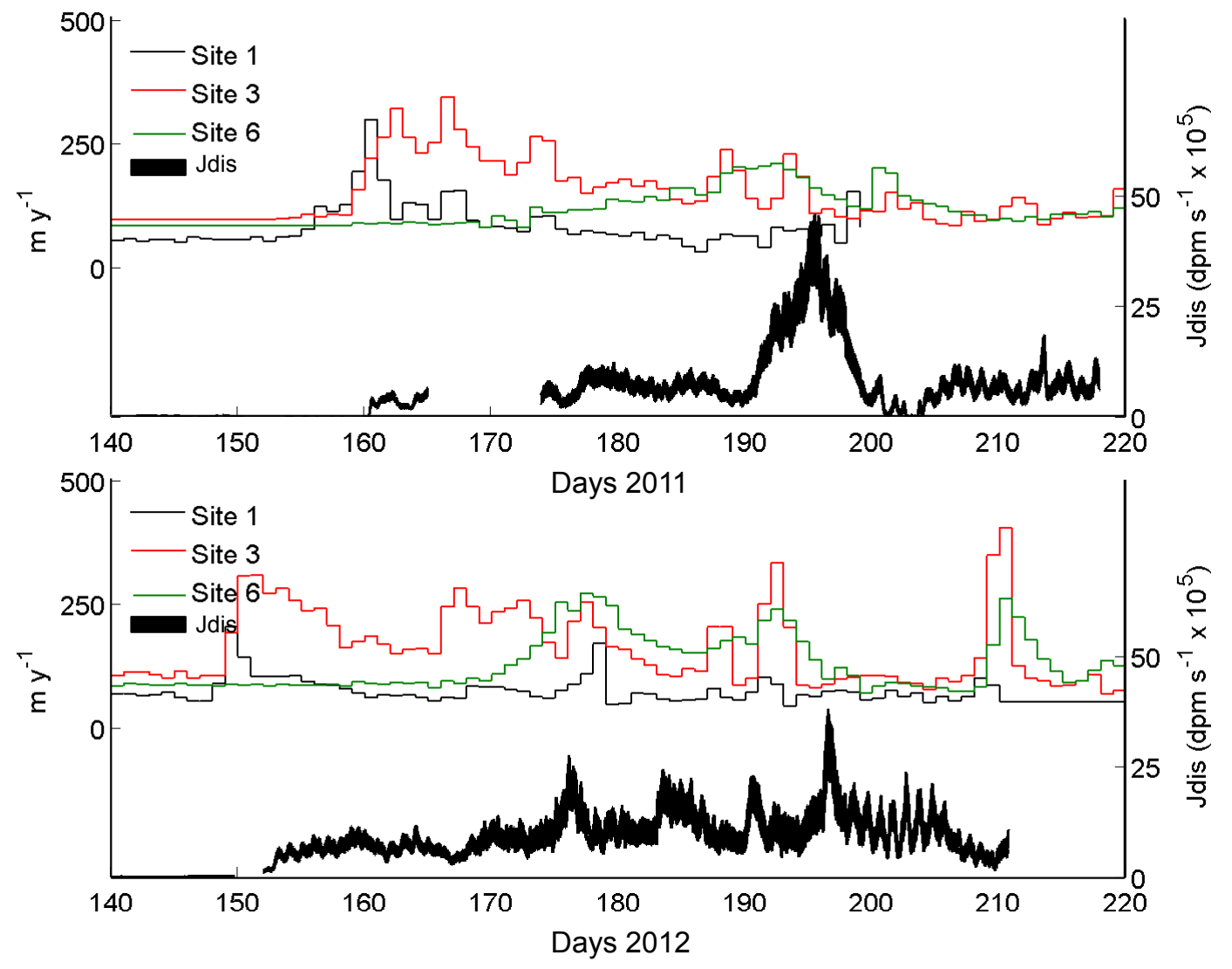

Figure 12: Relationships betweens $J_{\text {dis }}$ flux and glacial velocities at Stations 1, 3, and 6 in 2011 and 2012. Slower glacial velocity at Site 3 corresponds to peaks in $J_{d i s}$ during the 2012 melt season while this relationship was less clear in 2011. 

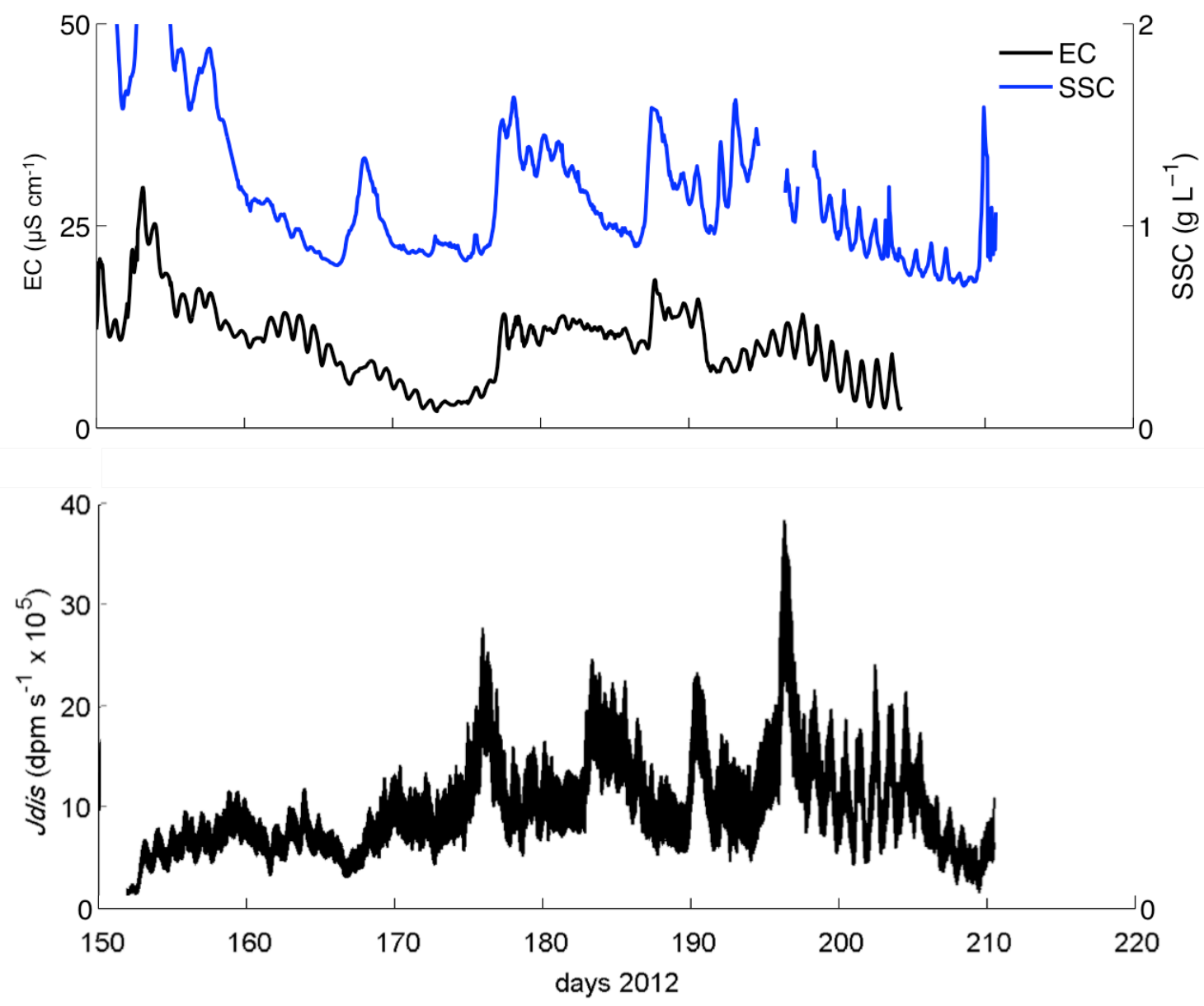

Figure 13: In 2012 there were multiple peaks in $J_{d i s}$ and SSC/EC. These events were clearly not related and indicate that supraglacial lake drainage events (as evidenced by simultaneous SSC/EC peaks) do not displace large quantities of distributed system meltwater. 


\section{References}

Andreasen, J. O. (1984), Glacier meltwater chemistry at two sub-polar glaciers in West Greenland, Rapp. Grønlands Geol. Undersøgelser, 120, 105-108.

Andrews, L. C., G. A. Catania, M. J. Hoffman, J. D. Gulley, M. P. Luthi, C. Ryser, R. L. Hawley, and T. A. Neumann (2014), Direct observations of evolving subglacial drainage beneath the Greenland Ice Sheet, Nature, 514(7520), 80-83.

Van Angelen, J. H., J. T. M. Lenaerts, S. Lhermitte, X. Fettweis, P. Kuipers Munneke, M. R. van den Broeke, E. van Meijgaard, and C. J. P. P. Smeets (2012), Sensitivity of Greenland Ice Sheet surface mass balance to surface albedo parameterization: a study with a regional climate model, Cryosph., 6(5), 1175-1186, doi:10.5194/tc-6-1175-2012.

Arendt, C. A., S. M. Aciego, and E. A. Hetland (2015), An open source Bayesian Monte Carlo isotope mixing model with applications in Earth surface processes, Geochemistry, Geophys. Geosystems, 16(5), 1274-1292.

Van As, D. et al. (2014), Increasing meltwater discharge from the Nuuk region of the Greenland ice sheet and implications for mass balance (1960-2012), J. Glaciol., 60(220), 314-322, doi:10.3189/2014JoG13J065.

Bartholomaus, T. C., R. S. Anderson, and S. P. Anderson (2008), Response of glacier basal motion to transient water storage, Nat. Geosci., 1(1), 33-37, doi:10.1038/ngeo.2007.52. 
Bartholomew, I., P. Nienow, D. Mair, A. Hubbard, M. a. King, and A. Sole (2010), Seasonal evolution of subglacial drainage and acceleration in a Greenland outlet glacier, Nat. Geosci., 3(6), 408-411, doi:10.1038/ngeo863.

Bartholomew, I., P. Nienow, A. Sole, D. Mair, T. Cowton, S. Palmer, and J. Wadham (2011a), Supraglacial forcing of subglacial drainage in the ablation zone of the Greenland ice sheet, Methods, 38, 1-5, doi:10.1029/2011GL047063.

Bartholomew, I., P. Nienow, A. Sole, D. Mair, T. Cowton, and M. A. King (2012), Short-term variability in Greenland Ice Sheet motion forced by time-varying meltwater drainage: Implications for the relationship between subglacial drainage system behavior and ice velocity, J. Geophys. Res. Earth Surf., 117(F3), doi:10.1029/2011JF002220.

Bartholomew, I. D., P. Nienow, A. Sole, D. Mair, T. Cowton, M. A. King, and S. Palmer (2011b), Seasonal variations in Greenland Ice Sheet motion : Inland extent and behaviour at higher elevations, Earth Planet. Sci. Lett., 307(3-4), 271-278, doi:10.1016/j.eps1.2011.04.014.

Bell, R. E. (2008), The role of subglacial water in ice-sheet mass balance, Nat. Geosci, 1(5), 297-304.

Bhatia, M. P., S. B. Das, E. B. Kujawinski, P. Henderson, A. Burke, and M. A. Charette (2011), Seasonal evolution of water contributions to discharge from a Greenland outlet glacier: insight from a new isotope-mixing model, J. Glaciol., 57(205), 929-941. 
Boulton, G. S., M. Hagdorn, P. B. Maillot, and S. Zatsepin (2009), Drainage beneath ice sheets: groundwater-channel coupling, and the origin of esker systems from former ice sheets, Quat. Sci. Rev., 28(7), 621-638.

Box, J. E., X. Fettweis, J. C. Stroeve, M. Tedesco, D. K. Hall, and K. Steffen (2012), Greenland ice sheet albedo feedback: thermodynamics and atmospheric drivers, Cryosph., 6(4), 821839, doi:10.5194/tc-6-821-2012.

Braithwaite, R. J., and O. B. Olesen (1989), Calculation of glacier ablation from air temperature, West Greenland, Springer Netherlands.

Butler, C. (2014), Hydrochemistry of the Greenland Ice Sheet, 245 pp., University of Bristol Ph.D. Thesis.

Chandler, D. M., J. L. Wadham, G. P. Lis, T. Cowton, A. Sole, I. Bartholomew, J. Telling, P. Nienow, E. B. Bagshaw, and D. Mair (2013), Evolution of the subglacial drainage system beneath the Greenland Ice Sheet revealed by tracers, Nat. Geosci., 6(3), 195-198.

Charette, M. A., W. S. Moore, and W. C. Burnett (2008), Uranium-and thorium-series nuclides as tracers of submarine groundwater discharge, U-Th Ser. nuclides Aquat. Syst. Elsevier, $155-191$.

Chen, G. (1999), GPS kinematic positioning for the airborne laser altimetry at Long Valley, California, Massachusetts Institute of Technology Ph.D. Thesis.

Chu, V. W. (2014), Greenland ice sheet hydrology: A review, Prog. Phys. Geogr., 38(1), 19-54. 
Cowton, T., P. Nienow, A. Sole, J. Wadham, G. Lis, I. Bartholomew, D. Mair, and D. Chandler (2013), Evolution of drainage system morphology at a land-terminating Greenlandic outlet glacier, J. Geophys. Res. Earth Surf., 118(1), 29-41.

Creyts, T. T., and C. G. Schoof (2009), Drainage through subglacial water sheets, J. Geophys. Res. Earth Surf., 114(F4).

Das, S. B., I. Joughin, M. D. Behn, I. M. Howat, M. A. King, D. Lizarralde, and M. P. Bhatia (2008), Fracture propagation to the base of the Greenland ice sheet during supraglacial lake drainage, Science, 320(5877), 778-781.

Dee, D. P. et al. (2011), The ERA-Interim reanalysis: configuration and performance of the data assimilation system, Q. J. R. Meteorol. Soc., 137(656), 553-597, doi:10.1002/qj.828.

Doyle, S. H., A. Hubbard, A. A. W. Fitzpatrick, D. As, A. B. Mikkelsen, R. Pettersson, and B. Hubbard (2014), Persistent flow acceleration within the interior of the Greenland ice sheet, Geophys. Res. Lett., 41(3), 899-905.

Ettema, J., M. R. den Broeke, E. van Meijgaard, W. J. de Berg, J. E. Box, and K. Steffen (2010), Climate of the Greenland ice sheet using a high-resolution climate model--Part 1: Evaluation, Cryosph., 4(4), 511-527.

Fitzpatrick, A. A. W., A. L. Hubbard, J. E. Box, D. J. Quincey, D. Van As, A. P. B. Mikkelsen, S. H. Doyle, C. F. Dow, B. Hasholt, and G. A. Jones (2014), A decade (2002--2012) of supraglacial lake volume estimates across Russell Glacier, West Greenland, Cryosph., 8(1), $107-121$. 
Flowers, G. E. (2015), Modelling water flow under glaciers and ice sheets, in Proceedings of the Royal Society of London A: Mathematical, Physical and Engineering Sciences, vol. 471.

Flowers, G. E., and G. K. C. Clarke (2002), A multicomponent coupled model of glacier hydrology 1. Theory and synthetic examples, J. Geophys. Res. Solid Earth, 107(B11), ECV-9.

Fountain, A. G., and J. S. Walder (1998), Water flow through temperate glaciers, Rev. Geophys., 36(3), 299-328.

Gat, J. R. (1996), Oxygen and hydrogen isotopes in the hydrologic cycle, Annu. Rev. Earth Planet. Sci., 24(1), 225-262.

Gulley, J. D., M. Grabiec, J. B. Martin, J. Jania, G. Catania, and P. Glowacki (2012), The effect of discrete recharge by moulins and heterogeneity in flow-path efficiency at glacier beds on subglacial hydrology, , 58(211), 926-940, doi:10.3189/2012JoG11J189.

Hawkings, J. R., J. L. Wadham, M. Tranter, R. Raiswell, L. G. Benning, P. J. Statham, A. Tedstone, P. Nienow, K. Lee, and J. Telling (2014), Ice sheets as a significant source of highly reactive nanoparticulate iron to the oceans, Nat. Commun., 5(3929), doi:10.1038/ncomms4929.

Hindshaw, R. S., J. Rickli, J. Leuthold, J. Wadham, and B. Bourdon (2014), Identifying weathering sources and processes in an outlet glacier of the Greenland Ice Sheet using $\mathrm{Ca}$ and Sr isotope ratios, Geochim. Cosmochim. Acta, 145(0), 50-71. 
Hock, R. (2003a), Temperature index melt modelling in mountain areas, J. Hydrol., 282(1-4), 104-115, doi:http://dx.doi.org/10.1016/S0022-1694(03)00257-9.

Hock, R. (2003b), Temperature index melt modelling in mountain areas, J. Hydrol., 282(1-4), 104-115.

Hofmann, H., B. S. Gilfedder, and I. Cartwright (2011), A novel method using a silicone diffusion membrane for continuous 222Rn measurements for the quantification of groundwater discharge to streams and rivers, Environ. Sci. Technol., 45(20), 8915-8921.

Hubbard, B., M. Sharp, M. Nielsen, I. C. Willis, and C. C. Smart (1995), Borehole water-level variations and the structure of the subglacial hydrological systelll of Haut Glacier d 'Arolla, Valais, Switzerland, J. Glaciol., 41(139), 572-583.

IAEA/WMO (2013), Global Network of Isotopes in Precipitation. The GNIP Database. Online at: http://www.iaea.org/water.

Kies, A., A. Nawrot, Z. Tosheva, and J. Jania (2011), Natural radioactive isotopes in glacier meltwater studies, Geochem. J., 45(6), 423-429.

Knight, P. G. (1989), Stacking of basal debris layers without bulk freezing-on: isotopic evidence from West Greenland, J. Glaciol., 35(120), 214-216.

Kuhn, M. (1993), Methods of assessing the effects of climatic changes on snow and glacier hydrology, IAHS Publ. Int. Assoc. Hydrol. Sci., 218, 135-144. 
Moon, T., I. Joughin, B. Smith, M. R. van den Broeke, W. J. van de Berg, B. Noël, and M. Usher (2014), Distinct patterns of seasonal Greenland glacier velocity, Geophys. Res. Lett., 41(20), 7209-7216, doi:10.1002/2014GL061836.

Morlighem, M., E. Rignot, J. Mouginot, X. Wu, H. Seroussi, E. Larour, and J. Paden (2013), High-resolution bed topography mapping of Russell Glacier, Greenland, inferred from Operation IceBridge data, J. Glaciol., 59(218), 1015-1023.

Ng, F. S. L. (2000), Coupled ice till deformation near subglacial channels and cavities, $J$. Glaciol., 46(155), 580-598.

Nghiem, S. V, D. K. Hall, T. L. Mote, M. Tedesco, M. R. Albert, K. Keegan, C. A. Shuman, N. E. DiGirolamo, and G. Neumann (2012), The extreme melt across the Greenland ice sheet in 2012, Geophys. Res. Lett., 39(20).

Ohmura, A. (2001), Physical Basis for the Temperature-Based Melt-Index Method, J. Appl. Meteorol., 40(4), 753-761.

Palmer, S., A. Shepherd, P. Nienow, and I. Joughin (2011), Seasonal speedup of the Greenland Ice Sheet linked to routing of surface water, Earth Planet. Sci. Lett., 302(3-4), 423-428, doi:10.1016/j.epsl.2010.12.037.

Parizek, B. R., and R. B. Alley (2004), Implications of increased Greenland surface melt under global-warming scenarios: ice-sheet simulations, Quat. Sci. Rev., 23(9-10), 1013-1027, doi:http://dx.doi.org/10.1016/j.quascirev.2003.12.024. 
Rae, J. G. L. et al. (2012), Greenland ice sheet surface mass balance: evaluating simulations and making projections with regional climate models, Cryosph., 6(6), 1275-1294, doi:10.5194/tc-6-1275-2012.

Raiswell, R. (1984), Chemical models of solute acquisition in glacial meltwaters, J. Glaciol., 30(104), 49-57.

Reeh, N., H. H. Thomsen, and H. B. Clausen (1987), The Greenland ice-sheet margin: A mine of ice for paleo-environmental studies, Palaeogeogr. Palaeoclimatol. Palaeoecol., 58(3), 229234.

Reijmer, C. H., M. R. van den Broeke, X. Fettweis, J. Ettema, and L. B. Stap (2012), Refreezing on the Greenland ice sheet: a comparison of parameterizations, Cryosph., 6(4), 743-762, doi:10.5194/tc-6-743-2012.

Rothlisberger, H. (1969), Water pressure in subglacial channels, in Union Géodésique et Géophysique Internationale. Association Internationale d'Hydrologie Scientifique. Commission de Neiges et Glaces. Symposium on the hydrology of Glaciers, Cambridge, 7, p. 97.

Schoof, C. (2010), Ice-sheet acceleration driven by melt supply variability, Nature, 468(7325), 803-806.

Schubert, M., A. Paschke, D. Bednorz, W. Bürkin, and T. Stieglitz (2012), Kinetics of the water/air phase transition of radon and its implication on detection of radon-in-water 
concentrations: practical assessment of different on-site radon extraction methods, Environ. Sci. Technol., 46(16), 8945-8951.

Sharp, M., K. Richards, I. Willis, N. Arnold, P. Nienow, W. Lawson, and J. Tison (1993), Geometry, bed topography and drainage system structure of the Haut Glacier d'Arolla, Switzerland, Earth Surf. Process. Landforms, 18(6), 557-571.

Shepherd, A. et al. (2012), A Reconciled Estimate of Ice-Sheet Mass Balance, Science, 338(6111), 1183-1189, doi:10.1126/science.1228102.

Shoemaker, E. M. (1986), Subglacial hydrology for an ice sheet resting on a deformable aquifer, J. Glaciol, 32(110), 20-30.

Singh, P., and N. Kumar (1996), Determination of snowmelt factor in the Himalayan region, Hydrol. Sci. J., 41(3), 301-310, doi:10.1080/02626669609491504.

Skidmore, M. L., and M. J. Sharp (1999), Drainage system behaviour of a High-Arctic polythermal glacier, Ann. Glaciol., 28(1), 209-215, doi:doi:10.3189/172756499781821922.

Smith, L. C. et al. (2015), Efficient meltwater drainage through supraglacial streams and rivers on the southwest Greenland ice sheet, Proc. Natl. Acad. Sci., 112(4), 1001-1006.

Sole, A., P. Nienow, I. Bartholomew, D. Mair, T. Cowton, A. Tedstone, and M. A. King (2013), Winter motion mediates dynamic response of the Greenland ice sheet to warmer summers, Geophys. Res. Lett., 40(15), 3940-3944. 
Stevens, L. A., M. D. Behn, J. J. McGuire, S. B. Das, I. Joughin, T. Herring, D. E. Shean, and M. A. King (2015), Greenland supraglacial lake drainages triggered by hydrologically induced basal slip, Nature, 522(7554), 73-76.

Sugden, D. E., P. G. Knight, N. Livesey, R. D. Lorrain, R. A. Souchez, J.-L. Tison, and J. Jouzel (1987), Evidence for two zones of debris entrainment beneath the Greenland ice sheet, Nature, 328(6127), 238-241.

Tedstone, A. J., P. W. Nienow, A. J. Sole, D. W. F. Mair, T. R. Cowton, I. D. Bartholomew, and M. A. King (2013), Greenland ice sheet motion insensitive to exceptional meltwater forcing, Proc. Natl. Acad. Sci., 110(49), 19719-19724.

Tedstone, A. J., P. W. Nienow, N. Gourmelen, and A. J. Sole (2014), Greenland ice sheet annual motion insensitive to spatial variations in subglacial hydraulic structure, Geophys. Res. Lett., 41(24), 8910-8917, doi:10.1002/2014GL062386.

Tranter, M. (1993), A conceptual model of solute acquisition by Alpine glacial meltwaters, $J$. Glaciol., 39(133).

Van de Wal, R. S. W. et al. (2015), Self-regulation of ice flow varies across the ablation area in south-west Greenland, Cryosph., 9(2), 603-611.

Walder, J. S. (1986), Hydraulics of subglacial cavities, J. Glaciol, 32(112), 439-445.

Werder, M. A., I. J. Hewitt, C. G. Schoof, and G. E. Flowers (2013), Modeling channelized and distributed subglacial drainage in two dimensions, J. Geophys. Res. Earth Surf., 118(4), $2140-2158$. 
Van Wessem, J. M., C. H. Reijmer, J. T. M. Lenaerts, W. J. van de Berg, M. R. van den Broeke, and E. van Meijgaard (2014), Updated cloud physics in a regional atmospheric climate model improves the modelled surface energy balance of Antarctica, Cryosph., 8(1), 125135, doi:10.5194/tc-8-125-2014.

Yde, J. C., and N. T. Knudsen (2004), The importance of oxygen isotope provenance in relation to solute content of bulk meltwaters at Imersuaq Glacier, West Greenland, Hydrol. Process., 139(February 2003), 125-139, doi:10.1002/hyp.1317.

Zwally, H. J., W. Abdalati, T. Herring, K. Larson, J. Saba, and K. Steffen (2002), Surface meltinduced acceleration of Greenland ice-sheet flow., Science, 297(5579), 218-22, doi:10.1126/science.1072708. 


\title{
Chapter 4
}

\section{Controls on the strontium, uranium, and radium isotope \\ fluxes from the Greenland Ice Sheet}

\begin{abstract}
This chapter presents time series $\mathrm{U}, \mathrm{Sr}$, and $\mathrm{Ra}$ isotope as well as major and trace element data from the dissolved and suspended sediment load of a glacial watershed in southwest Greenland predominated by silicate bedrock. The time series samples were collected from the spring to mid-summer during which subglacial drainage flow paths changed from predominately distributed to channelized drainage. Data is also presented from a sampling transect collected downriver from the ice sheet's terminus to the freshwater-saltwater mixing zone in the downstream fjord. In the time series samples, the ${ }^{87} \mathrm{Sr} /{ }^{86} \mathrm{Sr}$ ratio of the dissolved load varied from 0.7329 to 0.7558 with a discharge-weighted mean of 0.7382 . More radiogenic ${ }^{87} \mathrm{Sr} /{ }^{86} \mathrm{Sr}$ values were observed during early season distributed system-dominated drainage and were found to correlate to high $\mathrm{Ca} / \mathrm{Na}$ molar ratios indicative of stronger influence from dissolution of carbonate minerals. An acetic acid digestion of suspended sediment load samples had a mean ${ }^{87} \mathrm{Sr} /{ }^{86} \mathrm{Sr}$ value of $0.7473(\mathrm{n}=9$, stdev $=0.0038)$ suggesting that the trace carbonate fraction contained radiogenic Sr. A sequential total digestion of the residual suspended sediment load remaining after the acetic acid digestion had a mean ${ }^{87} \mathrm{Sr} /{ }^{86} \mathrm{Sr}$ value of 0.7170 . These results suggest that weathering of trace carbonates within the watershed controlled the high ${ }^{87} \mathrm{Sr} /{ }^{86} \mathrm{Sr}$
\end{abstract}


values in the early season. The decreasing ${ }^{87} \mathrm{Sr} /{ }^{86} \mathrm{Sr}$ values from spring to summer was likely the result of increased weathering of less radiogenic silicate minerals. The $\delta^{234} U$ value of the dissolved load from time series samples varied between 33-106 with a discharge-weighted average of 63. Samples collected along a transect moving downstream from the ice sheet terminus had decreasing $\delta^{234} \mathrm{U}$ values from 63 to 15 , with the lowest value being collected in the freshwater zone of the fjord. An experiment was conducted during which splits of a sample collected from the proglacial river were filtered and acidified between 0 and 18 days after collection. Results of this experiment showed that the $\delta^{234} U$ value decreased from 81 to 21 with increasing time between filtering. These results likely indicate that subglacial sediments have been stripped of the more mobile ${ }^{234} \mathrm{U}$ leaving behind $\delta^{234} \mathrm{U}$ depleted mineral surfaces that then impart low $\delta^{234} \mathrm{U}$ to the glacial meltwater. The $\left({ }^{228} \mathrm{Ra} /{ }^{226} \mathrm{Ra}\right)$ activity ratio of the dissolved load of the proglacial river varied from 17 to 5 and was significantly higher than the $\left({ }^{228} \mathrm{Ra} /{ }^{226} \mathrm{Ra}\right)$ value of a suspended sediment load sample, which was 2 . These data show that the high $\left({ }^{228} \mathrm{Ra} /{ }^{226} \mathrm{Ra}\right)$ ratio in the dissolved load was not the result of the source rock material but instead must be the result of the faster ingrowth rate of ${ }^{228} \mathrm{Ra}\left(\mathrm{t}_{1 / 2}=5.75 \mathrm{y}\right)$ relative to ${ }^{226} \mathrm{Ra}\left(\mathrm{t}_{1 / 2}=1600 \mathrm{y}\right)$, and extensive, repeated cycles of subglacial mineral surface weathering. The surprisingly high $\left({ }^{228} \mathrm{Ra} /{ }^{226} \mathrm{Ra}\right)$ activity ratio and low $\delta^{234} \mathrm{U}$ values in the dissolved load are both likely the result of repeated flushing of subglacial sediments driven by variable supraglacial meltwater inputs.

\section{Introduction}

Glaciers profoundly affect the landscapes they override. As an endmember of extreme physical weathering, glaciers produce highly abraded mineral surfaces, which can readily undergo chemical weathering (Anderson, 2007). While the majority of the dissolved load is 
supplied by weathering of carbonate minerals regardless of bedrock type (Tranter et al., 2002), weathering of glacial material downstream of the glacier could have a major effect on the global carbon cycle (Anderson, 2007) and the budgets of several elements - including Fe (Raiswell et al., 2006; Bhatia et al., 2013; Hawkings et al., 2014) - in seawater. Furthermore, the isotopic composition of glacial meltwater can be indicative of changing subglacial processes and weathering intensity to the extent that glacial systems can alter the isotopic composition of the oceans on glacial-interglacial time scales (Hodell et al., 1990; Blum and Erel, 1995; Rhodes et al., 2002; Robinson et al., 2004).

Under temperate "warm-based" glaciers and the marginal zones of the Greenland Ice Sheet (GrIS), meltwater is produced during winter months by geothermal and frictional heating at the base where it travels slowly to the ice margin through groundwater and small cavities at the ice bed (Kehew et al., 2012). During this time, meltwater residence time is long and higher concentrations of dissolved constituents are observed (Wadham et al., 2001). After spring melt begins, surface derived meltwater reaches the ice bed through fractures, crevasses and moulins (Das et al., 2008; Fountain and Walder, 1998; Sharp et al., 1993). From there, it travels to the ice margin through groundwater and a complex and evolving series of cavities and channels where transit times and water rock interactions are highly variable (Bartholomew et al., 2011a; 2011b; Boulton et al., 2009; Gulley et al., 2009; Piotrowski, 1997). Meltwater flow paths in the early melt season are through distributed systems composed of cavities that open behind bedrock bumps due to ice sliding (linked-cavity system; Walder, 1986), a water sheet of near uniform thickness at the ice bed (Flowers and Clarke, 2002; Creyts and Schoof, 2009), or water flow through permeable subglacial till (Shoemaker, 1986; Boulton et al., 2009). Following the onset of wide-scale surface melting, large channels open which act to quickly evacuate meltwater to 
the terminus (Röthlisberger, 1969). While channelized systems drain the majority of meltwater, exchange occurs between the channelized and the adjacent distributed system, often on diurnal time scales (Chapter 1).

\subsection{Radium isotopes}

The isotopes of radium ${ }^{226} \mathrm{Ra}\left(\mathrm{t}_{1 / 2}=1600\right)$ and ${ }^{228} \mathrm{Ra}\left(\mathrm{t}_{1 / 2}=5.7\right.$ years $)$ are decay products of the long-lived isotopes ${ }^{238} \mathrm{U}$ (for ${ }^{226} \mathrm{Ra}$ ) and ${ }^{232} \mathrm{Th}$ (for ${ }^{228} \mathrm{Ra}$ ). ${ }^{226} \mathrm{Ra}$ and ${ }^{228} \mathrm{Ra}$ are largely unsupported by their parent isotopes in solution and hence, continuous release of radium from the solid phase supports the activities observed in the aqueous phase (Moore, 1967). Therefore, the relative abundance of ${ }^{228} \mathrm{Ra}$ and ${ }^{226} \mathrm{Ra}$ in river systems usually reflects the abundance of $\mathrm{U}$ and Th within a drainage basin, and in most natural waters the activity ratio of $\left({ }^{228} \mathrm{Ra} /{ }^{226} \mathrm{Ra}\right)$ is $\sim 1$ (Moore and Edmond, 1984; Sarin et al., 1990; Kraemer and Curwick, 1991). However, in environments such as in tidal salt marshes and subterranean estuaries where extensive circulation of water extracts Ra from sediments, waters can become enriched in the shorter-lived ${ }^{228} \mathrm{Ra}$ isotope because of differences in the relative ingrowth rates from their parent isotopes and the frequency with which water circulates through the sediments (Charette, 2007; Gonneea et al., 2008).

Radium's reactivity with respect to particle adsorption is higher in freshwater relative to saltwater; generally between $50 \%-90 \%$ of the Ra flux carried by rivers to the ocean is adsorbed to the riverine suspended sediment and desorbs in estuaries (Key et al., 1985; Moore and Scott, 1986; Kraemer and Curwick, 1991). The Ra adsorbed to river suspended sediments is desorbed in estuaries during mixing with seawater as Ra sorption is partially controlled by ionic strength (Li and Chan, 1979; Key et al., 1985). Other factors that influence Ra sorption and desorption 
include the presence of Mn (hydr)oxides for which Ra has a very strong affinity (Gonneea et al., 2008).

\subsection{Uranium isotopes}

The energetic alpha decay of ${ }^{238} \mathrm{U}$ in rocks causes its great-granddaughter, ${ }^{234} \mathrm{U}$, to reside in a damage crystal site and therefore more easily mobilized into solution (Osmond and Cowart, 1976). Consequently, variations in the ratio of activities of ${ }^{234} U$ to ${ }^{238} U\left({ }^{234} U /{ }^{238} U\right)$ are typically greater than secular equilibrium, $\left({ }^{234} \mathrm{U} /{ }^{238} \mathrm{U}\right)=1$, in most natural waters. Rivers for example, generally have $\left({ }^{234} \mathrm{U} /{ }^{238} \mathrm{U}\right)$ between 1 to $>3$ in the dissolved load (Chabaux et al., 2003). High $\left({ }^{234} \mathrm{U} /{ }^{238} \mathrm{U}\right)$ are often found in the surface waters of catchments with high physical weathering rates and low rainfall where finely ground and abraded mineral surfaces allow for the disproportionate release of the more mobile ${ }^{234} U$ (von Strandmann et al., 2006; Robinson et al., 2004). In catchments with fairly uniform geology with high physical weathering, an increase in the ratio of surface area of sediment clasts to water volume generally results in an increase in $\left({ }^{234} \mathrm{U} /{ }^{238} \mathrm{U}\right)$ in the dissolved load (von Strandmann et al., 2006; von Strandmann et al., 2010). Low $\left.{ }^{(234} \mathrm{U} /{ }^{238} \mathrm{U}\right)$ values have been observed in waters draining catchments with high rainfall as the more mobile ${ }^{234} \mathrm{U}$ is stripped from mineral surfaces leaving the source material depleted in ${ }^{234} \mathrm{U}$ (Robinson et al., 2004). Hence, the $\left({ }^{234} \mathrm{U} /{ }^{238} \mathrm{U}\right)$ system has wide-ranging applications as tracers of weathering processes (Osmond et al., 1968; Cowart and Osmond, 1976; Dunk et al., 2002), groundwater flow (Paces et al., 2002).

The residence time of $U$ in the oceans with respect to river inputs is between $300-600 \mathrm{Kyr}$ and variations in $\left({ }^{234} \mathrm{U} /{ }^{238} \mathrm{U}\right)$ in the oceans can occur independently from variations in total uranium concentration (Dunk et al., 2002; Esat and Yokoyama, 2006). When dating marine 
carbonates, the initial $\left.{ }^{234} \mathrm{U} /{ }^{238} \mathrm{U}\right)$ of a sample is commonly used as a test of diagenetic alteration (e.g. Chen et al., 1991). This is based on assumption that seawater $\left.{ }^{234} U{ }^{238} U\right)$ has remained unchanged for the past 600,000 yrs. However, coral records show that the $\left({ }^{234} U /{ }^{238} U\right)$ in seawater changed between glacial and interglacial time periods and was potentially $7 \%$ lower during glacial periods (Yokoyama and Esat, 2004), yet the mechanism(s) causing this shift remain(s) unclear. Two hypotheses have been proposed. Rising sea levels following glacial periods may have mobilized excess ${ }^{234} \mathrm{U}$ stored in submerged coastal wetlands through submarine groundwater discharge (Dunk et al., 2002; Esat and Yokoyama, 2006). Alternatively, deglaciation and weathering of fine-grained glacial flour may have released a large flux of ${ }^{234} \mathrm{U}$ into rivers draining retreating ice sheets (Robinson et al., 2004). These two potential mechanisms need not be mutually exclusive: a recent study has shown that submarine groundwater discharge derived from the GrIS may provide an important flux of glacially derived solutes to the marine environment (DeFoor et al., 2011). Importantly, as terrestrial runoff makes up nearly $40 \%$ of the total uranium input to the ocean, only a small shift in average river water $\left({ }^{234} \mathrm{U}{ }^{238} \mathrm{U}\right)$ could alter the $\left({ }^{234} \mathrm{U} /{ }^{238} \mathrm{U}\right)$ of the ocean by the observed $7 \%$ during glacial-interglacial transitions (Robinson et al., 2004; Dunk et al., 2002).

Despite the possibility that glacial sediment and meltwater play a major role in controlling the ocean's $\left({ }^{234} \mathrm{U} /{ }^{238} \mathrm{U}\right)$ during glacial-interglacial transitions, the flux of $\mathrm{U}$ from modern ice sheets has not been investigated and few studies exist of the effect of subglacial weathering on $\left({ }^{234} U /{ }^{238} U\right)$ (von Strandmann et al., 2006; von Strandmann et al., 2010; Arendt, 2014). This is surprising because glacial systems provide an abundance of freshly abraded mineral surfaces, a process that has a strong effect on $\left({ }^{234} \mathrm{U} /{ }^{238} \mathrm{U}\right)$. Furthermore, weathering rates beneath glaciers and the margins of the GrIS are seasonally variable and are controlled by the 
dynamic and seasonal subglacial hydraulic systems, hence $\left({ }^{234} U{ }^{238} U\right)$ may also be a tracer of subglacial processes.

\subsection{Strontium isotopes}

In catchment studies, the ${ }^{87} \mathrm{Sr} /{ }^{86} \mathrm{Sr}$ ratio in water represents the contribution of weathering from different rock forming minerals rather than from whole rock weathering, with the exception of carbonate rocks that dissolve congruently (Åberg et al., 1989). This is because the ratio of $\mathrm{Rb} / \mathrm{Sr}$ in rocks varies between individual minerals of the same age and therefore the ${ }^{87} \mathrm{Sr} /{ }^{86} \mathrm{Sr}$ ratio changes because of decay of radioactive ${ }^{87} \mathrm{Rb}$ to stable (radiogenic) ${ }^{87} \mathrm{Sr}$ (Faure, 1986). The geochemical similarity of rubidium and potassium, coupled with the ${ }^{87} \mathrm{Rb}$ half-life of $4.88 \times 10^{10}$ years, causes old rocks rich in potassium to have very high ${ }^{87} \mathrm{Sr} /{ }^{86} \mathrm{Sr}$ ratios. Consequently, the ${ }^{87} \mathrm{Sr} /{ }^{86} \mathrm{Sr}$ isotope system is ideally suited for studying subglacial weathering in west Greenland, because of the presence of Achaean granitic bedrock with abundant potassium-rich minerals (Henriksen et al., 2000).

Glaciation causes extensive physical and chemical weathering and can alter the ${ }^{87} \mathrm{Sr} /{ }^{86} \mathrm{Sr}$ strontium flux to the ocean (Anderson et al., 2007). Weathering products from glaciers are thought to have a strong influence on the ocean's ${ }^{87} \mathrm{Sr} /{ }^{86} \mathrm{Sr}$ ratio (Zachos et al., 1999). For example, major changes in Earth's glacial history over the past 10 Ma correlate qualitatively with changes in marine ${ }^{87} \mathrm{Sr} /{ }^{86} \mathrm{Sr}$ (Blum and Erel, 1995, McArthur et al., 2012) potentially as the result of radiogenic strontium being released from glacial moraines. Therefore, the GrIS may be a source of highly radiogenic strontium important to the modern isotopic budget of the ocean; however, it has been largely under-sampled (Hagedorn and Hasholt, 2004; Hindshaw et al., 2014). 


\section{Methods}

\section{$2.1 \quad$ Site description:}

Samples were collected from Leverett Glacier, a large land-terminating glacier $\left(600 \mathrm{~km}^{2}\right)$ on the western margin of the GrIS $\left(67^{\circ} \mathrm{N}, 50^{\circ} \mathrm{W}\right.$; Figure 1). The glacier is ideal as it is large enough to be characteristic of many outlet glaciers of the GrIS, yet its meltwater is channeled through a single large proglacial river making effective sampling of bulk meltwater possible. Furthermore, the site has been well studied since the 2009 melt season (Bartholomew et al., 2010; 2011a; 2011b; 2012; Chandler et al., 2013; Cowton et al., 2012; 2013; Tedstone et al., 2013; 2014; Hawkings et al., 2014; Lawson et al., 2014).

Between 2009 and 2011, the Leverett Glacier proglacial river began flowing by late May and mid-summer flows were typically between $200-400 \mathrm{~m}^{3} / \mathrm{s}$ (Sole et al., 2013). In 2012, an exceptional melting event occurred during which nearly the entire surface of the GrIS was melting (Nghiem et al., 2012). Hence, the data presented here includes samples taken from the early melt season through peak flows that reached $\sim 800 \mathrm{~m}^{3} / \mathrm{s}$ (Tedstone et al., 2013). The Leverett Glacier proglacial river combines with three other proglacial rivers before reaching a fjord $\sim 25 \mathrm{~km}$ downstream (Figure 1).

As far as we know there are two Precambrian lithological units beneath Leverett Glacier (Figure 2). South of the glacier the bedrock is a late Achaean $(2.5 \mathrm{Ga})$ felsic intrusion related to the Qôrqut granite (Escher, 1971; Nutman et al., 2010). North of the glacier is the Ikertoq complex of the Nagssugtoqidian fold belt. This unit is composed of epidote amphibolite to amphibolite facies basement gneisses and granites (Henriksen et al., 2000). These metamorphic rocks are $\sim 1.85 \mathrm{Ga}$. The boundary between these two units beneath the glacier's catchment is 
unknown. However, previous work has suggested that sediments discharging Leverett Glacier are mainly derived from bedrock on the north side of the glacier (mostly from amphibolite lenses, grey orthogneiss), and that only minor sediment contributions are from the Qôrqut granite on the south side (Hindshaw et al., 2014). Minerals within the river sediment include plagioclase, hornblende, quartz, epidote, garnet, clinopyroxene, K-feldspar, biotite, apatite, and zircon, similar to what has been observed in rock samples (Hindshaw et al., 2014). Much of the biotite in the rocks and sediment has been weathered to chlorite and epidote (Hindshaw et al., 2014).

\subsection{Sample collection:}

Time series samples for major cation, trace element, and isotope analysis were collected from the proglacial river approximately $1 \mathrm{~km}$ downstream of the Leverett Glacier portal (Site 2 in Figure 1). Times reported in this work refer to local West Greenland Time Zone. During the 2011 field season, samples were collected for Ra isotopes analysis from May $20^{\text {th }}$ (day 140) through July $30^{\text {th }}$ (day 212) using methods described below. $\mathrm{pH}$ was measured during the 2011 field season using a $\mathrm{pH}$ probe calibrated repeatedly against three $\mathrm{pH}$ reference points $(\mathrm{pH}=4,7$, and 10).

From May $13^{\text {th }}$-July $30^{\text {th }}$ (days 134-212) in 2012, samples were collected for elemental concentrations and the isotopic composition of $\mathrm{Sr}$ and $\mathrm{U}$ at Location 2 (Figure 1). Samples were filtered to $0.45 \mu \mathrm{m}$ and collected in $0.5 \mathrm{~L}$ acid-cleaned high-density polyethylene bottles. Bottles were pre-acidified with Optima ${ }^{\mathrm{TM}}$ grade $\mathrm{HNO}_{3}$ to acidify samples to $\mathrm{pH}<2$ after filtering. Following collection, filters were stored in the dark at ambient temperatures until returning to the laboratory where they were oven dried, weighed, and stored at $2^{\circ} \mathrm{C}$ until analysis. 
On May $28^{\text {th }}, 2012$ five samples were also collected for elemental concentration and isotopic composition along a transect from the margin of the GrIS to the downstream fjord (Figure 1). The Leverett Glacier proglacial river combines with three other glacially fed rivers before reaching the downstream fjord (Figure 1). To determine the effect the suspended sediment load (SSL) had on element concentrations as well as U and Sr isotopes, I collected a $5 \mathrm{~L}$ sample on July $11^{\text {th }}$ (day 193) and then filtered splits of this sample at sequential time points over the next 18 days. In the following discussion these samples are referred to as delayed filtering samples. Prior to filtering and acidifying, these delayed filtering samples were kept sealed, in the dark and at ambient temperatures.

\subsection{Suspended sediment digestions:}

I completed an acetic acid digest of the SSL in the proglacial river to mobilize elements associated with the carbonate fraction (Blum et al., 1998; Jacobson and Blum, 2000). First, 30-60 mg of sediments were collected from the suspended sediment on dried filters and placed into Teflon ${ }^{\circledR}$ vials. Next, $10 \mathrm{~mL}$ of $10 \%$ acetic acid was added to each vial and digested for 24 hours. This solution was then centrifuged, decanted, and filtered. Following this, the acetic acid solution was dried and subsequently reconstituted in $5 \% \mathrm{HNO}_{3}$, diluted, and stored for trace element, major cation, and $\mathrm{Sr}$ isotope analyses as described below.

\subsection{Radium analysis:}

In 2011, samples were collected for Ra isotope analysis from May 20 ${ }^{\text {th }}$ (day 140) through July $30^{\text {th }}$ (day 212) from the Leverett Glacier proglacial river (Site 2, Figure 1). Between 40-200 L of river water was filtered using a $1 \mu \mathrm{m}$ Hytrex II 10" cartridge filter and then passed through 
$\mathrm{MnO}_{2}$ impregnated acrylic fibers (hereafter Mn fibers) at a flow rate of $0.2 \mathrm{~L} / \mathrm{min}$ to quantitatively sorb Ra onto the Mn fibers. In the laboratory, the Mn fibers were first rinsed with Ra-free water to remove any sub $1 \mu \mathrm{m}$ sediment that had collected onto the fibers. Samples were then ashed at $820^{\circ} \mathrm{C}$ for $16 \mathrm{~h}$, homogenized, placed in vials and capped with epoxy prior for storage for $>6$ weeks to allow ${ }^{226} \mathrm{Ra}$ and ${ }^{228} \mathrm{Ra}$ to reach secular equilibrium with their daughter isotopes. In addition to the Mn fibers, a suspended sediment sample collected from the Leverett Glacier proglacial river was also prepared for Ra isotope analysis. For this analysis, $19 \mathrm{~g}$ of sediment was prepared for counting in the same manner as the Mn fiber ash.

Radium-226 and ${ }^{228}$ Ra were subsequently measured using a well-type gamma spectrometer (Charette et al., 2001). The detectors were standardized using a NIST-Standard Reference Material 4967A $\left({ }^{226} \mathrm{Ra}\right)$ and a dissolved thorium nitrate powder $\left({ }^{228} \mathrm{Ra}\right)$ with daughters in equilibrium sorbed to Mn fibers and prepared in the same way as the samples. Three samples were chosen to be re-analyzed after two years to check for possible sediment contamination. If sediment contamination was an issue, ${ }^{228} \mathrm{Ra}$ would be supported by ${ }^{232} \mathrm{Th}$ decay from the sediments. Results of this test showed that samples had decayed in line with the half-life of ${ }^{228} \mathrm{Ra}$ between analyses, demonstrating that the extremely fine-grained SSL was not a source of contamination in my samples.

\subsection{Trace element, major cation and isotope analyses}

All trace metal, major cation and $\mathrm{Sr}$ and $\mathrm{U}$ isotope measurements were completed in clean room facilities. Teflon ${ }^{\circledR}$ vials were used throughout sample preparation procedures, and all materials were subjected to a rigorous cleaning procedure including a seven day $10 \% \mathrm{HCl}$ acid wash. Ultra-pure Optima ${ }^{\mathrm{TM}}$ acids were used at each step. 
Methods for major cation and trace element analysis have been described previously (Voss et al., 2014). Each sample was spiked with an internal In standard while blanks were prepared in a similar manner using Milli-Q $\mathrm{H}_{2} \mathrm{O}$. Standards were prepared from dilutions of the natural river water reference material SLRS-4 (National Research Council Canada) and amended natural spring water reference material SRM1640a (National Institute of Standards and Technology). Blanks and standard dilutions were interspersed with and analyzed on a Thermo Scientific Element2 single collector inductively-coupled plasma mass spectrometer (ICPMS). To introduce the sample to the plasma source, an argon flow nebulizer and quartz double pass spray chamber by means of self-aspiration was used. The ion beam was tuned scanning, U, In, and Sc. Isotopes measured in this study include: ${ }^{7} \mathrm{Li},{ }^{75} \mathrm{As},{ }^{85} \mathrm{Rb},{ }^{86} \mathrm{Sr},{ }^{87} \mathrm{Sr},{ }^{88} \mathrm{Sr},{ }^{95} \mathrm{Mo},{ }^{97} \mathrm{Mo},{ }^{137} \mathrm{Ba},{ }^{138} \mathrm{Ba}$, ${ }^{235} \mathrm{U}$, and ${ }^{238} \mathrm{U}$ at low mass resolution $(\mathrm{m} / \Delta \mathrm{m} \sim 300) ;{ }^{42} \mathrm{Ca},{ }^{43} \mathrm{Ca},{ }^{44} \mathrm{Ca},{ }^{48} \mathrm{Ca},{ }^{55} \mathrm{Mn},{ }^{56} \mathrm{Fe},{ }^{57} \mathrm{Fe}$ at medium resolution (m/ $\mathrm{m} \mathrm{m} \sim 3000$ ); and ${ }^{23} \mathrm{Na},{ }^{24} \mathrm{Mg},{ }^{25} \mathrm{Mg},{ }^{26} \mathrm{Mg},{ }^{39} \mathrm{~K}$ at high resolution $(\mathrm{m} / \Delta \mathrm{m}$ $\sim 10,000)$. When possible, multiple isotopes were measured of the same element to check for isobaric interferences and corrections were applied when needed. For each element, concentrations were calculated based on 7-point calibration curves of standard dilutions. Accuracy for dissolved trace elements and cations was the difference between concentrations determined from dilution curves of the two different standards (SLRS-4 and SRM1640a). A comparison between results of repeat analyses of the two standards and their certified concentrations is shown on Table 1. A correction for ions derived from sea salt in precipitation was not made, as I did not measure $\mathrm{Cl}^{-}$ions in snow or rainwater. However, previous work at Leverett Glacier has found that this correction is very small and will not change my interpretations (Butler, 2014). 


\section{$2.6 \quad\left({ }^{234} U{ }^{238} U\right)$ analysis}

Uranium isotopes were measured on the dissolved time series samples taken in the Leverett Glacier proglacial river (Site 2, Figure 1), the transect samples collected between the Leverett Glacier terminus and the downstream fjord, three samples from the freshwater-saltwater mixing zone within the fjord, and the six delayed filtering samples described above (Section 2.1). Uranium was separated from the matrix using Eichrom analytical grade 1x8 200-400 mesh anionexchange resin following a procedure outlined in Owens et al., (2011) and Weyer et al. (2008). The resin was rinsed with $50 \%$ trace metal grade $\mathrm{HCl}$ and then with Milli-Q $\mathrm{H}_{2} \mathrm{O}$ until the $\mathrm{pH}$ value returned to five. Next, the resin was rinsed with $25 \% \mathrm{HNO}_{3}$ and shaken 10 times over a 12-hour period. The resin was again rinsed with Milli-Q $\mathrm{H}_{2} \mathrm{O}$ until the $\mathrm{pH}$ value returned to five and then stored in $\sim 1 \% \mathrm{HNO}_{3}$.

Approximately $200 \mathrm{~mL}$ of the sample was evaporated to dryness at $75^{\circ} \mathrm{C}$ in a laminar flow hood. Then, $1 \mathrm{~mL}$ of concentrated $\mathrm{HNO}_{3}$ and $50 \mu \mathrm{L}$ of $\mathrm{H}_{2} \mathrm{O}_{2}$ were added to each sample, capped and refluxed overnight at $150^{\circ} \mathrm{C}$ on a hot plate. This solution was then evaporated to dryness at $75^{\circ} \mathrm{C}$ before being reconstituted in $3 \mathrm{~mL}$ of $7 \mathrm{~N} \mathrm{HNO}_{3}$, capped, and refluxed again overnight at $150^{\circ} \mathrm{C}$ on a hot plate. One $\mathrm{mL}$ of the cleaned resin was added to the columns before being washed and conditioned using, sequentially, three column volume (cv) additions of MilliQ $\mathrm{H}_{2} \mathrm{O}, 7 \mathrm{~N} \mathrm{HNO}_{3}, 0.1 \mathrm{~N} \mathrm{HNO}_{3}, 6 \mathrm{~N} \mathrm{HCl}$, and Milli-Q. Samples were then loaded onto the columns and cleaned using three $\mathrm{cv}$ of $7 \mathrm{~N} \mathrm{HNO}_{3}$. Teflon ${ }^{\circledR}$ beakers were placed beneath the columns, and $\mathrm{U}$ was eluted off of the columns using, sequentially, three cv additions of $6 \mathrm{~N} \mathrm{HCl}$, $0.1 \mathrm{~N} \mathrm{HCl}$, and Milli-Q $\mathrm{H}_{2} \mathrm{O}$. This solution was then evaporated to dryness at $75^{\circ} \mathrm{C}$ and subsequently reconstituted in $1 \mathrm{~mL}$ of $5 \% \mathrm{HNO}_{3}$ and stored until analysis.

Uranium isotope measurements were made using a Thermo Finnigan Neptune 
multicollector (MC)-ICPMS following a method adopted from Andersen et al. (2004). The instrument was tuned using the NBS-960 standard to achieve flat peak tops and stable signal intensity. Mass fractionation was corrected by bracketing samples with standard NBS U010 using the ${ }^{238} \mathrm{U} /{ }^{234} \mathrm{U}$ ratio of 18,354 (Richter et al., 2005). The more abundant isotopes ${ }^{238} \mathrm{U}$ and ${ }^{235} \mathrm{U}$ were measured statically in Faraday cups while the minor $\mathrm{U}$ isotope ${ }^{234} \mathrm{U}$ was measured using the central discrete-dynode secondary electron multiplier (SEM). The activity ratio of $\left({ }^{234} \mathrm{U} /{ }^{238} \mathrm{U}\right)$ was calculated assuming a ${ }^{234} \mathrm{U} /{ }^{238} \mathrm{U}$ ratio of $5.4891 \times 10^{-5}$ at secular equilibrium (Cheng et al., 2000). Using the activity ratio of samples, Equation 1 was used to calculate $\delta^{234} \mathrm{U}$

$$
\delta^{234} U=\left(\left[\frac{\left({ }^{234} U /{ }^{238} U\right)_{\text {sample }}}{\left({ }^{234} U /{ }^{238} U\right)_{\text {equilibrium }}}\right]-1\right) \times 1000
$$

Equation 1:

where $\left({ }^{234} \mathrm{U} /{ }^{238} \mathrm{U}\right)_{\text {equilibrium }}=1$. Results are reported in delta notation.

\section{$2.7 \quad{ }^{87} \mathrm{Sr} /{ }^{86} \mathrm{Sr}$ analysis}

Strontium isotope measurements were made on the dissolved and particulate load time series samples, as well as the fjord, downstream transect, and seawater digestion samples. Before strontium isotope measurements, samples were first purified to remove matrix ions using Sr Spec resin (Eichrom 100-150 $\mu \mathrm{m}$ ). The resin was first cleaned by rinsing three times with Milli-Q $\mathrm{H}_{2} \mathrm{O}$, three times with $6 \mathrm{~N} H N O_{3}$, and again five times with Milli-Q $\mathrm{H}_{2} \mathrm{O}$. Samples were brought to dryness on a hotplate before $100 \mu \mathrm{L}$ of concentrated $\mathrm{HNO}_{3}$ were added to the samples three 
times, bringing samples to dryness between acid additions. Dried samples were then reconstituted with $3 \mathrm{~mL}$ of $6 \mathrm{~N} \mathrm{HNO}_{3}$ while vials were still hot. Columns were slurry-packed under gentle vacuum with $200 \mu \mathrm{L}$ of free-column volume of the cleaned Sr Spec resin. Prior to loading samples, the resin was rinsed with three additions of $200 \mu \mathrm{L}$ of $6 \mathrm{~N} \mathrm{HNO}_{3}$. Re-suspended samples were next pulled through the resin under very gentle vacuum in $>20$ minutes. To remove $\mathrm{Rb}$ and other matrix ions, samples were cleaned on the column using five $1 \mathrm{~mL}$ rinses of $6 \mathrm{~N}$ $\mathrm{HNO}_{3}$. The suspended sediment digestion samples required ten $1 \mathrm{~mL}$ rinses of $6 \mathrm{~N} \mathrm{HNO}_{3}$ to remove $\mathrm{Rb}$ from the matrix. Finally, samples were eluted with $3 \mathrm{~mL}$ of Milli- $\mathrm{Q} \mathrm{H}_{2} \mathrm{O}$ added in $0.5 \mathrm{~mL}$ increments. Samples were then dried and reconstituted with $5 \% \mathrm{HNO}_{3}$ for isotope analysis.

Samples were analyzed on a Thermo Scientific Neptune MC-ICPMS by static measurement of ${ }^{82} \mathrm{Kr},{ }^{83} \mathrm{Kr},{ }^{84} \mathrm{Sr},{ }^{85} \mathrm{Rb},{ }^{86} \mathrm{Sr},{ }^{87} \mathrm{Sr}$, and ${ }^{88} \mathrm{Sr}$. The raw ${ }^{87} \mathrm{Sr} /{ }^{86} \mathrm{Sr}$ values were corrected for instrumental mass bias using a power law. Raw values were also corrected for ${ }^{86} \mathrm{Kr}$ and ${ }^{87} \mathrm{Rb}$ interferences. Sample results were then normalized to the standard reference material SRM 987 (US National Institute of Standards and Technology), which was analyzed every six samples. The certified value of this standard is ${ }^{87} \mathrm{Sr} /{ }^{86} \mathrm{Sr}=0.710240$ while the average ${ }^{87} \mathrm{Sr} /{ }^{86} \mathrm{Sr}$ value I measured was 0.710256. $(\mathrm{n}=15,1$ s.d. $=0.000025)$.

\section{$3 \quad$ Results}

\subsection{River discharge and $\mathrm{pH}$}

Results of river discharge have been described previously in Chapter 1 and 2. pH was measured in the proglacial river from May $12^{\text {th }}$-June $21^{\text {st }}$ (days 132-172) in 2011 (Table 2). pH 
varied between 8 and 7.1 until day 160 when $\mathrm{pH}$ sharply increased to $\mathrm{pH}=9$. Following this increase, $\mathrm{pH}$ slowly dropped until day 172.

\subsection{Dissolved major and trace metals results}

Hydrochemistry results for dissolved species discharging Leverett Glacier are summarized in Table 3. During the 2012 field season, concentrations of dissolved species were generally elevated in the early melt season while discharge was $<10 \mathrm{~m}^{3} / \mathrm{s}$ and decreased with increasing discharge. For example, Sr concentration was $257 \mathrm{nmol} / \mathrm{L}$ on May $14^{\text {th }}, 2012$ (day 135) when discharge was $1 \mathrm{~m}^{3} / \mathrm{s}$ and decreased to $47 \mathrm{nmol} / \mathrm{L}$ by June $12^{\text {th }}, 2012$ (day 164) when

discharge was $75 \mathrm{~m}^{3} / \mathrm{s}$ (Figure 3). Concentrations of some elements ( $\mathrm{Mg}, \mathrm{K}, \mathrm{Rb}, \mathrm{Sr}, \mathrm{Ba}, \mathrm{Mn}, \mathrm{Fe}$, and Co) increased following the major meltwater runoff event between days 190-194 (Chapters 1 and 2). For example, Co concentrations were typically $\sim 3 \mathrm{nmol} / \mathrm{L}$ before July 21 (day 190) when concentrations increased to $32 \mathrm{nmol} / \mathrm{L}$ (Table 3). Uranium concentrations were highest on the first day of sampling at $1.6 \mathrm{nmol} / \mathrm{L}$ on May $14^{\text {th }}$ (day 135) and decreased rapidly to $0.1 \mathrm{nmol} / \mathrm{L}$ by May $23^{\text {rd }}$ (day 143). Uranium concentrations remained between $0.1-0.4 \mathrm{nmol} / \mathrm{L}$ for the remainder of the sampling period. Strontium concentrations were also highest in the first samples collected (up to $257 \mathrm{nmol} / \mathrm{L}$ ) and decreased steadily over the next several weeks as discharge increased. Elemental concentrations of samples collected along the transect moving downstream from the GrIS are summarized in Table 4. In general, concentrations of major cations and trace elements decreased with distance from the glacier's front suggesting removal associated with SSL settling or dilution during mixing with other proglacial rivers. Site 5, however, which was located in freshwater zone of the fjord, yielded higher concentrations of most elements than the glacial meltwater. 
Elemental concentrations in the delayed filtering samples varied between filtering time points, though no trend was detected for any elements with increased time between sampling and filtering (Table 5). Of particular relevance to this chapter, changes in $\mathrm{U}$ and $\mathrm{Sr}$ concentrations were smaller than the analytical errors of the method so it is difficult to determine if concentrations increased or decreased (Table 1; Figure 4).

For elemental concentrations of samples collected from the fjord (Table 5), I assumed that $\mathrm{Na}$ was mixing conservatively in the saltwater-freshwater mixing zone and is likely a better indicator of salinity than the EC probe used to measure conductivity. Elements that behaved conservatively relative to $\mathrm{Na}$ through the saltwater-freshwater mixing zone included $\mathrm{Ca}, \mathrm{Mg}, \mathrm{Li}$, $\mathrm{Rb}, \mathrm{Sr}, \mathrm{U}$, and As. Elements that did not behave conservatively include $\mathrm{K}$ and $\mathrm{Mn}$, which increased markedly at the second sampling point, and then decreased as salinity increased further into the freshwater-saltwater mixing zone.

\subsection{Results of acetic acid digestion of the suspended sediment load}

Results of the acetic acid digestion are summarized in Table 6. No temporal trend was found with any element for this digestion. Predictably, the acetic acid digestion resulted in high $\mathrm{Ca}, \mathrm{Mg}$, and $\mathrm{K}$ concentrations and low or below detection limit concentrations of Na. Figure 5 of the molar ratios of $\mathrm{Mg} / \mathrm{Na}$ vs. $\mathrm{Ca} / \mathrm{Na}$ shows that the acetic acid digestion samples plot near the average composition of rivers draining watersheds with carbonate bedrock.

\section{$3.4 \quad{ }^{228} \mathrm{Ra}$ and ${ }^{226} \mathrm{Ra}$ results}

Radium isotope results are summarized in Table 10 and Figure 6 . The activity of Ra increased from 2 to $9 \mathrm{dpm} / 100 \mathrm{~L}$ for ${ }^{226} \mathrm{Ra}$ and from 30 to $140 \mathrm{dpm} / 100 \mathrm{~L}$ for ${ }^{228} \mathrm{Ra}$ at the onset of 
increased summer river discharge (May $8^{\text {th }}$, day 159; Figure 6). Following this large increase in Ra activities, Ra decreased linearly over the remainder of the sampling period, returning to activities in late July that were observed in May. The activity ratio of $\left({ }^{228} \mathrm{Ra} /{ }^{226} \mathrm{Ra}\right)$ was between $14-15$ in the early melt season before river discharge began to increase. Then, the $\left({ }^{228} \mathrm{Ra}{ }^{226} \mathrm{Ra}\right)$ ratio increased to 17 at the onset of the rise in river discharge, followed by a linear decrease to a value of 5 by July $30^{\text {th }}$ (day 212). The trend in Ra activities observed in the river largely follows changes in the $\mathrm{pH}$ of the proglacial river, though $\mathrm{pH}$ sampling coverage is limited to the early melt season.

\section{$3.5 \quad \delta^{234} U$ results}

Results from the $\delta^{234} \mathrm{U}$ and $\mathrm{U}$ concentration analyses of the time series meltwater samples are summarized in Table 3 and are displayed in Figure 7. The $\delta^{234} \mathrm{U}$ values varied between 43$106 \%$ while the mean value of all samples from the Leverett Glacier proglacial river was 62 . During the early melt season when river discharge was $<10 \mathrm{~m}^{3} / \mathrm{s}, \delta^{234} \mathrm{U}$ values of the glacial meltwater slowly decreased from $76 \%$ to $45 \%$ until May $28^{\text {th }}$ (day 149 ) when both $\delta^{234} U$ and discharge from the proglacial river began increasing (Figure 7). Shortly after the onset of summer melting and rising river discharge, $\delta^{234} \mathrm{U}$ reached a seasonal maximum of $106 \%$ on May $31^{\text {st }}$ (day 153). Following this, the $\delta^{234} U$ oscillated between $\delta^{234} U=51-82 \%$, with a second maximum was reached on July $17^{\text {th }}$ (day $199 ; \delta^{234} U=82 \%$ ). This second peak in $\delta^{234} \mathrm{U}$ occurred after the major melting event that occurred between days 190-194 that resulted in the seasonal maximum river discharge (Figure 7). No relationship was found between 1/U concentrations and $\delta^{234} U$ of the glacial meltwater. Furthermore, no relationships were found between $\delta^{234} U$ and any

other constituent measured in the glacial meltwater, including ${ }^{87} \mathrm{Sr} /{ }^{86} \mathrm{Sr}$. The exception was in the 
samples collected along a downstream transect moving away from the GrIS. In these samples ${ }^{87} \mathrm{Sr} /{ }^{86} \mathrm{Sr}$ and $\delta^{234} \mathrm{U}$ were strongly correlated $\left(\mathrm{r}^{2}=0.94, \mathrm{n}=4\right.$; Figure 8$)$.

Results from the sampling transect (Figure 1) are shown in Table 4 and Figure 8. A sample collected at the glacier's terminus at 7:00 on May $28^{\text {th }}$ (day 149) had $\delta^{234} U$ value of 63. One mile downstream the $\delta^{234} U$ value was $61 \%$ at 10:00. A third sample was taken from the proglacial river of Russell Glacier, which is adjacent to Leverett Glacier. This sample, which was collected $2 \mathrm{~km}$ downstream from the Russell Glacier terminus, yielded a $\delta^{234} \mathrm{U}$ value of $30 \%$. A fourth sample was taken in at 16:15 on May $28^{\text {th }}$ in the town of Kangerlussuaq where the Watson River drains into the fjord. The Watson River, which is fed by four glacial rivers including Russell and Leverett, had a $\delta^{234} U$ value of $33 \%$. Finally, a freshwater sample was taken from the fjord on June $17^{\text {th }}$ (day 169) and had the lowest $\delta^{234} U$ value observed in this study $\left(\delta^{234} U=15 \%\right.$ ). By contrast, a sample taken the day before (day 168) from Leverett River had a $\delta^{234} U$ value of $62 \%$. Samples collected from the fjord showed conservative mixing between glacial meltwater and seawater at least within the constraints of the analytical precision for U concentration (Figure 7).

Results of the delayed filtering experiment are shown in Table 5 and Figure 4. This experiment demonstrated that the $\delta^{234} U$ value of glacial meltwater decreased from $\delta^{234} U=81 \%$ o to $21 \%$ between the initial sample filtered immediately upon collection and the sample collected at the same time but filtered 18 days later. The $U$ concentrations between sampling points were overlapping within uncertainty and so at this time it is impossible to determine if there was an effect on concentration. This experiment was repeated with on July $24^{\text {th }}$ (day 206) when two samples were collected and one was filtered six days later. This experiment also resulted in a 
decrease in the $\delta^{234} \mathrm{U}$ value, this time from $53 \%$ to $31 \%$ and no apparent change in $\mathrm{U}$ concentration.

\section{6 $\quad{ }^{87} \mathrm{Sr} /{ }^{86} \mathrm{Sr}$ results}

The strontium isotope results for the dissolved time series samples collected in the Leverett Glacier proglacial river are summarized in Table 3 and Figure 3 . The ${ }^{87} \mathrm{Sr} r{ }^{86} \mathrm{Sr}$ ratio decreased gradually from 0.7513 to 0.7340 from May $14^{\text {th }}-$ July $6^{\text {th }}$ (days 134-188). A second peak in the ${ }^{87} \mathrm{Sr} /{ }^{86} \mathrm{Sr}$ ratio was observed during the major meltwater runoff event (Chapters 1 and 2) during which the ${ }^{87} \mathrm{Sr} /{ }^{86} \mathrm{Sr}$ ratio increased from 0.7340 to 0.7439 . The ${ }^{87} \mathrm{Sr} /{ }^{86} \mathrm{Sr}$ ratio of dissolved glacial runoff samples is positively correlated to the molar ratios of $\mathrm{Ca} / \mathrm{Na}\left(\mathrm{r}^{2}=0.74\right)$, $\mathrm{Ca} / \mathrm{Mg}\left(\mathrm{r}^{2}=0.52\right), \mathrm{Ca} / \mathrm{Sr}\left(\mathrm{r}^{2}=0.36\right)$, and negatively correlated to $\mathrm{Na} / \mathrm{Sr}\left(\mathrm{r}^{2}=0.43\right)$. With each of these relationships, early season samples collected prior to May $31^{\text {st }}$ (day 152) are separated from samples collected after May $31^{\text {st }}$ as they are more radiogenic and have higher $\mathrm{Ca} / \mathrm{Na}$ and $\mathrm{Sr} / \mathrm{Na}$ ratios than samples collected later in the season. In contrast, Hindshaw et al. (2014) who also measured ${ }^{87} \mathrm{Sr} r{ }^{86} \mathrm{Sr}$ ratios and elemental concentrations in the Leverett Glacier proglacial river, observed a positive trend between ${ }^{87} \mathrm{Sr} /{ }^{86} \mathrm{Sr}$ and $\mathrm{Na} / \mathrm{Sr}$ ratio but no temporal variation in the $\mathrm{Ca} / \mathrm{Sr}$ ratio in the same catchment. However, Hindshaw et al. (2014) began sampling only after river discharge reached $>100 \mathrm{~m}^{3} / \mathrm{s}$ and sampled for one month. Hence, their study only covers a period of time when channelized drainage dominated the subglacial hydrology as opposed to this study that covers periods of distributed and channelized system drainage ${ }^{87} \mathrm{Sr} /{ }^{86} \mathrm{Sr}$ results of the samples collected along a transect moving downstream from the GrIS (Figure 1) are shown on Figure 8 and Table 4. Similar to the $\delta^{234} \mathrm{U}$ results, the ${ }^{87} \mathrm{Sr} /{ }^{86} \mathrm{Sr}$ ratio decreased with distance from the ice sheet margin. The ${ }^{87} \mathrm{Sr} r{ }^{86} \mathrm{Sr}$ ratio at Site 2 was 0.7558 while at Site 5 this ratio decreased 
to 0.7359 . The ${ }^{87} \mathrm{Sr} /{ }^{86} \mathrm{Sr}$ ratio and $\delta^{234} \mathrm{U}$ values of the transect samples were strongly correlated (Figure 8). Results of the effect of the delayed filtering experiments on the ${ }^{87} \mathrm{Sr} /{ }^{86} \mathrm{Sr}$ ratio are shown on Figure 4 and Table 5. Between the sample filtered after 0.25 days and last time point filtered at 18.3 days, the ${ }^{87} \mathrm{Sr} /{ }^{86} \mathrm{Sr}$ ratio increased from 0.7400 to 0.7460 . A second sample that was collected on 7/24/12 and filtered 0 and 6 days after collection varied from 0.7358 to 0.7355 .

Strontium isotopes measured on the acetic acid digestion samples yielded ratios between ${ }^{87} \mathrm{Sr} /{ }^{86} \mathrm{Sr}=0.7406-0.7522$ and averaged 0.7471 (Table 6; Figure 3). These samples showed similar temporal changes as the dissolved samples and, with the exception of two early season samples, all the acetic acid digestion samples had higher ${ }^{87} \mathrm{Sr} /{ }^{86} \mathrm{Sr}$ ratios than their counterpart dissolved phase (Figure 3). In the two early season acetic acid digestion samples that had lower ${ }^{87} \mathrm{Sr} /{ }^{86} \mathrm{Sr}$ values than their dissolved counterparts, the ratio was only slightly lower ( 0.7488 to 0.7513 and 0.7522 to 0.7530$)$. In contrast, the total digestion samples had ${ }^{87} \mathrm{Sr} /{ }^{86} \mathrm{Sr}$ values that were significantly lower and ranged between $0.7153-0.7218$ with a mean value of $0.7170(n=14)$. The total digestion samples showed a slight decrease in the ${ }^{87} \mathrm{Sr} /{ }^{86} \mathrm{Sr}$ ratio with time, though not as large of a decrease as was observed in the dissolved samples, or the acetic acid digestion samples. These values are similar to observations made by Hindshaw et al. (2014) for bulk rock digestions of pink and grey orthogneiss, amphibolite, and garnet amphibolites samples collected near Leverett Glacier.

\section{$4 \quad$ Discussion}

\subsection{Hydrogeochemistry of meltwaters}

The discharge weighted mean of dissolved $U$ concentrations in the Leverett Glacier proglacial river was $0.13 \mathrm{nmol} / \mathrm{L}$, notably higher than $\mathrm{U}$ concentrations reported from proglacial 
rivers in basaltic watersheds in Iceland (0.0001-0.009 nmol/L; von Standmann et al., 2006). The $\mathrm{U}$ concentrations measured in the Leverett Glacier proglacial river were similar to average river waters (0.78 nmol/L; Palmer and Edmond, 1993). Dissolved Sr concentrations in the Leverett Glacier proglacial river were lower than most river systems (typically between 300 and 1000 nmol/L; Goldstein and Jacobsen, 1987) though concentrations were similar to those previously reported for Leverett Glacier (Hindshaw et al., 2014).

The molar ratios of $\mathrm{Ca} / \mathrm{Na}, \mathrm{Sr} / \mathrm{Na}$, and $\mathrm{Mg} / \mathrm{Na}$ of dissolved solutes in rivers can be used to help determine the lithologies rivers drain (Gaillardet et al., 1999). Figure 5 shows the Na normalized molar ratios of $\mathrm{Ca} / \mathrm{Na}, \mathrm{Sr} / \mathrm{Na}$, and $\mathrm{Mg} / \mathrm{Na}$ of the dissolved load and suspended sediment digestions from Leverett Glacier. For comparison, the typical geochemical composition of rivers draining watersheds dominated by basaltic, silicate, and carbonate bedrock as well as seawater are also plotted (Gaillardet et al., 1999). Unsurprisingly, the acetic acid digestion samples plot near carbonate-dominated watersheds while the total digestions samples plot near silicate dominated watersheds. There was a strong correlation between the molar ratios of $\mathrm{Ca} / \mathrm{Na}$ and $\mathrm{Sr} / \mathrm{Na}$ in the dissolved load $\left(\mathrm{r}^{2}=0.86\right)$ that was likely caused by mixing between end members and by the similar geochemical behavior of $\mathrm{Ca}$ and $\mathrm{Sr}$ (Figure 5).

Hydrologically, the glacial meltwater can be divided into two periods: early season distributed system drainage (prior to May $28^{\text {th }}$; day 149), and mid-season channelized drainage (after May 28 ${ }^{\text {th }}$, day 149). Day 149 corresponds to the onset of melting across the glacier's catchment (Chapter 2) and is likely when subglacial channels first began to dominate subglacial flow paths. This transition was seen geochemically: $\mathrm{Ca}$ is the most common cation in the glacial meltwater until day 149 while following this day, $\mathrm{Na}$ had the highest concentration (Figure 9; Table 3). Throughout the sampling period, $\mathrm{K}$ always has the third highest concentration followed 
by $\mathrm{Mg}$ (Table 3). This result is in contrast to most proglacial rivers where the abundance of cation concentrations is in order of decreasing concentration $\mathrm{Ca}, \mathrm{K}, \mathrm{Na}$, and $\mathrm{Mg}$ regardless of bedrock composition or time of sampling (Anderson et al., 2007). This is because calcite dissolution rates are $\sim 6$ orders of magnitude greater than rates measured for silicate minerals at pH conditions observed in natural waters (Plummer et al., 1979), and high rates of physical weathering in glacial watersheds continually exposes trace calcite minerals (Anderson et al., 2007). High $\mathrm{K}$ is observed because of enhanced release of interlayer cations from minerals such as chlorite and biotite during glacial grinding (Blum and Erel, 1995; Anderson et al., 1997). The molar ratios of $\mathrm{Ca} / \mathrm{Na}, \mathrm{Mg} / \mathrm{Na}$, and $\mathrm{Sr} / \mathrm{Na}$ also significantly decrease after day 149 (Figure 9). High $\mathrm{Ca} / \mathrm{Na}, \mathrm{Mg} / \mathrm{Na}$ and $\mathrm{Sr} / \mathrm{Na}$ are observed in the early season suggesting carbonate mineral phases are predominately weathered during this time or during the preceding winter. Following the onset of channelization, contributions from silicate mineral weathering likely become more important as evidenced by the increasing proportion of $\mathrm{Na}$ to other cations. Alternatively, new subglacial flow paths through regions dominated by silicate weathering could have opened. Based on my results and those of Hindshaw et al. (2014), minerals that are likely important contributors to the dissolved load during mid-season melting are chorite, biotite, hornblende, and plagioclase.

\subsection{Radium isotopes}

Radium-226 $\left(\mathrm{t}_{1 / 2}=1600 \mathrm{y}\right)$ and ${ }^{228} \mathrm{Ra}\left(\mathrm{t}_{1 / 2}=5.75 \mathrm{y}\right)$ have the same chemical behavior but different half-lives. In most surface and groundwater systems $\left({ }^{228} \mathrm{Ra} /{ }^{226} \mathrm{Ra}\right)$ is near 1 and largely reflects the activity ratio of the long-lived parent isotopes $\left({ }^{232} \mathrm{Th} /{ }^{238} \mathrm{U}\right)$ in the source rocks within the watershed (Moore and Edmond, 1984; Moore, 1967; Bhat and Krishnaswami, 1969; Sarin et 
al., 1990). By contrast, in the Leverett Glacier proglacial river, the $\left({ }^{228} \mathrm{Ra} /{ }^{226} \mathrm{Ra}\right)$ is $>10$ while $\left({ }^{228} \mathrm{Ra}{ }^{226} \mathrm{Ra}\right.$ ) measured in the suspended sediment sample was 2.1 (Table 10$)$. Consequently, unless the SSL does not represent the source material for Ra, the high $\left({ }^{228} \mathrm{Ra} /{ }^{226} \mathrm{Ra}\right)$ values in the dissolved load do not reflect the bedrock source. High $\left({ }^{228} \mathrm{Ra} /{ }^{226} \mathrm{Ra}\right)$ have also been observed in tidal marshes and in coastal aquifers where sediments are continually flushed with seawater (Charette 2007; Gonneea et al., 2008). Similarly, subglacial sediments are likely continually flushed with meltwater that weathers Ra from the source rock material for the high $\left({ }^{228} \mathrm{Ra} /{ }^{226} \mathrm{Ra}\right)$ to become established. This process would result in surface available ${ }^{228} \mathrm{Ra}$ being significantly higher than ${ }^{226} \mathrm{Ra}$ in the Leverett Glacier watershed, a result of the faster ingrowth rate of ${ }^{228} \mathrm{Ra}$ relative to ${ }^{226} \mathrm{Ra}$. A mechanism for this flushing is likely the diurnal changes in surface meltwater inputs that drive meltwater exchange between the distributed and channelized systems (Gulley et al., 2009; Werder et al., 2013). Larger meltwater runoff events, such as supraglacial lake drainages, also likely flush the distributed system with meltwater. This high degree of weathering with respect to Ra isotopes is in contrast to conventional understanding of subglacial sediments consisting of un-weathered mineral surfaces (e.g. Anderson, 2007).

Also unusual about $\mathrm{Ra}$ within the glacial catchment is that in most rivers the ${ }^{226} \mathrm{Ra}$ and ${ }^{228} \mathrm{Ra}$ activities are generally between of 4-10 dpm/100 L (Moore and Edmond, 1984; Moore, 1967; Bhat and Krishnaswami, 1969; Sarin et al., 1990). However, in the glacial meltwater, ${ }^{228} \mathrm{Ra}$ activities are notably higher. For a short period when discharge starts rising as the ice sheet surface begins melting, ${ }^{228} \mathrm{Ra}$ activities reach values generally only measured in saline groundwater, which can be between 100-600 dpm/100 L (Kelly and Moran, 2002; Charette et al., 2001; Scott and Moran, 2002). Interestingly, during this same period, the $\mathrm{pH}$ also increased significantly (Figure 6) though higher $\mathrm{pH}$ and lower ionic strength should lead to increased 
adsorption of $\mathrm{Ra}$ (Gonneea et al., 2008). In glacial meltwater, high $\mathrm{pH}$ is derived from carbonate and silicate hydrolysis reactions that occur when dilute meltwater first reaches fresh glacial flour (Tranter, 2007). Hence, the observed increase in $\mathrm{pH}$ occurred when meltwater first reached the ice sheet bed. The simultaneous increase in ${ }^{226} \mathrm{Ra}$ and ${ }^{228} \mathrm{Ra}$ activities suggests an expanded source of radium. While freshly exposed subglacial rock material would impart a $\left({ }^{228} \mathrm{Ra}{ }^{226} \mathrm{Ra}\right)$ ratio similar to the source material (the the SSL had a $\left({ }^{228} \mathrm{Ra} /{ }^{226} \mathrm{Ra}\right.$ ) ratio $\sim 2$ ), it is clear from the high $\left({ }^{228} \mathrm{Ra} /{ }^{226} \mathrm{Ra}\right)$ ratio observed during this period that the majority of Ra must come from previously weathered material. The subsequent decrease in Ra activities over the melt season may be due to increased channel efficiency and shorter water-rock interactions. The gradual decrease in the $\left({ }^{228} \mathrm{Ra} /{ }^{226} \mathrm{Ra}\right.$ ) ratio over the melt season (Figure 6) is likely due to increased exposure to freshly weathered mineral surfaces.

\subsection{Potential impact of colloids on dissolved ${ }^{87} \mathrm{Sr}{ }^{86} \mathrm{Sr}$ and $\delta^{234} \mathrm{U}$}

Hawkings et al. (2014) found significantly lower Fe concentrations between samples filtered to $0.45 \mu \mathrm{m}$ and to $0.02 \mu \mathrm{m}$ from the Leverett Glacier proglacial river. This was evidence that colloids were a significant component of dissolved Fe. Hence, sub $0.45 \mu \mathrm{m}$ particles could impact the $\mathrm{Sr}$ and $\mathrm{U}$ isotope results in this study. For example, the unusually low $\delta^{234} \mathrm{U}$ values measured in the dissolved load could be the result of colloids with a similar isotopic signature to the particulate load, which likely had $\delta^{234} U$ composition at or below secular equilibrium. Butler (2014) analyzed the size distribution of the SSL of the Leverett Glacier proglacial river using a Malvern Mastersizer, and found that $0.27 \%$ ( $\operatorname{stdev}=0.008 \%, \mathrm{n}=3$ ) of the SSL was $<0.45 \mu \mathrm{m}$. Using this result, I calculated the potential impact sub $0.45 \mu \mathrm{m}$ particles could have on the $\delta^{234} \mathrm{U}$ and ${ }^{87} \mathrm{Sr} r{ }^{86} \mathrm{Sr}$ results. For this calculation, I assumed that the mean $\mathrm{U}$ and $\mathrm{Sr}$ concentrations 
$(\mathrm{U}=0.8 \mu \mathrm{g} / \mathrm{g}, \mathrm{stdev}=0.2 \mu \mathrm{g} / \mathrm{g}, \mathrm{n}=17 ; \mathrm{Sr}=326 \mu \mathrm{g} / \mathrm{g}, \mathrm{stdev}=157, \mathrm{n}=17)$ and isotopic composition $\left({ }^{87} \mathrm{Sr} /{ }^{86} \mathrm{Sr}=0.7172\right.$, stdev $\left.=0.002, \mathrm{n}=10\right)$ from the total SSL digestions is representative of the sub $0.45 \mu \mathrm{m}$ particulate size fraction. For the $\delta^{234} U$ values of the SSL, I assumed a low $\delta^{234} U$ value of $-100 \%$. Using the mean $U$ concentration $(0.3 \mathrm{nmol} / \mathrm{L})$ and isotopic composition $\left(\delta^{234} \mathrm{U}=61 \%\right.$ of the dissolved load, and the average SSL concentration (1g/L; Hawkings et al., 2014), then true dissolved $\delta^{234} \mathrm{U}$ would be $66 \%$ if the measured value was $61 \%$. Repeating this exercise for $\mathrm{Sr}$ using a mean $\mathrm{Sr}$ concentrations of $82 \mathrm{nmol} / \mathrm{L}$ and isotopic ratio of ${ }^{87} \mathrm{Sr} /{ }^{86} \mathrm{Sr}=0.7451$ in the dissolved load, then the truly dissolved ${ }^{87} \mathrm{Sr} /{ }^{86} \mathrm{Sr}$ ratio would be 0.7488 if $0.27 \%$ of the SSL passed the filter (Figure 10). Based on these analyses, there was likely minimal impact of sub $0.45 \mu \mathrm{m}$ size particles on the $\mathrm{U}$ and $\mathrm{Sr}$ isotopic measurements made in this study.

\section{$4.4 \quad$ Uranium isotopes}

The glacial meltwater samples have $\delta^{234} U$ values that are notably lower than seawater $\left(\delta^{234} U=147 \%\right.$; Andersen et al., 2010), and they are more similar to watersheds with high rainfall and weathering than regions of high physical weathering (Robinson et al., 2004). Because glaciation causes high rates of physical weathering and produces abundant fresh mineral surfaces (Anderson et al., 2007), it seems likely that meltwater draining the GrIS would have extremely high $\delta^{234} U$ values. For comparison, several other glacial systems have been analyzed for $\delta^{234} U$ isotopes. A glacial meltwater sample collected in the dry values of Antarctica had $\delta^{234} U$ identical to seawater, which was taken as evidence that the $\mathrm{U}$ was derived from seawater (Henderson et al., 2006). This glacial meltwater in Antarctica differed from Leverett Glacier as meltwater runoff was much smaller and therefore extensive subglacial hydrological networks did not exist. von Strandmann et al. (2006) measured $\delta^{234} U$ in several glacial systems in basaltic terrain in Iceland. 
Relatively high $\delta^{234} U$ values were found in glacially fed rivers and ranged from $\delta^{234} U=130$ $1170 \%$. However, the glaciers measured in this study were smaller than Leverett Glacier and discharge from these glaciers was $<1 / 3$ of typical summer flows from Leverett Glacier.

As weathering of carbonates is an important source of solutes in all glacial watersheds regardless of bedrock type, this potential source of $U$ should be considered (Anderson et al., 2007). It would be expected that any trace carbonates found within the watershed would have $\delta^{234} U$ values at or near secular equilibrium and therefore could result in the low $\delta^{234} U$ values observed in the glacial river. However, there was no correlation between $\delta^{234} \mathrm{U}$ and the molar ratios of $\mathrm{Ca} / \mathrm{Na}$ or $\mathrm{Mg} / \mathrm{Na}$ in the time series or transect samples. Furthermore, the $\mathrm{Ca} / \mathrm{Na}$ molar ratio changed markedly from early to mid season samples (Figure 3) suggesting a shift in the influence of carbonate weathering, $\delta^{234} \mathrm{U}$ values in the time series samples did not vary substantially over the melt season. Further analysis of the acetic acid digest would be required to test this hypothesis.

Two lines of evidence suggest that the SSL has been depleted in ${ }^{234} \mathrm{U}$ beneath the GrIS. First, the $\delta^{234} \mathrm{U}$ value of river water decreased moving away from the GrIS (Figure 8). The lowest $\delta^{234} \mathrm{U}$ value measured in this study was in the freshwater zone of the downstream fjord. This suggests that proglacial sediments rapidly weather moving downstream from the ice sheet terminus similar to the findings of Vigier et al. (2001). These results imply that with increasing mineral weathering the glacial meltwater acquires lower $\delta^{234} U$. Second, the delayed filtering experiment found that with increasing time between sampling and filtering, the $\delta^{234} U$ value of the glacial meltwater decreased (Figure 4). This result can be explained by either two hypotheses. First, it is possible that with increasing time, more sub $0.45 \mu \mathrm{m}$ suspended sediment aggregates may form and therefore less sediment may pass through the filter over time. As sediment 
disaggregation is usually slower than aggregation in low energy environments (like the sample bottles) and occurs rapidly (Lick and Lick, 1988), the SSL would have had to have a $\delta{ }^{234} U$ value greater than the dissolved load for this hypothesis to be true. As it is highly unlikely that the $\delta^{234} \mathrm{U}$ value of the SSL is higher than the dissolved load, I discount this hypothesis. Furthermore, if sediment aggregation was preventing more and more of the sub $0.45 \mu \mathrm{m}$ particles from passing through the filter, I would expect non-conservative mixing between $U$ concentrations and $\delta^{234} U$ in the downstream fjord where sediment flocculation is occurring. In contrast, $U$ mixing in the fjord appears to be conservative (Figure 7).

A second hypothesis is that the suspended sediments are a source of relatively low $\delta^{234} \mathrm{U}$ and with increased time and water-rock interactions the dissolved load acquires a lower $\delta^{234} U$ value. Other watersheds with very low $\delta^{234} U$ in the dissolved phase generally have extensive rainfall where the more easily weathered ${ }^{234} \mathrm{U}$ has been stripped from sediments (Robinson et al., 2004). Sediments beneath the GrIS are subjected to extensive meltwater flushing as summertime surface meltwater inputs drive pressure changes in subglacial channels that force water in and out of distributed system drainage networks (Gulley et al., 2009; Werder et al., 2013). This process likely acts to strip the more easily weathered ${ }^{234} \mathrm{U}$ from minerals surfaces similar to watersheds with high rainfall. The $\delta^{234} \mathrm{U}$ results are therefore similar to the observed $\left({ }^{228} \mathrm{Ra} /{ }^{226} \mathrm{Ra}\right)$ ratio in the glacial watershed, whereby extensive sediment flushing has depleted Ra from sediments allowing the faster ingrowth rate of ${ }^{228} \mathrm{Ra}$ to raise the $\left({ }^{228} \mathrm{Ra} /{ }^{226} \mathrm{Ra}\right)$ ratio.

Coral records show that during the last ice age, the ocean's $\delta^{234} U$ value may have been $\sim 10 \%$ lower than modern seawater (Figure 11; Yokoyama et al., 2004). If the GrIS is an analog to continental ice sheets during the last ice age, then meltwater may have provided a forcing mechanism for the observed drop in seawater $\delta^{234} U$. My results imply that at that the onset of 
glaciation, ${ }^{234} \mathrm{U}$ is weathered from sediments while once ice sheets are established glaciation may be a source of low $\delta^{234} \mathrm{U}$ to the ocean.

\subsection{Strontium isotopes}

Over the sampling period, the ${ }^{87} \mathrm{Sr} /{ }^{86} \mathrm{Sr}$ ratio in the dissolved load gradually decreased, with the exception of a slight increase that occurred following the massive meltwater runoff event in July 2012 (Chapter 1 and 2). The ${ }^{87} \mathrm{Sr} /{ }^{86} \mathrm{Sr}$ ratio is positively correlated to the molar ratios of $\mathrm{Ca} / \mathrm{Na}\left(\mathrm{r}^{2}=0.74\right), \mathrm{Ca} / \mathrm{Mg}\left(\mathrm{r}^{2}=0.52\right), \mathrm{Ca} / \mathrm{Sr}\left(\mathrm{r}^{2}=0.36\right)$, and negatively correlated to $\mathrm{Na} / \mathrm{Sr}$ $\left(\mathrm{r}^{2}=0.43\right.$; Figure 12). These findings suggest that a Ca-bearing mineral phase is largely controlling the ${ }^{87} \mathrm{Sr} /{ }^{86} \mathrm{Sr}$ ratio in the glacial meltwater. While carbonates are normally assumed to have low ${ }^{87} \mathrm{Sr} /{ }^{86} \mathrm{Sr}$ ratios because of low $\mathrm{Rb}$ concentrations (e.g. Hindshaw et al., 2014), watersheds in the Himalayas and the Fraser River have been found to have radiogenic disseminated calcite veins that control the ${ }^{87} \mathrm{Sr} r{ }^{86} \mathrm{Sr}$ ratio of the dissolved load despite a silicate bedrock (Blum et al, 1998; Jacobson and Blum, 2000; Voss, 2014). The results of the acetic acid digestion clearly show that the trace amounts of carbonate minerals within the SSL contain radiogenic ${ }^{87} \mathrm{Sr} /{ }^{86} \mathrm{Sr}$. Furthermore, Figure 12 showing the molar ratios of $\mathrm{Ca} / \mathrm{Sr}, \mathrm{Na} / \mathrm{Sr}$, and $\mathrm{Ca} / \mathrm{Na}$ vs. ${ }^{87} \mathrm{Sr} /{ }^{86} \mathrm{Sr}$ demonstrates that the carbonate phase likely influences meltwater's ${ }^{87} \mathrm{Sr} /{ }^{86} \mathrm{Sr}$ ratio. Hence, it is likely that the high ${ }^{87} \mathrm{Sr} /{ }^{86} \mathrm{Sr}$ observed in the early season is derived from weathering of radiogenic trace carbonates.

The mid-season decrease in the ${ }^{87} \mathrm{Sr} /{ }^{86} \mathrm{Sr}$ ratio in the glacial meltwater is likely due to increasing contributions from less radiogenic silicate minerals. This is evidenced by the decreasing molar ratios of $\mathrm{Mg} / \mathrm{Na}, \mathrm{Sr} / \mathrm{Na}, \mathrm{Ca} / \mathrm{Na}$, and $\mathrm{Ca} / \mathrm{Sr}$ (Figure 9). In Figure 12, which shows the ${ }^{87} \mathrm{Sr} /{ }^{86} \mathrm{Sr}$ ratio relative to the molar ratios of $\mathrm{Ca} / \mathrm{Sr}, \mathrm{Na} / \mathrm{Sr}$, and $\mathrm{Ca} / \mathrm{Na}$, there is no one 
source with high $\mathrm{Na}, \mathrm{Sr}$, and low ${ }^{87} \mathrm{Sr} /{ }^{86} \mathrm{Sr}$ values that meltwaters appear to be mixing between. For example, while chlorite and hornblende have high $\mathrm{Na} / \mathrm{Sr}$ and low ${ }^{87} \mathrm{Sr} /{ }^{86} \mathrm{Sr}$ ratios, both of these mineral phases have very high $\mathrm{Ca} / \mathrm{Sr}$ and $\mathrm{Ca} / \mathrm{Na}$ molar ratios suggesting they are not important. Instead, incongruent mineral weathering of several silicate minerals, ion exchange, and secondary mineral precipitation may be influencing the molar ratios of the mid-season glacial meltwater samples.

The results of the delayed filtering experiments and the transect samples show contrasting results. While the ${ }^{87} \mathrm{Sr} /{ }^{86} \mathrm{Sr}$ ratio of the delayed filtering samples increased in between filtering time points (Figure 4), the ${ }^{87} \mathrm{Sr} /{ }^{86} \mathrm{Sr}$ ratio of samples collected along the transect moving downstream from the GrIS decreased with distance (Figures 8). This result may suggest that moving away from the ice sheet, contributions from radiogenic carbonates become less important. However, the SSL near the ice sheet terminus still carries enough radiogenic trace carbonate to increase the ${ }^{87} \mathrm{Sr} /{ }^{86} \mathrm{Sr}$ ratio between filtering time points. Downstream, the highly reactive calcite on the surfaces of the SSL particles may become less abundant, increasing the importance of contributions from silicate minerals. This hypothesis is supported by the molar ratios of $\mathrm{Ca} / \mathrm{Na}$, which decreases with decreasing ${ }^{87} \mathrm{Sr} /{ }^{86} \mathrm{Sr}$ in these samples (Table 4).

This study provides an example of radiogenic trace carbonates influencing the ${ }^{87} \mathrm{Sr} /{ }^{86} \mathrm{Sr}$ ratio of a watershed. Furthermore, these results are in contrast to ${ }^{87} \mathrm{Sr} /{ }^{86} \mathrm{Sr}$ ratios in most watersheds where carbonates and silicates are assumed to have low and high ${ }^{87} \mathrm{Sr} /{ }^{86} \mathrm{Sr}$ ratios, respectively (e.g. Raymo and Ruddiman, 1992). Because of the importance of carbonate weathering in subglacial weathering (Anderson, 2007; Tranter, 2007), identifying the ${ }^{87} \mathrm{Sr} /{ }^{86} \mathrm{Sr}$ ratio of the carbonate endmember is essential to determining the controls on Sr isotopes of glacial meltwater. 


\subsection{Chemical index of alteration}

The chemical index of alteration (CIA) was developed by Nesbitt and Young (1982) as a measure of the degree of chemical weathering clastic sediments had undergone. The CIA is based on the assumption that the dominant process during chemical weathering is the degradation of feldspars and the formation of clay minerals:

Equation 2:

$$
\mathrm{CIA}_{\text {molar }}=\mathrm{Al}_{2} \mathrm{O}_{3} /\left(\mathrm{CaO}^{*}+\mathrm{Na}_{2} \mathrm{O}+\mathrm{K}_{2} \mathrm{O}\right)
$$

where $\mathrm{CaO}^{*}$ is the proportion of $\mathrm{CaO}$ not associated with carbonates (Goldberg and Humayun, 2010). In general, glacial sediments and loess have a $\mathrm{CIA}_{\text {molar }}$ ratio of $\sim 1$ while tropical soils have a CIA $A_{\text {molar }}$ ratio of 1-5 (Goldberg and Humayun, 2010). Using values reported for a total digestion of Leverett Glacier proglacial river sediments reported by Hindshaw et al. (2014), I derived a CIA $_{\text {molar }}$ ratio. Using Equation 2, I found that the Leverett Glacier proglacial sediments have a $\mathrm{CIA}_{\text {molar }}$ ratio of 0.8-0.9. While values close to 1 suggest little to no alteration of feldspars to clays, a CIA $A_{\text {molar }}$ ratio $<1$ suggests the presence of carbonates within the sediments (Goldberg and Humayun, 2010). This finding is consistent with the broader results of this study that trace carbonates found in the bedrock may play a role in the subglacial chemical weathering. Hence, the CIA ${ }_{\text {molar }}$ ratio suggests that chemical weathering in the Leverett Glacier watershed may not include extensive feldspar weathering and therefore could be limited to weathering Ra and $\mathrm{U}$ from mineral surfaces.

4.6 Flux of Ra, Sr and U from the Greenland Ice Sheet 
I estimated the $\mathrm{Ra}, \mathrm{Sr}$, and $\mathrm{U}$ fluxes from the GrIS assuming that these fluxes from Leverett Glacier are representative of fluxes from other GrIS outlet glaciers. For these calculations, I assumed a meltwater flux from the GrIS similar to the average annual runoff from the GrIS from 2001-2012 of $438 \mathrm{~km}^{3}$, and discharge weighted mean Ra, Sr, and U concentrations. Using these assumptions, the ${ }^{226} \mathrm{Ra}$ and ${ }^{228} \mathrm{Ra}$ from the GrIS would be $9.2 \times 10^{12}$ $\mathrm{dpm} / \mathrm{y}$ and $1 \times 10^{14} \mathrm{dpm} / \mathrm{y}$ for ${ }^{226} \mathrm{Ra}$ and ${ }^{228} \mathrm{Ra}$ respectively. This flux is likely underestimated by a factor of $2-3$ as $50-90 \%$ of $\mathrm{Ra}$ is likely particle bound and therefore an additional amount of $\mathrm{Ra}$ could desorb from suspended sediments within the fjords (Key et al., 1985; Moore and Scott, 1986; Kraemer and Curwick, 1991). Using a conservative estimate that $50 \%$ of the Ra is particle bound (Key et al., 1985; Moore and Scott, 1986), and the SSL concentration in the water entering the fjord is $0.5 \mathrm{~g} / \mathrm{L}$ (similar to sample collected at Site 5; Figure 1), and using the measured ${ }^{228} \mathrm{Ra}$ and ${ }^{226} \mathrm{Ra}$ activity of the SSL of $1.02 \mathrm{dpm} / \mathrm{g}$ and $0.48 \mathrm{dpm} / \mathrm{g}$ respectively, then the sediment bound Ra flux would be $1.1 \times 10^{14} \mathrm{dpm} / \mathrm{y}$ for ${ }^{228} \mathrm{Ra}$ and $5 \times 10^{13} \mathrm{dpm} / \mathrm{y}$ for ${ }^{226} \mathrm{Ra}$. This suggests that about half of the ${ }^{228} \mathrm{Ra}$ flux is carried by the SSL while twice as much ${ }^{226} \mathrm{Ra}$ is carried by the SSL as the dissolved load. Therefore, the Ra flux from the GrIS is likely within the same order of magnitude as many world rivers including the Mississippi, Ganga and the Brahmaputra (Moore and Edmond, 1984; Moore, 1967; Bhat and Krishnaswamy, 1969; Sarin et al., 1990).

The discharge weighted mean U concentration from Leverett Glacier is $0.13 \mathrm{nmol} / \mathrm{L}$ while the discharge weighted mean isotopic composition is $\delta^{234} U=67$. Using these values, the total $\mathrm{U}$ flux from the GrIS is likely $5.7 \times 10^{4} \mathrm{~mol} / \mathrm{y}$. For comparison, the $\mathrm{U}$ flux from the Mississippi was estimated to be $1.2 \times 10^{6}-1.5 \times 10^{6} \mathrm{~mol} / \mathrm{y}$ (Grzymko et al., 2007), while the global $\mathrm{U}$ flux through all rivers to the ocean was estimated at $42( \pm 14.5) \times 10^{6} \mathrm{~mol} / \mathrm{y}$ (Dunk et al., 2002). 
Hence, the current U flux from the GrIS may not be globally important for the ocean's U budget.

The discharge weighted mean $\mathrm{Sr}$ concentration was $63 \mathrm{nmol} / \mathrm{L}$ while the discharge weighted mean ${ }^{87} \mathrm{Sr} /{ }^{86} \mathrm{Sr}$ ratio was 0.7382 . Assuming these values are representative GrIS meltwater, then the Sr flux from the GrIS is $2.8 \times 10^{7} \mathrm{~mol} / \mathrm{y}$. The global riverine flux of $\mathrm{Sr}$ to the ocean has been estimated at $33 \times 10^{9} \mathrm{~mol} / \mathrm{y}$ (Palmer and Edmond, 1989), hence, the GrIS Sr flux contributes only a small portion of the global Sr input. While the U and Sr fluxes from the GrIS are currently small, following past ice ages, these fluxes were likely much higher (Robinson et al., 2004).

\section{Conclusions}

The silicate rocks within the Leverett Glacier catchment contain trace amounts of carbonates with high $\mathrm{Ca} / \mathrm{Na}, \mathrm{Sr} / \mathrm{Na}$, and ${ }^{87} \mathrm{Sr} /{ }^{86} \mathrm{Sr}$ ratios. In the early melt season during distributed system dominated drainage, the proglacial river derives the majority of its $\mathrm{Sr}$ from weathering carbonates. After the onset of wide scale melting across the catchment, incongruent weathering of silicate minerals causes a shift to lower $\mathrm{Ca} / \mathrm{Na}, \mathrm{Mg} / \mathrm{Na}$, and $\mathrm{Sr} / \mathrm{Na}$ molar ratios and a decrease in the ${ }^{87} \mathrm{Sr} /{ }^{86} \mathrm{Sr}$ in the glacial meltwater. As meltwater moves downstream from the GrIS, the ${ }^{87} \mathrm{Sr} /{ }^{86} \mathrm{Sr}$ ratio becomes less radiogenic likely due to less weathering of radiogenic calcite and increased weathering of silicate minerals. This study provides an example of a watershed where weathering of trace amounts of radiogenic carbonates can strongly influence the ${ }^{87} \mathrm{Sr} /{ }^{86} \mathrm{Sr}$ ratio of a glacial watershed.

The low $\delta^{234} \mathrm{U}$ and high $\left({ }^{228} \mathrm{Ra} /{ }^{226} \mathrm{Ra}\right)$ ratios found in the glacial watershed suggest that the subglacial sediments are extensively washed by glacial meltwater. The U isotope results resemble watersheds in areas of high precipitation where the more easily mobilized ${ }^{234} \mathrm{U}$ has been 
stripped away (Robinson et al., 2004). However, the CIA of proglacial river sediments suggests that chemical weathering may not extend to weathering of feldspars into secondary mineral phases. While weathering of trace carbonates may supply low $\delta^{234} U$ to the dissolved phase, $\delta^{234} U$ did not correlate to $\mathrm{Ca} / \mathrm{Na}$ or $\mathrm{Mg} / \mathrm{Na}$ in the dissolved samples suggesting carbonate weathering is not important in controlling $\delta^{234} \mathrm{U}$ in the Leverett Glacier watershed. Similarly, the Ra results resemble shallow groundwater in tidal marshes where extensive weathering has stripped Ra from sediment surfaces allowing the faster ingrowth rate of ${ }^{228} \mathrm{Ra}$ to increase the $\left({ }^{228} \mathrm{Ra} /{ }^{226} \mathrm{Ra}\right)$ ratio. Both isotope systems suggest subglacial sediments are repeatedly flushed with glacial meltwater and that glacial meltwater. Glacial meltwater from the GrIS is therefore a source of low $\delta^{234} U$ and high $\left({ }^{228} \mathrm{Ra} /{ }^{226} \mathrm{Ra}\right)$ water to the ocean. These results suggest that during the ice ages, ice sheets may provide a forcing mechanism to lower the ocean's $\delta^{234} U$ value.

Future work should focus on the impact of the SSL on the Sr and U isotopic composition of the glacial meltwater. For example, filtering to $0.02 \mu \mathrm{m}$ for $\mathrm{U}$ and $\mathrm{Sr}$ isotopic analysis would reveal the true dissolved $\mathrm{Sr}$ and $\mathrm{U}$ isotopic flux from the GrIS. Furthermore, measuring the $\mathrm{U}$ concentration of the delayed filtering samples using isotope dilution would determine whether $\mathrm{U}$ concentrations increased or decreased between filtering time points. 
Table 1: Results of analysis of certified reference materials. Day 1 samples include the Leverett Glacier Proglacial river, the transect samples, fjord samples and the delayed filtering samples. All sediment digestions were completed during Day 2.

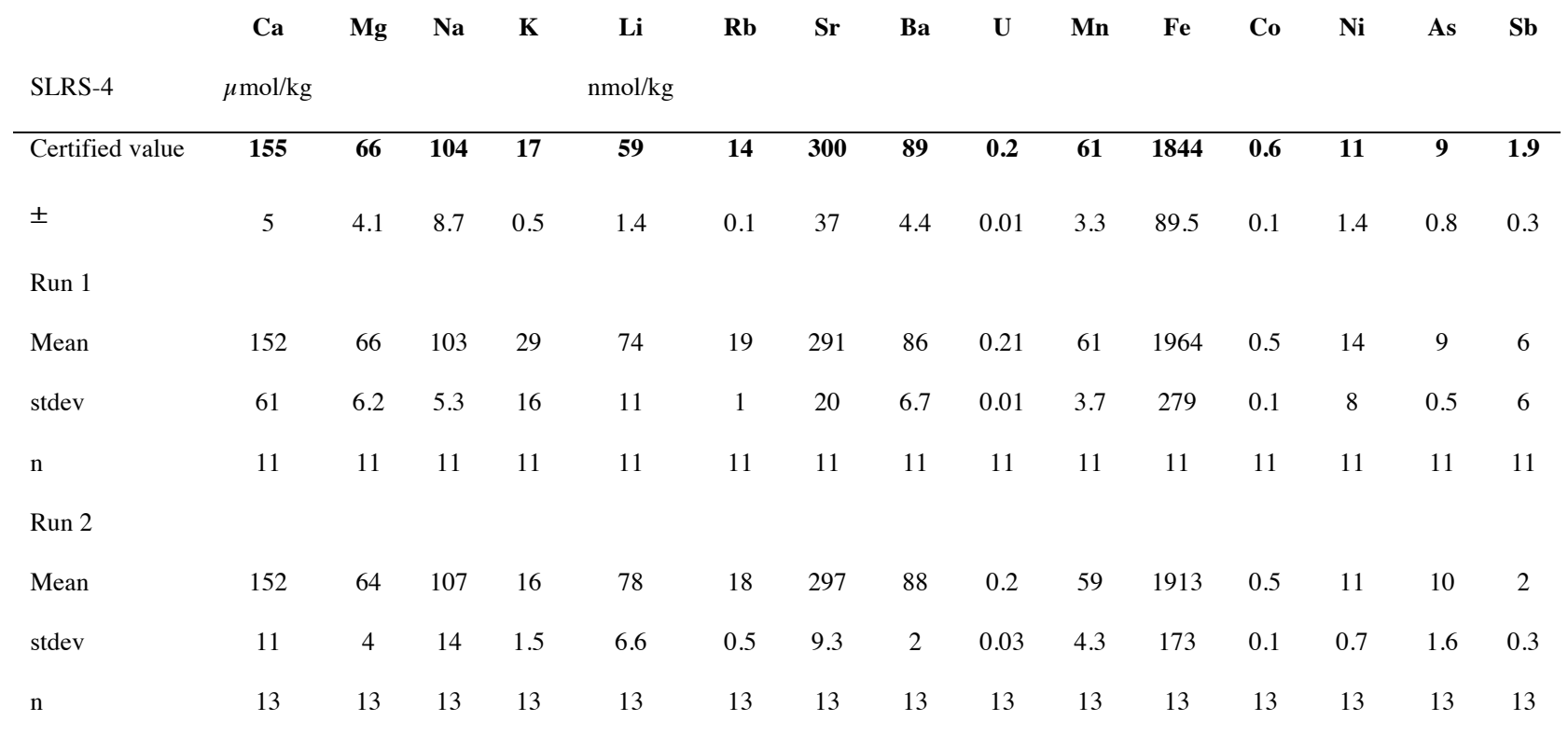

SRM 1640a

\begin{tabular}{|c|c|c|c|c|c|c|c|c|c|c|c|c|c|c|}
\hline Known value & 140 & 44 & 137 & 15 & - & 1438 & 1105 & 107 & 735 & 659 & 343 & 431 & 108 & 42 \\
\hline \pm & 0.5 & 0.2 & 1.3 & 0.1 & - & 10.4 & 6 & 1.1 & 6.6 & 32.2 & 4.1 & 2.4 & 0.9 & 0.4 \\
\hline \multicolumn{15}{|l|}{ Run 1} \\
\hline Mean & 139 & 45 & 138 & 26 & - & 1423 & 1106 & 111 & 730 & 644 & 345 & 430 & 107 & 42 \\
\hline stdev & 7.8 & 4.8 & 12 & 13 & - & 77 & 47 & 13 & 52.7 & 126 & 26 & 39 & 5.9 & 2.9 \\
\hline $\mathrm{n}$ & 14 & 14 & 14 & 14 & - & 14 & 14 & 14 & 14 & 14 & 14 & 14 & 14 & 14 \\
\hline \multicolumn{15}{|l|}{ Run 2} \\
\hline Mean & 137 & 43 & 134 & 15 & & 1435 & 1102 & 109 & 737 & 151 & 340 & 428 & 110 & 43 \\
\hline stdev & 9.8 & 3.6 & 6.5 & 1.1 & & 15.7 & 13.2 & 8.1 & 41 & 34 & 14 & 14 & 8.7 & 2.3 \\
\hline $\mathrm{n}$ & 10 & 10 & 10 & 10 & & 10 & 10 & 10 & 10 & 10 & 10 & 10 & 10 & 10 \\
\hline
\end{tabular}


Table 2: $\mathrm{pH}$ of the proglacial river measured in 2011.

\begin{tabular}{|c|c|c|}
\hline Date & Day (2011) & pH \\
\hline $5 / 12 / 11$ 13:00 & 132.5 & 7.9 \\
\hline $5 / 12 / 11 \quad 18: 20$ & 132.8 & 7.9 \\
\hline $5 / 13 / 11 \quad 10: 45$ & 133.4 & 8.0 \\
\hline $5 / 13 / 1115: 10$ & 133.6 & 7.9 \\
\hline $5 / 13 / 1116: 25$ & 133.7 & 7.9 \\
\hline $5 / 14 / 1111: 25$ & 134.5 & 7.9 \\
\hline $5 / 15 / 1110: 50$ & 135.5 & 7.8 \\
\hline 5/16/11 0:00 & 136.0 & 7.8 \\
\hline $5 / 17 / 1112: 10$ & 137.5 & 7.8 \\
\hline $5 / 19 / 1115: 10$ & 139.6 & 7.9 \\
\hline $5 / 20 / 1118: 15$ & 140.8 & 7.8 \\
\hline $5 / 21 / 11 \quad 13: 38$ & 141.6 & 7.9 \\
\hline $5 / 24 / 1114: 42$ & 144.6 & 8.0 \\
\hline $5 / 25 / 11$ 19:06 & 145.8 & 7.8 \\
\hline $5 / 27 / 11 \quad 16: 02$ & 147.7 & 7.7 \\
\hline $5 / 27 / 11$ 18:02 & 147.8 & 7.7 \\
\hline $5 / 28 / 11 \quad 12: 20$ & 148.5 & 7.8 \\
\hline $5 / 28 / 1112: 56$ & 148.5 & 7.8 \\
\hline $5 / 28 / 11 \quad 19: 39$ & 148.8 & 7.7 \\
\hline $5 / 29 / 11 \quad 18: 48$ & 149.8 & 7.7 \\
\hline $5 / 30 / 1118: 54$ & 150.8 & 7.6 \\
\hline $5 / 31 / 1122: 31$ & 151.9 & 7.5 \\
\hline $6 / 1 / 11 \quad 16: 25$ & 152.7 & 7.5 \\
\hline $6 / 2 / 11 \quad 17: 15$ & 153.7 & 7.4 \\
\hline $6 / 5 / 11 \quad 15: 25$ & 156.64 & 7.3 \\
\hline 6/5/11 16:00 & 156.67 & 7.3 \\
\hline 6/6/11 17:56 & 157.7 & 8.0 \\
\hline $6 / 7 / 117: 20$ & 158.3 & 7.7 \\
\hline $6 / 8 / 115: 30$ & 159.2 & 7.9 \\
\hline $6 / 8 / 117: 55$ & 159.3 & 7.9 \\
\hline $6 / 11 / 1116: 45$ & 162.7 & 8.5 \\
\hline 6/14/11 0:37 & 165.0 & 9.0 \\
\hline
\end{tabular}


Table 2 continued:

\begin{tabular}{lcc}
\multicolumn{1}{l}{ Date } & Day (2011) & pH \\
\hline $6 / 14 / 1112: 40$ & 165.5 & 9.0 \\
$6 / 15 / 1115: 50$ & 166.7 & 9.0 \\
$6 / 16 / 1112: 44$ & 167.5 & 8.8 \\
$6 / 16 / 11 ~ 13: 30$ & 167.6 & 8.8 \\
$6 / 19 / 110: 00$ & 170.0 & 8.8 \\
$6 / 21 / 1117: 45$ & 172.7 & 8.8
\end{tabular}


Table 3: Leverett River time series samples

\begin{tabular}{|c|c|c|c|c|c|c|c|c|c|c|c|c|c|c|c|c|c|c|}
\hline $\begin{array}{l}\text { Leverett River } \\
\text { date }\end{array}$ & day of year & $\begin{array}{c}\mathrm{Ca} \\
\mu \mathrm{mol} / \mathrm{L}\end{array}$ & $\mathrm{Mg}$ & $\mathrm{Na}$ & $\mathrm{K}$ & $\begin{array}{c}\mathrm{Li} \\
\mathrm{nmol} / \mathrm{L}\end{array}$ & $\mathrm{Rb}$ & $\mathrm{Sr}$ & $\mathrm{Ba}$ & $\mathrm{U}$ & Mn & $\mathrm{Fe}$ & Co & $\mathrm{Ni}$ & As & $\mathrm{Sb}$ & $\begin{array}{c}{ }^{87} \mathrm{Sr} /{ }^{86} \mathrm{Sr} \\
-\end{array}$ & $\begin{array}{c}\delta^{234} U \\
-\end{array}$ \\
\hline $5 / 13 / 12$ 17:45 & 134.7 & & & & & & & & & & & & & & & & & 71 \\
\hline $5 / 14 / 12$ 14:45 & 135.6 & 173 & 43 & 120 & 63 & 181 & 14 & 257 & 27 & 1.6 & 131 & 947 & 0.9 & - & 0.5 & 0.6 & 0.7513 & 60 \\
\hline $5 / 14 / 1220: 45$ & 135.9 & 100 & 22 & 61 & 32 & 96 & 7 & 130 & 13 & 0.7 & 76 & 86 & 0.4 & - & 0.3 & 0.6 & 0.7534 & 62 \\
\hline 5/15/12 3:15 & 136.1 & 102 & 25 & 69 & 37 & 109 & 8 & 146 & 20 & 0.9 & 89 & 1007 & 0.8 & - & 0.3 & 0.6 & & 61 \\
\hline 5/16/12 5:30 & 137.2 & 35 & 13 & 38 & 22 & 117 & 10 & 64 & 43 & 0.1 & 107 & 8040 & 3.3 & 7 & 0.3 & 0.6 & & \\
\hline 5/17/12 10:45 & 138.4 & 105 & 33 & 78 & 43 & 175 & 20 & 162 & 54 & 0.7 & 228 & 9818 & 4.7 & 12 & 0.4 & 0.6 & 0.7493 & 53 \\
\hline 5/17/12 15:45 & 138.7 & 93 & 25 & 62 & 35 & 111 & 10 & 136 & 21 & 0.4 & 156 & 1852 & 1.5 & - & 0.3 & 0.7 & 0.753 & 55 \\
\hline 5/18/12 8:40 & 139.4 & 99 & 26 & 67 & 38 & 131 & 12 & 147 & 27 & 0.5 & 156 & 2564 & 1.7 & - & 0.3 & 0.6 & 0.7532 & 53 \\
\hline $5 / 18 / 12$ 15:40 & 139.7 & & & & & & & & & & & & & & & & 0.7532 & 50 \\
\hline
\end{tabular}

\begin{tabular}{|c|c|c|c|c|c|c|c|c|c|c|c|c|c|c|c|c|c|c|}
\hline 5/22/12 10:00 & 143.4 & 87 & 21 & 55 & 33 & 107 & 9 & 123 & 23 & 0.3 & 129 & 1797 & 1.3 & - & 0.3 & 0.6 & 0.7511 & 53 \\
\hline 5/22/12 17:00 & 143.7 & 70 & 18 & 44 & 27 & 86 & 9 & 100 & 25 & 0.2 & 121 & 2574 & 1.5 & - & 0.3 & 0.6 & & 49 \\
\hline $5 / 23 / 120: 15$ & 144.0 & 66 & 18 & 41 & 26 & 96 & 8 & 91 & 22 & 0.2 & 121 & 2324 & 1.6 & - & 0.3 & 0.6 & 0.7511 & 43 \\
\hline 5/23/12 16:00 & 144.7 & 48 & 11 & 31 & 16 & 50 & 4 & 62 & 7 & 0.1 & 65 & 47 & 0.7 & - & 0.1 & 0.7 & 0.751 & 51 \\
\hline $5 / 26 / 120: 30$ & 147.0 & 50 & 12 & 30 & 16 & 59 & 4 & 71 & 8 & 0.2 & 69 & 307 & 0.6 & - & 0.2 & 0.6 & 0.75095 & 50 \\
\hline $5 / 28 / 127: 00$ & 149.3 & 48 & 13 & 35 & 21 & 73 & 7 & 65 & 15 & 0.2 & 91 & 1907 & 1.2 & - & 0.2 & 0.6 & & 63 \\
\hline 5/28/12 10:00 & 149.4 & 43 & 11 & 26 & 17 & 57 & 6 & 55 & 10 & 0.1 & 102 & 650 & 0.9 & - & 0.2 & 0.9 & 0.7558 & 61 \\
\hline $5 / 31 / 129: 30$ & 152.4 & 54 & 18 & 71 & 34 & 161 & 15 & 89 & 37 & 0.1 & 130 & 6863 & 2.9 & 4.3 & 0.3 & 0.6 & 0.7433 & 72 \\
\hline 5/31/12 23:00 & 153.0 & 38 & 10 & 50 & 22 & 91 & 6 & 55 & 10 & 0.2 & 41 & 933 & 1.4 & - & 0.2 & 0.6 & 0.7438 & 106 \\
\hline
\end{tabular}


Table 3 continued:

\begin{tabular}{|c|c|c|c|c|c|c|c|c|c|c|c|c|c|c|c|c|c|c|}
\hline Leverett River & & $\mathrm{Ca}$ & $\mathrm{Mg}$ & $\mathrm{Na}$ & $\mathrm{K}$ & $\mathrm{Li}$ & $\mathrm{Rb}$ & $\mathrm{Sr}$ & $\mathrm{Ba}$ & $\mathrm{U}$ & $\mathrm{Mn}$ & $\mathrm{Fe}$ & Co & $\mathrm{Ni}$ & As & $\mathrm{Sb}$ & ${ }^{87} \mathrm{Sr} /{ }^{86} \mathrm{Sr}$ & $\delta^{234} U$ \\
\hline date & day of year & $\mu \mathrm{mol} / \mathrm{L}$ & & & & $\mathrm{nmol} / \mathrm{L}$ & & & & & & & & & & & - & - \\
\hline $6 / 3 / 12 \quad 12: 30$ & 155.5 & 43 & 15 & 68 & 35 & 178 & 13 & 71 & 35 & 0.2 & 97 & 6371 & 2.5 & 2.4 & 0.4 & 0.6 & 0.7446 & 64 \\
\hline 6/6/12 18:00 & 158.8 & 36 & 11 & 53 & 24 & 105 & 5 & 47 & 11 & 0.1 & 41 & 1643 & 0.7 & - & 0.2 & 0.6 & 0.7452 & 69 \\
\hline 6/8/12 11:00 & 160.5 & 36 & 12 & 49 & 24 & 113 & 9 & 56 & 29 & 0.1 & 83 & 5413 & 2.1 & 0.1 & 0.2 & 0.6 & 0.74 & \\
\hline $6 / 11 / 1214: 00$ & 163.6 & 41 & 12 & 54 & 25 & 107 & 7 & 59 & 17 & 0.1 & 62 & 2436 & 1.1 & - & 0.2 & 0.6 & 0.7409 & 66 \\
\hline 6/12/12 0:45 & 164.0 & 31 & 11 & 44 & 19 & 85 & 5 & 47 & 20 & 0.1 & 66 & 3113 & 1.3 & - & 0.2 & 0.6 & & \\
\hline $6 / 14 / 1212: 30$ & 166.5 & 24 & 7 & 28 & 14 & 57 & 5 & 36 & 19 & 0.05 & 56 & 2772 & 1.7 & - & 0.1 & 0.6 & 0.7397 & 51 \\
\hline $6 / 15 / 1223: 00$ & 168.0 & 30 & 10 & 34 & 19 & 84 & 6 & 45 & 21 & 0.1 & 59 & 3475 & 1.8 & - & 0.2 & 0.6 & 0.7406 & \\
\hline 6/16/12 11:30 & 168.5 & 20 & 5 & 21 & 13 & 42 & 2 & 20 & 4 & 0.1 & 17 & 417 & 1.3 & - & 0.1 & 0.6 & 0.7409 & \\
\hline $6 / 23 / 12$ 15:00 & 175.6 & 24 & 10 & 53 & 13 & 49 & 3 & 35 & 8 & 0.1 & 41 & 1241 & 0.6 & - & 0.1 & 0.6 & 0.7339 & 69 \\
\hline
\end{tabular}

$\stackrel{\sim}{N}$

\begin{tabular}{|c|c|c|c|c|c|c|c|c|c|c|c|c|c|c|c|c|c|c|}
\hline $6 / 25 / 12$ 17:15 & 177.7 & 41 & 15 & 47 & 26 & 109 & 10 & 64 & 38 & 0.1 & 90 & 7523 & 3.1 & 6.2 & 0.2 & 0.6 & 0.7362 & 49 \\
\hline $7 / 6 / 12 \quad 10: 30$ & 188.4 & 34 & 18 & 56 & 27 & 174 & 18 & 67 & 56 & 0.1 & 137 & 13297 & 5.4 & 22 & 1.2 & 0.7 & 0.734 & 66 \\
\hline 7/7/12 12:00 & 189.5 & 54 & 40 & 68 & 45 & 297 & 43 & 120 & 152 & 0.3 & 361 & 35662 & 14 & 76 & 0.5 & 0.6 & 0.7352 & 66 \\
\hline 7/8/12 0:00 & 190.0 & 42 & 17 & 52 & 32 & 154 & 16 & 71 & 51 & 0.2 & 119 & 11446 & 4.7 & 16 & 0.3 & 0.6 & 0.7383 & 75 \\
\hline $7 / 17 / 126: 00$ & 199.3 & 50 & 23 & 54 & 33 & 177 & 20 & 93 & 96 & 0.2 & 223 & 14749 & 30 & 27 & 0.4 & 0.6 & 0.7439 & 82 \\
\hline 7/21/12 18:00 & 203.8 & 46 & 24 & 48 & 36 & 132 & 23 & 78 & 70 & 0.1 & 186 & 17046 & 33 & 29 & 0.3 & 0.6 & 0.7437 & \\
\hline 7/24/12 0:00 & 206.0 & 11 & 2 & 10 & - & 23 & 2 & 10 & 5 & 0.01 & 18 & 567 & 21 & - & 0.0 & 0.6 & 0.7397 & 76 \\
\hline $7 / 24 / 1216: 00$ & 206.7 & 34 & 14 & 36 & 20 & 95 & 12 & 58 & 42 & 0.1 & 116 & 8895 & 19 & 9.4 & 0.2 & 0.6 & 0.7358 & 53 \\
\hline $7 / 30 / 120: 30$ & 212.0 & 41 & 13 & 49 & 25 & 106 & 7 & 56 & 23 & 0.1 & 75 & 4208 & 1.7 & - & 0.2 & 1.1 & 0.7329 & 21 \\
\hline
\end{tabular}


Table 4: Results from sampling transect moving downstream of the GrIS. Site locations are shown on Figure 2.

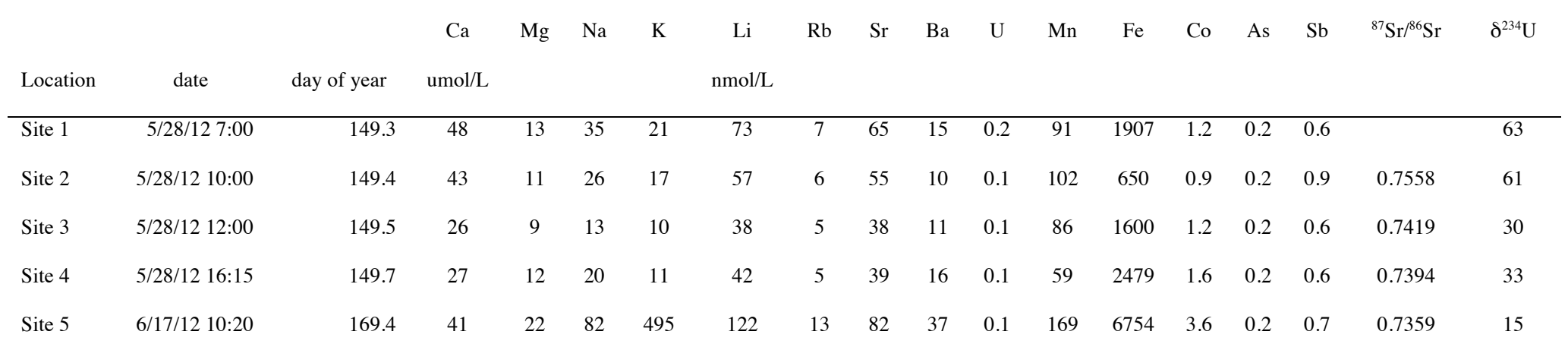


Table 5: Results of elemental and isotopic analyses of samples collected from a pingo near the glacier's terminus, the downstream fjord, and the delayed filtering experiments.

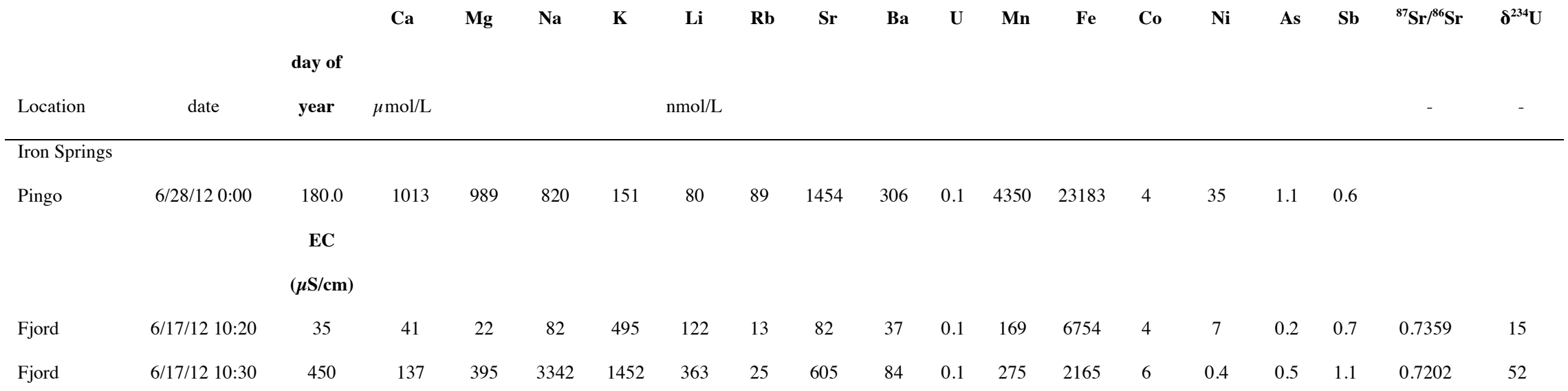

$\stackrel{\overrightarrow{5}}{\vec{P}}$

\begin{tabular}{|c|c|c|c|c|c|c|c|c|c|c|c|c|c|c|c|c|c|c|}
\hline Fjord & $6 / 17 / 12$ 11:00 & 4500 & 381 & 1999 & 16636 & 334 & 916 & 53 & 2880 & 160 & 0.2 & 203 & 3882 & 15 & 23 & 3.4 & 12.9 & 0.7109 \\
\hline Fjord & 6/17/12 11:45 & 8200 & 516 & 3386 & 27436 & 28 & 1433 & 74 & 4885 & 102 & 0.7 & 65 & - & 2 & - & 4.7 & 12.7 & 0.71006 \\
\hline Fjord & 6/17/12 12:00 & 10500 & 1243 & 7050 & 70316 & 69 & 3526 & 178 & 11842 & 221 & 1.7 & 95 & - & 11 & - & 8.1 & 12.4 & 0.7099 \\
\hline
\end{tabular}


Table 5 continued:

\begin{tabular}{|c|c|c|c|c|c|c|c|c|c|c|c|c|c|c|c|c|c|c|c|}
\hline & & & $\mathrm{Ca}$ & Mg & $\mathrm{Na}$ & $\mathbf{K}$ & $\mathbf{L i}$ & $\mathbf{R b}$ & $\mathrm{Sr}$ & $\mathbf{B a}$ & $\mathbf{U}$ & Mn & $\mathrm{Fe}$ & Co & $\mathrm{Ni}$ & As & Sb & ${ }^{87} \mathrm{Sr} /{ }^{86} \mathrm{Sr}$ & $\delta^{234} U$ \\
\hline \multicolumn{20}{|l|}{ Delayed } \\
\hline Filtering & Date & Time point & $\mu \mathrm{mol} /$ & & & & $\mathrm{nmol} /$ & & & & & & & & & & & & \\
\hline experiments & Sampled & (days) & $\mathrm{L}$ & & & & $\mathrm{L}$ & & & & & & & & & & & - & - \\
\hline $7 / 11 / 12$ & $7 / 11 / 12$ & & & & & & & & & & & & & & & & & & \\
\hline \multirow[t]{6}{*}{ 18:00 } & 18:00 & 0 & 44 & 23 & 47 & 29 & 128 & 15 & 65 & 46 & 0.2 & 129 & 10566 & 4 & 13 & 0.3 & 0.6 & & 81 \\
\hline & & 0.25 & 35 & 23 & 34 & 26 & 177 & 28 & 60 & 88 & 0.2 & 225 & 22373 & 9 & 43 & 0.3 & 0.6 & 0.7400 & 66 \\
\hline & & 1 & 37 & 18 & 46 & 31 & 163 & 21 & 58 & 60 & 0.1 & 151 & 14727 & 6 & 24 & 0.3 & 0.6 & 0.7426 & 49 \\
\hline & & 8.2 & 29 & 18 & 32 & 20 & 122 & 18 & 54 & 63 & 0.1 & 153 & 14604 & 20 & 23 & 0.3 & 0.6 & 0.7415 & 29 \\
\hline & & 10 & 47 & 37 & 52 & 42 & 221 & 40 & 96 & 117 & 0.1 & 294 & 28699 & 44 & 59 & 0.3 & 0.6 & 0.7437 & 32 \\
\hline & & 18.3 & 46 & 20 & 43 & 38 & 115 & 19 & 72 & 49 & 0.1 & 132 & 11226 & 9 & 16 & 0.3 & 0.6 & 0.7460 & 21 \\
\hline
\end{tabular}

$\stackrel{\vec{v}}{\cup}$

$7 / 24 / 12$

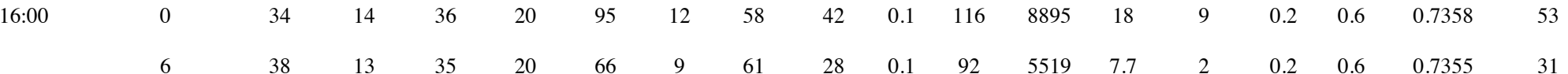


Table 6: Acetic Acid digestion of SSL. Dash indicates concentrations below detection limit.

\begin{tabular}{lcccccccccc} 
& $\mathrm{Ca}$ & $\mathrm{Mg}$ & $\mathrm{Na}$ & $\mathrm{K}$ & $\mathrm{Mn}$ & $\mathrm{Li}$ & $\mathrm{Rb}$ & $\mathrm{Sr}$ & $\mathrm{Ba}$ & ${ }^{87} \mathrm{Sr} /{ }^{86} \mathrm{Sr}$ \\
Date & $\mu \mathrm{g} / \mathrm{g}$ & $\mu \mathrm{g} / \mathrm{g}$ & $\mu \mathrm{g} / \mathrm{g}$ & $\mu \mathrm{g} / \mathrm{g}$ & $\mu \mathrm{g} / \mathrm{g}$ & $\mu \mathrm{g} / \mathrm{g}$ & $\mu \mathrm{g} / \mathrm{g}$ & $\mu \mathrm{g} / \mathrm{g}$ & $\mu \mathrm{g} / \mathrm{g}$ & \\
\hline $5 / 14 / 1214: 45$ & & & & & & & & & & 0.7488 \\
$5 / 17 / 1215: 45$ & & & & & & & & & & 0.7522 \\
$5 / 31 / 1223: 00$ & 1837 & 990 & 67 & 1047 & 69 & 2.9 & 4.6 & 11.5 & 65 & 0.7496 \\
$6 / 3 / 1212: 30$ & 2567 & 1427 & 101 & 1256 & 87 & 3.6 & 5.9 & 13.2 & 72 & \\
$6 / 6 / 1218: 00$ & 3344 & 2273 & 425 & 1429 & 113 & 4.1 & 4.4 & 24.2 & 110 & 0.7406 \\
$6 / 15 / 1223: 00$ & 372 & 556 & - & 861 & 41 & 2.4 & 5.2 & 3.8 & 31 & \\
$6 / 16 / 1211: 30$ & 1800 & 1290 & 117 & 871 & 62 & 2.5 & 3.5 & 10.3 & 53 & \\
$7 / 2 / 1218: 00$ & 2063 & 1470 & 16 & 1211 & 61 & 3.2 & 5.8 & 10.3 & 66 & \\
$7 / 6 / 1210: 30$ & 1349 & 1696 & 97 & 1220 & 56 & 3.0 & 5.0 & 10.7 & 123 &
\end{tabular}

그

$\begin{array}{ccccccccccc}7 / 7 / 1212: 00 & - & - & - & 482 & 35 & 1.8 & 2.7 & - & 34 & 0.7442 \\ 7 / 8 / 120: 00 & - & 229 & - & 643 & 25 & 1.8 & 3.7 & - & 31 & 0.7442 \\ 7 / 19 / 1216: 00 & 338 & 598 & - & 1018 & 40 & 2.6 & 5.7 & - & 40 & \\ 7 / 24 / 120: 00 & 96 & 0 & - & 415 & 9 & 0.9 & 2.1 & - & 8 & \\ 7 / 30 / 120: 30 & 1714 & 948 & - & 764 & 47 & 2.0 & 3.5 & 7.9 & 41 & 0.7456 \\ 7 / 30 / 120: 30 & 2177 & 1210 & - & 1037 & 55 & 3.5 & 5.7 & 8.4 & 61 & \end{array}$


Table 6 continued: Delayed filtering samples.

\begin{tabular}{lccccccccccc} 
& & $\mathrm{Ca}$ & $\mathrm{Mg}$ & $\mathrm{Na}$ & $\mathrm{K}$ & $\mathrm{Mn}$ & $\mathrm{Li}$ & $\mathrm{Rb}$ & $\mathrm{Sr}$ & $\mathrm{Ba}$ & ${ }^{87} \mathrm{Sr}{ }^{86} \mathrm{Sr}$ \\
Date & time point (days) & $\mu \mathrm{g} / \mathrm{g}$ & $\mu \mathrm{g} / \mathrm{g}$ & $\mu \mathrm{g} / \mathrm{g}$ & $\mu \mathrm{g} / \mathrm{g}$ & $\mu \mathrm{g} / \mathrm{g}$ & $\mu \mathrm{g} / \mathrm{g}$ & $\mu \mathrm{g} / \mathrm{g}$ & $\mu \mathrm{g} / \mathrm{g}$ & $\mu \mathrm{g} / \mathrm{g}$ & \\
\hline 7/11/12 18:00 & 0 & 2099 & 1606 & 14 & 896 & 68 & 3.1 & 4.4 & 13.2 & 77 & 0.7497 \\
$7 / 12 / 120: 00$ & 0.25 & 1324 & 951 & - & 1158 & 50 & 2.6 & 5.4 & 8.7 & 54 & \\
$7 / 19 / 1223: 00$ & 8.2 & - & 266 & - & 459 & 16 & 1.2 & 2.4 & - & 21 & \\
$7 / 30 / 120: 30$ & 18.3 & 953 & 880 & - & 750 & 37 & 2.1 & 3.3 & 6.3 & 45 & 0.7510
\end{tabular}


Table 7: Results from Hindshaw et al. (2014) total digestion of sediment collected near the Leverett Glacier proglacial river for comparison. The range in concentrations measured in this study is similar to those reported in Hindshaw et al. (2014).

\begin{tabular}{lccccccc} 
& $\mathrm{CaO}$ & $\mathrm{MgO}$ & $\mathrm{Na}_{2} \mathrm{O}$ & $\mathrm{K}_{2} \mathrm{O}$ & $\mathrm{MnO}$ & $\mathrm{FeOa}$ & $\mathrm{Sr}$ \\
& wt. \% & wt. \% & wt. \% & wt. \% & wt. \% & wt. \% & ug/g \\
\hline river sediment & 5.8 & 3.1 & 2.6 & 1 & 0.3 & 12.5 & 246 \\
river sediment & 4.7 & 1.9 & 3.6 & 1.5 & 0.1 & 6 & 352 \\
river sediment & 3.4 & 1 & 4.3 & 1.5 & 0 & 1.9 & - \\
sand & 4.1 & 1.6 & 3.7 & 2 & 0.1 & 4.8 & 328 \\
moraine sediment & 3.7 & 1.2 & 3.6 & 1.8 & 0.1 & 3.9 & 330 \\
dirt cone & 3.4 & 1.1 & 3.8 & 2.2 & 0 & 3.3 & 345 \\
dirt cone & 3.7 & 1.3 & 3.5 & 1.7 & 0.1 & 4.1 & 325
\end{tabular}

$\stackrel{๗}{\infty}$

$\begin{array}{lllllll}\text { proglacial lake sediment } \quad 2.9 & 0.9 & 3.7 & 2.3 & 0.1 & 2.5 & 338\end{array}$


Table 8: Results of Ra isotope analysis from 2011 samples.

\begin{tabular}{|c|c|c|c|c|}
\hline \multirow[b]{2}{*}{ Date } & \multirow[b]{2}{*}{ Day } & \multicolumn{2}{|r|}{${ }^{228} \mathrm{Ra}$} & \multirow[b]{2}{*}{$\left({ }^{228} \mathrm{Ra}{ }^{226} \mathrm{Ra}\right)$} \\
\hline & & $\mathrm{dpm} / 100 \mathrm{~L}$ & $\mathrm{dpm} / 100 \mathrm{~L}$ & \\
\hline $5 / 20 / 1114: 43$ & 140.6 & 2 & 27 & 15 \\
\hline 5/25/11 19:06 & 145.8 & 2 & 30 & 15 \\
\hline $5 / 27 / 1119: 20$ & 147.8 & 1 & 20 & 14 \\
\hline $6 / 1 / 11$ 16:00 & 152.7 & 1 & 11 & 15 \\
\hline 6/7/11 14:45 & 158.6 & 2 & 28 & 17 \\
\hline 6/9/11 21:50 & 160.9 & 9 & 139 & 15 \\
\hline $6 / 12 / 1118: 45$ & 163.8 & 8 & 127 & 17 \\
\hline $6 / 25 / 1112: 00$ & 176.5 & 5 & 61 & 13 \\
\hline 7/3/11 0:00 & 185.5 & 6 & 69 & 11 \\
\hline 7/10/11 0:00 & 192.5 & 4 & 45 & 12 \\
\hline 7/21/11 0:00 & 203.5 & 1 & 5 & 9 \\
\hline 7/29/11 0:00 & 211.0 & 3 & 15 & 5 \\
\hline \multirow[t]{3}{*}{ 7/30/11 23:00 } & 212.8 & 2 & 24 & 12 \\
\hline & & ${ }^{226} \mathrm{Ra}$ & ${ }^{228} \mathrm{Ra}$ & $\left({ }^{228} \mathrm{Ra}{ }^{226} \mathrm{Ra}\right)$ \\
\hline & & $\mathrm{dpm} / \mathrm{g}$ & $\mathrm{dpm} / \mathrm{g}$ & \\
\hline SSL & & 0.48 & 1.02 & 2.1 \\
\hline
\end{tabular}




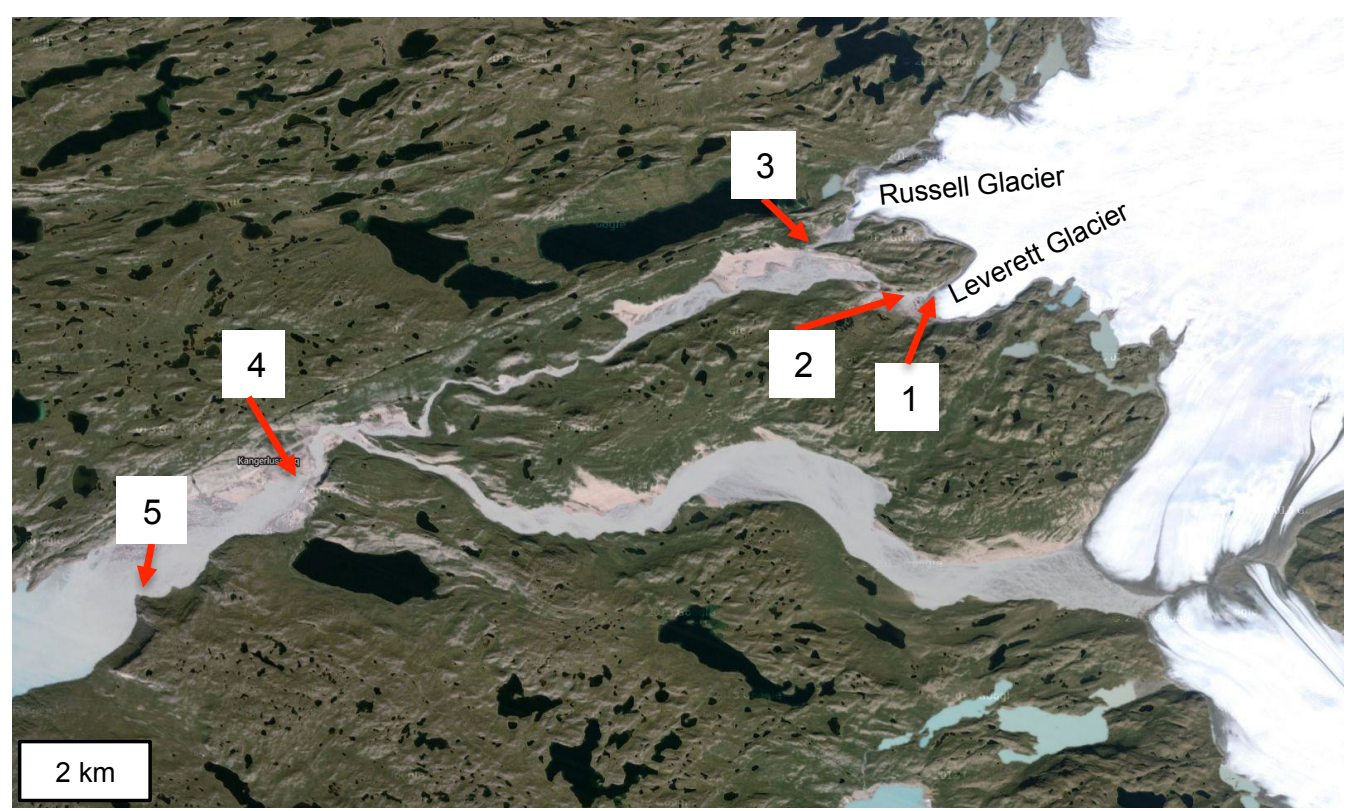

Figure 1: Map of the study area showing the sampling transect moving downstream from Leverett Glacier. Site 1 is directly at the Leverett Glacier's terminus $\left(67^{\circ} 03^{\prime} 57.81^{\prime} \mathrm{N}\right.$, $\left.50^{\circ} 10^{\prime} 01.83^{\prime \prime}\right)$, Site 2 is $1 \mathrm{~km}$ downstream where all time series samples were collected for this study $\left(67^{\circ} 03\right.$ '49.9'N, 50²' $\left.17.17^{\prime \prime} \mathrm{W}\right)$. Site 3 is downstream from Russell Glacier directly above mixing with Leverett Glacier's proglacial river $\left(67^{\circ} 04^{\prime} 50.80^{\prime \prime} \mathrm{N}, 50^{\circ} 16^{\prime} 36.77^{\prime \prime} \mathrm{W}\right)$. Site 4 is the Watson River in Kangerlussuaq (6700'18.43'N, 5041'15.19') while Site 5 is in the freshwater zone of the fjord (66 $67^{\prime}$ '02.83’N, 5041'15.19”). 


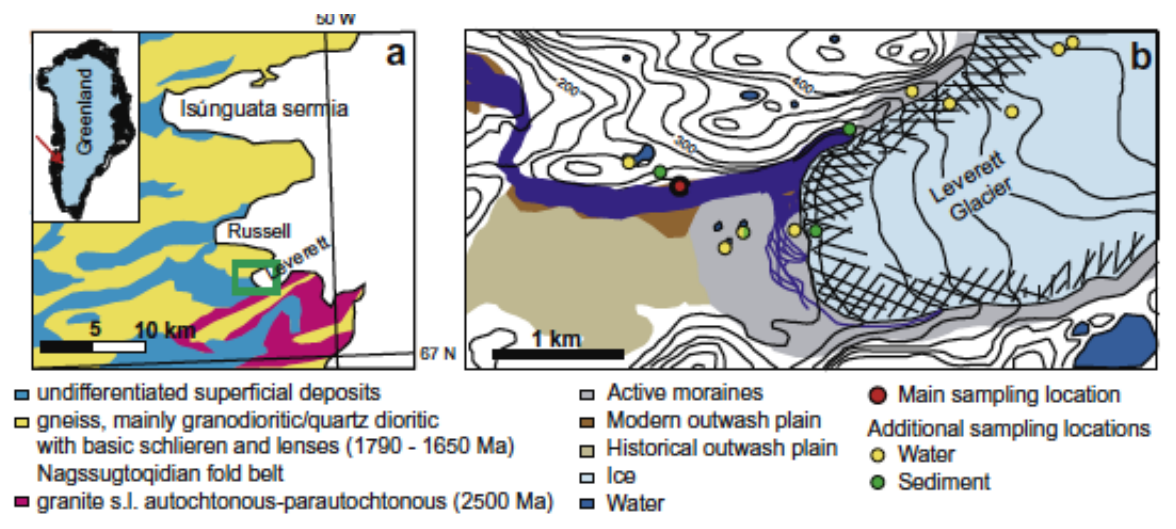

Figure 2: simplified geological map of Leverett Glacier from Hindshaw et al. (2014). 


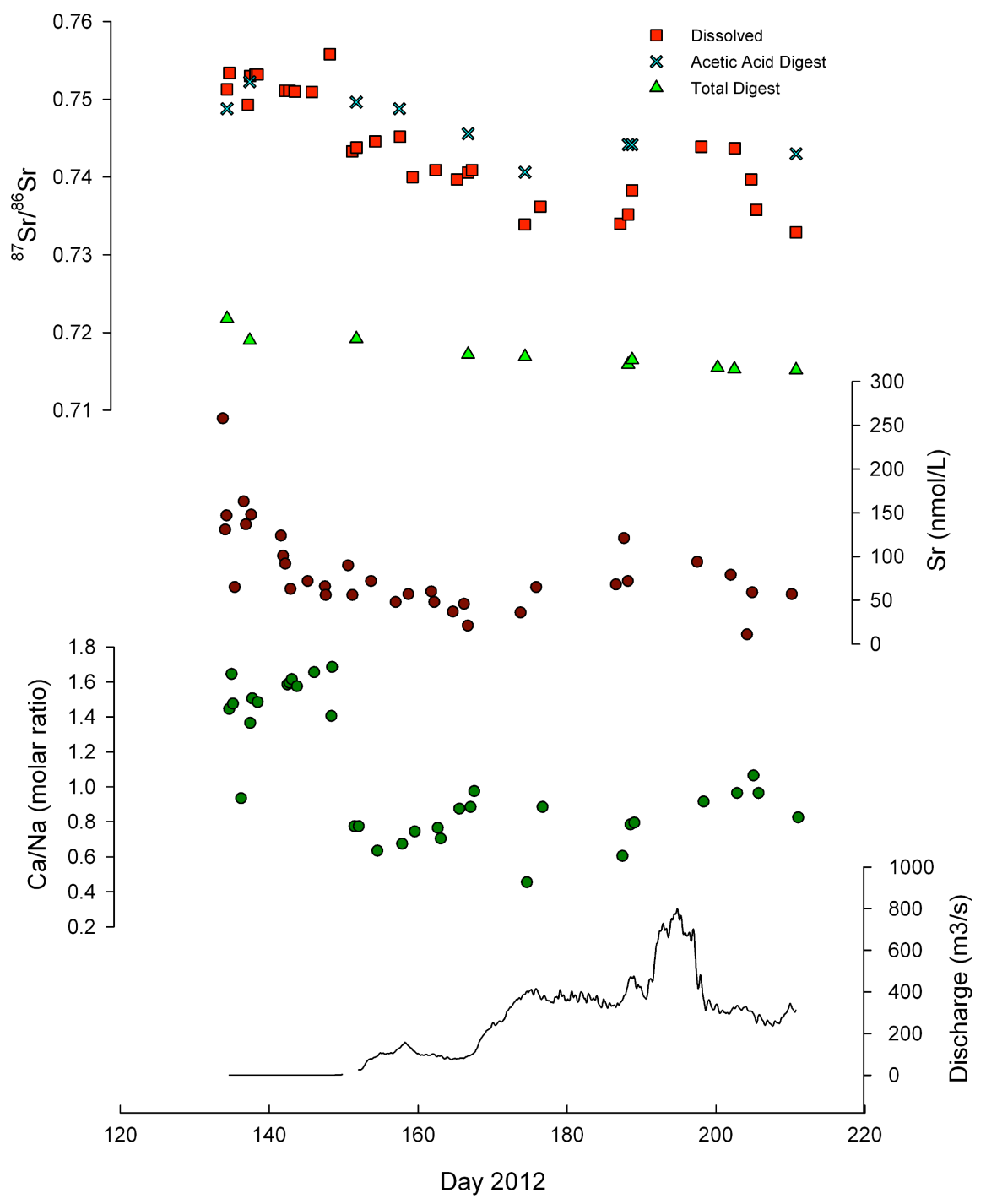

Figure 3: Results from ${ }^{87} \mathrm{Sr} /{ }^{86} \mathrm{Sr}$ analyses of dissolved samples, acetic acid, and total digestion samples (top panel). Also shown are $\mathrm{Sr}$ concentration and $\mathrm{Ca} / \mathrm{Na}$ molar ratios of the dissolved load as well as river discharge. 

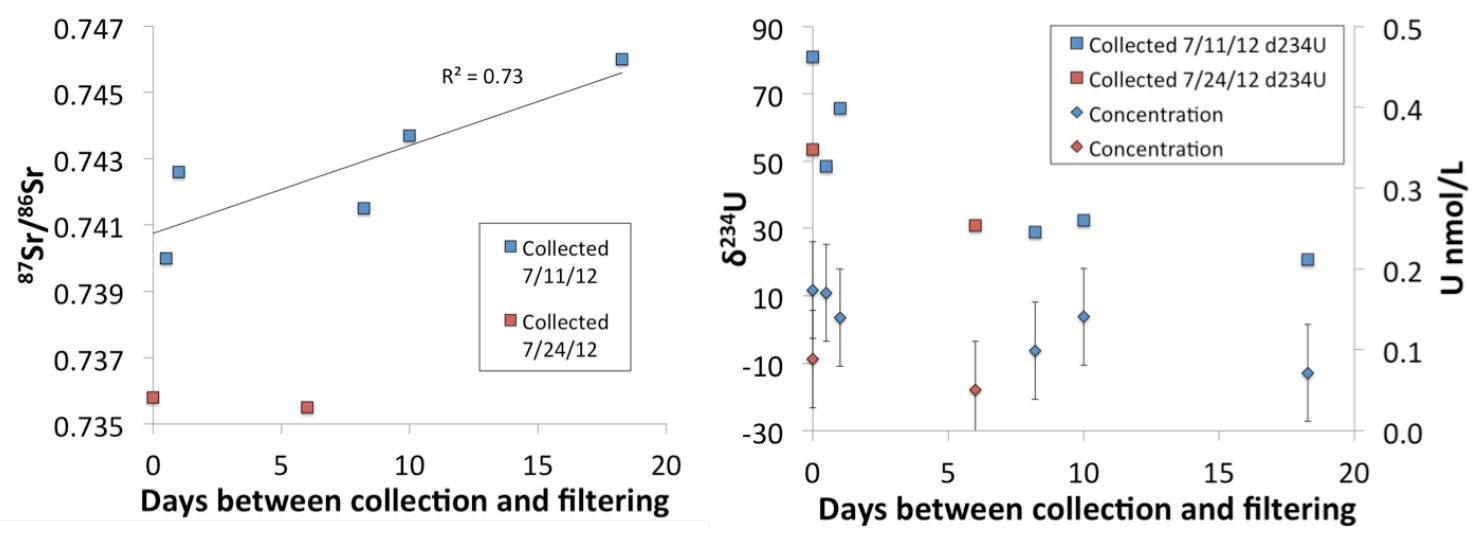

Figure 4: Results from the delayed filtering experiment showing changes in ${ }^{87} \mathrm{Sr} /{ }^{86} \mathrm{Sr}$ (left panel) and $\delta^{234} U$ and $U$ concentrations (right panel) over time. Errors on $U$ concentration measurements represent two standard deviations of triplicate samples of similar concentration. Analytical precision was not high enough to determine if $\mathrm{U}$ or $\mathrm{Sr}$ concentrations increased or decreased between sampling points. 

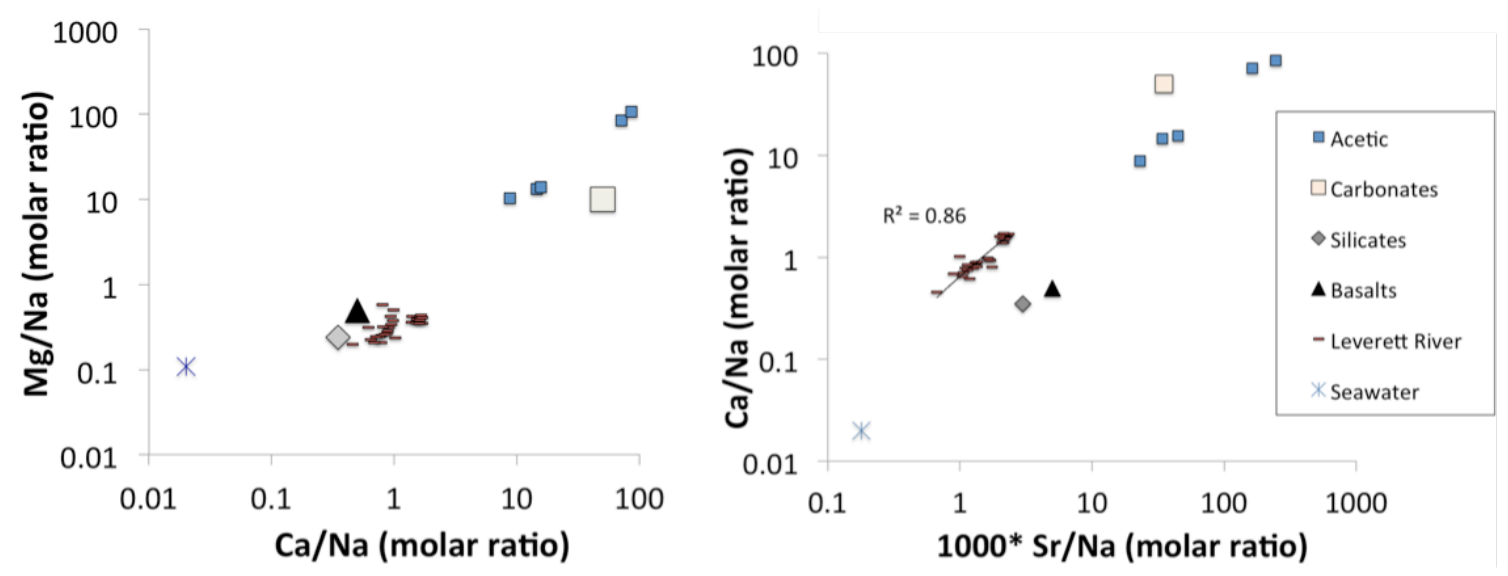

Figure 5: Molar ratios of $\mathrm{Mg} / \mathrm{Na}$ vs. $\mathrm{Ca} / \mathrm{Na}$ (left panel) and $\mathrm{Ca} / \mathrm{Na}$ vs. $1000 \times \mathrm{Sr} / \mathrm{Na}$ (right panel of dissolved samples and digestion samples from Leverett Glacier. Also shown are average values of rivers draining basaltic, granitic, and carbonate bedrock, as well as the composition of seawater (Gaillardet et al., 1999). 


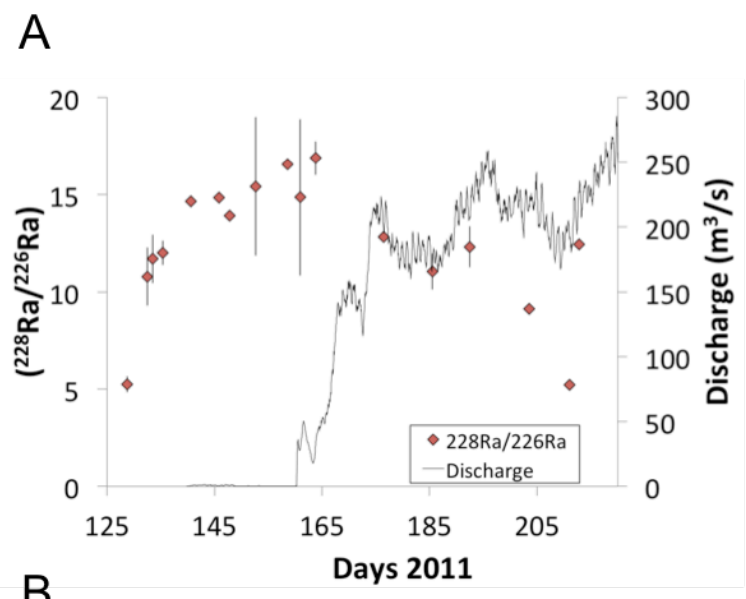

B

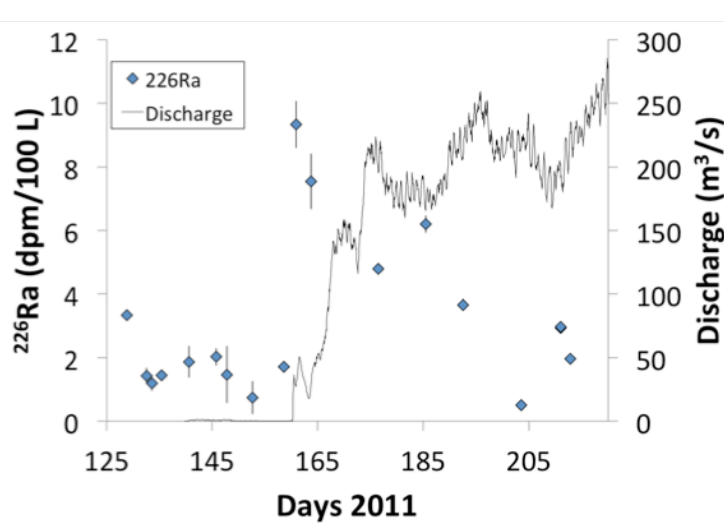

C

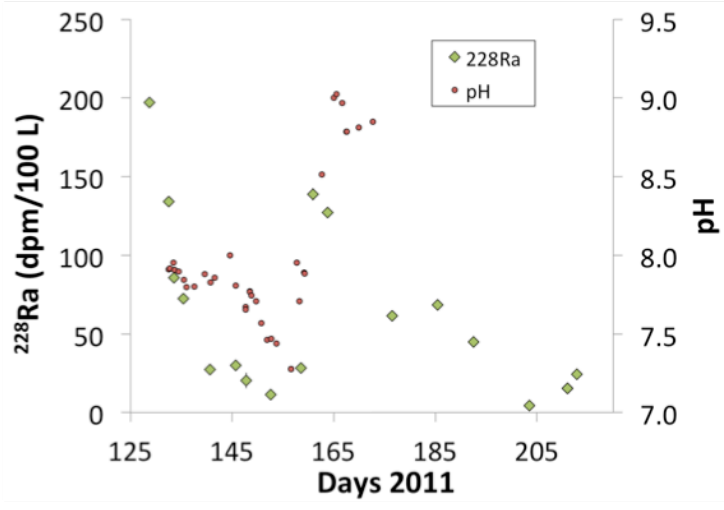

Figure 6: Radium isotope results from the 2011 field season. Plot A shows discharge of the proglacial river and ${ }^{226} \mathrm{Ra}$ while Plot B shows ${ }^{228} \mathrm{Ra}$. Plot $\mathrm{C}$ shows $\left({ }^{228} \mathrm{Ra} /{ }^{226} \mathrm{Ra}\right)$. Note that $\left({ }^{228} \mathrm{Ra} /{ }^{226} \mathrm{Ra}\right)$ measured in the SSL is $\sim 2$. Plot D shows the relationship between the activity of ${ }^{228} \mathrm{Ra}$ and $\mathrm{pH}$ in the proglacial river. It is hypothesized that the simultaneous increase in $\mathrm{Ra}$ activities and $\mathrm{pH}$ are caused by catchment expansion and meltwater access to fresh glacial flour (pH) and expanded Ra source material. For samples where error bars are not shown, uncertainty is smaller than marker size. 


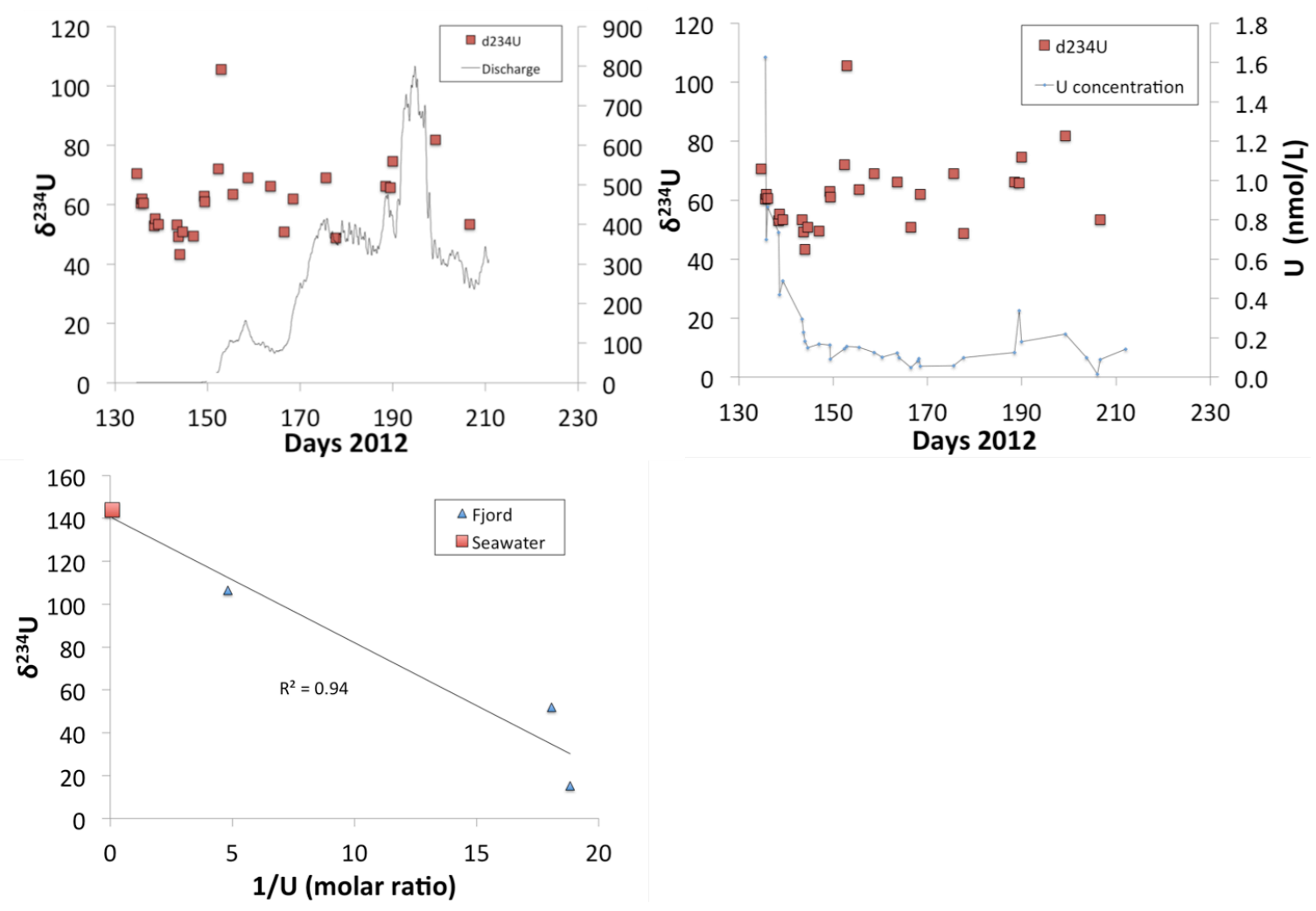

Figure 7: Time series samples from the Leverett Glacier proglacial river showing $\delta^{234} U$ and river discharge on the left plot and $\delta^{234} U$ and $U$ concentrations on the right plot. The bottom plot shows $\delta^{234} U$ vs. $1 / \mathrm{U}$ of samples collected in the fjord. The straight line represents conservative mixing between the glacial meltwater and seawater. 

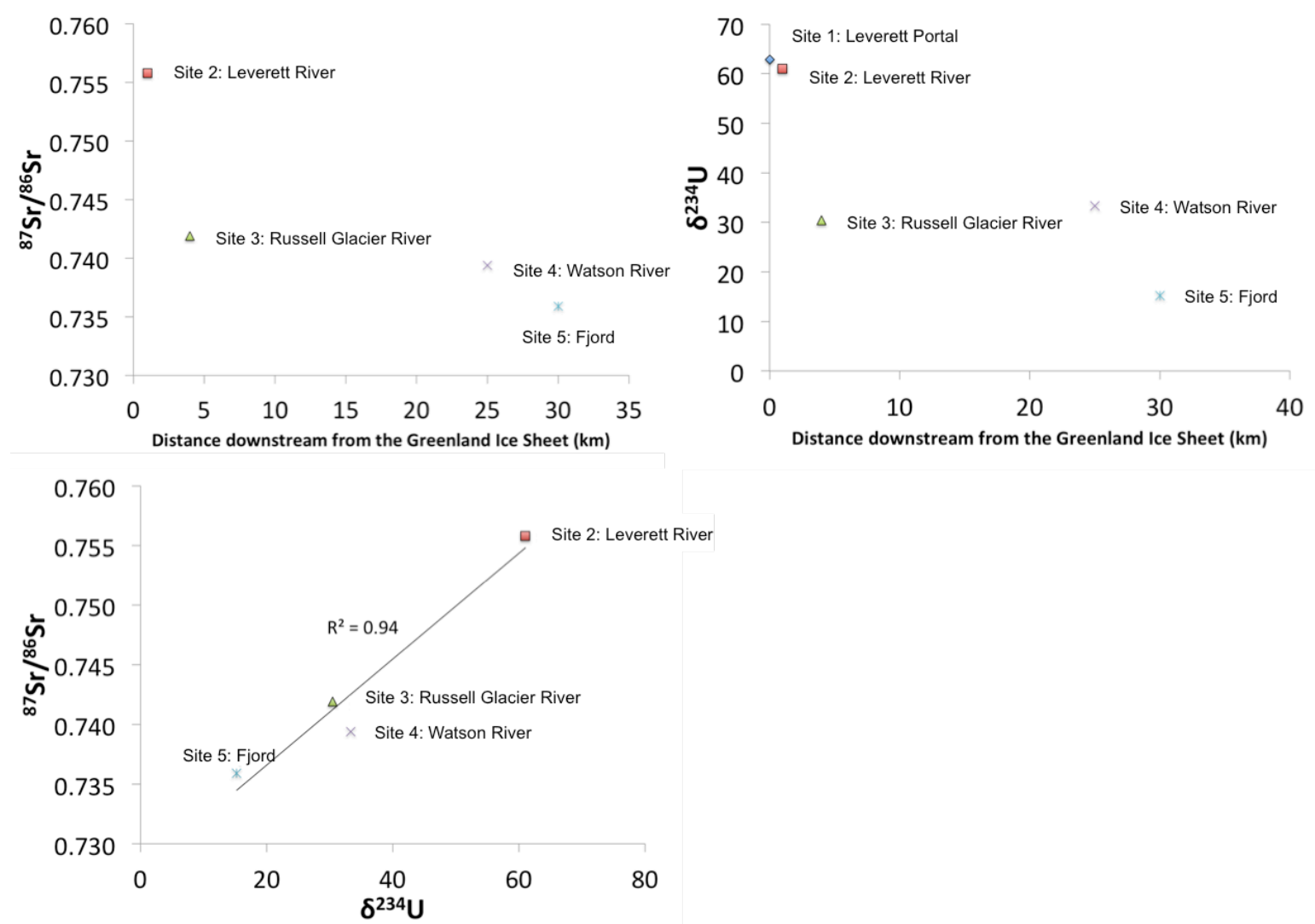

Figure 8: ${ }^{87} \mathrm{Sr} /{ }^{86} \mathrm{Sr}$ and $\delta^{234} \mathrm{U}$ results from transect samples. Both ${ }^{87} \mathrm{Sr} /{ }^{86} \mathrm{Sr}$ and $\delta^{234} \mathrm{U}$ decrease with distance from the ice sheet and are strongly correlated $\left(r^{2}=0.94\right.$; bottom plot). 

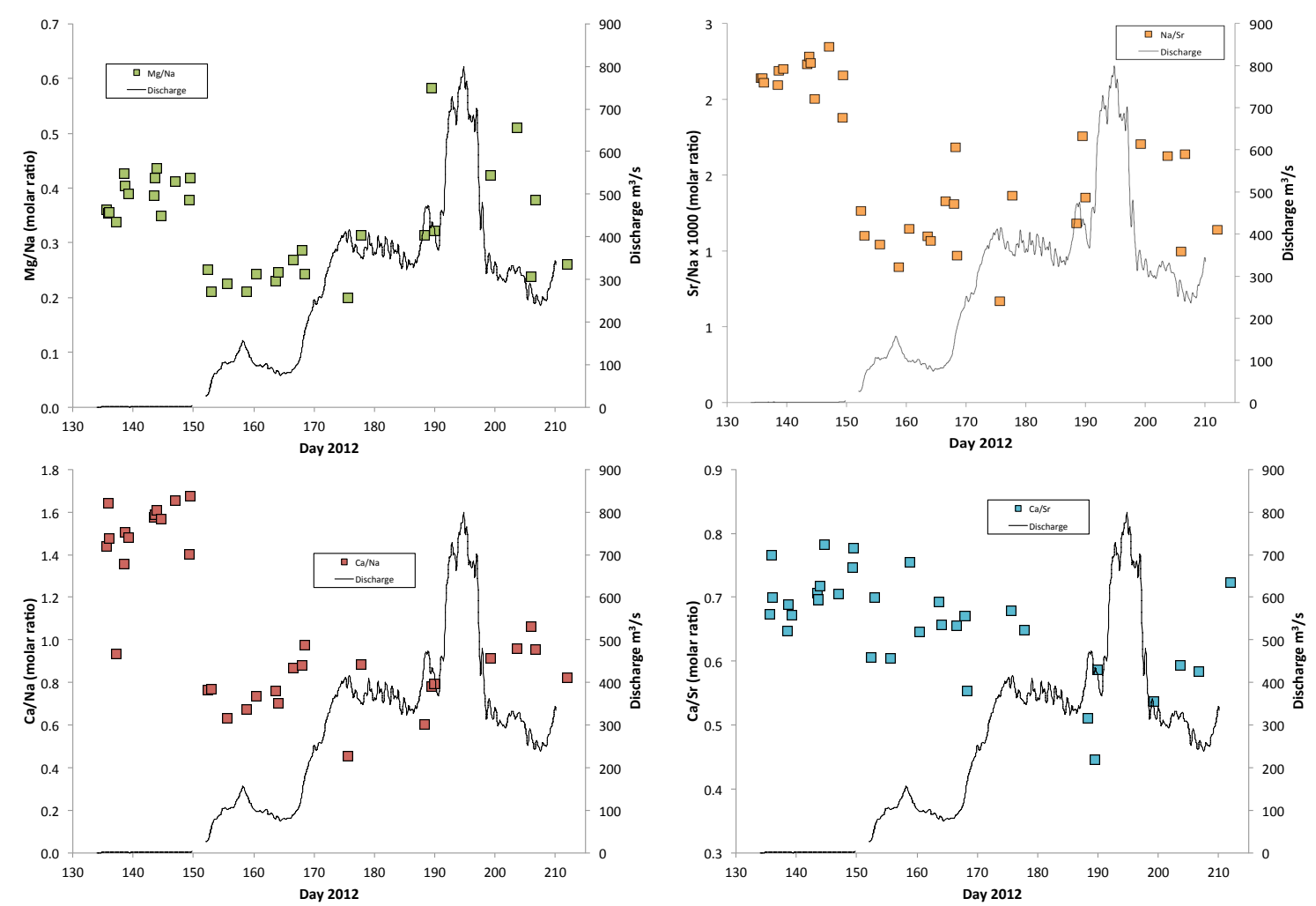

Figure 9: Temporal changes in molar ratios of $\mathrm{Mg} / \mathrm{Na}, \mathrm{Sr} / \mathrm{Na} \times 1000, \mathrm{Ca} / \mathrm{Na}$, and $\mathrm{Ca} / \mathrm{Sr}$ and river discharge. A distinct change was found between waters collected during the early and late melt season. Early season meltwaters had higher molar ratios of $\mathrm{Mg} / \mathrm{Na}, \mathrm{Sr} / \mathrm{Na}, \mathrm{Ca} / \mathrm{Na}$, and $\mathrm{Ca} / \mathrm{Sr}$ than samples collected after extensive melting occurred on the ice sheet surface. 


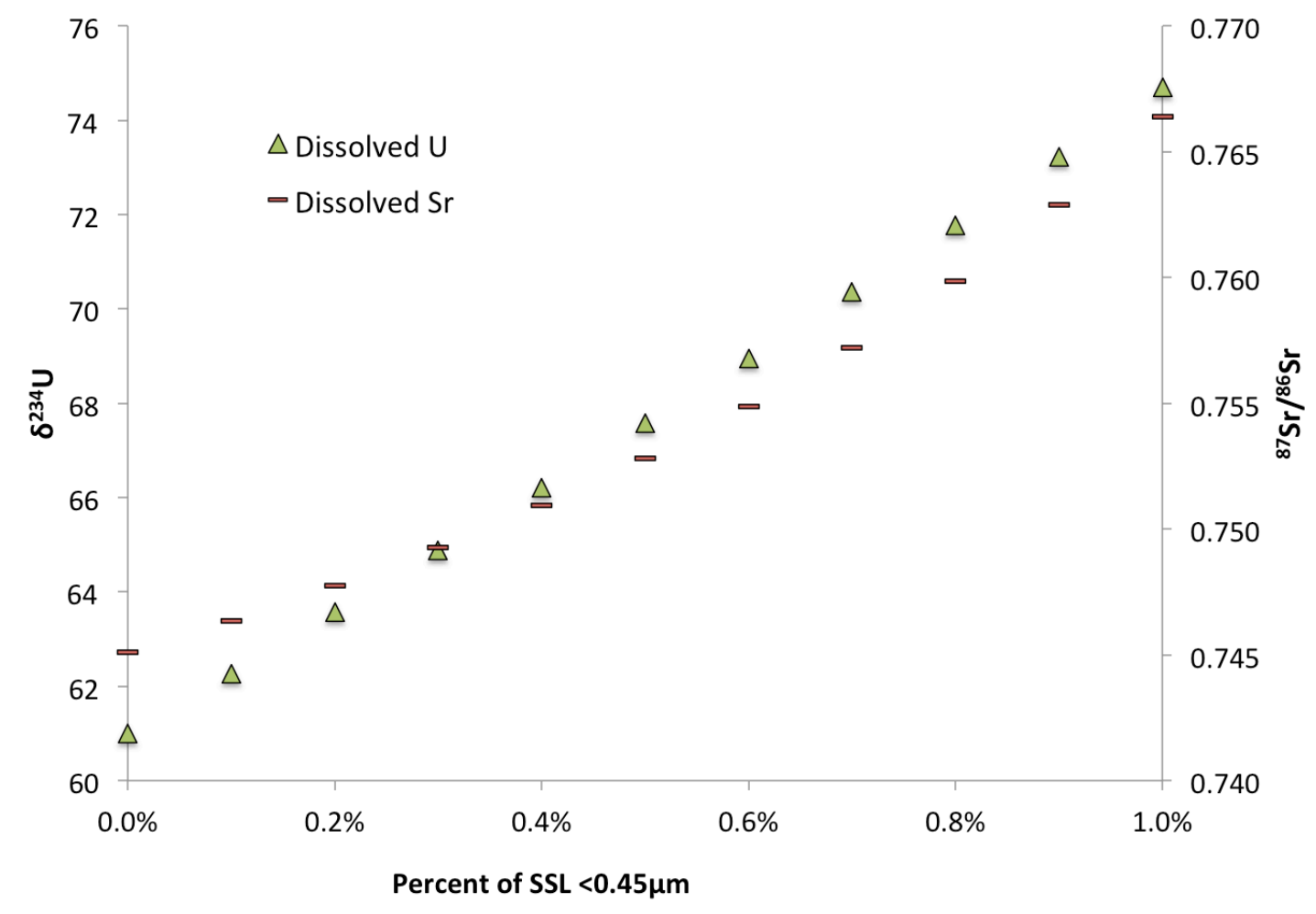

Figure 10: The calculated potential effect of the SSL on reported Sr and U isotopic composition the dissolved load. Butler (2014) reported that $0.27 \%$ of the SSL was $<0.45 \mu \mathrm{m}$ and therefore could potentially pass through the $0.45 \mu \mathrm{m}$ pore size filters used in this study. This plot shows the potential effect of the sub $0.45 \mu \mathrm{m}$ particulate load on the dissolved samples reported in this study. 


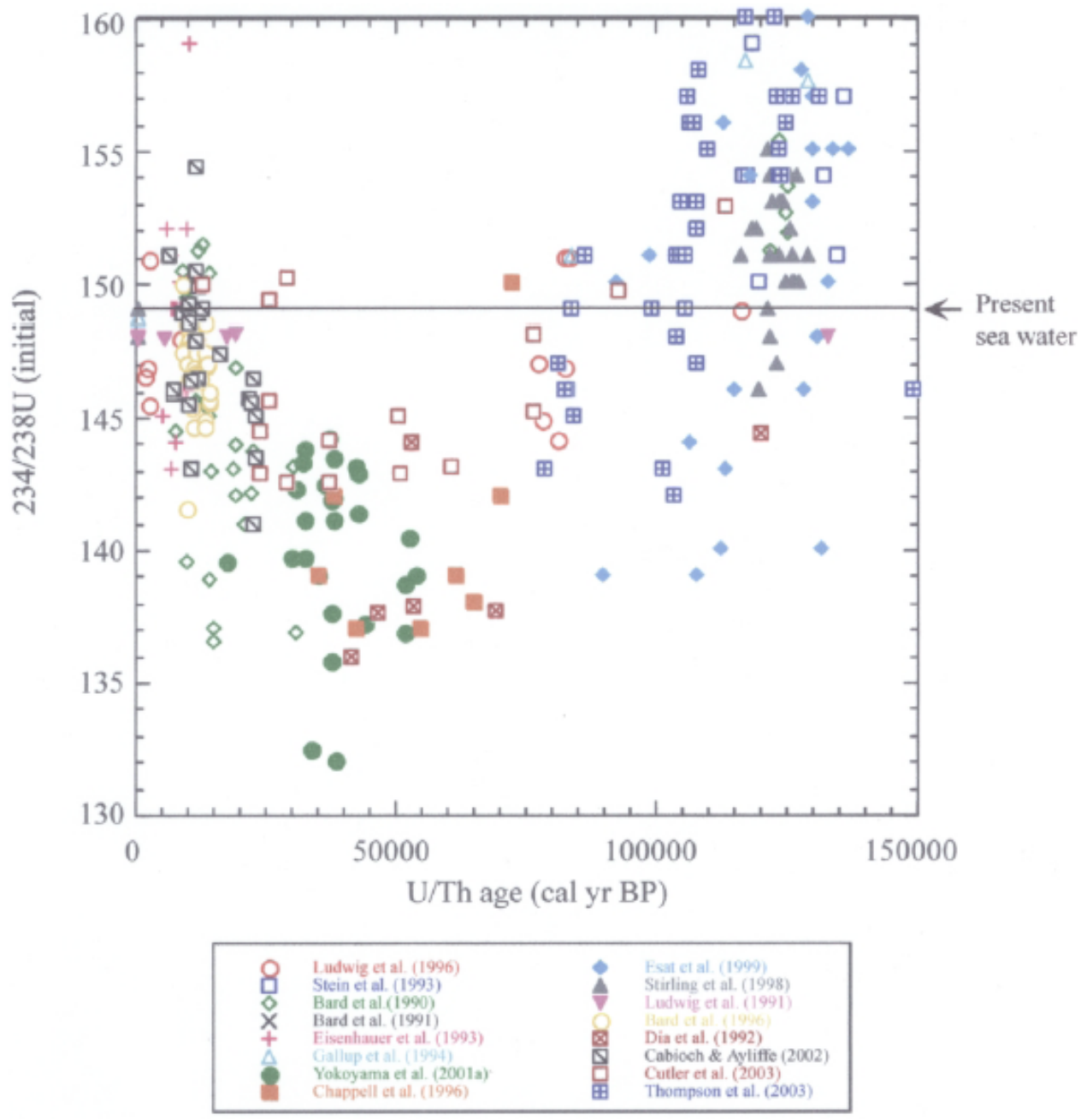

Figure 11: A compilation of coral records showing variations in seawater $\delta^{234} U$ over time.

During the last glacial period (12 Ka-112 Ka) seawater $\delta^{234} \mathrm{U}$. 

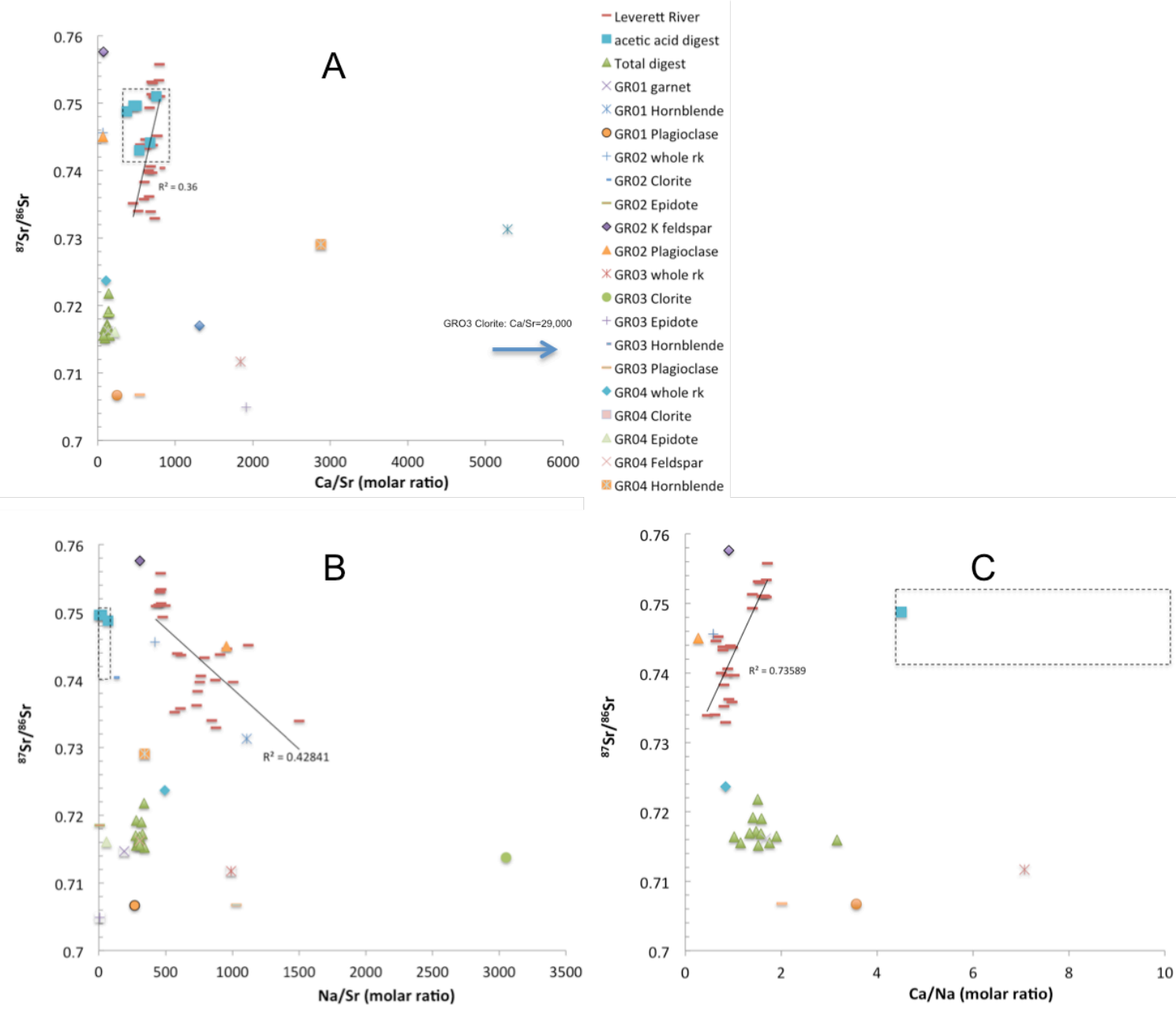

Figure 12: Molar ratios of $\mathrm{Ca} / \mathrm{Sr}$ (Plot A), Na/Sr (Plot B), and $\mathrm{Ca} / \mathrm{Na}\left(\mathrm{Plot} \mathrm{C}\right.$ ) versus ${ }^{87} \mathrm{Sr} /{ }^{86} \mathrm{Sr}$.

Included are samples from this study: dissolved time series samples (Leverett River), and acetic acid digestions. Also plotted are mineral separates and whole rock digestions quantified in Hindshaw et al. (2014). Dotted boxes denote range of acetic acid digestion. 


\section{References:}

Åberg, G., G. Jacks, and P. J. Hamilton (1989), Weathering rates and ${ }^{87} \mathrm{Sr} /{ }^{86} \mathrm{Sr}$ ratios: an isotopic approach, J. Hydrol., 109(1), 65-78.

Andersen, M. B., C. H. Stirling, E. K. Potter, and A. N. Halliday (2004), Toward epsilon levels of measurement precision on ${ }^{234} \mathrm{U} /{ }^{238} \mathrm{U}$ by using MC-ICPMS, Int. J. Mass Spectrom., 237(23), 107-118.

Andersen, M. B., C. H. Stirling, B. Zimmermann, and A. N. Halliday (2010), Precise determination of the open ocean 234U/238U composition, Geochemistry, Geophys. Geosystems, 11(12).

Anderson, S. P. (2007), Biogeochemistry of Glacial Landscape Systems, Annu. Rev. Earth Planet. Sci., 35(1), 375-399.

Anderson, S. P., J. I. Drever, and N. F. Humphrey (1997), Chemical weathering in glacial environments Chemical weathering in glacial environments, Geology, 25(5), 399-402, doi:10.1130/0091-7613(1997)025<0399.

Arendt, C. A. (2014), Impacts of melt runoff from the Greenland Ice Sheet on seawater ${ }^{234} \mathrm{U} /{ }^{238} \mathrm{U}$ composition, in 2014 GSA Annual Meeting in Vancouver, British Columbia.

Bartholomew, I., P. Nienow, D. Mair, A. Hubbard, M. a. King, and A. Sole (2010), Seasonal evolution of subglacial drainage and acceleration in a Greenland outlet glacier, Nat. Geosci., 3(6), 408-411, doi:10.1038/ngeo863. 
Bartholomew, I., P. Nienow, A. Sole, D. Mair, T. Cowton, S. Palmer, and J. Wadham (2011a), Supraglacial forcing of subglacial drainage in the ablation zone of the Greenland ice sheet, Methods, 38, 1-5, doi:10.1029/2011GL047063.

Bartholomew, I., P. Nienow, A. Sole, D. Mair, T. Cowton, S. Palmer, and J. Wadham (2011b), Supraglacial forcing of subglacial drainage in the ablation zone of the Greenland ice sheet, Geophys. Res. Lett., 38(8), doi:10.1029/2011GL047063.

Bartholomew, I., P. Nienow, A. Sole, D. Mair, T. Cowton, and M. A. King (2012), Short-term variability in Greenland Ice Sheet motion forced by time-varying meltwater drainage: Implications for the relationship between subglacial drainage system behavior and ice velocity, J. Geophys. Res. Earth Surf., 117(F3), doi:10.1029/2011JF002220.

Bartholomew, I. D., P. Nienow, A. Sole, D. Mair, T. Cowton, M. A. King, and S. Palmer (2011c), Seasonal variations in Greenland Ice Sheet motion : Inland extent and behaviour at higher elevations, Earth Planet. Sci. Lett., 307(3-4), 271-278, doi:10.1016/j.eps1.2011.04.014.

Bhat, S. G., and S. Krishnaswamy (1969), Isotopes of uranium and radium in Indian rivers, in Proceedings of the Indian Academy of Sciences-Section A, vol. 70, pp. 1-17.

Bhatia, M. P., E. B. Kujawinski, S. B. Das, C. F. Breier, P. B. Henderson, and M. A. Charette (2013), Greenland meltwater as a significant and potentially bioavailable source of iron to the ocean, Nat. Geosci., 6(4), 274-278, doi:10.1038/ngeo1746. 
Blum, J. D., and Y. Erel (1995), A silicate weathering mechanism linking increases in marine 87Sr/86Sr with global glaciation, Nature, 373, 415-418, doi:doi:10.1038/373415a0.

Blum, J. D., C. A. Gazis, A. D. Jacobson, and C. Page Chamberlain (1998), Carbonate versus silicate weathering in the Raikhot watershed within the High Himalayan Crystalline Series, Geology, 26(5), 411-414.

Boulton, G. S., M. Hagdorn, P. B. Maillot, and S. Zatsepin (2009), Drainage beneath ice sheets : groundwater - channel coupling, and the origin of esker systems from former ice sheets, Quat. Sci. Rev., 28(7-8), 621-638, doi:10.1016/j.quascirev.2008.05.009.

Butler, C. (2014), Hydrochemistry of the Greenland Ice Sheet, 245 pp., University of Bristol, Ph.D. Thesis.

Chabaux, F., J. Riotte, and O. Dequincey (2003), U-Th-Ra fractionation during weathering and river transport, Rev. Mineral. Geochemistry, 52(1), 533-576.

Chandler, D. M., J. L. Wadham, G. P. Lis, T. Cowton, A. Sole, I. Bartholomew, J. Telling, P. Nienow, E. B. Bagshaw, and D. Mair (2013), Evolution of the subglacial drainage system beneath the Greenland Ice Sheet revealed by tracers, Nat. Geosci., 6(3), 195-198.

Charette, M. (2001), Utility of radium isotopes for evaluating the input and transport of groundwater-derived nitrogen to a Cape Cod estuary, Limnol. Oceanogr., 46(2), 465-470.

Charette, M. A. (2007), Hydrologic forcing of submarine groundwater discharge: Insight from a seasonal study of radium isotopes in a groundwater-dominated salt marsh estuary, Limnol. Oceanogr., 52(1), 230-239. 
Chen, J. H., H. A. Curran, B. White, and G. J. Wasserburg (1991), Precise chronology of the last interglacial period: 234U-230Th data from fossil coral reefs in the Bahamas, Geol. Soc. Am. Bull., 103(1), 82-97.

Cheng, H., R. L. Edwards, J. Hoff, C. D. Gallup, D. A. Richards, and Y. Asmerom (2000), The half-lives of uranium-234 and thorium-230, Chem. Geol., 169(1), 17-33.

Cowton, T., P. Nienow, I. Bartholomew, A. Sole, and D. Mair (2012), Rapid erosion beneath the Greenland ice sheet, Geology, 40(4), 343-346, doi:10.1130/G32687.1.

Cowton, T., P. Nienow, A. Sole, J. Wadham, G. Lis, I. Bartholomew, D. Mair, and D. Chandler (2013), Evolution of drainage system morphology at a land - terminating Greenlandic outlet glacier, Earth, 118, 1-13, doi:10.1029/2012JF002540.

Creyts, T. T., and C. G. Schoof (2009), Drainage through subglacial water sheets, J. Geophys. Res. Earth Surf., 114(F4).

Das, S. B., I. Joughin, M. D. Behn, I. M. Howat, M. A. King, D. Lizarralde, and M. P. Bhatia (2008), Fracture propagation to the base of the Greenland ice sheet during supraglacial lake drainage, Science, 320(5877), 778-781.

DeFoor, W., M. Person, H. C. Larsen, D. Lizarralde, D. Cohen, and B. Dugan (2011), Ice sheetderived submarine groundwater discharge on Greenland's continental shelf, Water Resour. Res., 47(7).

Dunk, R. M., R. A. Mills, and W. J. Jenkins (2002), A reevaluation of the oceanic uranium budget for the Holocene, Chem. Geol., 190(1-4), 45-67. 
Erel, Y., J. D. Blum, E. Roueff, and J. Ganor (2004), Lead and strontium isotopes as monitors of experimental granitoid mineral dissolution, Geochim. Cosmochim. Acta, 68(22), 46494663, doi:http://dx.doi.org/10.1016/j.gca.2004.04.022.

Esat, T. M., and Y. Yokoyama (2006), Variability in the uranium isotopic composition of the oceans over glacial-interglacial timescales, Geochim. Cosmochim. Acta, 70(16), 41404150.

Escher, A. (1971), Geological map of Greenland, 1: 500000, Søndre Strømfjord--Nûgssuaq, sheet 3, Copenhagen Geol. Surv. Greenl.

Flowers, G. E., and G. K. C. Clarke (2002), A multicomponent coupled model of glacier hydrology 1. Theory and synthetic examples, J. Geophys. Res. Solid Earth, 107(B11), ECV-9.

Fountain, A. G., and J. S. Walder (1998), Water flow through temperate glaciers, Rev. Geophys., 36(3), 299-328.

Gaillardet, J., B. Dupré, P. Louvat, and C. J. Allegre (1999), Global silicate weathering and $\mathrm{CO}_{2}$ consumption rates deduced from the chemistry of large rivers, Chem. Geol., 159(1), 3-30.

Goldberg, K., and M. Humayun (2010), The applicability of the Chemical Index of Alteration as a paleoclimatic indicator: An example from the Permian of the Paraná Basin, Brazil, Palaeogeogr. Palaeoclimatol. Palaeoecol., 293(1-2), 175-183, doi:http://dx.doi.org/10.1016/j.palaeo.2010.05.015. 
Goldstein, S. J., and S. B. Jacobsen (1987), The Nd and Sr isotopic systematics of river-water dissolved material: implications for the sources of $\mathrm{Nd}$ and $\mathrm{Sr}$ in seawater, Chem. Geol. Isot. Geosci. Sect., 66(3), 245-272.

Gonneea, M., P. J. Morris, H. Dulaiova, and M. A. Charette (2008), New perspectives on radium behavior within a subterranean estuary, Mar. Chem., 109, 250 - 267, doi:10.1016/j.marchem.2007.12.002.

Grzymko, T. J., F. Marcantonio, B. A. McKee, and C. M. Stewart (2007), Temporal variability of uranium concentrations and $234 \mathrm{U} / 238 \mathrm{U}$ activity ratios in the Mississippi river and its tributaries, Chem. Geol., 243(3), 344-356.

Gulley, J. (2009), Structural control of englacial conduits in the temperate Matanuska Glacier, Alaska, USA, J. Glaciol., 55(192), 681-690.

Hagedorn, B., and B. Hasholt (2004), Hydrology, geochemistry and Sr isotopes in solids and solutes of the meltwater from Mittivakkat Gletscher, SE Greenland., Nord. Hydrol., 35, $369-380$.

Hawkings, J. R., J. L. Wadham, M. Tranter, R. Raiswell, L. G. Benning, P. J. Statham, A. Tedstone, P. Nienow, K. Lee, and J. Telling (2014), Ice sheets as a significant source of highly reactive nanoparticulate iron to the oceans, Nat. Commun., 5(3929), doi:10.1038/ncomms4929. 
Hellstrom, J. C., and M. T. McCulloch (2000), Multi-proxy constraints on the climatic significance of trace element records from a New Zealand speleothem, Earth Planet. Sci. Lett., 179(2), 287-297.

Henderson, G. M., B. L. Hall, A. Smith, and L. F. Robinson (2006), Control on $\left({ }^{234} U{ }^{238} U\right)$ in lake water: A study in the Dry Valleys of Antarctica, Chem. Geol., 226(3), 298-308.

Henriksen, N., A. K. Higgins, F. Kalsbeek, and T. C. R. Pulvertaft (2000), Greenland from Archaean to Quaternary: descriptive text to the Geological map of Greenland 1: 2500 000,

Hindshaw, R. S., J. Rickli, J. Leuthold, J. Wadham, and B. Bourdon (2014), Identifying weathering sources and processes in an outlet glacier of the Greenland Ice Sheet using $\mathrm{Ca}$ and Sr isotope ratios, Geochim. Cosmochim. Acta, 145, 50-71.

Hodell, D. A., G. A. Mead, and P. A. Mueller (1990), Variation in the strontium isotopic composition of seawater ( $8 \mathrm{Ma}$ to present): Implications for chemical weathering rates and dissolved fluxes to the oceans, Chem. Geol. Isot. Geosci. Sect., 80(4), 291-307.

Jacobson, A. D., and J. D. Blum (2000), Ca/Sr and ${ }^{87} \mathrm{Sr} /{ }^{86} \mathrm{Sr}$ geochemistry of disseminated calcite in Himalayan silicate rocks from Nanga Parbat: Influence on river-water chemistry, Geology, 28(5), 463-466.

Kehew, A. E., J. A. Piotrowski, and F. Jørgensen (2012), Earth-Science Reviews Tunnel valleys : Concepts and controversies - A review, Earth Sci. Rev., 113(1-2), 33-58, doi:10.1016/j.earscirev.2012.02.002. 
Kelly, R. P., and S. B. Moran (2002), Seasonal changes in groundwater input to a well-mixed estuary estimated using radium isotopes and implications for coastal nutrient budgets, Limnol. Oceanogr., 47(6), 1796-1807.

Key, R. M., R. F. Stallard, W. S. Moore, and J. L. Sarmiento (1985), Distribution and flux of ${ }^{226} \mathrm{Ra}$ and ${ }^{228} \mathrm{Ra}$ in the Amazon River estuary, J. Geophys. Res. Ocean., 90(C4), 6995-7004.

Kraemer, T. F., and P. B. Curwick (1991), Radium isotopes in the lower Mississippi River, $J$. Geophys. Res., 96(90), 2797, doi:10.1029/90JC02456.

Lawson, E. C., J. L. Wadham, M. Tranter, M. Stibal, G. P. Lis, C. E. H. Butler, J. LaybournParry, P. Nienow, D. Chandler, and P. Dewsbury (2014), Greenland Ice Sheet exports labile organic carbon to the Arctic oceans, Biogeosciences, 11(14), 4015-4028.

Li, Y.-H., and L.-H. Chan (1979), Desorption of Ba and $226 \mathrm{Ra}$ from river-borne sediments in the Hudson estuary, Earth Planet. Sci. Lett., 43(3), 343-350.

Lick, W., and J. Lick (1988), Aggregation and disaggregation of fine-grained lake sediments, $J$. Great Lakes Res., 14(4), 514-523.

Ludwig, K. R., K. R. Simmons, B. J. Szabo, I. J. Winograd, J. M. Landwehr, A. C. Riggs, and R. J. Hoffman (1992), Mass-spectrometric ${ }^{230} \mathrm{Th}^{234}{ }^{23-}{ }^{238} \mathrm{U}$ dating of the Devils Hole calcite vein, Science, 258(5080), 284-287.

McArthur, J. M., R. J. Howarth, and G. A. Shields (2012), Strontium isotope stratigraphy, Geol. time scale, 1, 127-144. 
Moore, D. G., and M. R. Scott (1986), Behavior of ${ }^{226}$ Ra in the Mississippi River mixing zone, $J$. Geophys. Res. Ocean., 91(C12), 14317-14329.

Moore, W. S. (1967), Amazon and Mississippi River concentrations of uranium, thorium, and radium isotopes, Earth Planet. Sci. Lett., 2(3), 231-234.

Moore, W. S., and J. M. Edmond (1984), Radium and barium in the Amazon River system, $J$. Geophys. Res. Ocean., 89(C2), 2061-2065.

Nghiem, S. V, D. K. Hall, T. L. Mote, M. Tedesco, M. R. Albert, K. Keegan, C. A. Shuman, N. E. DiGirolamo, and G. Neumann (2012), The extreme melt across the Greenland ice sheet in 2012, Geophys. Res. Lett., 39(20).

Nutman, A. P., C. R. L. Friend, and J. Hiess (2010), Setting of the 2560 Ma Qorqut granite complex in the Archean crustal evolution of southern West Greenland, Am. J. Sci., 310(9), $1081-1114$.

Osmond, J. K., and J. B. Cowart (1976), The theory and uses of natural uranium isotopic variations in hydrology, At. Energy Rev., 14, 621-678.

Osmond, J. K., H. S. Rydell, and M. I. Kaufman (1968), Uranium Disequilibrium in Groundwater - an Isotope Dilution Approach in Hydrologic Investigations, Science, 162(3857), 997-999.

Owens, S. A., K. O. Buesseler, and K. W. W. Sims (2011), Re-evaluating the ${ }^{238}$ U-salinity relationship in seawater : Implications for the $\mathrm{U}-{ }^{234} \mathrm{Th}$ disequilibrium method, Mar. Chem., 127(1-4), 31-39, doi:10.1016/j.marchem.2011.07.005. 
Paces, J. B., K. R. Ludwig, Z. E. Peterman, and L. A. Neymark (2002), ${ }^{234} U /{ }^{238} U$ evidence for local recharge and patterns of ground-water flow in the vicinity of Yucca Mountain, Nevada, USA, Appl. Geochemistry, 17(6), 751-779.

Palmer, M. R., and J. M. Edmond (1989), The strontium isotope budget of the modern ocean, Earth Planet. Sci. Lett., 92(1), 11-26.

Palmer, M. R., and J. M. Edmond (1993), Uranium in river water, Geochim. Cosmochim. Acta, 57(20), 4947-4955.

Piotrowski, J. A. (1997), Subglacial groundwater flow during the last glaciation in northwestern Germany, Sediment. Geol., 111(1), 217-224.

Plummer, L. N., D. L. Parkhurst, and T. M. L. Wigley (1979), Critical review of the kinetics of calcite dissolution and precipitation, in Chemical modeling-speciation, sorption and kinetics in aqueous systems, American Chemical Society, Washington, DC (1979), pp. 537573.

Raymo, M. E., and W. F. Ruddiman (1992), Tectonic forcing of late Cenozoic climate, Nature, 359(6391), 117-122.

Rhodes, M. K., A. R. Carroll, J. T. Pietras, B. L. Beard, and C. M. Johnson (2002), Strontium isotope record of paleohydrology and continental weathering, Eocene Green River Formation, Wyoming, Geology, 30(2), 167-170.

Richter, S., A. Alonso, W. De Bolle, H. Kühn, A. Verbruggen, R. Wellum, and P. D. P. Taylor (2005), Re-certification of a series of uranium isotope reference materials: IRMM-183, 
IRMM-184, IRMM-185, IRMM-186 and IRMM-187, Int. J. Mass Spectrom., 247(1), 3739.

Robinson, L. F., G. M. Henderson, and L. Hall (2004), Climatic Control of Riverine and Seawater Uranium-Isotope Ratios, Science, 305(851), 89, doi:10.1126/science.1099673.

Rothlisberger, H. (1969), Water pressure in subglacial channels, in Union Géodésique et Géophysique Internationale. Association Internationale d'Hydrologie Scientifique. Commission de Neiges et Glaces. Symposium on the hydrology of Glaciers, Cambridge, 7, p. 97.

Sarin, M. M., S. Krishnaswami, and W. S. Moore (1990), Chemistry of uranium, thorium, and radium isotopes in the Ganga-Brahmaputra river system: weathering processes and fluxes to the Bay of Bengal, Geochim. Cosmochim. Acta, 54(5), 1387-1396.

Sharp, M., K. Richards, I. Willis, N. Arnold, P. Nienow, W. Lawson, and J. Tison (1993), Geometry, bed topography and drainage system structure of the Haut Glacier d'Arolla, Switzerland, Earth Surf. Process. Landforms, 18(6), 557-571.

Shoemaker, E. M. (1986), Subglacial hydrology for an ice sheet resting on a deformable aquifer, J. Glaciol, 32(110), 20-30.

Stolzenbach, K. D., K. A. Newman, and C. S. Wong (1992), Aggregation of fine particles at the sediment-water interface, J. Geophys. Res. Ocean., 97(C11), 17889-17898.

Von Strandmann, P. A. E. P., K. W. Burton, R. H. James, P. van Calsteren, S. R. Gíslason, and F. Mokadem (2006), Riverine behaviour of uranium and lithium isotopes in an actively 
glaciated basaltic terrain, Earth Planet. Sci. Lett., 251(1-2), 134-147, doi:http://dx.doi.org/10.1016/j.epsl.2006.09.001.

Von Strandmann, P. A. E. P., K. W. Burton, R. H. James, P. van Calsteren, and S. R. Gislason (2010), Assessing the role of climate on uranium and lithium isotope behaviour in rivers draining a basaltic terrain, Chem. Geol., 270(1-4), 227-239.

Tedstone, A. J., P. W. Nienow, A. J. Sole, D. W. F. Mair, T. R. Cowton, I. D. Bartholomew, and M. A. King (2013), Greenland ice sheet motion insensitive to exceptional meltwater forcing, Proc. Natl. Acad. Sci., 110(49), 19719-19724.

Tedstone, A. J., P. W. Nienow, N. Gourmelen, and A. J. Sole (2014), Greenland ice sheet annual motion insensitive to spatial variations in subglacial hydraulic structure, Geophys. Res. Lett., 41(24), 8910-8917, doi:10.1002/2014GL062386.

Tranter, M. (2007), Glacial chemical weathering, runoff composition and solute fluxes, Glacier Sci. Environ. Chang., 71-75.

Tranter, M., M. J. Sharp, H. R. Lamb, G. H. Brown, B. P. Hubbard, and I. C. Willis (2002), Geochemical weathering at the bed of Haut Glacier d'Arolla, Switzerland a new model, Hydrol. Process., 16(5), 959-993.

Vigier, N., B. Bourdon, S. Turner, and C. J. Allègre (2001), Erosion timescales derived from Udecay series measurements in rivers, Earth Planet. Sci. Lett., 193(3-4), 549-563, doi:http://dx.doi.org/10.1016/S0012-821X(01)00510-6. 
Voss, B. M. et al. (2014), Tracing river chemistry in space and time: Dissolved inorganic constituents of the Fraser River, Canada, Geochim. Cosmochim. Acta, 124, 283-308.

Walder, J. S. (1986), Hydraulics of subglacial cavities, J. Glaciol, 32(112), 439-445.

Werder, M. A., I. J. Hewitt, C. G. Schoof, and G. E. Flowers (2013), Modeling channelized and distributed subglacial drainage in two dimensions, J. Geophys. Res. Earth Surf., 118(4), $2140-2158$

Weyer, S., A. D. Anbar, A. Gerdes, G. W. Gordon, T. J. Algeo, and E. A. Boyle (2008), Natural fractionation of 238U/235U, Geochim. Cosmochim. Acta, 72(2), 345-359.

Yokoyama, Y., and T. M. Esat (2004), Long term variations of uranium isotopes and radiocarbon in the surface seawater recorded in corals, Glob. Environ. Chang. Ocean L., 1, 279-309.

Zachos, J. C., B. N. Opdyke, T. M. Quinn, C. E. Jones, and A. N. Halliday (1999), Early cenozoic glaciation, antarctic weathering, and seawater $87 \mathrm{Sr} / 86 \mathrm{Sr}$ : is there a link?, Chem. Geol., 161(1), 165-180. 


\section{Chapter 5}

\section{Concluding Remarks and Future Research Directions}

Each summer within the ablation zone of the Greenland Ice Sheet (GrIS), supraglacial meltwater runoff induces short-term variations in glacial velocity while also influencing subglacial rock weathering. These variables are in part controlled by the interaction between subglacial channelized and distributed system drainage. In Chapter 2, I showed that the distributed system supplies $>90 \%$ of the ${ }^{222} \mathrm{Rn}$ flux in the Leverett Glacier proglacial river. Therefore, ${ }^{222} \mathrm{Rn}$ can be used as a passive flow tracer of distributed system meltwater drainage. From spring to mid-summer, $J_{d i s}$, the flux of ${ }^{222} \mathrm{Rn}$ attributed to the distributed system, grew with increasing river discharge as the growing water flux outweighed the decrease in ${ }^{222} \mathrm{Rn}$ activities. $J_{d i s}$ was subsequently converted to the distributed system flux $\left(Q_{d i s}\right)$ using laboratory estimates of the ${ }^{222} \mathrm{Rn}$ activity within the distributed system. Uncertainties in $Q_{d i s}$ are largely related to variable ${ }^{222} \mathrm{Rn}$ transit times in in the channelized system and ${ }^{222} \mathrm{Rn}$ activities in the distributed system. Hence, future studies should endeavor to measure ${ }^{222} \mathrm{Rn}$ at the ice sheet bed through boreholes similar to those described in Andrews et al. (2014). Ideally, ${ }^{222} \mathrm{Rn}$ would be repeatedly measured at multiple locations within the channelized and non-channelized regions of the ice sheet bed. Doing so would help determine the likely range of ${ }^{222} \mathrm{Rn}$ in the distributed system and 
would provide better constraints on $Q_{\text {dis }}$ estimates. Repeat measurements of ${ }^{222} \mathrm{Rn}$ at the ice sheet bed would also help to determine if ${ }^{222} \mathrm{Rn}$ is at secular equilibrium in the distributed system or whether this environment is regularly flushed.

Despite nearly twice as much proglacial river discharge in 2012 than in 2011, it was unclear whether or not $Q_{d i s}$ was significantly higher in 2012. As fluxes from the distributed system likely make up the bulk of chemical fluxes from the GrIS, it is difficult to determine the extent to which solute fluxes will increase from the GrIS during climate warming. Future studies measuring ${ }^{222} \mathrm{Rn}$ in proglacial rivers should attempt to measure trace element and isotope concentrations at high temporal resolution during spikes in distributed system drainage to determine how solute fluxes scale with distributed system fluxes. This work would have potential implications for modeling chemical fluxes delivered to the ocean during glacialinterglacial cycles.

In Chapter 3, I investigated the impact of supraglacial meltwater inputs on glacial velocity and distributed system drainage. Using a positive degree-day model and the regional climate model RACMO2.3, I found that meltwater runoff drives short-term variations in glacial velocity throughout the melt season. Fast early season velocities were initiated by the onset of melting on the glacier's catchment and the formation of efficient channelized drainage. Time series measurements of $\delta^{18} \mathrm{O}$ and $\delta^{2} \mathrm{H}$ were made in the proglacial river as well as along a transect moving up the glacier's catchment to $40 \mathrm{~km}$ from the ice sheet margin. Results of the $\delta^{18} \mathrm{O}$ and $\delta^{2} \mathrm{H}$ analyses showed that the main source of meltwater changed from basal ice at the ice sheet margin to being predominately sourced from $\sim 40 \mathrm{~km}$ from the ice sheet margin. Average mid-season $\delta^{18} \mathrm{O}$ and $\delta^{2} \mathrm{H}$ values in the proglacial river were slightly heavier in 2012 suggesting more intense melting higher within the catchment. This result was corroborated with 
on-ice temperature measurements taken from across the glacier's catchment that showed average temperatures were higher in 2012 than in 2011. This work demonstrates the utility of measuring $\delta^{18} \mathrm{O}$ and $\delta^{2} \mathrm{H}$ in glacial meltwater to infer the source of meltwater and corroborate results from meltwater runoff models.

A large spike in $J_{d i s}$ was observed in 2011 that corresponded to a period of channel expansion as determined by $\mathrm{SF}_{6}$ tracer experiments (Chandler et al., 2013). Four large spikes in $J_{d i s}$ occurred in 2012 that followed periods of rapid supraglacial meltwater inputs. This finding suggests that during rapid increases of supraglacial meltwater runoff, channels are pressurized and new connections are formed with the distributed system. As runoff decreases, these new distributed system connections subsequently drain, supplying the observed spikes in $J_{d i s}$. This finding provides a mechanism for regulating ice sheet velocity across the ablation zone of the GrIS. Rapid increases in meltwater inputs induce temporary glacial acceleration while increasing the connectivity to the distributed system, which subsequently drains. Less water in the distributed system following the summer leads to lower basal water pressure in the winter and less sliding. While this process has been hypothesized before (Sole et al., 2013) and is supported by pressure measurements through bore holes set in the distributed system (Andrews et al., 2014; van de Wal et al., 2015), this study provides the first observational evidence that distributed system meltwater drains following rapid increases in meltwater runoff and during channel expansion.

Using continuous ${ }^{222} \mathrm{Rn}$ monitoring in proglacial rivers and streams provides a simple, cost-effective method for determining the timing and relative magnitude of distributed system drainage. Monitoring ${ }^{222} \mathrm{Rn}$ in proglacial rivers should be expanded to other outlet glaciers of the GrIS and to large alpine glaciers with active hydrological cycles. This work could be used to 
answer numerous questions related to subglacial hydrology, solute fluxes, and ice sheet dynamics. This method is limited by the nature of the proglacial river. While hypothetically ${ }^{222} \mathrm{Rn}$ could be measured at the ice sheet margin in marine terminating sections of the GrIS, serious logistical challenges would need to be overcome in order to sample these environments. Furthermore, many glaciers discharge into lakes and braided streams impeding measurements of the ${ }^{222} \mathrm{Rn}$ flux of bulk meltwater.

In Chapter 4, I investigated the effect of glacial hydrology on subglacial weathering using $\mathrm{Sr}, \mathrm{U}$, and Ra isotopes. In the dissolved load, higher ${ }^{87} \mathrm{Sr} /{ }^{86} \mathrm{Sr}$ ratios were associated with early season meltwater samples and higher $\mathrm{Ca} / \mathrm{Na}$ molar ratios. An acetic acid digestion of the suspended sediment load (SSL), designed to mobilize the carbonate fraction, found that trace carbonates within the watershed contain radiogenic ${ }^{87} \mathrm{Sr} /{ }^{86} \mathrm{Sr}$. Based on these results, radiogenic trace carbonates within the predominately silicate watershed appear to control the ${ }^{87} \mathrm{Sr} /{ }^{86} \mathrm{Sr}$ ratio in the dissolved phase. However, mid-summer samples collected moving downstream from the ice sheet terminus had progressively lower ${ }^{87} \mathrm{Sr} /{ }^{86} \mathrm{Sr}$ ratios. This was likely from additional weathering from less radiogenic silicate mineral phases or from input from additional water sources such as shallow groundwater. While it is understood that carbonate weathering is important for solute fluxes in glacial catchments (Anderson et al., 2007), this study demonstrates that carbonate weathering is important for the Sr isotope flux as well.

The $\delta^{234} U$ of the dissolved load was lower than seawater (Andersen et al., 2010) with a discharge-weighted mean of 67. It was determined experimentally that when meltwater was allowed to be in contact with the SSL for longer times before filtering and acidifying the sample, the $\delta^{234} U$ value of the dissolved load decreased. Furthermore, samples collected along a transect moving downstream from the GrIS margin had progressively lower $\delta^{234} U$ values. I interpreted 
these results as evidence that subglacial sediments have been repeatedly flushed with meltwater such that the more easily weathered ${ }^{234} \mathrm{U}$ isotope has been stripped from mineral surfaces leaving the $U$ source material ${ }^{234} U$-depleted. The change in $U$ concentration was less clear due to analytical uncertainties; future investigators should measure $U$ concentrations using isotope dilution (Owens et al., 2011). While $\delta^{234} U$ values in the dissolved phase did not correlate to molar ratios of $\mathrm{Ca} / \mathrm{Na}$ or $\mathrm{Mg} / \mathrm{Na}$, weathering of trace carbonates may still be a source of ${ }^{234} \mathrm{U}$ depleted U. Selective leaches that target the carbonate phase (as were performed for $\mathrm{Sr}$ isotopes) would help quantify its relative magnitude.

Results from this thesis suggest that during the onset of glaciation, ${ }^{234} \mathrm{U}$ is stripped from mineral surfaces but that after extensive glacial hydrological systems develop the U flux to the ocean is ${ }^{234} \mathrm{U}$-depleted relative to the ocean. Hence, large scale glaciation may provide a mechanism for the potential shift in the ocean's $\delta^{234} U$ value from glacial to interglacial cycles. These findings highlight the need for a better understanding of oceanic U flux variability over geologic time scales.

The $\left({ }^{228} \mathrm{Ra} /{ }^{226} \mathrm{Ra}\right)$ value in the dissolved load was significantly higher than the source material. This can best be explained by repeated flushing of the distributed system with meltwater stripping Ra from mineral surfaces and the faster ingrowth rate of ${ }^{228} \mathrm{Ra}\left(\mathrm{t}_{1 / 2}=5.75 \mathrm{y}\right)$ relative to ${ }^{226} \mathrm{Ra}\left(\mathrm{t}_{1 / 2}=1600 \mathrm{y}\right)$. Furthermore, the ${ }^{228} \mathrm{Ra}$ flux from Leverett Glacier suggests that the GrIS may be a major Ra source to the North Atlantic and Arctic Oceans not currently accounted for in global mass balance models. Measuring the Ra flux from other outlet glaciers of the GrIS are needed to further test this hypothesis. Uranium and Ra isotopic analyses demonstrate that despite the continual generation of new mineral surfaces in the subglacial environment 
(Anderson et al., 2007), chemical weathering is still important due to extensive flushing of subglacial sediments by supraglacial meltwater inputs.

\section{References}

Anderson, S. P. (2007), Biogeochemistry of Glacial Landscape Systems, Annu. Rev. Earth Planet. Sci., 35(1), 375-399.

Andrews, L. C., G. A. Catania, M. J. Hoffman, J. D. Gulley, M. P. Luthi, C. Ryser, R. L. Hawley, and T. A. Neumann (2014), Direct observations of evolving subglacial drainage beneath the Greenland Ice Sheet, Nature, 514(7520), 80-83.

Bartholomew, I., P. Nienow, D. Mair, A. Hubbard, M. a. King, and A. Sole (2010), Seasonal evolution of subglacial drainage and acceleration in a Greenland outlet glacier, Nat. Geosci., 3(6), 408-411, doi:10.1038/ngeo863.

Owens, S. A., K. O. Buesseler, and K. W. W. Sims (2011), Re-evaluating the 238 U-salinity relationship in seawater : Implications for the $\mathrm{U}-234$ Th disequilibrium method, Mar. Chem., 127(1-4), 31-39, doi:10.1016/j.marchem.2011.07.005.

Rothlisberger, H. (1969), Water pressure in subglacial channels, in Union Géodésique et Géophysique Internationale. Association Internationale d'Hydrologie Scientifique. Commission de Neiges et Glaces. Symposium on the hydrology of Glaciers, Cambridge, 7, p. 97. 
Sole, A., P. Nienow, I. Bartholomew, D. Mair, T. Cowton, A. Tedstone, and M. A. King (2013), Winter motion mediates dynamic response of the Greenland ice sheet to warmer summers, Geophys. Res. Lett., 40(15), 3940-3944.

Van de Wal, R. S. W. et al. (2015), Self-regulation of ice flow varies across the ablation area in south-west Greenland, Cryosph., 9(2), 603-611.

Werder, M. A., I. J. Hewitt, C. G. Schoof, and G. E. Flowers (2013), Modeling channelized and distributed subglacial drainage in two dimensions, J. Geophys. Res. Earth Surf., 118(4), $2140-2158$. 


\section{Appendix}

\section{Mercury in glacial meltwater}

Dissolved and particulate $\mathrm{Hg}$ was measured in the Leverett Glacier proglacial river at Site 2 (Chapter III, Figure 1). Samples for total dissolved $\mathrm{Hg}$ analysis were filtered to $0.45 \mu \mathrm{m}$ and collected in $250 \mathrm{~mL}$, acid-washed borosilicate glass bottles, oxidized with $\mathrm{BrCl}$ and analyzed by cold vapor atomic fluorescence spectrometry following $\mathrm{SnCl}_{2}$ reduction and gold-trap preconcentration (Lamborg et al., 2012).

Table 1: Total dissolved $\mathrm{Hg}$ in the Leverett Glacier proglacial river.

\begin{tabular}{lc} 
day & $\mathrm{pmol} / \mathrm{L}$ \\
\hline 134.7 & 56 \\
135.6 & 135 \\
135.9 & 76 \\
136.1 & 230 \\
139.4 & 84 \\
143.4 & 9 \\
143.7 & 83 \\
147.0 & 64 \\
149.3 & 105 \\
155.5 & 29
\end{tabular}


Particulate $\mathrm{Hg}$ was determined from suspended sediment collected on $0.45 \mu \mathrm{m}$ filters. Filters were first oven-dried overnight at $55^{\circ} \mathrm{C}$ before being digested overnight with $2 \mathrm{~N}^{-N_{3}}$. The digest was subsequently treated similar to the dissolved samples to measure $\mathrm{Hg}$ concentration of the particulate load (Lamborg et al., 2012).

Table 2: Mercury adsorbed to the suspended sediment load in the Leverett Glacier proglacial river.

\begin{tabular}{lc} 
day & $\mu \mathrm{mol} / \mathrm{kg}$ \\
\hline 137.2 & 34 \\
138.4 & 84 \\
139.7 & 63 \\
149.4 & 50 \\
160.5 & 62 \\
160.8 & 43 \\
168.0 & 12 \\
168.5 & 8 \\
190.0 & 30 \\
193.8 & 56
\end{tabular}

\section{Reference}

Lamborg, C. H., C. R. Hammerschmidt, G. A. Gill, R. P. Mason, and S. Gichuki (2012), An intercomparison of procedures for the determination of total mercury in seawater and recommendations regarding mercury speciation during GEOTRACES cruises, Limnol. Oceanogr. Methods, 10(2), 90-100. 